EUNICE SILVA SANTOS

\title{
AVALIAÇÃO ESTATÍSTICA DO ERRO DE MODELOS DE RESISTÊNCIA PARA ELEMENTOS LINEARES DE CONCRETO ARMADO DA ABNT NBR 6118:2007
}

\author{
Dissertação apresentada à Escola de \\ Engenharia de São Carlos da \\ Universidade de São Paulo, como parte \\ dos requisitos para obtenção do título de \\ Mestre em Engenharia de Estruturas. \\ Orientador: André Teófilo Beck
}

SÃO CARLOS 
AUTORIZO A REPRODUÇÃO TOTAL OU PARCIAL DESTE TRABALHO, POR QUALQUER MEIO CONVENCIONAL OU ELETRÔNICO, PARA FINS DE ESTUDO E PESQUISA, DESDE QUE CITADA A FONTE.

Ficha catalográfica preparada pela Seção de Atendimentos ao Usuário do Serviço de Biblioteca - EESC/USP.

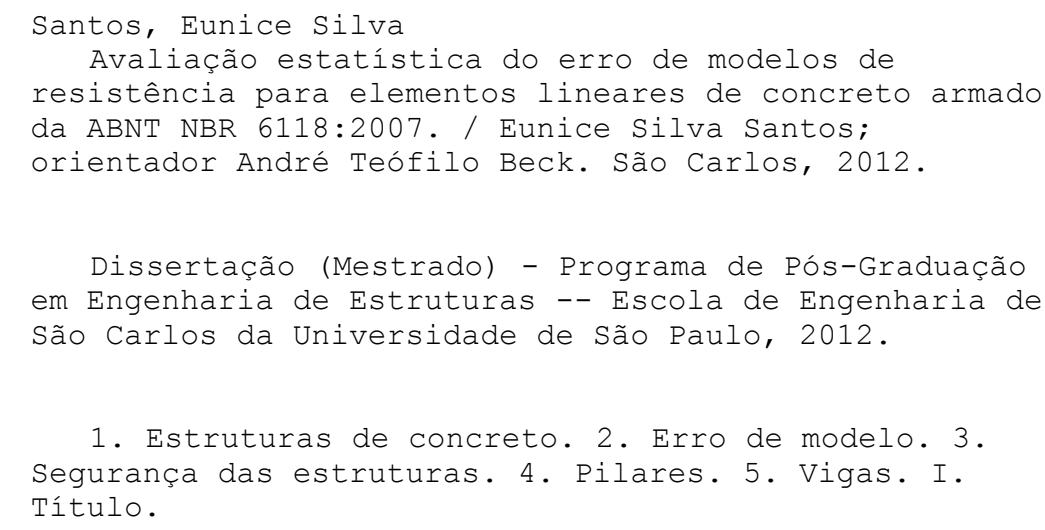

1. Estruturas de concreto. 2. Erro de modelo. 3. Segurança das estruturas. 4. Pilares. 5. Vigas. I. Título. 



\section{FOLHA DE JULGAMENTO}

Candidata: Engenheira EUNICE SILVA SANTOS.

Título da dissertação: "Avaliação estatística do erro de modelos de resistência para elementos lineares de concreto armado da ABNT NBR 6118:2007".

Data da defesa: 03/08/2012

\section{Comissão Julgadora:}

Prof. Dr. André Teófilo Beck (Orientador)

(Escola de Engenharia de São Carlos/EESC)

Prof. Dr. Edson Denner Leonel

(Escola de Engenharia de São Carlos/EESC)

Prof ${ }^{a}$. Dr ${ }^{\mathrm{a}}$. Sofia Maria Carrato Diniz

(Universidade Federal de Minas Gerais/UFMG)
Resultado:
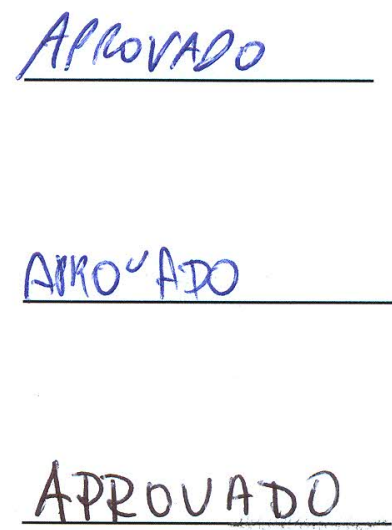

Coordenador do Programa de Pós-Graduação em Engenharia Civil (Engenharia de Estruturas):

Profa. Associada Ana Lucia Homce de Cresce El Debs

Presidente da Comissão de Pós-Graduação:

Prof. Titular Denis Vinicius Coury 


\section{AgRAdeCimentos}

Ao meu orientador professor André T. Beck, pela paciência e dedicação sem medidas e pelos conhecimentos transmitidos, indispensáveis para o desenvolvimento da pesquisa.

Àqueles sem os quais nada seria possível, meus pais e minhas irmãs, de quem a saudade tornou-se estímulo, obrigada por todo amor e apoio sempre presentes mesmo à distância.

Aos amigos e colegas do SET, em especial Juliana, minha amiga-irmã, cujo o companheirismo de todas as horas tanto me faz falta, e Marcelo, Emerson e Luiz Henrique pela ajuda com as disciplinas do mestrado.

A todos amigos e colegas que fiz em São Carlos, principalmente à Raquel, minha querida roommate pelas boas conversas, amizade e pelo inglês, a Raphael, Mariane, Sr. Mariano e D. Elza por amenizarem a saudade de minha família.

A Chris, Pamela, meu conterrâneo Gramoza, minha sobrinha amada Silvinha, as primas Laís e Liliany e demais amigos e familiares, a quem não dei a devida atenção, mas que continuam a torcer por mim.

Aos que muito me ajudaram no ingresso ao mestrado, Ciro, Prof. Pedro, D. Nancy e Sr. Teixeira.

A todos os professores e funcionários do Departamento de Engenharia de Estruturas da Escola de Engenharia de São Carlos - USP, por contribuem com minha formação e estarem sempre dispostos a ajudar.

À CAPES pelo auxílio financeiro durante o mestrado. 



\section{RESUMO}

SANTOS, E. S. Avaliação estatística do erro de modelos de resistência para elementos lineares de concreto armado da ABNT NBR 6118:2007. 2012. 126 p. Dissertação (Mestrado) - Escola de Engenharia de São Carlos, Universidade de São Paulo, São Carlos, 2012.

Um projeto de estruturas deve considerar incertezas intrínsecas às variáveis presentes na estrutura e na concepção estrutural, como intensidade e distribuição das ações, propriedades mecânicas dos materiais, parâmetros geométricos da estrutura e modelos de cálculo e de análise estrutural. Desta forma, a segurança estrutural só pode ser medida em termos probabilísticos. O presente estudo aborda uma análise estatística da variável aleatória Erro de Modelo para a previsão da capacidade resistente de elementos lineares (vigas e pilares) segundo requisitos das normas de estruturas de concreto ABNT NBR 6118:2003 e ACI 318-2002. A variável Erro de Modelo é obtida pela razão entre observações dos valores "reais" e os valores obtidos segundo os requisitos normativos. Os valores "reais" de resistência dos pilares de concreto armado foram obtidos a partir de uma base de dados experimentais levantada de pesquisas sobre este elementos. O principal objetivo deste trabalho é avaliar a influência de cada parâmetro considerado, como resistência média a compressão do concreto, taxa de armadura, esbeltez dos pilares, altura útil e domínios de ruína das vigas, deformação dos elementos concreto e aço, sobre a resistência última dos elementos. Os resultados obtidos demonstram que os modelos da norma brasileira são conservadores e tendenciosos em relação os parâmetros estudados.

Palavras-Chave: estruturas de concreto, erro de modelo, segurança das estruturas, pilares, vigas 



\section{ABSTRACT}

\section{SANTOS, E. S. Statistical evaluation of resistance modelling error for para elementos}

lineares de concreto armado da ABNT NBR 6118:2007. 2012. 126 p. Master's thesis. Escola de Engenharia de São Carlos, Universidade de São Paulo, São Carlos, 2012.

In a design of structures, it should be considered the intrinsic uncertainties to the present variables in the structure and in the structural concept, such as intensity and action distribution, mechanic properties of the material, geometric parameters of the structure and structural analysis and calculus models. Thus, the structural safety can only be measured in probabilistic terms. The present study approaches a statistical analysis of Model Error random variable for the prediction of resistant capacity of linear elements (columns and beams) according to the ABNT NBR 6118:2003 e ACI 318-2002 concrete structures building code requirements. The Model Error variable is obtained by the ratio between observation of "real" values and the values obtained according to the building code requirements. The "real" values of resistance in the concrete structure columns were obtained from an experimental data base acquired from researches on the same elements. The main objective of this work é to evaluate the influence of each considered parameter, such the concrete average resistance to compression, reinforcement rate, columns slenderness, serviceable height and ruin domains in beams, deformation of concrete and steel elements, about the last resistance of the elements. The obtained results show that Brazilian building code are conservative and tendentious in relation to the studied parameters

Keywords: concrete structures, model error, structural safety, columns, beams 



\section{LISTA DE FIGURAS}

FIGURA 3.1 - DOMÍNIOS DE DEFORMAÇÃO PARA SOLICITAÇÕES NORMAIS (ABNT NBR 6118:2007) ...............................14

FIGURA 3.2 - DIAGRAMA TENSÃO-DEFORMAÇÃO IDEALIZADO (ABNT NBR 6118:2007) ...........................................16

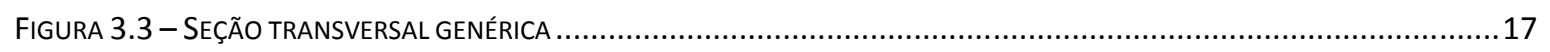

FIGURA 3.4 - DIAGRAMAS DE TENSÃO E DEFORMAÇÃO, SEGUNDO ABNT NBR 6118:2007 .......................................18

FIGURA 3.5 - DIAGRAMA DE DEFORMAÇÕES E BLOCO DE TENSÕES RETANGULAR, SEGUNDO ACI 318-2002 .........................19

FIGURA 3.6 - DOMÍNIOS DE DEFORMAÇÃO NA FLEXÃO, SEGUNDO REQUISITOS DO ACI 318-2002 ....................................20

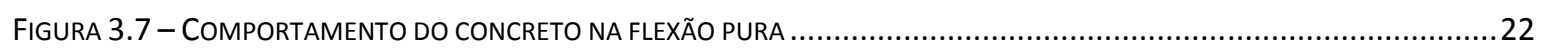

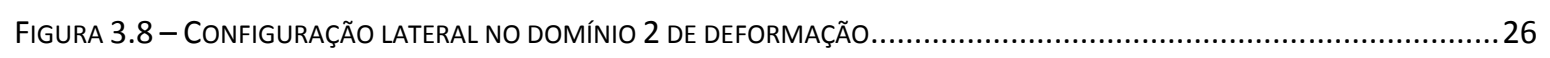

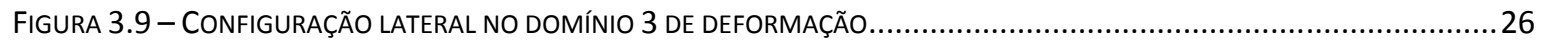

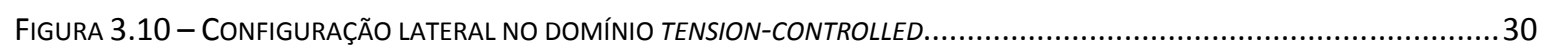

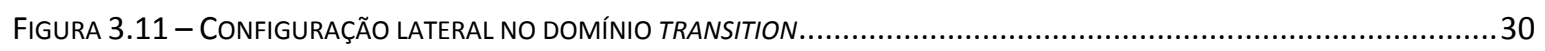

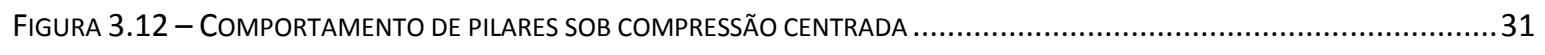

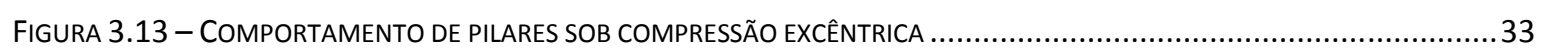

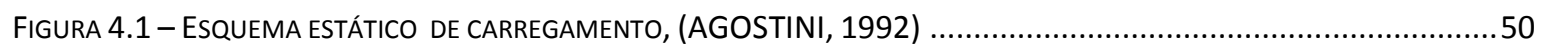

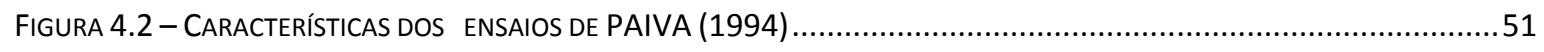

FIGURA 4.3 - ESQUEMA DE MONTAGEM DO PÓRTICO E DE CARREGAMENTO (LIMA, 1997) .............................................54

FIGURA 4.4 - DISPOSITIVO EXPERIMENTAL E MODELO DE VALLADARES (1997) ................................................5

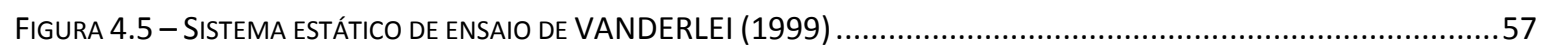

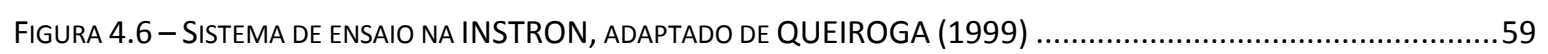

FIGURA 4.7 - ESQUEMA DE APLICAÇÃO DE FORÇAS NO MODELO DE ADORNO (2004) ….........................................64

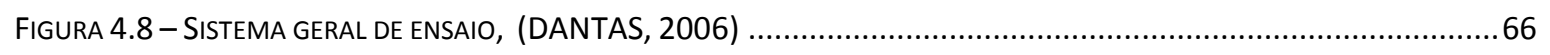

FIGURA 4.9 - DETALHE dA ARTICULAÇÃO SUPERIOR (A) E ESQUEMA DE CARREGAMENTO (B), (DANTAS, 2006) ..................67

FIGURA 5.1 - VARIÁVEL ERRO dO MODELO ABNT NBR 6118:2007 PARA VIGAS - (A) HISTOGRAMA E DISTRIBUIÇÃO dE DENSIDADE DE PROBABILIDADE, (B) DISTRIBUIÇÃO ACUMULADA DE PROBABILIDADE.

FIGURA 5.2 - VARIÁVEL ERRO DO MODELO ABNT NBR 6118:2007 PARA PILARES COM RIGIDEZ APROXIMADA - (A) HISTOGRAMA E DistRIBUIÇÃo de DENSIDADE DE PROBABILIDADE, (B) DISTRIBUIÇÃo ACUMULADA DE PROBABILIDADE ... 82

FIGURA 5.3 - VARIÁVEL ERRO DO MODELO ABNT NBR 6118:2007 PARA PILARES COM CURVATURA APROXIMADA - (A) HISTOGRAMA E DistribUIÇÃo de DENSIDADE DE PROBABILIDADE, (B) DISTRIBUIÇÃo ACUMULADA DE PROBABILIDADE ...83

FIGURA 5.4 - VARIÁVEL ERRO DO MODELO ACI 318-2002 PARA PILARES - (A) HISTOGRAMA E DISTRIBUIÇÃO DE DENSIDADE DE PROBABILIDADE, (B) DISTRIBUIÇÃO ACUMULADA DE PROBABILIDADE.

FIGURA 5.5 - VARIÁVEL ERRO DO MODELO NBR 6118:2007 PARA PILARES SOB COMPRESSÃO EXCÊNTRICA PELO MÉTODO DA RIGIDEZ APROXIMADA - (A) HISTOGRAMA E DISTRIBUIÇÃO DE DENSIDADE DE PROBABILIDADE, (B) DISTRIBUIÇÃO ACUMULADA DE PROBABILIDADE

FIGURA 5.6 - VARIÁVEL ERRO DO MODELO NBR 6118:2007 PARA PILARES SOB COMPRESSÃO EXCÊNTRICA PELO MÉTODO DA CURVATURA APROXIMADA - (A) HISTOGRAMA E DISTRIBUIÇÃO DE DENSIDADE DE PROBABILIDADE, (B) DISTRIBUIÇÃO ACUMULADA DE PROBABILIDADE 
FIGURA 5.7 - VARIÁVEL ERRO DO MODELO ACI 318-2002 PARA PILARES SOB COMPRESSÃO EXCÊNTRICA PELO MÉTODO DA CURVATURA APROXIMADA - (A) HISTOGRAMA E DISTRIBUIÇÃO DE DENSIDADE DE PROBABILIDADE, (B) DISTRIBUIÇÃO ACUMULADA DE PROBABILIDADE

FIGURA 5.8 - VARIÁVEL ERRO DO MODELO NBR 6118:2007 PARA PILARES SOB COMPRESSÃO CENTRADA PELO MÉTODO DA RIGIDEZ APROXIMADA - (A) HISTOGRAMA E DISTRIBUIÇÃO DE DENSIDADE DE PROBABILIDADE, (B) DISTRIBUIÇÃO ACUMULADA DE PROBABILIDADE

FIGURA 5.9 - VARIÁVEL ERRO DO MODELO NBR 6118:2007 PARA PILARES SOB COMPRESSÃO CENTRADA PELO MÉTODO DA CURVATURA APROXIMADA - (A) HISTOGRAMA E DISTRIBUIÇÃO DE DENSIDADE DE PROBABILIDADE, (B) DISTRIBUIÇÃO ACUMULADA DE PROBABILIDADE

FIGURA 5.10 - VARIÁVEL ERRO DO MODELO ACI 318-2002 PARA PILARES SOB COMPRESSÃO CENTRADA - (A) HISTOGRAMA E DISTRIBUIÇÃO DE DENSIDADE DE PROBABILIDADE, (B) DISTRIBUIÇÃO ACUMULADA DE PROBABILIDADE..... .85

Figura 6.1 - Relação entre o ERro de Modelo e A VARIÁvel ResistênCia Média À Compressão do Concreto para PILARES SOB CARGA CENTRADA. (A) ABNT NBR 6118:2007, MODELO DA RIGIDEZ APROXIMADA, (B) ABNT NBR 6118:2007, MODELO DA CURVATURA APROXIMADA, (C) ACI 318-2002.

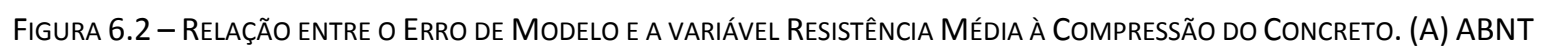
NBR 6118:2007, MODELO DA RIGIDEZ APROXIMADA, (B) ABNT NBR 6118:2007, MODELO DA CURVATURA APROXIMADA, (C) ACI 318-2002. 90

Figura 6.3 - RelaÇÃo ENTRE o ERRo de Modelo de VIGAS dA ABNT NBR 6118:2007 e A VARIÁVEL ReSISTÊNCIA MédIA À COMPRESSÃO DO CONCRETO.

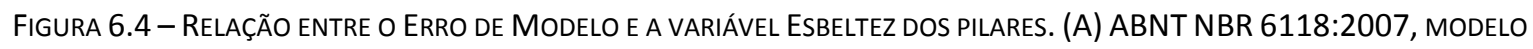
DA RIGIDEZ APROXIMADA, (B) ABNT NBR 6118:2007, MODELO DA CURVATURA APROXIMADA, (C) ACI 318-2002...92

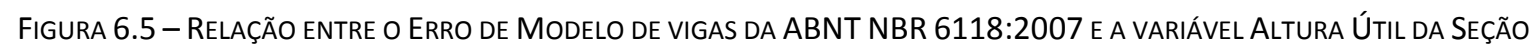
DAS VIGAS.

Figura 6.6 - Relação entre o ERRo de Modelo de VIGAS dA ABNT NBR 6118:2007 e A VARIÁvel de RAZÃo PosiçÃo dA LINHA NEUTRA E ALTURA ÚtIL DAS VIGAS

Figura 6.7 - Relação entre o ERro de Modelo e a variável TAXa de Armadura Longitudinal dos Pilares. (A) ABNT NBR 6118:2007, MODELO DA RIGIDEZ APROXIMADA, (B) ABNT NBR 6118:2007, MODELO DA CURVATURA APROXIMADA, (C) ACl 318-2002

Figura 6.8 - RELAÇÃo entre o ERRo de Modelo de VIGAS dA ABNT NBR 6118:2007 E A VARIÁVEL TAXA de ARMAdURA LONGITUDINAL DAS VIGAS.

Figura 6.9 - RelaÇÃo entre o Erro de Modelo e a Variável TAXa de Armadura TransVersal dos Pilares. (A) ABNT NBR 6118:2007, MODELO DA RIGIDEZ APROXIMADA, (B) ABNT NBR 6118:2007, MODELO DA CURVATURA APROXIMADA,(C) ACI 318-2002

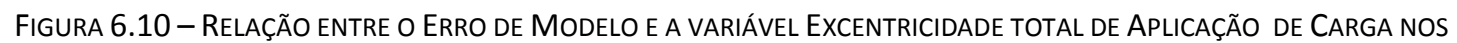
PILARES. ABNT NBR 6118:2007, MODELO DA RIGIDEZ APROXIMADA.

FIGURA 6.11 - RELAÇÃo ENTRE O ERRO de MOdELO E A VARIÁVEL EXCENTRICIDADE INICIAL DE APLICAÇÃo de CARGA NOS PILARES. (A) ABNT NBR 6118:2007, MODELO DA RIGIDEZ APROXIMADA, (B) ABNT NBR 6118:2007, MODELO DA CURVATURA APROXIMADA,(C) ACI 318-2002. 


\section{LISTA DE QUADROS E TABELAS}

\section{QUADROS}

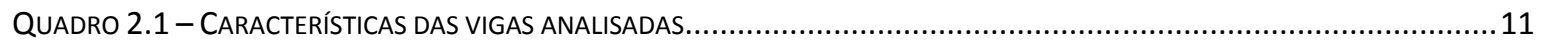

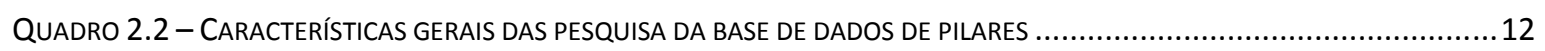

QUADRO 3.1 - DOMÍNIOS DE DEFORMAÇÃO E INTERVALOS DA LINHA NEUTRA - ABNT NBR 6118:2007 ...........................18

QUADRO 3.2 - DOMÍNIOS DE DEFORMAÇÃO E INTERVALOS DA LINHA NEUTRA - ACI 318-2002 _....................................2 21

\section{TABELAS}

TABELA 5.1 - CARACTERÍSTICAS FÍSICAS E GEOMÉTRICAS DOS MODELOS DE VIGA..........................................................47

TABELA 5.2 - CARACTERÍSTICAS FÍSICAS E GEOMÉTRICAS DOS MODELOS DE AGOSTINI (1992) ......................................49

TABELA 5.3 - CARACTERÍSTICAS FÍSICAS E GEOMÉTRICAS DOS MODELOS DE PAIVA (1994) ..........................................52

TABELA 5.4 - CARACTERÍSTICAS FÍSICAS E GEOMÉTRICAS DOS MODELOS DE LIMA (1997) .............................................53

TABELA 5.5 - CARACTERÍSTICAS FÍSICAS E GEOMÉTRICAS DOS MODELOS DE VALLADARES (1997) ....................................55

TABELA 5.6 - CARACTERÍSTICAS FÍSICAS E GEOMÉTRICAS DOS MODELOS DE VANDERLEI (1999) .....................................57

TABELA 5.7 - CARACTERÍSTICAS FÍSICAS E GEOMÉTRICAS DOS MODELOS DE QUEIROGA (1999) .....................................58

TABELA 5.8 - CARACTERÍSTICAS FÍSICAS E GEOMÉTRICAS DOS MODELOS DE RAMOS (2001) ........................................60

TABELA 5.9 - CARACTERÍSTICAS FÍSICAS E GEOMÉTRICAS DOS MODELOS DE LIMA JUNIOR (2003).................................61

TABELA 5.10 - CARACTERÍSTICAS FÍSICAS E GEOMÉTRICAS DOS MODELOS DE OLIVEIRA (2004) .....................................63

TABELA 5.11 - CARACTERÍSTICAS FÍSICAS E GEOMÉTRICAS DOS MODELOS DE ADORNO (2004) ......................................64

TABELA 5.12 - CARACTERÍSTICAS FÍSICAS E GEOMÉTRICAS DOS MODELOS DE ARAÚJO (2004) ........................................65

TABELA 5.13 - CARACTERÍSTICAS FÍSICAS E GEOMÉTRICAS DOS MODELOS DE DANTAS (2006)......................................66

TABELA 5.14 - CARACTERÍSTICAS FÍSICAS E GEOMÉTRICAS DOS MODELOS DE SANTOS (2009) .....................................68

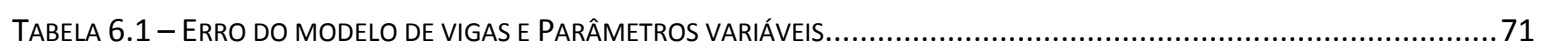

TABELA 6.2 - ERRO DOS MODELOS DE PILARES E PARÂMETROS VARIÁVEIS ................................................................77 


\section{LISTA DE SiglaS}

$\begin{array}{ll}\text { ABNT } & \text { ASSOCIAÇ̃̃o BRASILEIRA DE NORMAS TÉCNICAS } \\ \text { ACI } & \text { AMERICAN CONCRETE INSTITUTE } \\ \text { ANSI } & \text { AMERICAN NATIONAL STANDARD INSTITUTE } \\ \text { EESC } & \text { ESCOLA DE ENGENHARIA DE SÃo CARLOS } \\ \text { JCSS } & \text { JOINT COMMITTEE ON STRUCTURAL SAFETY } \\ \text { NBR } & \text { NORMA BRASILEIRA REGISTRADA } \\ \text { SET } & \text { DEPARTAMENTO DE ENGENHARIA DE ESTRUTURAS DA EESC } \\ \text { UFG } & \text { UNIVERSIDADE FEDERAL DE GOIÁS } \\ \text { UFMG } & \text { UNIVERSIDADE FEDERAL DE MINAS GERAIS } \\ \text { UFRGS } & \text { UNIVERSIDADE FEDERAL DO RIO GRANDE DO SUL } \\ \text { UNB } & \text { UNIVERSIDADE DE BRASíLIA } \\ \text { UNICAMP } & \text { UNIVERSIDADE ESTADUAL DE CAMPINAS } \\ \text { USP } & \text { UNIVERSIDADE DE S̃̃O PAULO }\end{array}$




\section{LISTA de Símbolos}

A

$A_{c}$

$A_{c c}$

$\mathrm{A}_{\mathrm{s}}$

$A_{s, i}$

$A_{s, t}$

$\alpha_{1}$

b

c

$\beta_{1}$

$d_{i}$

e

$e_{i}$

$e_{1}$

$e_{2}$

$E_{\text {ci }}$

$E_{c s}$

$E_{c t}^{\prime}$

$E_{s}$

$\varepsilon_{\mathrm{c}}$

$\mathcal{E}_{\mathrm{cC}, \max }$

$\varepsilon_{\text {ccu }}$
ÁREA DA SEÇÃO TRANSVERSAL DO ELEMENTO

ÁREA DA SEÇÃO TRANSVERSAL DE CONCRETO DO PILAR; OU ÁREA DO NÚCLEO DE CONCRETO LIMITADA PELA ARMADURA TRANSVERSAL

ÁREA DE CONCRETO COMPRIMIDO

ÁREA TOTAL DE AÇO NA SEÇÃO TRANSVERSAL DE CONCRETO

ÁREA DE AÇO NA CAMADA i DA ARMADURA LONGITUDINAL

ÁREA DA SEÇÃO TRANSVERSAL DAS ARMADURAS TRACIONADAS

PARÂMETRO PARA OBTENÇÃO DA RESISTÊNCIA DO CONCRETO NA ESTRUTURA A PARTIR DA RESISTÊNCIA DE CORPOS-DE-PROVA (ACI 318-2002)

MENOR DIMENSÃO DA SEÇÃO TRANSVERSAL DO PILAR OU DIMENSÃO DA BASE DA SEÇÃO TRANSVERSAL DA VIGA

COBRIMENTO DA ARMADURA

ÍNDICE DE REDUÇÃO DA PROFUNDIDADE DA LINHA NEUTRA - ACI 318-2002

DISTÂNCIA DA FACE MAIS COMPRIMIDA DA SEÇÃO AO CENTRO DE GRAVIDADE DA ARMADURA DA CAMADA i

EXCENTRICIDADE DO CARREGAMENTO

EXCENTRICIDADE INICIAL DE APLICAÇÃO DO CARREGAMENTO

EXCENTRICIDADE DE PRIMEIRA ORDEM

EXCENTRICIDADE DECORRENTE DOS EFEITOS DE SEGUNDA ORDEM

MÓDULO DE ELASTICIDADE INICIAL DO CONCRETO

MÓDULO DE ELASTICIDADE SECANTE DO CONCRETO

MÓDULO DE ELASTICIDADE SECANTE NA TENSÃO $f_{c}^{\prime}$

MÓDULO DE ELASTICIDADE DO AÇO

DEFORMAÇÃO DO CONCRETO

DEFORMAÇÃO DO CONCRETO NA FIBRA MAIS COMPRIMIDA

DEFORMAÇÃO ÚLTIMA DO CONCRETO COMPRIMIDO 


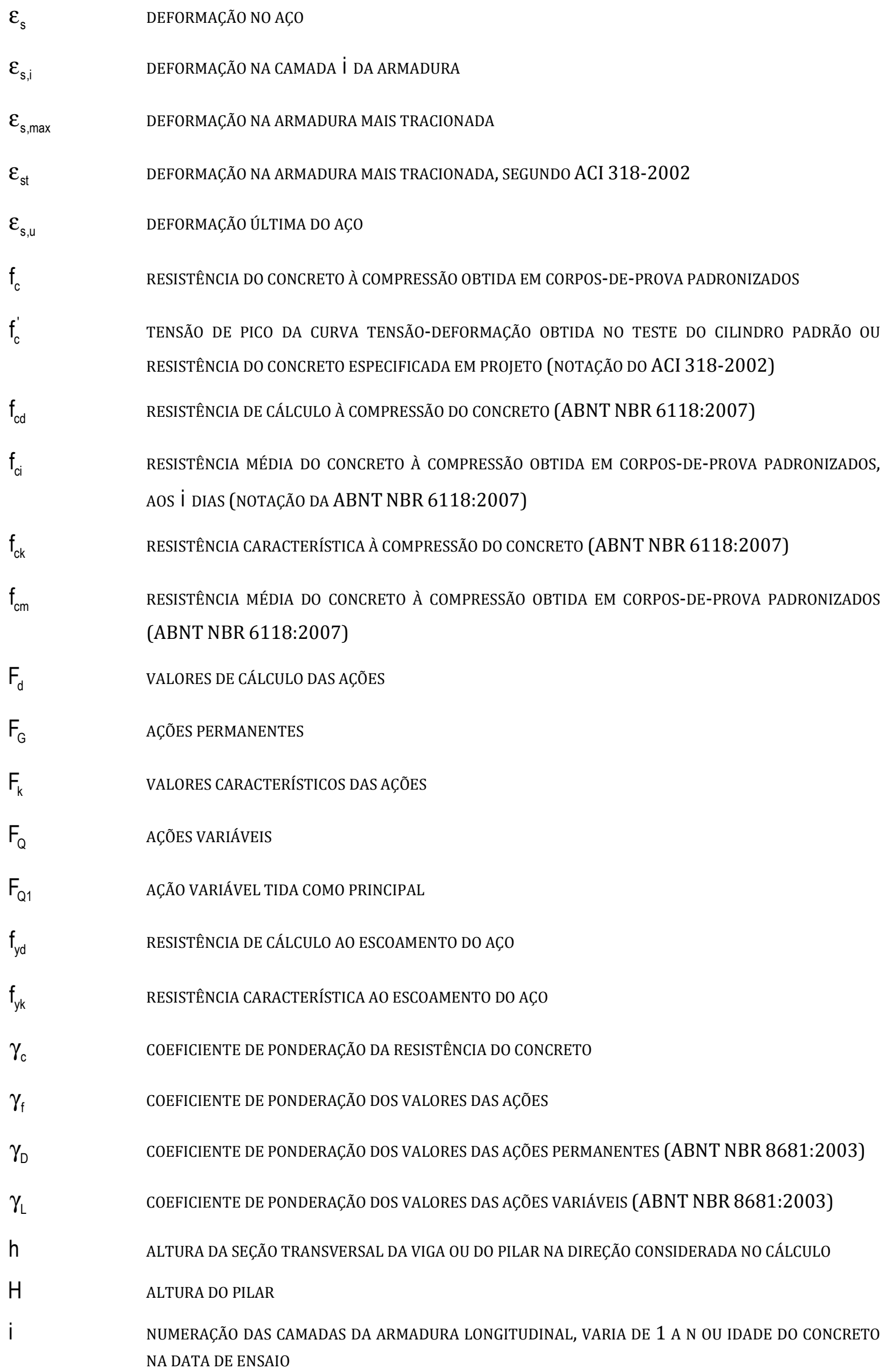




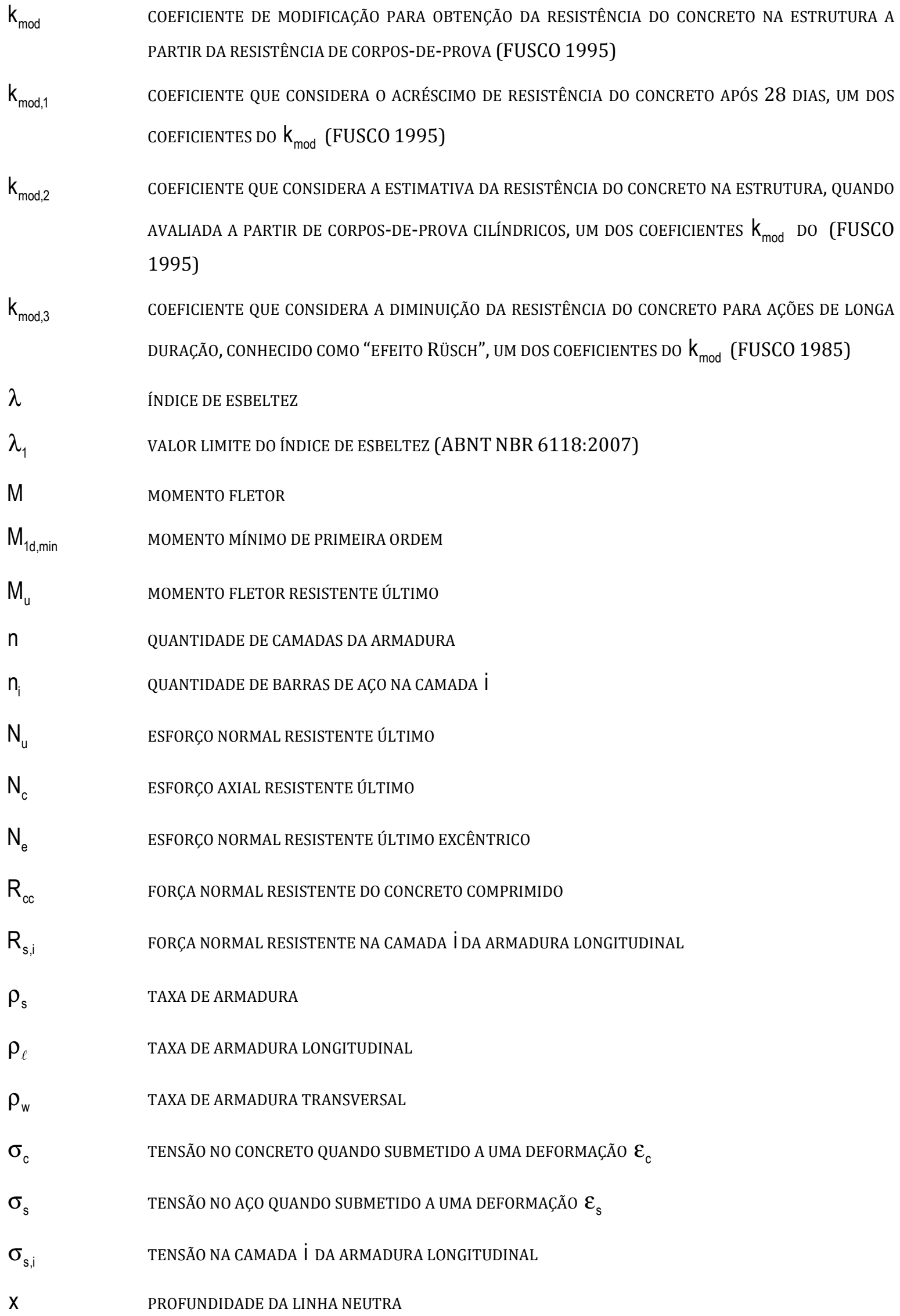




\section{SUMÁRIO}

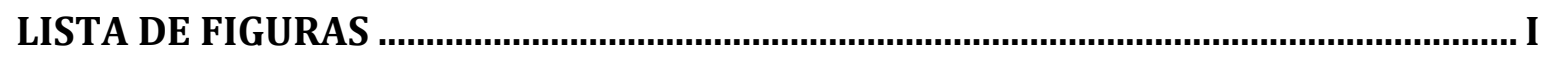

LISTA DE QUADROS E TABELAS ……..................................................................... III

LISTA DE SIGLAS ..................................................................................................

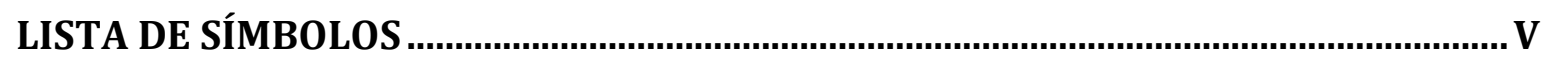

CAPÍTULO 1: INTRODUÇÃO ….............................................................................. 1

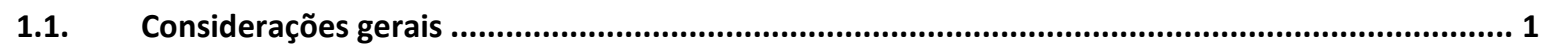

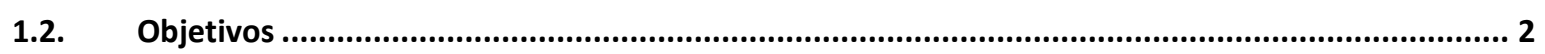

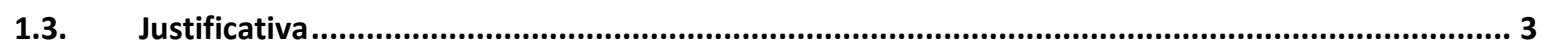

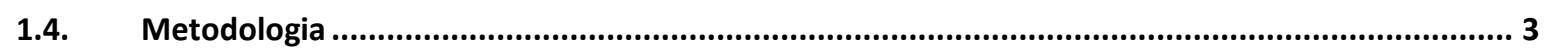

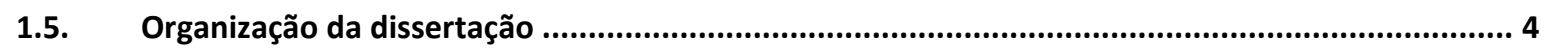

CAPÍTULO 2: REVISÃO BIBLIOGRÁFICA ….............................................................. 5

2.1. Metodologias de dimensionamento de estruturas .......................................................... 5

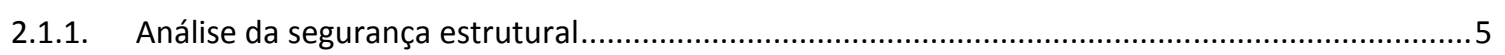

2.2. Cálculo e normalização de estruturas concreto.....................................................................6

2.2.1. Pesquisas sobre uso da variável Erro de Modelo na calibração modelos de previsão de

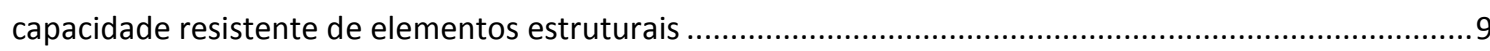

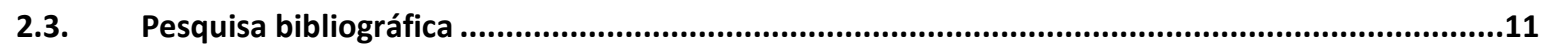

\section{CAPÍTULO 3: MODELOS DE PREVISÃO DA CAPACIDADE RESISTENTE ÚLTIMA 13}

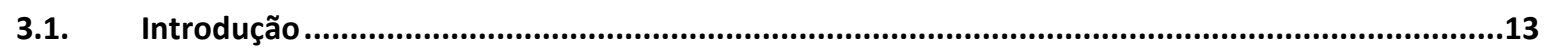

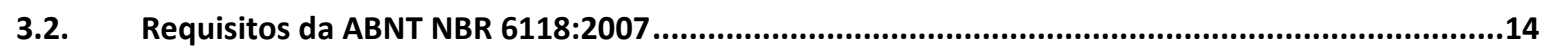

3.2.1. Deformações limite e Domínios de deformação ..................................................................14

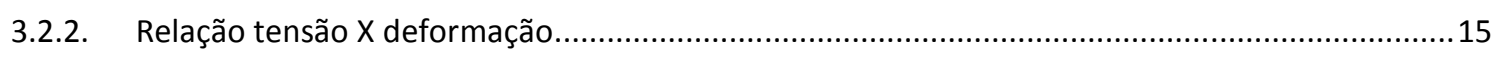

3.2.3. Cálculo de deformações na seção transversal .....................................................................17

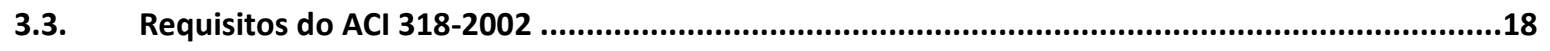

3.3.1. Deformações limites e Domínios de deformação ......................................................................19

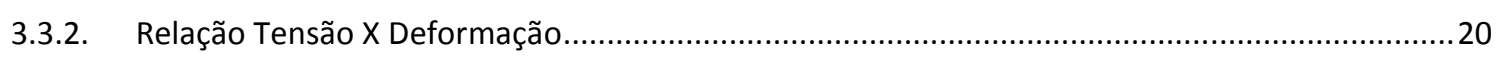


3.3.3. Cálculo de deformações na seção transversal ..................................................................21

3.4. Verificação da capacidade resistente de vigas sujeitas à flexão pura ..........................................21

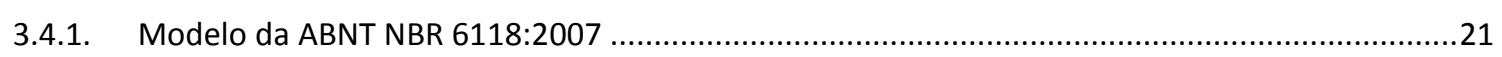

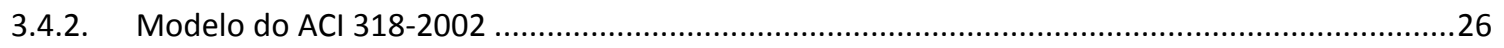

3.5. Verificação da capacidade resistente de pilares solicitados à compressão centrada....................30

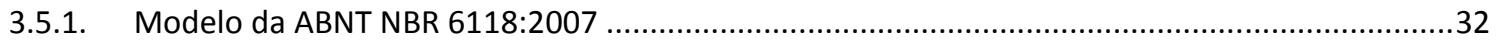

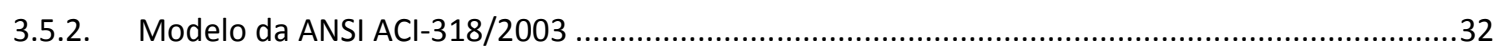

3.6. Verificação da capacidade resistente de pilares solicitados à compressão excêntrica normal .....33

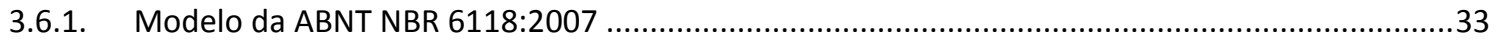

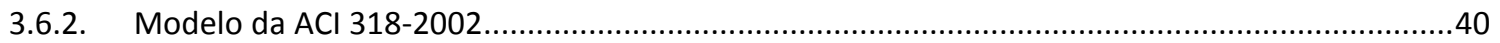

\section{CAPÍTULO 4: DADOS EXPERIMENTAIS SOBRE A RESISTÊNCIA DE ELEMENTOS} LINEARES DE CONCRETO ARMADO ......................................................................... 47

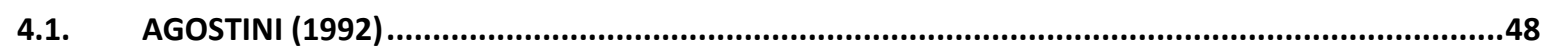

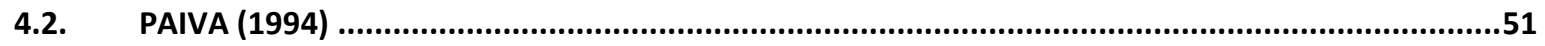

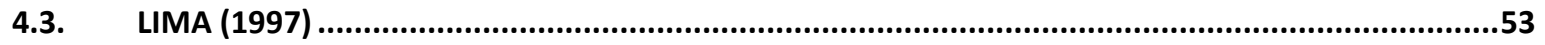

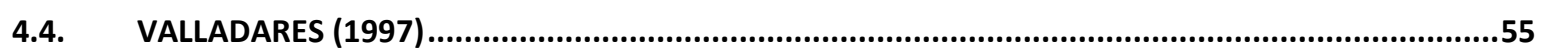

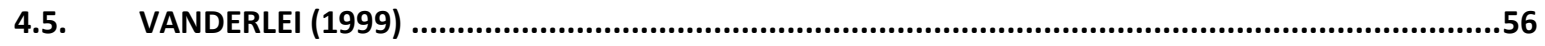

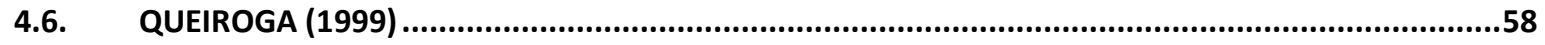

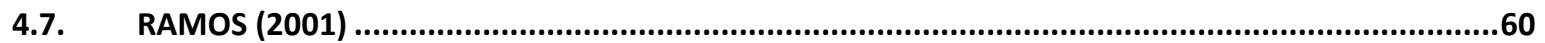

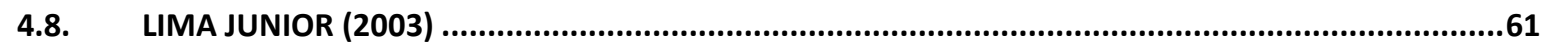

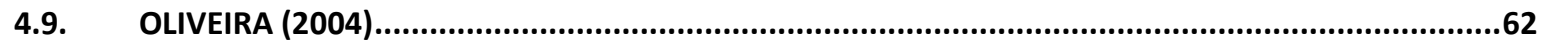

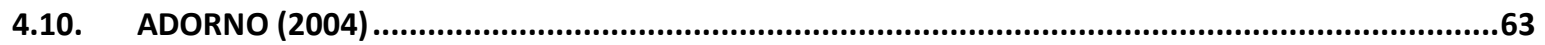

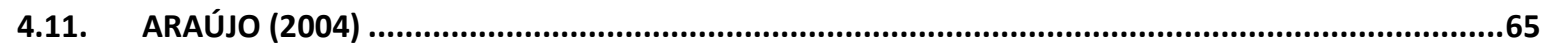

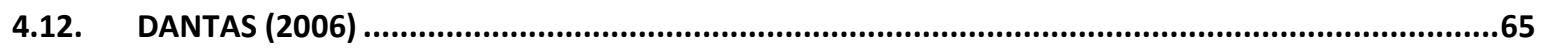

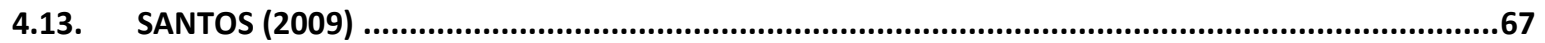

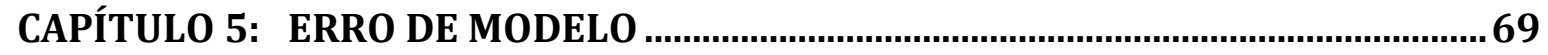

5.1. Considerações sobre Erro de Modelo ...................................................................................69

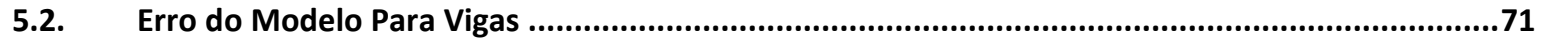

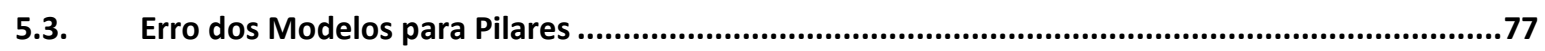

5.4. Distribuições de probabilidade para as variáveis aleatórias erro de modelo ..............................81

CAPÍTULO 6: ANÁLISE DE RESULTADOS.................................................................... 87 
6.1. Análise estatística da correlação entre a variável Erro de Modelo e os parâmetros variáveis dos

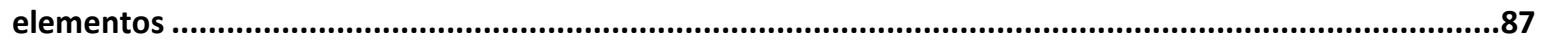

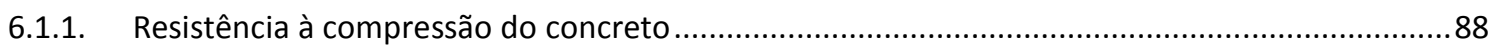

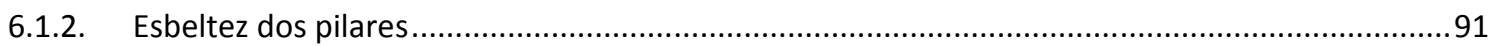

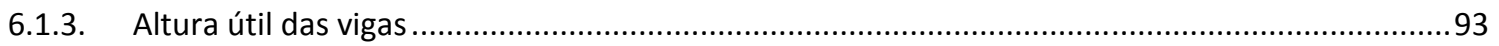

6.1.4. Razão posição da linha neutra e altura útil das vigas ...........................................................93

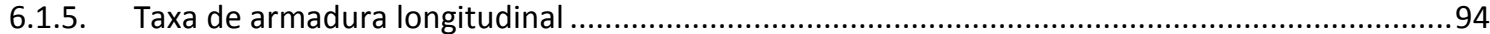

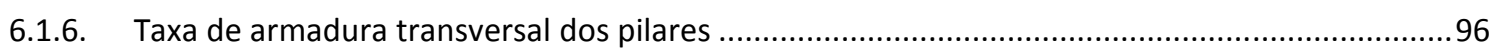

6.1.7. Excentricidade inicial de aplicação de carga nos pilares..........................................................98

CAPÍTULO 7: CONCLUSÕES....................................................................................101

REFERÊNCIAS BIBLIOGRÁFICAS .......................................................................... 103 


\section{Capítulo 1: InTRODUÇão}

\subsection{CONSIDERAÇõES GERAIS}

Dentre os materiais estruturais, o concreto é, sem dúvidas, o mais utilizado. A maioria das atividades dentro da construção civil está direta ou indiretamente relacionada com obras de concreto armado, pois mesmo que a estrutura não seja de concreto armado, alguns elementos serão.

Estudos frequentes sobre comportamento não-linear físico e geométrico, análises computacionais, otimização de projeto e, consequentemente, construção e aprimoramento de softwares e modelos teóricos visam representem de maneira satisfatória o comportamento estrutural do concreto armado.

Assim sendo, a evolução da tecnologia na engenharia e o maior conhecimento sobre comportamentos mecânicos do concreto e do aço têm conferido ao concreto um desempenho estrutural cada vez maior, tornando comum o uso de concretos com resistência e durabilidade superiores. Todo esse cenário torna necessária a adequação dos códigos de elaboração de projetos às estruturas atuais, para que estas sejam, simultaneamente, seguras e econômicas.

Um projeto de estruturas deve considerar incertezas intrínsecas às variáveis presentes na estrutura e na concepção estrutural, como intensidade e distribuição das ações, propriedades mecânicas dos materiais, parâmetros geométricos da estrutura, e modelos de cálculo e de análise estrutural.

Desta forma, a segurança estrutural só pode ser medida em termos probabilísticos. Determinar a probabilidade de ocorrência de uma situação de falha de um sistema estrutural, como um todo ou de seus elementos isoladamente, é processo complexo e sua utilização cotidiana é inviável. Portanto, as normas utilizam, como forma de avaliar os estados limites de segurança das estruturas, métodos semi-probabilísticos, nos quais os coeficientes parciais de segurança "controlam", de maneira simplificada, o risco de falha e garantem uma margem de segurança estrutural. 
Entretanto, os coeficientes parciais de segurança das normas brasileiras têm origem em normas estrangeiras equivalentes, e não foi realizada uma análise sistemática das incertezas sobre materiais e ações para a realidade brasileira. Para que seja possível mensurar a probabilidade de falha das estruturas nacionais e calibrar os coeficientes da norma brasileira, é preciso, inicialmente, realizar uma melhor investigação sobre as características estatísticas das variáveis que influenciam a capacidade e a solicitação das estruturas e, portanto, a ruína das mesmas.

A investigação sobre os parâmetros de resistência do presente trabalho foi orientada segundo NOWAK E SZERSZEN (2003), no qual foi desenvolvido um modelo estatístico de resistência, que considera que a resistência influenciada por três fatores (variáveis aleatórias): propriedades dos materiais, fabricação e análise profissional. O parâmetro de propriedades dos materiais foi derivado de uma base de dados de ensaios realizados pela indústria norte-americana de concreto. Os dados foram analisados e determinados a função de distribuição probabilidade acumulada e outros parâmetros estatísticos. Este artigo, juntamente com SZERSZEN (2003), documenta a calibração do código americano ACI 318-1999.

\subsection{OBJETIVOS}

A pesquisa desenvolvida teve como intuito dar subsídios a uma futura calibração de coeficientes de segurança das normas brasileiras de projetos de estruturas de concreto. Para tanto os objetivos foram:

- Quantificação do erro de modelos da norma brasileira de Projeto de Estruturas de Concreto - ABNT NBR 6118:2007 - referentes ao cálculo da resistência de elementos lineares, vigas e pilares, sujeitos, respectivamente, à flexão pura e à compressão axial e excêntrica;

- Avaliar a influência de cada parâmetro considerado, como resistência média a compressão do concreto, taxa de armadura, esbeltez dos pilares, altura útil e domínios de ruína das vigas, deformação dos elementos concreto e aço, sobre a resistência última dos elementos;

- Analisar a adequação de modelos da ABNT NBR 6118:2007, segundo a qual referese apenas a concretos de resistência usual (até 50MPa), para elementos confeccionados com concreto de resistência superior; 
É de fundamental importância ressaltar que, em maio de 2007, em virtude da necessidade de compatibilização da ABNT NBR 6118:20033 com o texto enviado para ISO com o intuito de reconhecer da norma brasileira como um código de padrão internacional (cuja aprovação foi efetivada em abril 2008), foi aprovada uma emenda na qual foram adicionadas referências para as normas NBR 15200:2004 (Projeto de estruturas de concreto em situação de incêndio - Procedimento) e NBR 15421:2006 (Projeto de estruturas resistentes a sismos - Procedimento), assim como pequenas correções nas tabelas $11.3 \mathrm{e}$ 17.2. Ou seja, a NBR 6118:2007 não apresenta alteração no que se refere ao dimensionamento de elemento lineares de concreto armado, e não abrange estruturas de concreto com resistência superior a $50 \mathrm{MPa}$.

\subsection{JUSTIFICATIVA}

Atualmente, o grande desafio da tecnologia de concreto parece ser aumentar a durabilidade das estruturas, recuperar estruturas danificadas e entender o complexo mecanismo químico e mecânico dos cimentos e concretos. Para isto, uma nova geração de concretos está sendo desenvolvida, métodos tradicionais de execução e cálculo de concreto estão sendo revistos, teorias não-lineares e da mecânica da fratura estão sendo desenvolvidas.

Portanto, é grande a importância da adequação das normas vigentes ao desenvolvimento atual da tecnologia e das teorias sobre concreto. Têm sido realizadas diversas pesquisas com uso da ferramenta da confiabilidade estrutural com o intuito de calibrar normas atuais e desenvolver códigos que orientem projetos ótimos, nos quais a probabilidade de falha pode ser escolhida de acordo com o custo total da estrutura.

Com isso para que a probabilidade de falha das estruturas não seja superior à aceitável, os modelos normativos de previsão de capacidade resistente das estruturas e de atuação das ações devem apresentar o menor erro possível quando comparado com resistências e solicitações reais. Para tanto, inicialmente deve-se quantificar o erro dos modelos, intuito principal da presente pesquisa.

\subsection{METODOLOGIA}

A metodologia deste trabalho foi dividida nas seguintes etapas:

- pesquisa bibliográfica para levantamento de uma base de dados com resultados experimentais da resistência última de elementos lineares, vigas e pilares, solicitados, respectivamente, à flexão pura e à compressão centrada e excêntrica; 
- cálculo das forças resistentes teóricas para tais elementos segundo os requisitos estabelecidos pelas normas ABNT NBR 6118:2007 e ACI 318-2002;

- cálculo da variável aleatória erro de modelo para cada modelo abordado e ajuste das respectivas distribuiçõos estatísticas.

\subsection{ORGANIZAÇÃO DA DISSERTAÇÃo}

No capítulo 2 são apresentados, de maneira concisa, as metodologias de dimensionamento das estruturas, níveis de seguranças em projetos estruturais, breve histórico da normalização destes e uma visão geral sobre a base de dados que foi analisada na pesquisa.

No capítulo 3, define-se os modelos para dimensionamento e verificação dos elementos estudados segundo ABNT NBR 6118:2007 e ACI 318-2002.

A seguir, são expostas no capítulo 4 a descrição das características dos elementos que compõem a base de dados e respectivos ensaios.

O capítulo 5 traz as tabelas com os erros de cada modelo estudado e uma apresentação inicial das curvas de distribuição de probabilidade das variáveis erro de modelo.

No sexto capítulo é feita a análise dos resultados obtidos de acordo com cada parâmetro variável e que influencia a resistência última dos elementos.

O último capítulo apresenta as conclusões da pesquisa e sugestões para futuros estudos relacionados à presente pesquisa. 


\section{Capítulo 2: REVISÃo BIBLIOGRÁFICA}

\subsection{METODOLOGIAS DE DIMENSIONAMENTO DE ESTRUTURAS}

A primeira metodologia a ser utilizada para o dimensionamento de estruturas foi o Método das Tensões Admissíveis. Consiste em calcular, no regime elástico-linear, o valor da tensão para o carregamento máximo esperado e compará-lo à tensão admissível dos materiais empregados. A tensão admissível é uma fração de alguma tensão limite, definida pelo limite do comportamento elástico-linear ou pela instabilidade do elemento. A razão entre a tensão limitante e a admissível é nomeada de fator de segurança. O fator de segurança, que era baseado em bom senso e experiência, tendo o papel de ajustar a possibilidade de ocorrência de valores desfavoráveis das ações e das propriedades dos materiais e, ainda, as incertezas do modelo teórico.

A partir da necessidade de utilização de coeficientes de resistência distintos para os diferentes materiais componentes da estrutura e para a ponderação de cada tipo de ação, além da possibilidade quantificar incertezas através de estatística e probabilidade, surgiu o Método dos Estados Limites. Os chamados coeficientes parciais são aplicados aos valores característicos das variáveis (resistências e solicitações) transformando-os em valores de cálculo. Os estados limites representam os cenários de falha e são adotados como critério de segurança pelas normas de projeto de estruturas.

\subsubsection{ANÁliSE DA SEGURANÇA ESTRUTURAL}

Em geral, os métodos de análise da segurança estrutural são divididos em níveis de confiabilidade.

A análise determinística realizada conforme o Método das Tensões Admissíveis não permite que seja uma quantificação da segurança estrutural, representando o menor nível de nível de análise. O Método dos Estados Limites englobam os demais níveis de análise.

Os chamados métodos semi-probabilístico, nos quais as ações e resistências são caracterizadas por valores médios ou característicos afetados pelos coeficientes parciais e as grandezas são todas consideradas independentes ou perfeitamente dependentes entre si, configuram o nível básico de avaliação de segurança. 
Uma análise probabilística simplificada das variáveis, que são descritas por sua média e desvio padrão e considera-se a correlação entre estas, representa um nível de quantificação da segurança mais elaborado. Neste nível, assume-se que todas as variáveis possuem distribuição de probabilidade Normal. Para avaliar o estado da estrutura é utilizada uma equação de estado limite, na qual o "zero" da função indica a superfície limite, os valores positivos configuram situações de segurança, e valores negativos, domínio de falha.

A melhor análise de segurança estrutural é representada por uma análise de probabilidade completa. As incertezas são consideradas segundo funções de distribuição probabilística que aproximam as diversas variáveis aleatórias, estas são definidas por um valor esperado (média), uma medida de dispersão (desvio padrão ou coeficiente de variação), e uma distribuição conjunta de probabilidade destas variáveis.

Como a probabilidade de falha assume valores extremamente baixos, define-se a probabilidade de ruína através do índice de confiabilidade, que é a representação geométrica da menor distância entre a superfície de falha e a origem (no espaço normal padrão).

Segue abaixo a evolução histórica do cálculo estrutural.

\subsection{CÁlCUlo E NORMAliZAÇÃo DE ESTRUTURAS CONCRETO}

Baseado em VASCONCELOS (1985), KAEFER (1998), é apresentado um histórico de desenvolvimento e normalização de estruturas de concreto armado.

No início do século XX os avanços em teoria e prática da construção de estruturas de concreto armado eram muito restritos, pois havia poucas publicações que disponibilizassem informações técnicas. Até então, os fatos significativos no desenvolvimento do concreto armado foram:

- Execução de vigotas e pequenas lajes com emprego de concreto armado por Coignet François (industrial francês) em 1852;

- Joseph Monier (jardineiro francês) registrou entre 1867 e 1878 patentes para construção, primeiramente de vasos, tubos e depósitos e, depois, de elementos de construção.

- Em 1886, o engenheiro alemão Gustav Adolf Wayss comprou as patentes de Monier, desenvolvendo pesquisas experimentais (publicadas entre 1902 e 1908 pela 
empresa Wayss e Freytag) para o uso do concreto armado como material de construção.

- François Hennebique (construtor francês e construtor autodidata) construiu em 1880 a primeira laje armada com barras de aço de seção circular, em 1892, integrou elementos de pilares e vigas e executou o primeiro pórtico monolítico e patenteou a primeira viga com estribos.

- Na Ecole des Ponts et Chausées, França, em 1897, teve início o primeiro curso formal do dimensionamento de estruturas de concreto armado, por Charles Rabut.

Entre 1890 e 1900 começou a haver uma rápida proliferação de revistas tratando de temas relacionados com cimento e concreto. E na virada do século, a publicação de livros sobre a engenharia de concreto tornou-se mais frequente, ao mesmo tempo em que os países começam a regulamentar o uso do concreto armado. Muitos livros tornaram-se clássicos, traduzidos para diversas línguas, como o livro de concreto armado de Emil Mörsch, engenheiro alemão, publicado em 1902. Resultado de diversos ensaios experimentais, suas teorias deram origem às primeiras normas para o cálculo e construção em concreto armado.

Em 1904, a Associação Germânica de Arquitetos e Engenheiros e a Associação Alemã do Concreto iniciaram o projeto preliminar de normalização para dimensionamento, execução e ensaio de estruturas de concreto armado que se tornaram base para a regulamentação que logo depois foi promulgada pelo governo da Prússia. Os regulamentos determinaram exame de projetos pelas autoridades da construção, sendo que seus relatórios seriam utilizados dois anos depois para uma revisão destes regulamentos.

Em 1906, a França promulgou sua normalização, bastante liberal, expressando o desejo de encorajar as experiências e o avanço da tecnologia. No entanto, tensões máximas admissíveis para aço, ferro e diferentes tipos de concreto foram estabelecidas em valores conservadores para a época, gerando várias críticas.

A Inglaterra, em 1907, publicou o primeiro relatório do Joint Committee, uma junta criada em 1906 com membros do Concrete Institute, que reunia o Reinforced Concrete Committee, British Fire Prevention Committee e empresas atuantes na área. Nos quatro anos seguintes foram publicadas revisões deste primeiro código de 1907, muito similar ao código de concreto armado francês. Em 1915 quando o London County Council promulgou a regulamentação para a área metropolitana, este diferia muito pouco da versão do Joint Committee. 
Normas para a utilização do concreto armado foram desenvolvidas nos Estados Unidos por uma junta, que incluía representantes do American Society for Testing and Materials e organizações dos engenheiros civis, engenheiros ferroviários e fabricantes de cimento. Tendo achado que os resultados e interpretações dos testes realizados até o momento eram inconclusivos, a junta americana decidiu instituir um programa de pesquisa, distribuindo recursos a 11 Universidades. Em 1903, começam sete anos de testes de laboratório, seguidos de cinco anos de testes em edifícios reais. Apesar de todo este trabalho, quando as normas foram publicadas em 1917, sofreram duras críticas.

No Brasil, a partir de 1924 quase todos os cálculos estruturais passaram a serem feitos aqui, com destaque para o engenheiro estrutural Emílio Baumgart. O país publicou seu primeiro regulamento em 1931, na revista Cimento Armado. O coeficiente de segurança era introduzido de maneira determinística e se aplicava à resistência de cada material, concreto e aço. A resistência era interpretada como média de um certo número, não especificado, de corpos-de-prova.

No final dos anos 60 e início de 70, questionou a eficiência das normas de segurança baseadas no método das tensões admissíveis. Iniciando assim estudos para o Método dos Estados Limites. Mas os critérios de projeto normativos continuaram baseados no princípio das tensões admissíveis até meados da década de 80 e o único coeficiente segurança foi ajustado, ao longo dos anos, com base na experiência passada, num processo de tentativa e erro.

Foi criado, em 1971, o Joint Committee on Structural Safety (JCSS), comitê formado por vários profissionais de países da Europa, com objetivo de coordenar e harmonizar as atividades pré-normativas, desenvolvendo pesquisas na área de confiabilidade, segurança estrutural e análise de risco (VROUWENVELDER, 1997). A idéia básica é que os princípios de confiabilidade e segurança devem ser os mesmos para todos os tipos de materiais e elementos encontrados nas estruturas de engenharia civil e construção. Este comitê teve larga influência no conteúdo de confiabilidade presentes em normas como o CEB e o Eurocode.

Em 1978, Bruce Ellingwood liderou o desenvolvimento de um novo formato para as normas americanas, baseado no método dos estados limites, no qual considerou-se que a falha estrutural ocorreria quando ultrapassada uma condição limite, escrita em termos das variáveis resistência $\mathrm{R}$ e solicitação $\mathrm{S}$. Os coeficientes parciais de segurança foram introduzidos, sendo um coeficiente para cada uma das ações e um coeficiente para a 
resistência do elemento estrutural. A solicitação foi entendida um somatório de efeitos ponderados dos carregamentos. Desta forma, criou-se de uma margem de segurança em relação a cada uma das principais variáveis aleatórias do problema. O novo formato adotado nas normas americanas passou a ser conhecido como LRFD, Load and Resistance Factor Design.

Somente na década 90, as normas européias começaram a evoluir para um formato baseado em estados limites. Estas normas adotam um coeficiente parcial de segurança para cada um dos materiais constituintes do elemento estrutural, ao invés de um único coeficiente para a solicitação e, independente da combinação, utilizam coeficientes parciais de segurança fixos correspondente a cada ação. No entanto, nota-se uma clara intenção de fundamentar o Eurocode em medidas probabilísticas de segurança, a julgar pelo conteúdo do anexo C: "Base para o projeto em coeficientes parciais e análise de confiabilidade" (EUROCODE, 2001).

As normas brasileiras de "Ações e Segurança nas Estruturas" (ABNT NBR 8681:2003) e de "Projeto e execução de estruturas de aço e de estruturas mistas aço-concreto de edifícios" (ABNT NBR 8800:2008) realizam combinações de ações semelhantes às normas européias.

\subsubsection{Pesquisas Sobre uso da VARiável ERro de Modelo NA CALIBRAÇÃO MODELOS DE PREVISÃO DE CAPACIDADE RESISTENTE DE ELEMENTOS ESTRUTURAIS}

Como citado anteriormente, na década de 70 foram publicados dados estatísticos a respeito das cargas variáveis de edifícios e em seguida dados estatísticos a respeito das cargas de neve nas estruturas (ELLINGWOOD, 1977). Ainda foi publicado um estudo de combinações de cargas para estruturas de concreto armado com coeficientes de ponderação determinados com base em análises de confiabilidade (ELLINGWOOD, 1980). Informações a respeito da velocidade de ventos em aeroportos americanos foram levantadas, possibilitando o desenvolvimento de parâmetros estatísticos a respeito das cargas de vento.

Um artigo baseado nas pesquisas anteriores e em dados levantados por um grupo de pesquisadores indicava um conjunto de coeficientes ponderadores e combinações de cargas para qualquer tipo de estrutura e forneciam critérios para a determinação de resistências compatíveis com os carregamentos gerados (ELLINGWOOD et. al., 1980). Após a criação 
deste trabalho, inúmeras outras normas de projeto americanas basearam-se nele para desenvolver seus métodos de análise e coeficientes ponderadores.

Os artigos NOWAK e SZERSZEN (2003) e SZERSZEN e NOWAK (2003), como citado anteriormente, documentam a calibração do código americano para estruturas de concreto, considerando a probabilidade de falha medida em termos de confiabilidade estrutural. $\mathrm{O}$ processo de calibração pode ser dividido em passo:

- estudo dos parâmetros estatísticos de resistência por meio de modelos de resistências para os elementos estruturais estudados;

- escolha das combinações das ações aplicando-se a regra de Turkstra;

- seleção de um índice de confiabilidade alvo para todos os casos de projeto, dependendo do tipo de estrutura, de material e das consequências de falha;

- cálculo e seleção fatores de redução da resistência para os estados limites considerados e combinações de carregamentos de projeto estabelecidos com os coeficientes de ação da ASCE 7-98.

No Brasil, o trabalho de NOGUEIRA (2006), sobre pilares curtos de concreto armado, apresenta a importância variável erro de modelo nas análises de confiabilidade e de calibração de normas. Os valores "experimentais" da resistência foram gerados a partir de simulação de Monte Carlos. Além deste outros trabalhos tem sido feitos na UFMG nesta área, dentre estes uma pesquisa desenvolvida por Adriana B. Ribeiro sobre aplicação de confiabilidade estrutural na análise de vigas de concreto sujeitas ao esforço cortante. A base de dados desta pesquisa é constituída por valores experimentais de resistência de vigas com e sem armadura transversal.

Uma análise de confiabilidade para verificar a segurança de pilares mistos preenchidos de seção circular, dimensionados por quatros normas diferentes, apresentou informações importantes (OLIVEIRA et. al, 2008). O trabalho chegou a resultados que mostram a real influência da utilização da variável erro de modelo no índice de confiabilidade, comprovando a necessidade de seu uso no processo de calibração de normas.

Um estudo sobre o modelo de calibração de coeficientes com base em confiabilidade para as normas brasileiras de estruturas metálicas foi exposto em SOUZA JUNIOR (2009), no entanto por falta de dados nacionais para descrever a variável erro de modelo foram adotados valores retirados de pesquisas internacionais. Ainda foram apresentados no mesmo trabalho dados estatísticos de vento baseados na realidade brasileira e uma 
comparação entre os coeficientes parciais adotados na NBR 8800:2008 com os mesmos coeficientes obtidos através do processo de calibração proposto.

Dando continuidade aos estudos de calibração de modelos de previsão de resistência, foram desenvolvidas no SET, Departamento de Estruturas da EESC/USP, três pesquisas em que se fez amplos estudos sobre: ligações parafusadas e perfis metálicos formados a frio, em BOLADIM (2011); peças fletidas de madeira, em ADOLFS (2011); e pilares curtos solicitados à compressão centrada, em SANTIAGO (2011).

\subsection{PESQUISA BIBLIOGRÁFICA}

Foi realizada uma vasta pesquisa bibliográfica em teses e dissertações nacionais à procura de dados sobre ensaios de vigas e pilares sob solicitações normais.

No entanto, devido à escassez de dados sobre na análise de vigas, a avaliação foi realizada através da comparação com os parâmetros da variável erro de modelo fornecidos por NOWAK E SZERSZEN (2003). No Quadro 2.1 são apresentadas as características das vigas analisadas. Com o objetivo de estudar os parâmetros que influenciam a capacidade resistente última das vigas, variou-se os seguintes parâmetros: altura da seção transversal, taxa de armadura longitudinal e resistência à compressão do concreto. Para cada uma destas combinações de características analisou-se vigas com concretos nas classes C20, C25, C30, C35, C40, C45, C50, C60, C70, C80, C90 E C100, totalizando assim 144 vigas analisadas.

\begin{tabular}{|c|c|c|c|c|}
\hline $\mathbf{h}(\mathbf{c m})$ & \multicolumn{3}{|c|}{$\boldsymbol{\rho}_{\text {st }}(\%)$} & $\mathbf{A}_{\text {sc }}$ \\
\hline $\mathbf{3 0}$ & 0,55 & 0,80 & 1,04 & $2 \phi 6.3 \mathrm{~mm}$ \\
\hline $\mathbf{4 0}$ & 1,27 & 1,51 & 1,74 & $2 \phi 8.0 \mathrm{~mm}$ \\
\hline $\mathbf{5 0}$ & 2,00 & 2,26 & 2,51 & $2 \phi 10.0 \mathrm{~mm}$ \\
\hline $\mathbf{6 0}$ & 2,76 & 3,03 & 3,16 & $3 \phi 10.0 \mathrm{~mm}$ \\
\hline
\end{tabular}

QUADRO 2.1 - CARACTERÍSTICAS DAS VIGAS ANALISADAS

No Quadro 2.2 são apresentadas as características gerais, solicitação e resistência do concreto, das pesquisas das quais foram retirados os dados experimentais que compõe a base de dados para estudos dos pilares. A descrição das pesquisas da base de dados encontra-se no Capítulo 4. 


\begin{tabular}{|c|c|c|}
\hline PESQUISA & Solicitação & $\begin{array}{c}\text { Intervalo de } \mathbf{f}_{\mathbf{c}} \\
\text { (MPa) }\end{array}$ \\
\hline AGOSTINI (1992) & compressão centrada & ] $19,84]$ \\
\hline PAIVA (1994) & compressão centrada & ] $19,75]$ \\
\hline LIMA (1997) & $\begin{array}{c}\text { compressão centrada e } \\
\text { flexo-compressão normal }\end{array}$ & ] $79,95]$ \\
\hline VALLADARES (1997) & flexo-compressão normal & ] $29,82]$ \\
\hline VANDERLEI (1999) & flexo-compressão normal & ] $82,90]$ \\
\hline QUEIROGA (1999) & compressão centrada & ] $53,67]$ \\
\hline RAMOS (2001) & compressão centrada & ] $23,29]$ \\
\hline LIMA JUNIOR (2003) & compressão centrada e & ] $43,98]$ \\
\hline flexo-compressão normal & ] $39,67]$ \\
\hline OLIVEIRA (2004) & compressão centrada & ] $42,47]$ \\
\hline ADORNO (2004) & flexo-compressão normal & ] $40,56]$ \\
\hline ARAÚJO (2004) & flexo-compressão normal & ] $42,46]$ \\
\hline DANTAS (2006) & flexo-compressão normal & ] $33,38]$ \\
\hline SANTOS (2009) & flexo-compressão normal & ] $37,46]$ \\
\hline
\end{tabular}

QUADRO 2.2 - CARACTERÍSTICAS GERAIS DAS PESQUISA DA BASE DE DADOS DE PILARES 


\section{Capítulo 3: Modelos de Previsão da CaPaCidade RESISTENTE ÚlTIMA}

\subsection{INTRODUÇÃo}

A presente pesquisa limita-se ao estudo dos elementos de concreto armado mais usuais vigas e pilares. Estes são elementos lineares, cujo comprimento é pelo menos três vezes maior que a maior dimensão da seção transversal, e que têm, respectivamente, como esforços solicitantes preponderantes, flexão e compressão. Analisaram-se vigas solicitadas à flexão pura e pilares solicitados à compressão centrada e excêntrica.

O objetivo deste capítulo é apresentar a previsão da capacidade resistente de vigas e pilares, usando modelos que seguem as recomendações da ABNT NBR 6118:2007 e do ACI 3182002.

Os esforços de ruína - forças de compressão e momentos fletores últimos - encontrados em cada elemento da base de dados foram comparados com os respectivos esforços resistentes teóricos. A resistência teórica foi calculada segundo os princípios de equilíbrio estático da seção transversal, a compatibilidade de deformações e os requisitos estabelecidos pela ABNT NBR 6118:2007 e pelo ACI 318-2002.

A condição de equilíbrio estático da seção transversal é atendida pela igualdade entre as forças normais (tração e compressão) nela atuantes e pelo equilíbrio entre os momentos resistente e solicitante.

A compatibilidade entre as deformações é satisfeita através de duas considerações. A primeira refere-se à perfeita aderência entre o aço e o concreto, e a segunda diz respeito à Hipótese de Bernoulli, segundo a qual as seções transversais permanecem planas durante a deformação. Dessa forma, a deformação em qualquer posição da seção transversal, seja aço ou concreto, é proporcional à distância ao eixo neutro (onde a deformação é nula) e depende do modo de ruína.

As considerações e simplificações sugeridas pela ABNT NBR 6118:2007 e pelo ACI 3182002 são apresentadas a seguir. 


\subsection{REQUISITOS DA ABNT NBR 6118:2007}

A norma ABNT NBR 6118:2007 fixa requisitos básicos exigíveis para projeto de estruturas de concreto simples, armado e protendido, e aplica-se a concretos convencionais com massa específica seca entre 2000 e $2800 \mathrm{~kg} / \mathrm{m}^{3}$ e classe de resistência C10 a C50. No entanto, foram também analisados elementos que não se enquadram nestes quesitos, buscando, de tal forma, verificar a possível adequação dos modelos já existentes a concretos de resistência superior.

O dimensionamento de elementos de concreto armado segue a teoria de estado limite último, pela qual a falha de um membro determina a ruína para o elemento. O estado limite último para solicitações normais pode ocorrer por ruptura (esmagamento) do concreto, quando $\varepsilon_{c c, \max }=\varepsilon_{c c u}$, ou por deformação plástica excessiva da armadura longitudinal, em que $\varepsilon_{\mathrm{s}, \max }=\varepsilon_{\mathrm{su}}=1,0 \%$.

Em síntese, sob a ação de forças normais, aliadas ou não à flexão, o que determina a falha do elemento de concreto armado é a deformação excessiva de um dos componentes.

\subsubsection{DEFORMAÇõES LIMITE E DOMÍNIOS DE DEFORMAÇÃO}

São apresentados na Figura 3.1 os domínios que caracterizam a distribuição de deformações na seção transversal em situações de ruína sob solicitações normais.

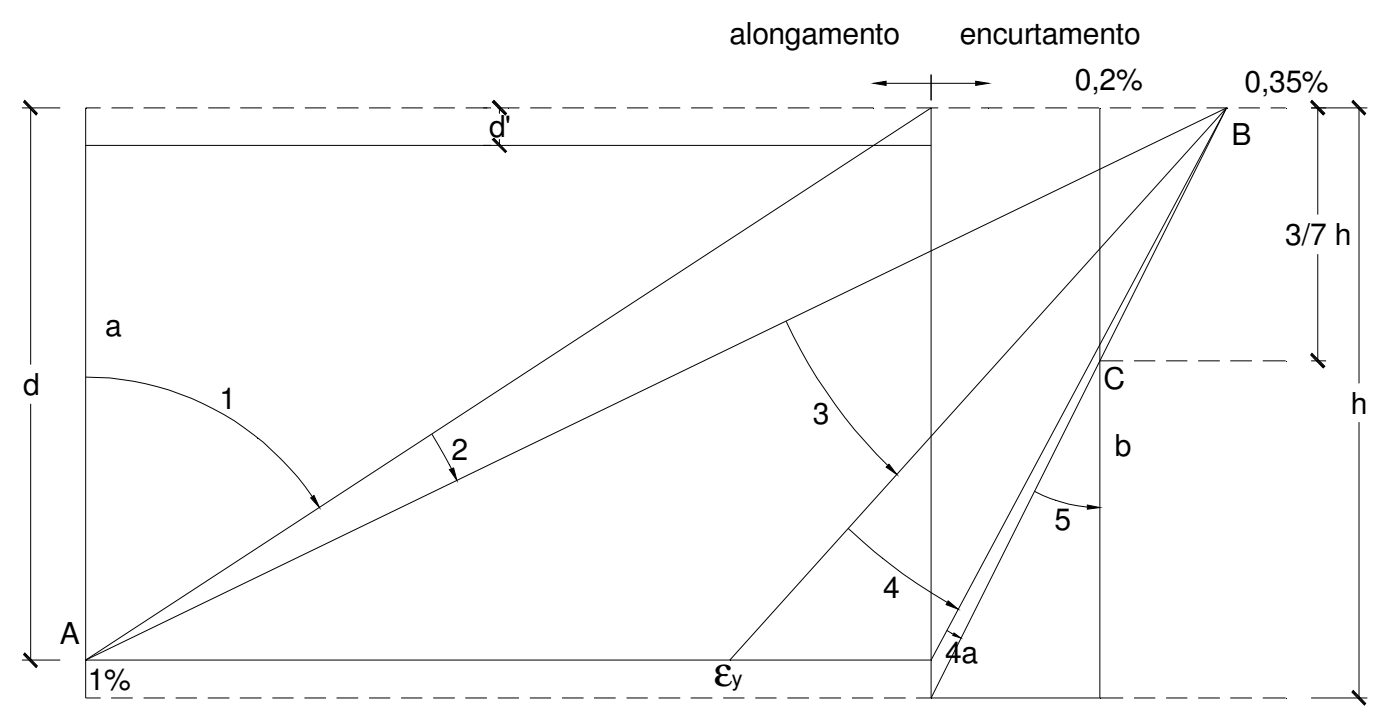

FIGURA 3.1 - DOMÍNIOS DE DEFORMAÇÃO PARA SOLICITAÇõES NORMAIS (ABNT NBR 6118:2007)

Os domínios distinguem-se pelo modo de ruína, consequentemente, pelo nível de deformação na armadura e no concreto e pelo tipo de solicitação do elemento estrutural.

A ruína por deformação plástica excessiva da armadura ocorre nos seguintes domínios: 
a) Reta a: tração uniforme na seção transversal, ocorre em elementos solicitados a tração axial;

b) Domínio 1: tração não uniforme na seção transversal, típica de elementos sob esforço normal de tração com pequena excentricidade;

c) Domínio 2: a linha neutra corta a seção, ou seja, há também compressão na seção transversal. Inclui casos de flexão pura ou flexão composta com forças normais com grande excentricidade, $\varepsilon_{c c, \max }<0,35 \%$.

Nos domínios abaixo, a ruína advém do esmagamento do concreto comprimido:

d) Domínio 3: inclui os mesmos casos do domínio 2, mas $\varepsilon_{\mathrm{cc}, \max }=\varepsilon_{\mathrm{ccu}}=0,35 \% \mathrm{e} \mathrm{a}$ armadura mais tracionada encontra-se em escoamento $-\varepsilon_{\mathrm{y}}<\varepsilon_{\mathrm{s}, \max }<\varepsilon_{\mathrm{su}}=1,0 \%$;

e) Domínio 4: também inclui casos de flexão pura e flexão composta (compressão) com grande excentricidade, $\varepsilon_{\mathrm{cc} \text {, max }}=\varepsilon_{\mathrm{ccu}}=0,35 \%$, e a deformação na armadura mais tracionada é inferior à correspondente ao início do escoamento;

f) Domínio 4a: a linha neutra encontra-se na região de cobrimento da armadura tracionada, portanto a seção útil encontra-se totalmente comprimida, com $\varepsilon_{\mathrm{cc}, \max }=\varepsilon_{\mathrm{ccu}}=0,35 \%$

g) Domínio 5: seção transversal apresenta compressão não uniforme, inclui casos de flexo-compressão com pequena excentricidade, o encurtamento último do concreto é variável $-0,2 \%<\varepsilon_{\mathrm{cc}, \max }=\varepsilon_{\text {cсu }}<0,35 \%$ - sendo que $3 / 7 \mathrm{~h}$ (ponto $\mathrm{C}$ ) a partir da face mais comprimida a deformação é $0,2 \%$;

h) Reta b: compressão uniforme na seção transversal, apresentada em elementos solicitados a compressão axial, o encurtamento último do concreto é $\varepsilon_{\text {cсu }}=0,2 \%$.

\subsubsection{RELAÇÃO TENSÃO X DEFORMAÇÃo}

O diagrama tensão-deformação idealizado para o concreto, mostrado na Figura 3.2 pode ser empregado em análises do estado limite último, permitindo o cálculo da tensão atuante no concreto de acordo com a deformação do mesmo. 


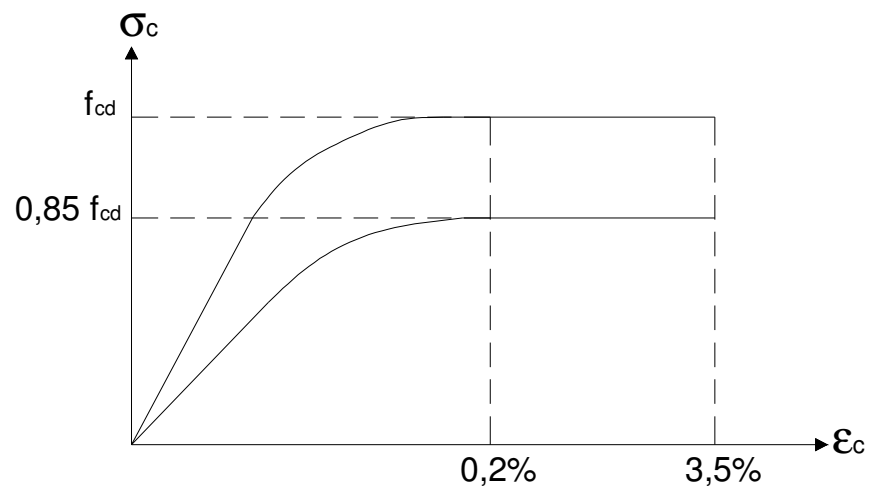

FIGURA 3.2 - DiAGRAMA TENSÃO-DEFORMAÇão IDEALIZADO (ABNT NBR 6118:2007)

Para tensões de compressão menores que $0,5 \mathrm{f}_{\mathrm{c}}$, admite-se uma relação linear entre tensões e deformações, adotando-se para módulo de elasticidade o valor secante dado pela expressão (3.1). Para tensões de compressão superiores $0,5 f_{c}$ e deformações inferiores a 0,2\% pode-se relacionar tensão e deformação através da expressão (3.2).

$$
\begin{aligned}
& E_{c s}=0,85 \cdot E_{c i} \therefore E_{c i}=5600 \cdot f_{c k}^{1 / 2} \\
& \sigma_{c}=0,85 f_{c d}\left[1-\left(1-\frac{\varepsilon_{c}}{0,2 \%}\right)^{2}\right]
\end{aligned}
$$

No entanto, a norma permite que seja utilizado um diagrama de tensões retangular simplificado, assim como o apresentado na Figura 3.4, no qual a tensão na fibra mais comprimida $\sigma_{c}$ continua igual a $0,85 f_{c d}$ e é aplicado um fator multiplicativo de 0,8 à posição da linha. As diferenças entre resultados obtidos usando os dois diagramas são pequenas e aceitáveis.

Segundo FUSCO (1995), o valor 0,85 corresponde a um coeficiente que representa a relação entre a resistência à compressão do concreto nas condições reais de carregamento da estrutura e nas condições de ensaio em laboratório. Este coeficiente único, $\mathrm{k}_{\text {mod }}$, agrupa três influências:

- acréscimo de resistência do concreto obtido depois dos 28 dias até se atingir alguns anos de idade, da ordem de $20 \%-\mathrm{k}_{\bmod , 1}=1,20$;

- efeito deletério de ações de longa duração sobre a resistência do concreto, reduzindo-a em $75 \%$ da resistência potencial que poderia ser atingida com longos períodos de maturação, "efeito Rüsch" $-\mathrm{k}_{\text {mod, } 2}=0,75$; 
- diferença entre a resistência do concreto da estrutura e a dos corpos de prova de controle, proveniente da influência das placas da prensa sobre os corpos de prova, utiliza-se um coeficiente de redução $\mathrm{k}_{\text {mod, } 3}=0,95$.

Portanto:

$$
\begin{gathered}
\mathrm{k}_{\text {mod }}=\mathrm{k}_{\text {mod }, 1} \cdot \mathrm{k}_{\text {mod }, 2} \cdot \mathrm{k}_{\text {mod, } 3} \\
\mathrm{f}_{\mathrm{c} \text { estrutura }}=\mathrm{k}_{\text {mod }} \cdot \mathrm{f}_{\mathrm{c}, 28}
\end{gathered}
$$

Para a pesquisa em questão, algumas particularidades tiveram de ser consideradas na determinação do $\mathrm{k}_{\bmod }$. Ou seja, como os elementos estruturais (vigas e pilares) e os corposde-prova foram ensaiados no mesmo dia e sob ações de curta duração, os respectivos coeficientes receberam o valor igual a 1,00. Além disso, a data dos ensaios foi aos i dias e, portanto, teve-se $\mathrm{f}_{\mathrm{ci}}$ ao invés de $\mathrm{f}_{\mathrm{c} 28}$. Deste modo, a relação passou a ser:

$$
\mathrm{f}_{\mathrm{c}, \text { elemento }}=\mathrm{k}_{\text {mod }} \cdot \mathrm{f}_{\mathrm{ci}} \text {, onde } \mathrm{k}_{\text {mod }}=\mathrm{k}_{\text {mod, } 3}=0,95 \text {. }
$$

Dessa forma, foi admito que a ruptura do concreto ocorrera sob uma tensão de $0,95 f_{c i}$, resistência média à compressão obtida pelos corpos-de-prova no dia do ensaio.

\subsubsection{CÁLCULO DE DEFORMAÇõES NA SEÇÃO TRANSVERSAL}

De posse das recomendações feitas pela ABNT NBR 6118:2007 e considerando uma seção genérica (Figura 3.3) de um elemento linear de concreto armado, é possível fazer algumas conclusões sobre deformações e tensões no concreto e no aço.

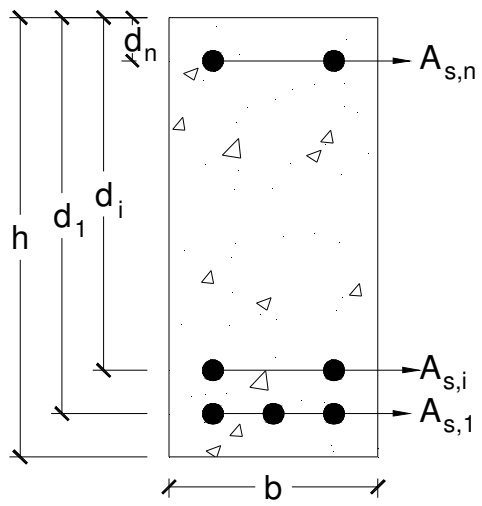

FIGURA 3.3 - SEÇÃO TRANSVERSAL GENÉRICA n - quantidade de camadas da armadura

i - numeração das camadas, varia de 1 a n

$n_{i}$ - quantidade de barras de aço na camada $i$

b - espessura da seção transversal

h - altura da seção transversal

$d_{i}$ - distância da face mais comprimida da seção ao centro de gravidade da armadura da camada $\mathrm{i}$ $A_{s, i}$ - área de aço na camada $\mathrm{i}$

São apresentados, na Figura 3.4, os diagramas de deformação e de tensão (parábolaretângulo e retangular) sugeridos pela ABNT NBR 6118:2007 para casos de flexão pura ou composta com pequena excentricidade. 


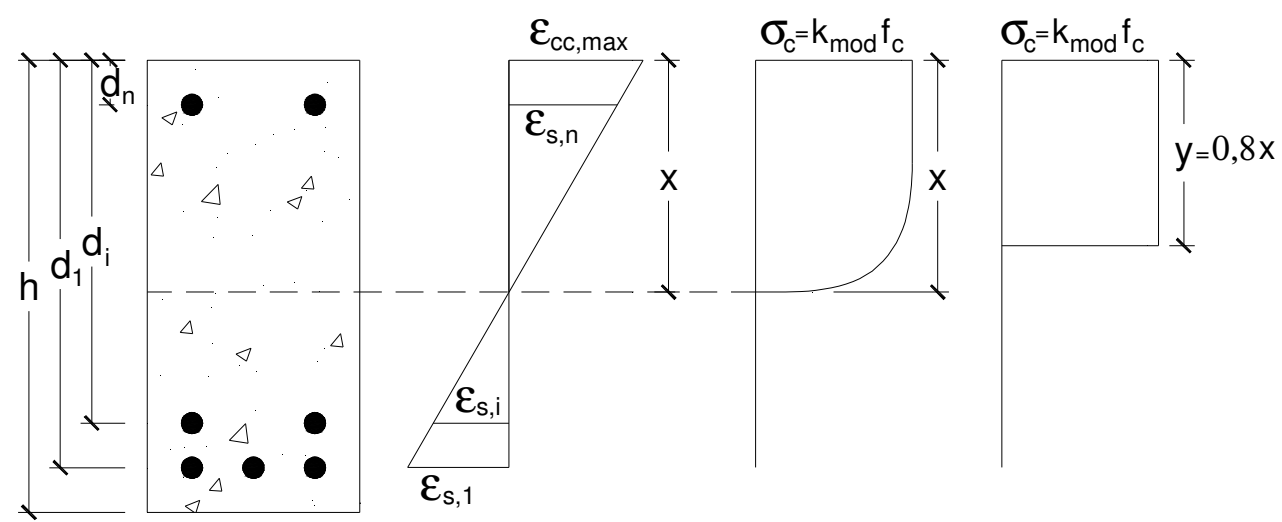

FIGURA 3.4 - DiAGRAMAS DE TENSÃo E DEFORMAÇÃO, SEGUNDO ABNT NBR 6118:2007

As fórmulas para o cálculo das deformações nas armaduras e o intervalo de variação da posição da linha neutra, conforme o domínio de deformação em que se encontra a seção, são apresentadas no Erro! Fonte de referência não encontrada.:

\begin{tabular}{|c|c|c|}
\hline DOMÍNIO & Intervalo de $x$ & $\begin{array}{c}\text { Deformação na } \\
\text { armadura }\end{array}$ \\
\hline reta a & $x=-\infty$ & $\varepsilon_{\mathrm{s}, \mathrm{i}}=-1 \%$ \\
\hline domínio 1 & $-\infty<x \leq 0$ & \multirow[b]{2}{*}{$\varepsilon_{\mathrm{s}, \mathrm{i}}=0,010 \cdot \frac{\left(\mathrm{x}-\mathrm{d}_{\mathrm{i}}\right)}{\mathrm{d}_{1}-\mathrm{x}}$} \\
\hline domínio 2 & $0<x \leq \frac{3,5}{13,5} \cdot d_{1}$ & \\
\hline domínio 3 & $\frac{3,5}{13,5} \cdot d_{1}<x \leq \frac{0,0035}{0,0035+f_{y} / E_{s}} \cdot d_{1}$ & \multirow{2}{*}{$\varepsilon_{\mathrm{s}, \mathrm{i}}=0,0035 \cdot \frac{\left(\mathrm{x}-\mathrm{d}_{\mathrm{i}}\right)}{\mathrm{x}}$} \\
\hline domínio 4 & $\frac{0,0035}{0,0035+f_{y} / E_{s}} \cdot d_{1}<x \leq h$ & \\
\hline domínio 5 & $\mathrm{~h}<\mathrm{x}<+\infty$ & $\varepsilon_{\mathrm{s}, \mathrm{i}}=0,002 \cdot \frac{\left(\mathrm{x}-\mathrm{d}_{\mathrm{i}}\right)}{\mathrm{x}-3 / 7 \cdot \mathrm{h}}$ \\
\hline reta $b$ & $x=+\infty$ & $\varepsilon_{\mathrm{s}, \mathrm{i}}=0,2 \%$ \\
\hline
\end{tabular}

QUADRO 3.1 - DOMÍNIOS DE DEFORMAÇÃO E INTERVALOS DA LINHA NEUTRA - ABNT NBR 6118:2007

\subsection{REQUISITOS DO ACI 318-2002}

O ACI 318-2002 estabelece requisitos mínimos para projeto e construção de elementos estruturais de concreto de qualquer estrutura erguida sob os requisitos do código geral de construção americano. Para o concreto estrutural, a resistência especificada à compressão não deve ser inferior a 2500psi (17MPa) e não há restrição à resistência à compressão máxima, nem à massa específica ou ao tipo de agregado. A norma abrange todo o espectro de aplicações estruturais de concreto. 


\subsubsection{DEFORMAÇõES LIMITES E DOMÍNIOS DE DEFORMAÇÃo}

Segundo ACI 318-2002, a resistência nominal à flexão de um membro é atingida quando o encurtamento na fibra mais comprimida do concreto alcança o limite de deformação de 0,3\% ou quando o alongamento da camada de armadura mais tracionada é maior ou igual 0,5\%. As deformações na armadura e no concreto são determinadas a partir de uma distribuição linear conforme o diagrama de deformações apresentado na Figura 3.5.

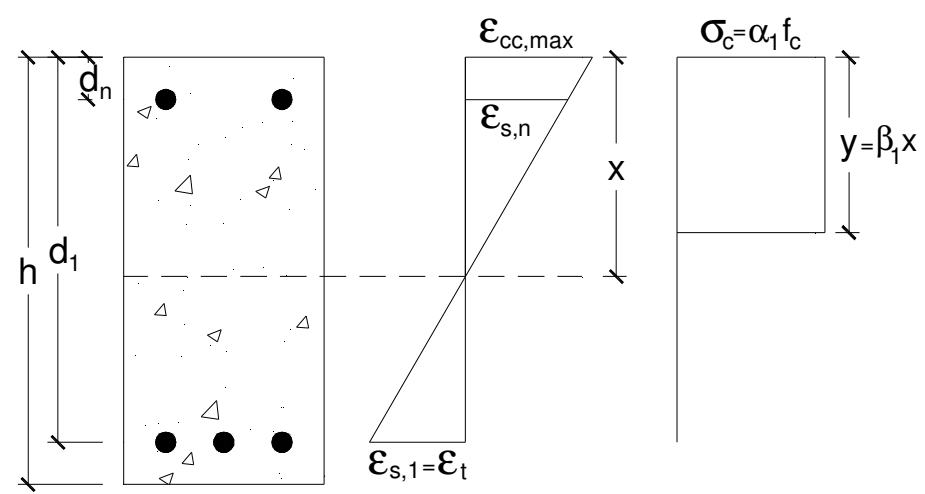

FIGURA 3.5 - DiAGRAMA DE DEFORMAÇÕES E BLOCO DE TENSÕES RETANGULAR, SEGUNDO ACI 318-2002

No estado limite para flexão, norma utiliza conceitos de tension-controlled, quando o alongamento na armadura mais tracionada, $\varepsilon_{\mathrm{t}}$, for igual ou maior a $0,5 \%$, e compressioncontrolled, quando $\varepsilon_{\mathrm{t}}$ for igual ou menor que deformação do aço no início do escoamento e a face (mais) comprimida do concreto tiver deformação igual ao valor limite. Para aço Classe 60 e para todos os aços de protensão, a deformação no início do escoamento pode ser assumida como igual a $0,2 \%$. Algumas seções, como aquelas em que a carga axial é pequena e momentos fletores são grandes ou sujeitas a esforços normais de grande excentricidade, terão $\varepsilon_{\mathrm{t}}$ entre os limites acima. Essas seções estão em uma região entre tension-controlled e compression-controlled, nomeada pela norma por trasition.

Em seções configuradas pelos domínios tension-controlled e trasition, é esperado um aviso de falha com deformação excessiva e fissuras, enquanto em seções compression-controlled, é esperada uma ruína frágil, com pouco aviso da falha iminente.

A partir das deformações limites estabelecidas pela norma americana, foi possível construir um diagrama das configurações de deformação da seção transversal de elementos flexionados no estado limite último. (Figura 3.6) 


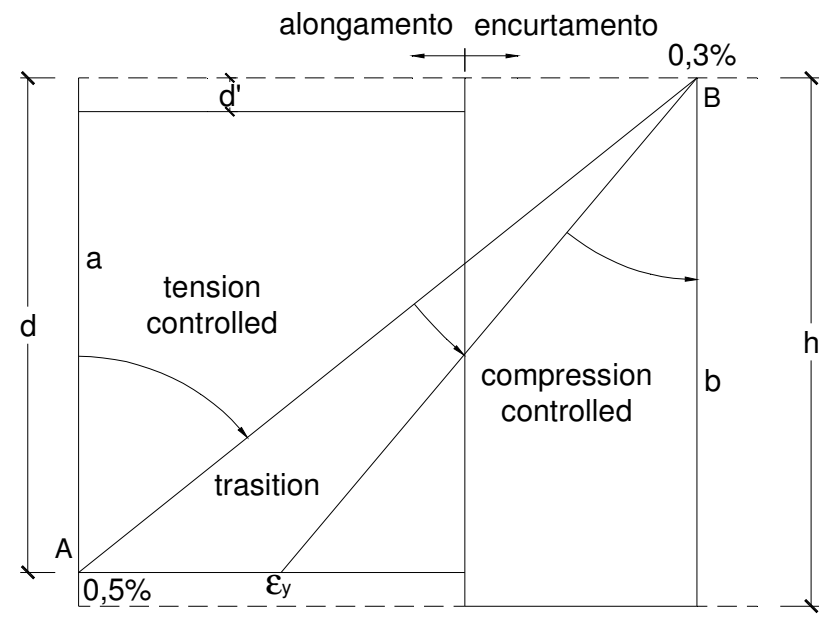

FIGURA 3.6 - DOMÍNIOS DE DEFORMAÇÃO NA FLEXÃO, SEGUNDO REQUISITOS DO ACI 318-2002

Os fatores de redução da resistência especificados pela norma são: 0,65 na região de compression-controlled, aumentando linearmente com a deformação até atingir 0,90 na região de tension-controlled, portanto em regiões transitions esse fator dado por:

$$
\phi=0,65+\frac{250}{3}\left(\varepsilon_{\mathrm{t}}-0,002\right)
$$

\subsubsection{RELAÇÃO TENSÃo X DEFORMAÇÃO}

O ACI 318-2002 especifica a determinação da resistência à compressão do concreto usando corpos-de-prova cilíndricos de dimensões $15 \mathrm{~cm}$ x $30 \mathrm{~cm}$. De acordo com os dados do ensaio, pode-se assumir diagramas retangulares, trapezoidais, parabólicos ou outros que fornecem a distribuição de tensão de compressão em função da deformação do concreto.

O diagrama retangular de tensões assumido pelo ACI é definido por dois parâmetros, $\alpha_{1}$ e $\beta_{1}$, como mostra a Figura 3.5. O parâmetro $\alpha_{1}$ é assumido como uma constante igual a 0,85. O parâmetro $\beta_{1}$ é igual a 0,85 para concretos com resistência até $28 \mathrm{MPa}$ (4000psi), e deve ser reduzido linearmente a uma razão de 0,05 para cada $7 \mathrm{MPa}(1000 \mathrm{psi})$ de resistência excedente a $28 \mathrm{MPa}$, mas não deve ser menor que 0,65. Assim, quando a resistência do concreto estiver entre $28 \mathrm{MPa}$ e $62 \mathrm{MPa}$, a fórmula para o cálculo de $\beta_{1}$ é:

$$
\beta_{1}=0,85-0,05 \cdot \frac{f_{c}^{\prime}-28}{7}, \text { com } f_{c}^{\prime} \text { em MPa. }
$$

Os coeficientes $\alpha_{1}$ e $\beta_{1}$ têm como equivalentes na norma brasileira, respectivamente, $k_{\text {mod }}$ e 0,8 (fator de redução da profundidade da linha neutra no diagrama de tensão retangular simplificado). 


\subsubsection{CÁlCULO DE DEFORMAÇõES NA SEÇÃO TRANSVERSAL}

Usando como referência a seção genérica apresentada na Figura 3.3, as recomendações feitas pela ACI 318-2002 e os domínios criados a partir do código, são apresentadas no Quadro 3.2 as fórmulas para o cálculo das deformações nas armaduras e o intervalo de posição da linha neutra para cada domínio.

\begin{tabular}{|c|c|c|}
\hline \multicolumn{1}{|c|}{ DOMÍNIO } & \multicolumn{2}{|c|}{$\begin{array}{c}\text { Deformação na } \\
\text { armadura }\end{array}$} \\
\hline tension-controlled & $0<\mathrm{x} \leq \frac{3}{8} \cdot \mathrm{d}_{1}$ & \multirow{2}{*}{$\varepsilon_{\mathrm{s}, \mathrm{i}}=0,005 \cdot \frac{\left(\mathrm{x}-\mathrm{d}_{\mathrm{i}}\right)}{\mathrm{d}_{1}-\mathrm{x}}$} \\
\hline transition & $\frac{3}{8} \cdot \mathrm{d}_{1}<\mathrm{x} \leq \frac{0,003}{0,003+\frac{\mathrm{f}}{\mathrm{y}} / \mathrm{E}_{\mathrm{s}}} \cdot \mathrm{d}_{1}$ & \multirow{2}{*}{$\varepsilon_{\mathrm{si}}=0,003 \cdot \frac{\left(\mathrm{x}-\mathrm{d}_{\mathrm{i}}\right)}{\mathrm{x}}$} \\
\hline compression-controlled & $\frac{0,003}{0,003+\frac{\mathrm{f}_{\mathrm{y}} / \mathrm{E}_{\mathrm{s}}}{\mathrm{n}} \cdot \mathrm{d}_{1}<\mathrm{x}<+\infty}$ & \\
\hline axial compression & $\mathrm{x}=+\infty$ & \\
\hline
\end{tabular}

QUADRO 3.2 - DOMÍNIOS DE DEFORMAÇ̃̃o E INTERVALOS DA LINHA NEUTRA - ACI 318-2002

É importante ressaltar que a ruína é determinada apenas pelo encurtamento excessivo do concreto, portanto todos os domínios possuem a mesma expressão para a deformação

\subsection{VERIFICAÇÃO DA CAPACIDADE RESISTENTE DE VIGAS SUJEITAS À FLEXÃO PURA}

O estado limite último de vigas depende do tipo de solicitação - normal ou transversal. Quando somente o momento fletor atua na seção, com forças cortantes e normais nulas, diz-se que as vigas estão sujeitas à flexão pura. Neste trabalho foram analisadas apenas vigas sob flexão pura.

\subsubsection{MODELO DA ABNT NBR 6118:2007}

O dimensionamento segundo a ABNT NBR 6118:2007 é feito considerando o estado limite último, portanto estádio III de carregamento. Neste nível de solicitação, a seção transversal das vigas encontra-se plastificada, desprezando a resistência à tração do concreto, e as deformações não são proporcionais às tensões de compressão. É utilizado o diagrama de tensões retangular simplificado. 


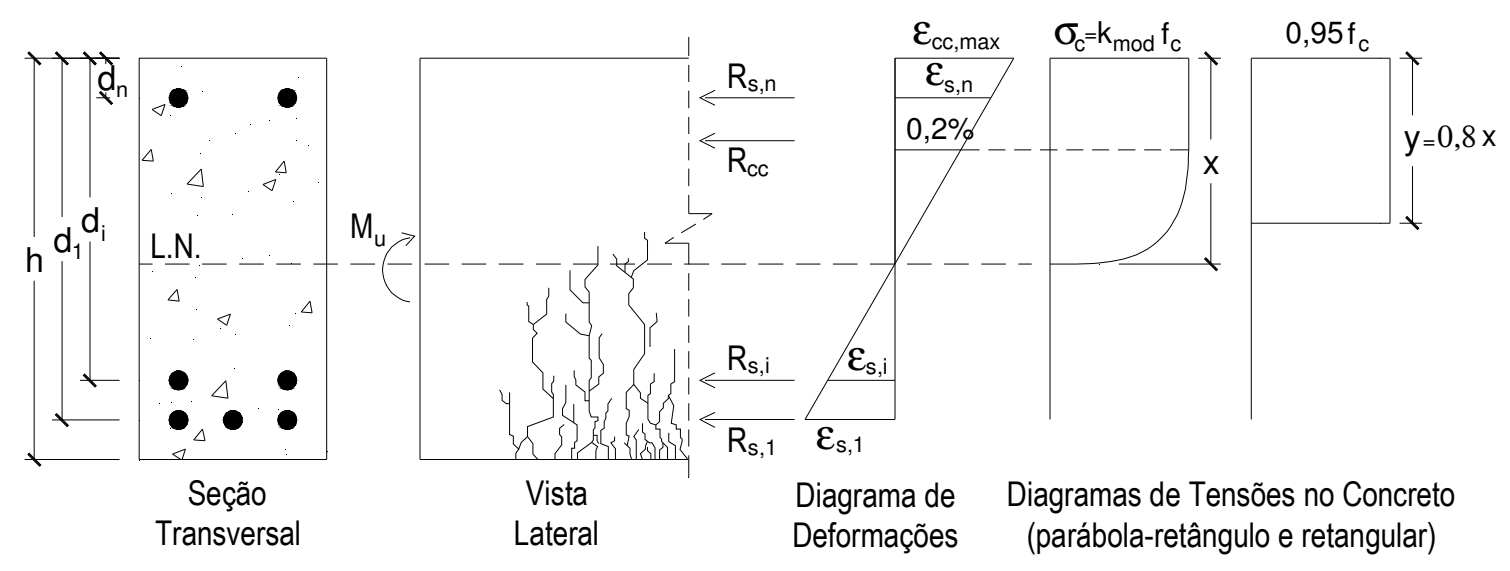

FIGURA 3.7 - COMPORTAMENTO DO CONCRETO NA FLEXÃO PURA

As equações que configuram o equilíbrio estático da seção, em caso de flexão pura, são:

$$
\begin{gathered}
\mathrm{R}_{\mathrm{cc}}+\sum_{\mathrm{i}=1}^{\mathrm{n}} \mathrm{R}_{\mathrm{s}, \mathrm{i}}=0 \\
\mathrm{M}_{\mathrm{u}}+\mathrm{R}_{\mathrm{cc}} \cdot \mathrm{y} / 2+\sum_{\mathrm{i}=1}^{\mathrm{n}}\left(\mathrm{R}_{\mathrm{s}, \mathrm{i}} \cdot \mathrm{d}_{\mathrm{i}}\right)=0
\end{gathered}
$$

utilizando a nomenclatura especificada na Figura 3.3 e sendo: $M_{u}$ o momento de ruína da peça, $R_{c c}$ a força normal resistente do concreto comprimido e $R_{s, i}$ a força normal resistente da armadura da camada i.

As forças resistentes do concreto e da armadura são:

$$
\begin{gathered}
R_{c c}=A_{c c} \cdot \sigma_{c}=y \cdot b \cdot f_{c, v i g a} \\
R_{s, i}=A_{s, i} \cdot \sigma_{s, i}
\end{gathered}
$$

onde $\sigma_{c}$ é a tensão no concreto comprimido e $\sigma_{\mathrm{s}, \mathrm{i}}$ é a tensão na armadura da camada i. Substituindo as expressões de reações (3.6) e (3.7) na equação de equilíbrio das forças (3.5) e de momentos (3.6) e sabendo que $y=0,8 \cdot \times$ e $f_{c, \text { viga }}=k_{\text {mod }} \cdot f_{c}$, tem-se:

$$
\begin{gathered}
0,8 \cdot b \cdot k_{\text {mod }} \cdot f_{c} \cdot x+\sum_{i=1}^{n}\left(A_{s, i} \cdot \sigma_{s, i}\right)=0 \\
M_{u}+0,32 \cdot b \cdot k_{\text {mod }} \cdot f_{c} \cdot x^{2}+\sum_{i=1}^{n}\left(A_{s, i} \cdot \sigma_{s, i} \cdot d_{i}\right)=0
\end{gathered}
$$

A equação (3.8) fornece a profundidade da linha neutra e a equação (3.9) fornece o momento de ruína. Entretanto, a incógnita $x$, que define a posição da linha neutra, não pode ser obtida diretamente. É necessário saber qual a configuração (domínio de deformação) na ruína da seção transversal. 
Inicialmente, supõe-se que a ruína ocorre no domínio 2. Como mencionado anteriormente, esse domínio é caracterizado pelo alongamento excessivo na camada da armadura mais tracionada, $\varepsilon_{\mathrm{s}, 1}=1,0 \%$ e encurtamento na face mais comprimida da seção inferior a $\varepsilon_{c c u}$. Portanto, é provável que todas as armaduras tracionadas estejam em escoamento e, consequentemente, sejam submetidas a uma tensão $\sigma_{s}=-f_{y}$, exceto quando a posição de uma armadura $d_{i}$ for menor que $d_{2, \text { lim }}$, variável que mede a maior distância da face comprimida ao ponto em que uma armadura ali localizada ainda estaria em escoamento.

Essas considerações são apresentadas no algoritmo a seguir.

\section{ALGORITMO A - Cálculo de $M_{u}$ em vigas submetidas à flexão pura, segundo ABNT}

\section{NBR 6118:2007:}

\section{A.1 Verificação de escoamento nas camadas da armadura no domínio 2}

Por semelhanças dos triângulos $A B C$ e ADE, na Figura 3.8, calcula-se $d_{2, \text { lim }}$.

O cálculo de $d_{2, \text { lim }}$ é feito de maneira conservadora, supondo que a linha neutra esteja no limite entre os domínios 2 e 3, e assim, reduzindo a possibilidade dos níveis de armadura estarem em escoamento.

$$
\frac{d_{2, \lim }}{d_{1}}=\frac{0,0035+\varepsilon_{y}}{0,0135} \rightarrow d_{2, \lim }=\frac{0,0035+f_{y} / E_{s}}{0,0135} \cdot d_{1}
$$

Nas camadas em que $d_{i} \geq d_{2, \text { lim }}, \sigma_{s, i}=-f_{y}$. Caso contrário, calcula-se a tensão na armadura através da lei de Hooke $\sigma_{\mathrm{s}, \mathrm{i}}=\mathrm{E}_{\mathrm{s}} \cdot \varepsilon_{\mathrm{s}, \mathrm{i}}$, usando a deformação conforme a equação do Quadro 3.1 para o domínio 2.

\section{A.2 Cálculo da posição da linha neutra no domínio 2}

Substituindo a fórmula de $\sigma_{\mathrm{s}, \mathrm{i}}$ na equação (3.8), sendo j o número de camadas de aço em escoamento e organizando a equação em termos de $x$, a equação de equilíbrio de forças apresenta-se da seguinte forma:

$$
\begin{gathered}
\left(0,8 \cdot b \cdot k_{\text {mod }} \cdot f_{c}\right) \cdot x^{2}+ \\
-\left(0,8 \cdot b \cdot d_{1} \cdot k_{\text {mod }} \cdot f_{c}+f_{y} \cdot \sum_{i=1}^{j} A_{s, i}+0,01 \cdot E_{s} \cdot \sum_{i=j+1}^{n} A_{s, i}\right) \cdot x+ \\
+d_{1} \cdot f_{y} \cdot \sum_{i=1}^{j} A_{s, i}+0,01 \cdot E_{s} \cdot \sum_{i=j+1}^{n}\left(A_{s, i} \cdot d_{i}\right)=0
\end{gathered}
$$




\section{A.3 Cálculo do momento resistente último no domínio 2}

Se o valor encontrado para $\mathrm{x}$ estiver no intervalo referente ao domínio 2 , como apresentado no Quadro 3.1, o próximo passo é calcular o momento resistente último através da equação (3.12). Caso contrário, admite-se que a configuração de deformação na ruína está no domínio 3.

$$
\begin{aligned}
M_{u}= & -0,32 \cdot b \cdot k_{\bmod } \cdot f_{c} \cdot x^{2}+f_{y} \cdot \sum_{i=1}^{j}\left(A_{s, i} \cdot d_{i}\right)+ \\
& -\frac{0,01 \cdot E_{s}}{d_{1}-x} \cdot \sum_{i=j+1}^{n}\left[A_{s, i} \cdot\left(x-d_{i}\right) \cdot d_{i}\right]
\end{aligned}
$$

No domínio 3 a ruína ocorre por esmagamento do concreto com deformação na face comprimida de $\varepsilon_{\mathrm{cc}, \max }=0,35 \%$. A armadura mais tracionada está em escoamento, mas com deformação inferior a $\varepsilon_{\mathrm{su}}$. O procedimento para o cálculo da posição da linha neutra $\mathrm{x}$ e do momento resistente último é semelhante ao realizado anteriormente:

\section{A.4 Verificação de escoamento nos níveis de armadura no domínio 3}

Por semelhanças dos triângulos ABC e ADE, na Figura 3.9, pode-se calcular $d_{3, \text { lim }}$ :

$$
\frac{d_{3, \text { lim }}}{x}=\frac{0,0035+\varepsilon_{y}}{0,0035} \rightarrow d_{3, \text { lim }}=\frac{0,0035+f_{y} / E_{s}}{0,0035} \cdot x
$$

Como $d_{3, \text { lim }}$ é função de $x$, inicialmente, supõe-se que a profundidade da linha neutra seja igual ao valor encontrado no passo A.2 e calcula-se $d_{3, \text { lim }}$. Nas camadas de armadura em que $d_{i} \geq d_{3, \text { lim }}, \sigma_{s, i}=-f_{y}$. Para as demais camadas, utiliza-se a lei de Hooke para o cálculo das tensões, usando a fórmula de deformação do Quadro 3.1 para o domínio 3 .

\section{A.5 Cálculo da posição da linha neutra no domínio 3}

Sendo j o número de camadas em escoamento e conhecendo a tensão nas armaduras, a equação para o cálculo da linha neutra:

$$
\begin{gathered}
\left(0,8 \cdot b \cdot k_{\bmod } \cdot f_{c}\right) \cdot x^{2}-\left(f_{y} \cdot \sum_{i=1}^{j} A_{s, i}-0,0035 \cdot E_{s} \cdot \sum_{i=j+1}^{n} A_{s, i}\right) \cdot x+ \\
-0,0035 \cdot E_{s} \cdot \sum_{i=j+1}^{n}\left(A_{s, i} \cdot d_{i}\right)=0
\end{gathered}
$$


Somente para verificação, pode-se ainda recalcular $d_{3 \text { lim }}$ e confirmar se o número de camadas em escoamento é, realmente, j.

\section{A.6 Cálculo do momento resistente último no domínio 3}

Se o valor encontrado para $\mathrm{x}$ no item anterior estiver no intervalo apresentado no Quadro 3.1 para o domínio 3, calcula-se o momento último resistente pela fórmula (3.15). Caso contrário, a configuração de deformação na ruína corresponde ao domínio 4.

$$
\begin{aligned}
M_{u}= & -0,32 \cdot b \cdot k_{\text {mod }} \cdot f_{c} \cdot x^{2}+f_{y} \cdot \sum_{i=1}^{j}\left(A_{s, i} \cdot d_{i}\right)+ \\
& -\frac{0,0035 \cdot E_{s}}{x} \cdot \sum_{i=j+1}^{n}\left[A_{s, i} \cdot\left(x-d_{i}\right) \cdot d_{i}\right]
\end{aligned}
$$

$\mathrm{O}$ procedimento para o cálculo da posição da posição da linha neutra $\mathrm{x}$ e do momento resistente último é semelhante ao realizado anteriormente:

\section{A.7 Cálculo da posição da linha neutra no domínio 4}

No domínio 4, a ruína também ocorre por esmagamento do concreto com deformação $\varepsilon_{c c, \max }=0,35 \%$ e todas as armaduras estão sob tensões inferiores a $f_{y}$.

$$
\left(0,8 \cdot b \cdot k_{\bmod } \cdot f_{c}\right) \cdot x+\sum_{i=1}^{n}\left(A_{s, i} \cdot E_{s} \cdot \varepsilon_{s, i}\right)=0
$$

Substituindo a expressão para a deformação das armaduras no domínio 4 na equação (3.16) e organizando em função de $x$, tem-se:

$$
\begin{gathered}
\left(0,8 \cdot b \cdot k_{\bmod } \cdot f_{c}\right) \cdot x^{2}+\left(0,0035 \cdot E_{s} \cdot \sum_{i=1}^{n} A_{s, i}\right) \cdot x+ \\
-0,0035 \cdot E_{s} \cdot \sum_{i=1}^{n}\left(A_{s, i} \cdot d_{i}\right)=0
\end{gathered}
$$

O último passo é o cálculo da capacidade da viga.

\section{A.8 Cálculo do momento resistente último no domínio 4}

$$
M_{u}=-0,32 \cdot b \cdot k_{\text {mod }} \cdot f_{c} \cdot x^{2}-\frac{0,0035 \cdot E_{s}}{x} \cdot \sum_{i=1}^{n}\left[A_{s, i} \cdot\left(x-d_{i}\right) \cdot d_{i}\right]
$$

\section{FIM DO ALGORITMO A}




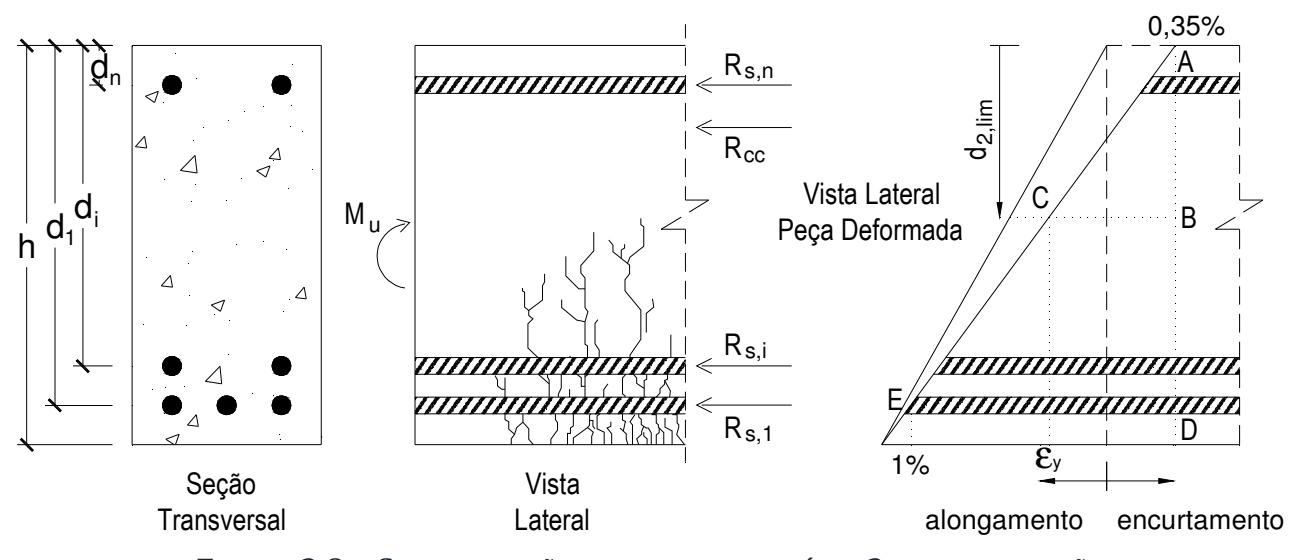

FIGURA 3.8 - CONFIGURAÇÃO LATERAL NO DOMÍNIO 2 DE DEFORMAÇÃO

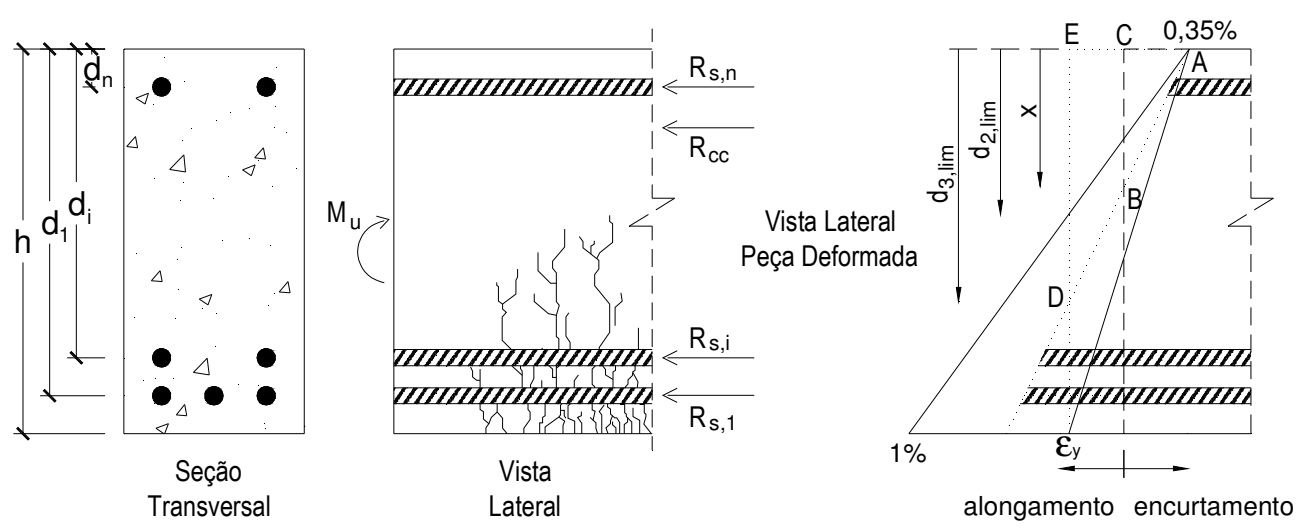

FIGURA 3.9 - CONFIGURAÇÃO LATERAL NO DOMÍNIO 3 DE DEFORMAÇÃO

\subsubsection{MODELO DO ACI 318-2002}

O modelo de dimensionamento proposto pelo ACI 318-2002 para elementos fletidos é semelhante ao da norma brasileira. A resistência à tração do concreto também é desprezada. Portanto, as equações de equilíbrio estático e as expressões das resultantes no concreto e nas armaduras são as mesmas já apresentadas, (3.5) a (3.7).

Substituindo as expressões de reações na equação de equilíbrio e sabendo que $y=\beta_{1} \cdot x$ e $\mathrm{f}_{\mathrm{c}, \text { viga }}=\alpha_{1} \cdot \mathrm{f}_{\mathrm{c}}$, tem-se:

$$
\begin{gathered}
\beta_{1} \cdot b \cdot \alpha_{1} \cdot f_{c} \cdot x+\sum_{i=1}^{n}\left(A_{s, i} \cdot \sigma_{s, i}\right)=0 \\
M_{u}+\beta^{2} / 2 \cdot b \cdot k_{\text {mod }} \cdot f_{c} \cdot x^{2}+\sum_{i=1}^{n}\left(A_{s, i} \cdot \sigma_{s, i} \cdot d_{i}\right)=0
\end{gathered}
$$

De posse das características físicas e geométricas do elemento, a equação (3.19) indica a profundidade da linha neutra e a equação (3.20), o momento de ruína. O procedimento é o mesmo utilizado no modelo brasileiro: para encontrar a posição da linha neutra $x$, é necessário presumir, inicialmente, em que domínio de deformação ocorre a ruína. 
Existe uma correspondência entre os domínios de deformação criados a partir dos requisitos estabelecidos pelo ACI 318-2002 e com aqueles propostos pela norma brasileira. Respeitando as deformações limites apresentadas em cada código, o domínio tensioncontrolled equivale ao domínio 2, o domínio transition ao domínio 3 e o compressioncontrolled ao domíno 4.

Inicialmente, supõe-se que a ruína ocorre no domínio tension-controlled, caracterizado pelo alongamento excessivo na armadura mais tracionada, $\varepsilon_{\mathrm{s}, \max }=0,5 \%$, e encurtamento na face mais comprimida da seção inferior a $\varepsilon_{\text {ccu }}$. O cálculo é feito conforme o algoritmo B:

\section{ALGORITMO B - Cálculo de $\mathrm{M}_{u}$ em vigas submetidas à flexão pura, segundo ACI} 318-2002:

\section{B.1 Verificação de escoamento nos níveis de armadura no domínio tension- controlled}

Para o cálculo da tensão nas armaduras, calcula-se $d_{t c, l i m}$, por semelhanças dos triângulos $\mathrm{ABC}$ e $\mathrm{ADE}$ da Figura 3.10, e verifica-se quantas camadas estão em escoamento, com tensão $\sigma_{\mathrm{s}, \mathrm{i}}=-f_{\mathrm{y}}$. $\mathrm{O}$ cálculo de $d_{\mathrm{tc}, \mathrm{lim}}$ é feito de maneira conservadora, supondo que a linha neutra esteja no limite entre os domínios tensioncontrolled e transition, para que não haja previsão de escoamento em armaduras que não o estão.

$$
\frac{d_{t c, \text { lim }}}{d_{1}}=\frac{0,003+\varepsilon_{y}}{0,008} \rightarrow d_{t c, \text { lim }}=\frac{0,003+f_{y} / E_{s}}{0,008} \cdot d_{1}
$$

Nas armaduras em que $d_{i} \geq d_{t c, \text { lim }}, \sigma_{s, i}=-f_{y}$. Caso contrário, calcula-se a tensão na armadura através da lei de Hooke $\sigma_{\mathrm{s}, \mathrm{i}}=\mathrm{E}_{\mathrm{s}} \cdot \varepsilon_{\mathrm{s}, \mathrm{i}}$, usando a deformação conforme a equação do Quadro 3.2 para o domínio tension-controlled.

\section{B.2 Cálculo da posição da linha neutra no domínio tension-controlled}

Substituindo o valor de $\sigma_{\mathrm{s}, \mathrm{i}}$ na equação (3.19), sendo j o número de camadas de aço em escoamento e organizando a equação em termos de $x$, a equação de equilíbrio de forças apresenta-se na equação (3.22): 


$$
\begin{gathered}
\left(\beta_{1} \cdot b \cdot \alpha_{1} \cdot f_{c}\right) \cdot x^{2}+ \\
-\left(\beta_{1} \cdot b \cdot d_{1} \cdot \alpha_{1} \cdot f_{c}+f_{y} \cdot \sum_{i=1}^{j} A_{s, i}+0,005 \cdot E_{s} \cdot \sum_{i=j+1}^{n} A_{s, i}\right) \cdot x+ \\
+d_{1} \cdot f_{y} \cdot \sum_{i=1}^{j} A_{s, i}+0,005 \cdot E_{s} \cdot \sum_{i=j+1}^{n}\left(A_{s, i} \cdot d_{i}\right)=0
\end{gathered}
$$

\section{B.3 Cálculo do momento resistente último no domínio tension-controlled}

Se o valor encontrado para $\mathrm{x}$ estiver no intervalo referente ao domínio tensioncontrolled, como apresentado no Quadro 3.2, o próximo passo é calcular o momento resistente último através da equação (3.23). Caso contrário, é suposto que a posição da linha neutra encontra-se no domínio transition.

$$
\begin{aligned}
M_{u}= & -\beta_{1}^{2} / 2 \cdot b \cdot \alpha_{1} \cdot f_{c} \cdot x^{2}+f_{y} \cdot \sum_{i=1}^{j}\left(A_{s, i} \cdot d_{i}\right)+ \\
& -\frac{0,005 \cdot E_{s}}{d_{1}-x} \cdot \sum_{i=j+1}^{n}\left[A_{s, i} \cdot\left(x-d_{i}\right) \cdot d_{i}\right]
\end{aligned}
$$

No domínio transition, a ruína ocorre por esmagamento do concreto com deformação na face comprimida de $\varepsilon_{\mathrm{cc}, \max }=0,3 \%$, a armadura mais tracionada está em escoamento, mas com deformação inferior a $\varepsilon_{\mathrm{su}}$.

\section{B.4 Verificação de escoamento nas camadas de armadura no domínio transition}

Por semelhanças dos triângulos ABC e ADE, na Figura 3.11, pode-se calcular $d_{t, \text { lim }}$ :

$$
\frac{d_{t, \text { Iim }}}{x}=\frac{0,003+\varepsilon_{y}}{0,003} \rightarrow d_{t, \text { im }}=\frac{0,003+\frac{f_{y}^{y} / E_{s}}{0,003} \cdot x}{x}
$$

Como $d_{t, \text { lim }}$ é função de $x$, antes de calculá-lo deve-se supor que a que profundidade da linha neutra seja igual ao valor encontrado no passo B.2. Nas camadas de armadura cuja posição $d_{i} \geq d_{t, \text { lim }}, \sigma_{s, i}=-f_{y}$. Para as demais camadas, utiliza-se lei de Hooke e as fórmulas de deformação do Quadro 3.2 para o cálculo das tensões no domínio transition.

\section{B.5 Cálculo da posição da linha neutra para seções no domínio transition}

Sendo j o número de camadas de aço em escoamento, a equação para o cálculo da posição da linha neutra é: 


$$
\begin{gathered}
\left(\beta_{1} \cdot b \cdot \alpha_{1} \cdot f_{c}\right) \cdot x^{2}+ \\
-\left(f_{y} \cdot \sum_{i=1}^{j} A_{s, i}-0,003 \cdot E_{s} \cdot \sum_{i=j+1}^{n} A_{s, i}\right) \cdot x+ \\
-0,003 \cdot E_{s} \cdot \sum_{i=j+1}^{n}\left(A_{s, i} \cdot d_{i}\right)=0
\end{gathered}
$$

Somente para verificação, pode-se ainda recalcular $d_{t, \text { lim }}$ e confirmar se o número de camadas em escoamento é, realmente, j.

\section{B.6 Cálculo do momento resistente último no domínio transition}

Se o valor encontrado para $x$ no item anterior estiver no intervalo apresentado no Quadro 3.2 para o domínio transition, calcula-se o momento último resistente:

$$
\begin{aligned}
& M_{u}=-\beta_{1}^{2} / 2 \cdot b \cdot \alpha_{1} \cdot f_{c} \cdot x^{2}+f_{y} \cdot \sum_{i=1}^{j}\left(A_{s, i} \cdot d_{i}\right)+ \\
& -\frac{0,003 \cdot E_{s}}{x} \cdot \sum_{i=j+1}^{n}\left[A_{s, i} \cdot\left(x-d_{i}\right) \cdot d_{i}\right]=0
\end{aligned}
$$

Caso contrário, a configuração de deformação na ruína equivale ao domínio compression-controlled.

\section{B.7 Cálculo da posição da linha neutra no domínio compression-controlled}

No domínio compression-controlled, a ruína também ocorre por esmagamento do concreto com deformação $\varepsilon_{c c, \max }=0,3 \%$ e todas as armaduras têm deformações inferiores a $\varepsilon_{\mathrm{y}}$.

$$
\left(\beta_{1} \cdot b \cdot \alpha_{1} \cdot f_{c}\right) \cdot x+\sum_{i=1}^{n}\left(A_{s, i} \cdot E_{s} \cdot \varepsilon_{s, i}\right)=0
$$

Substituindo a expressão para a deformação das armaduras no domínio compression-controlled na equação (3.27) e organizando em função de $\mathrm{x}$, tem-se:

$$
\left(\beta_{1} \cdot b \cdot \alpha_{1} \cdot f_{c}\right) \cdot x^{2}+\left(0,003 \cdot E_{s} \cdot \sum_{i=1}^{n} A_{s, i}\right) \cdot x-0,003 \cdot E_{s} \cdot \sum_{i=1}^{n}\left(A_{s, i} \cdot d_{i}\right)=0
$$

B.8 Cálculo do momento resistente último no domínio compressioncontrolled

$$
M_{u}=-\beta_{1}^{2} / 2 \cdot b \cdot \alpha_{1} \cdot f_{c} \cdot x^{2}-\frac{0,003 \cdot E_{s}}{x} \cdot \sum_{i=1}^{n}\left[A_{s, i} \cdot\left(x-d_{i}\right) \cdot d_{i}\right]
$$

\section{FIM DO ALGORITMO B}



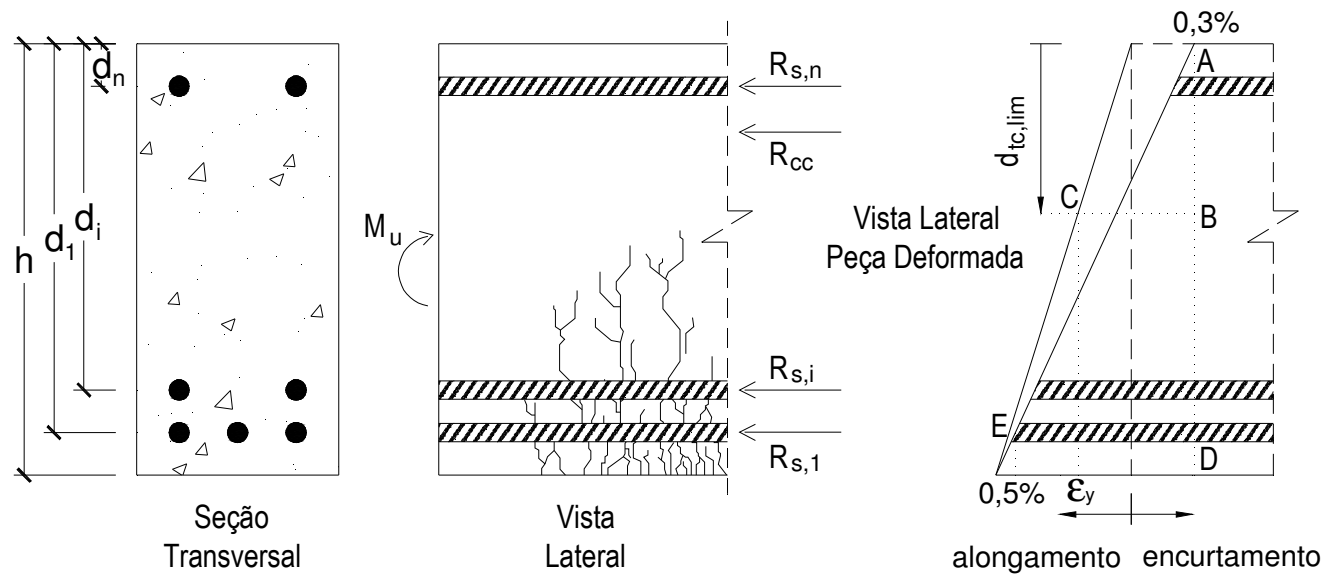

FiguRA 3.10 - CONFIGURAÇÃO LATERAL NO DOMÍNIO TENSION-CONTROLLED
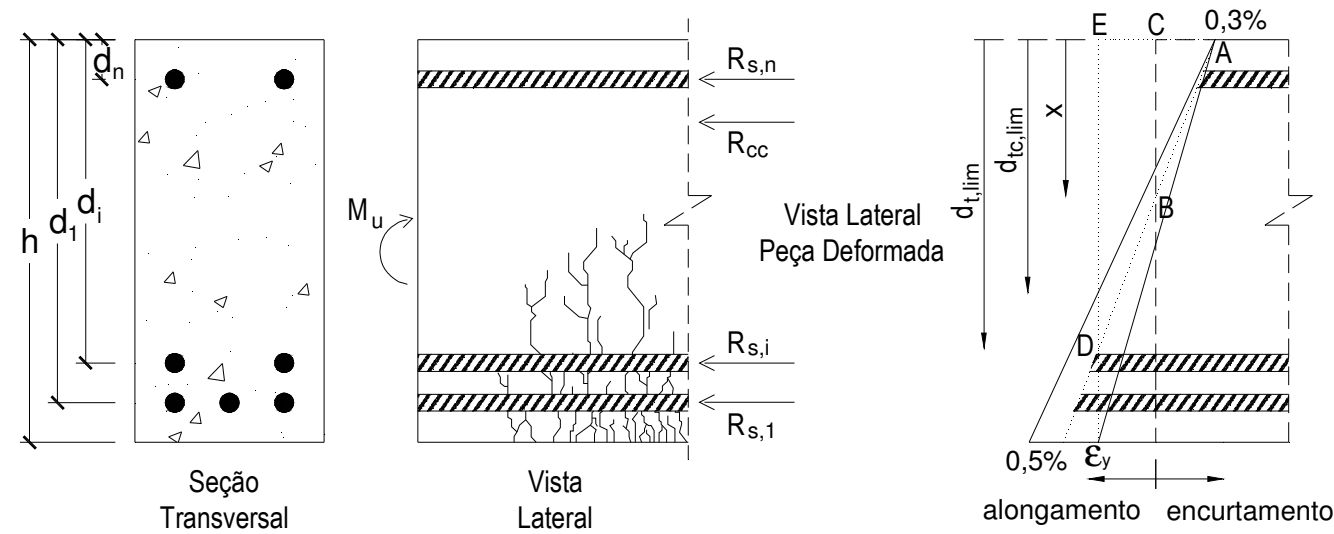

FIGURA 3.11 - CONFIGURAÇÃO LATERAL NO DOMÍNIO TRANSITION

\subsection{VERIFICAÇÃO DA CAPACIDADE RESISTENTE DE PILARES SOLICITADOS À COMPRESSÃO CENTRADA}

Pilares são elementos lineares submetidos, essencialmente, a esforços de compressão. A compressão pode ser:

- centrada, quando a força atua no centro de gravidade da seção transversal;

- normal, quando a força atua em um dos eixos de inércia da seção transversal;

- oblíqua, quando a força atua fora dos dois eixos de inércia da seção.

Os pilares podem atingir o estado limite último por solicitações normais ou por instabilidade devido à flambagem. No entanto, foram abordados neste trabalho apenas casos de compressão centrada e normal (flexo-compressão) e estado limite último devido a solicitações normais. 
Teoricamente, em pilares com solicitação centrada, a capacidade resistente última pode ser medida somando as resistências do concreto e da armadura longitudinal, e levando em consideração ou não o ganho de resistência devido ao confinamento do núcleo de concreto pelas armaduras longitudinal e transversal. Como é observado na Figura 3.12, o equilíbrio de forças é $\mathrm{N}_{\mathrm{u}}=\mathrm{R}_{\mathrm{cc}}+\sum_{\mathrm{i}=1}^{\mathrm{n}} \mathrm{R}_{\mathrm{si}}$.
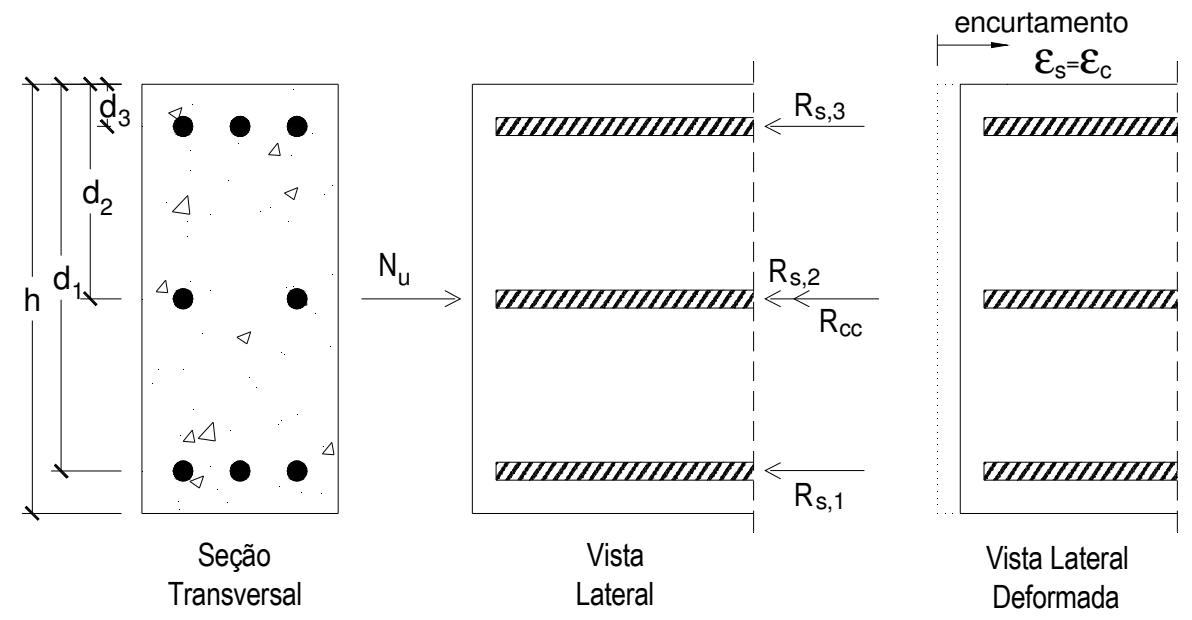

FIGURA 3.12 - COMPORTAMENTO DE PILARES SOB COMPRESSÃO CENTRADA

O que determina a ruína do elemento é o encurtamento excessivo do concreto, que é equivalente à deformação máxima em todas as camadas da armadura. Portanto, a tensão é igualmente distribuída entre as barras de aço e a deformação no concreto é constante.

No entanto, as forças axiais (tração ou compressão) constituem, na verdade, idealizações de cálculo. Mesmo com cargas aplicadas no eixo dos pilares, na prática sempre existem excentricidades nas solicitações, decorrentes de imprecisões construtivas, excentricidade das forças nos extremos e de momentos por causa das ligações.

Nas conclusões de LIMA (1997), o aparecimento de excentricidades acidentais ocorre em função de características dos ensaios tais como:

- Aplicação de força excêntrica uniformemente distribuída em uma placa, com resultante excêntrica em relação ao eixo do pilar, ao invés de uma ação concentrada;

- Variação da geometria do pilar próximo das extremidades;

- Consideração de articulação na base do pilar, o que não ocorre totalmente, pois a dimensão do pilar na direção do momento restringe esta rotação.

Contudo, são apresentados a seguir os modelos propostos pelos códigos brasileiro e americano, seguindo os requisitos estabelecidos e desconsiderando essas excentricidades acidentais. 


\subsubsection{MODELO DA ABNT NBR 6118:2007}

Embora a norma recomende a consideração de um momento mínimo para quantificar o efeito de imperfeições locais e, consequentemente, de excentricidades acidentais, esta também estabelece a deformação última do concreto em casos de compressão centrada, $\varepsilon_{\text {cсu }}=0,2 \%$. A partir das considerações feitas, o esforço normal resistente poderia ser calculado pelas seguintes expressões:

$$
\mathrm{N}_{\mathrm{u}}=\mathrm{R}_{\mathrm{cc}}+\sum_{\mathrm{i}=1}^{\mathrm{n}} \mathrm{R}_{\mathrm{s}, \mathrm{i}}
$$

Sabendo que as tensões no concreto e no aço são, respectivamente, $\sigma_{c}=k_{\bmod } \cdot f_{c}=0,95 \cdot f_{c}$ e $\sigma_{\mathrm{s}}=\mathrm{E}_{\mathrm{s}} \cdot \varepsilon_{\mathrm{ccu}}=0,002 \cdot \mathrm{E}_{\mathrm{s}}$, as resultantes de compressão no concreto e na armadura são:

$$
\begin{gathered}
R_{c c}=A_{c} \cdot \sigma_{c}=0,95\left(b \cdot h-\sum_{i=1}^{n} A_{s, i}\right) \cdot f_{c} \\
R_{s}=\sum_{i=1}^{n} R_{s, i}=0,002 E_{s} \cdot \sum_{i=1}^{n} A_{s, i}
\end{gathered}
$$

Logo:

$$
N_{u}=0,95\left(b \cdot h-\sum_{i=1}^{n} A_{s, i}\right) \cdot f_{c}+0,002 E_{s} \cdot \sum_{i=1}^{n} A_{s, i}
$$

Ressalta-se que a maioria dos autores considera que a tensão atuante no aço é igual a $f_{y}$. Sendo $A_{c}$, a área da seção transversal e $A_{s}$, a área total da armadura longitudinal, neste caso, a força última seria:

$$
N_{u}=0,95\left(A_{c}-A_{s}\right) \cdot f_{c}+A_{s} \cdot f_{y}
$$

$\mathrm{Na}$ presente pesquisa, foi utilizada a recomendação da norma, considerando uma excentricidade mínima de primeira ordem (3.35) quando o índice de esbeltez do elemento fora menor que o valor limite. Para esbeltezes maiores que o valor limite, também foram contabilizados os efeitos de segunda ordem. Desta forma, a solicitação é tida como excêntrica e o cálculo da capacidade do pilar é feito conforme apresentado no item 3.7.

$$
e_{1, \min }=0,015+0,03 \cdot h
$$

onde $\mathrm{h}$ é altura da seção transversal, em metros, na direção considerada.

\subsubsection{MODELO DA ANSI ACI-318/2003}

O código americano utiliza a expressão (3.36) para o cálculo da força máxima a ser aplicada axialmente em membros sujeitos somente à compressão. 


$$
N_{u}=0,80\left(A_{c}-A_{s}\right) \cdot f_{c}+A_{s} \cdot f_{y}
$$

onde $A_{c}$ é a área da seção transversal e $A_{s}$ a área total da armadura longitudinal e o fator 0,80 é utilizado quando armadura transversal é composta por estribos, e abrange a relação entre as resistências do concreto no elemento e no corpo-de-prova, e os efeitos da excentricidade acidental.

\subsection{VERIFICAÇÃO DA CAPACIDADE RESISTENTE DE PILARES SOLICITADOS À COMPRESSÃO EXCÊNTRICA NORMAL}

Devido às características dos ensaios analisados, optou-se pela configuração de forças atuantes conforme apresentado na Figura 3.13 para pilares solicitados à compressão excêntrica.

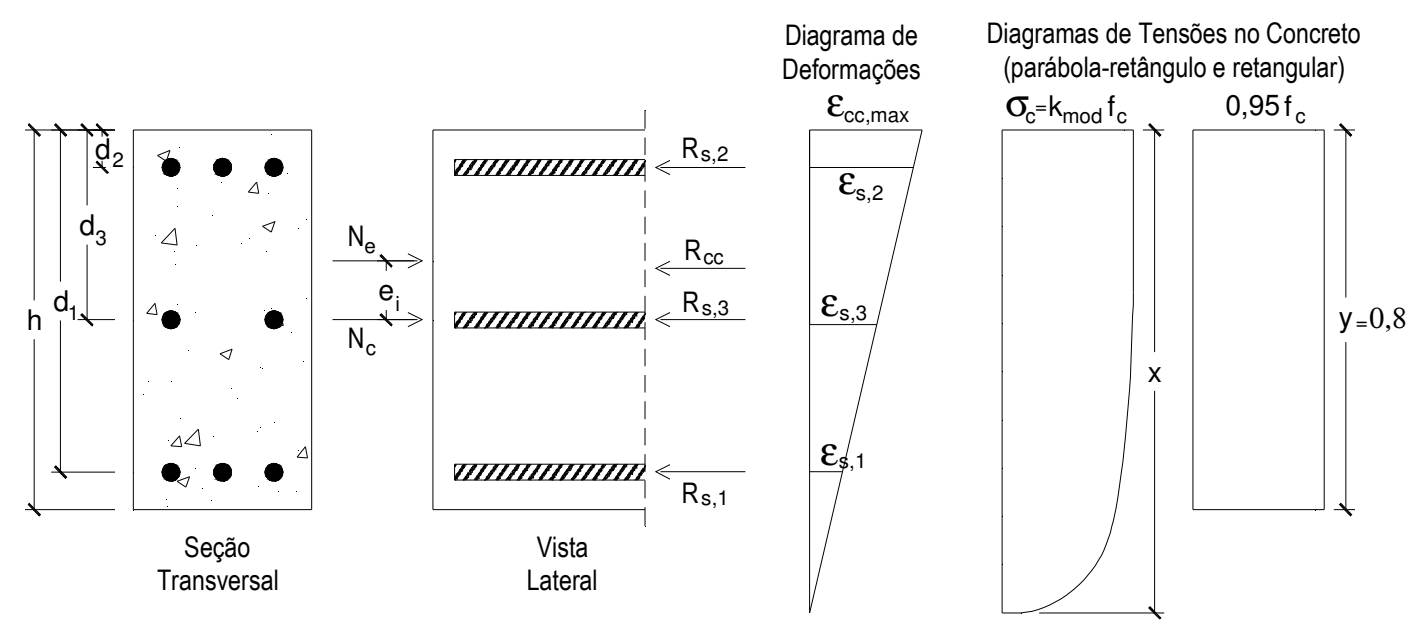

FIGURA 3.13 - COMPORTAMENTO DE PILARES SOB COMPRESSÃO EXCÊNTRICA

Dessa forma, foi possível avaliar os ensaios em que havia duas forças aplicadas, uma centrada $N_{c}$ e outra excêntrica $N_{e}$, e ainda, analisar casos de compressão centrada com ocorrência de excentricidade acidental.

\subsubsection{MODELO DA ABNT NBR 6118:2007}

Como já dito, a norma brasileira recomenda a consideração da existência de um momento mínimo devido a imperfeições locais nos pilares. Consequentemente, mesmo cargas aplicadas no eixo dos elementos são sujeitas a uma excentricidade mínima, que deve ser prevista na verificação de segurança. Portanto, as equações de equilíbrio de forças e de momento apresentam-se, respectivamente, da seguinte forma:

$$
\mathrm{N}_{\mathrm{c}}+\mathrm{N}_{\mathrm{e}}=\mathrm{R}_{\mathrm{cc}}+\sum_{\mathrm{i}=1}^{\mathrm{n}} \mathrm{R}_{\mathrm{s}, \mathrm{i}}
$$




$$
N_{c} \cdot\left(0,5 \cdot h-e_{c}\right)+N_{e} \cdot\left(0,5 \cdot h-e_{e}\right)=R_{c c} \cdot 0,5 y+\sum_{i=1}^{n}\left(R_{s, i} \cdot d_{i}\right)
$$

sendo: $e_{c}$, excentricidade de carga $N_{c}$, se não houver efeitos de segunda ordem, é equivalente a $e_{1, \min }$ (expressão (3.35)), e $e_{e}$, excentricidade total somando efeitos de primeira e segunda ordem, quando houver, da carga $\mathrm{N}_{\mathrm{e}}$.

Substituindo as reações (3.6) e (3.7) em (3.37) e (3.38) e sabendo que $y=0,8 x$ e $\mathrm{f}_{\mathrm{c}, \text { elemento }}=\mathrm{k}_{\text {mod }} \cdot \mathrm{f}_{\mathrm{c}}$, tem-se:

$$
\begin{gathered}
N_{c}+N_{e}=0,8 \cdot b \cdot k_{\bmod } \cdot f_{c} \cdot x+\sum_{i=1}^{n} A_{s, i} \cdot \sigma_{s, i} \\
N_{c} \cdot\left(0,5 \cdot h-e_{c}\right)+N_{e} \cdot\left(0,5 \cdot h-e_{e}\right)=0,32 \cdot b \cdot k_{\bmod } \cdot f_{c} \cdot x^{2}+\sum_{i=1}^{n}\left(A_{s, i} \cdot \sigma_{s, i} \cdot d_{i}\right)
\end{gathered}
$$

Diferente do procedimento de cálculo realizado para as vigas, existem três incógnitas $-\mathrm{N}_{c}$, $\mathrm{N}_{\mathrm{e}}$ e $\mathrm{x}$ - e somente duas equações de equilíbrio, o que torna necessário uma terceira relação. No entanto, na única pesquisa analisada - VANDERLEI (1999) - em que a metodologia de ensaio consistia na aplicação de duas forças, foi estabelecida uma razão $p$ entre a carga excêntrica e a centrada de 5\%. A relação (3.41) foi usada para reduzir o número de incógnitas do processo de cálculo.

$$
\mathrm{N}_{\mathrm{e}}=\mathrm{p} \cdot \mathrm{N}_{\mathrm{c}}
$$

Incluindo esta relação nas equações de equilíbrio, tem-se:

$$
\begin{gathered}
N_{c}=\frac{1}{1+p} \cdot\left(0,8 \cdot b \cdot k_{\bmod } \cdot f_{c} \cdot x+\sum_{i=1}^{n} A_{s, i} \cdot \sigma_{s, i}\right) \\
N_{c} \cdot\left[\left(0,5 \cdot h-e_{c}\right)+p \cdot\left(0,5 \cdot h-e_{e}\right)\right]=0,32 \cdot b \cdot k_{\bmod } \cdot f_{c} \cdot x^{2}+\sum_{i=1}^{n}\left(A_{s, i} \cdot \sigma_{s, i} \cdot d_{i}\right)
\end{gathered}
$$

E substituindo a expressão (3.42) na (3.43), tem-se uma única incógnita x :

$$
\begin{gathered}
{\left[\left(0,5 \cdot h-e_{c}\right)+p \cdot\left(0,5 \cdot h-e_{e}\right)\right] \cdot\left(0,8 \cdot b \cdot k_{\bmod } \cdot f_{c} \cdot x+\sum_{i=1}^{n} A_{s, i} \cdot \sigma_{s, i}\right)} \\
-(1+p) \cdot\left[0,32 \cdot b \cdot k_{\bmod } \cdot f_{c} \cdot x^{2}+\sum_{i=1}^{n}\left(A_{s, i} \cdot \sigma_{s, i} \cdot d_{i}\right)\right]=0
\end{gathered}
$$

Entretanto, os ensaios de pilares são realizados, em geral, com apenas uma carga de compressão, seja esta aplicada com ou sem excentricidade. Para avaliar estes ensaios e, ainda, considerando a existência de excentricidade mesmo em casos de compressão centrada, a equação (3.44) pode ser reescrita da seguinte forma: 


$$
(0,5 \cdot h-e)\left(0,8 \cdot b \cdot k_{\bmod } \cdot f_{c} \cdot x+\sum_{i=1}^{n} A_{s, i} \cdot \sigma_{s, i}\right)-0,32 \cdot b \cdot k_{m o d} \cdot f_{c} \cdot x^{2}+\sum_{i=1}^{n}\left(A_{s, i} \cdot \sigma_{s, i} \cdot d_{i}\right)=0
$$

Antes de ser feito o cálculo da posição do eixo neutro $x$ e, posteriormente, dos esforços resistentes últimos $N_{c}, N_{e}$ ou $N_{u}$, é necessário conhecer as excentricidades de atuação (final) cada uma dessas forças. O deslocamento final de uma carga em relação ao eixo do pilar é medido somando os efeitos de primeira e segunda ordem.

A excentricidade de primeira ordem, $e_{1}$, deve-se à excentricidade de aplicação da carga e/ou a imperfeições locais. Desta forma:

$$
e_{1} \geq\left\{\begin{array}{l}
e_{i} \\
e_{1, \text { min }}
\end{array}\right.
$$

onde $e_{i}$ é a distância do ponto de aplicação da carga ao eixo do pilar e $e_{1, \text { min }}$, excentricidade acidental ou surgidas devido imperfeições locais.

Quando os deslocamentos alteram de maneira significativa os esforços internos de primeira ordem, cuja análise fora realizada através das condições de equilíbrio na configuração geométrica inicial, a norma recomenda que seja feita uma avaliação de segunda ordem.

\section{Efeitos de segunda ordem}

Segundo a ABNT NBR 6118:2007, os esforços locais de $2^{\mathrm{a}}$ ordem em elementos isolados podem ser desprezados quando o índice de esbeltez $\lambda$ for menor que o valor limite $\lambda_{1}$. Calculados pelas expressões:

$$
\begin{gathered}
\lambda=\ell_{\mathrm{e}} / \mathrm{i}, \text { onde } \mathrm{i}=\frac{\mathrm{h}}{\sqrt{12}} \\
\lambda_{1}=\frac{25+12,5 \cdot \mathrm{e}_{1} / \mathrm{h}}{\alpha_{\mathrm{b}}}, \text { onde } \frac{35}{\alpha_{b}} \leq \lambda_{1} \leq 90
\end{gathered}
$$

Sendo: $\ell_{\mathrm{e}}$, comprimento de flambagem do pilar; i, o raio de giração para seções retangulares; h, a dimensão da seção na direção considerada; e $e_{1}$, a excentricidade de $1^{\text {a }}$ ordem. O valor de $\alpha_{b}$ deve ser obtido conforme estabelecido a seguir:

- Pilares biapoiados sem forças transversais:

$$
\alpha_{b}=0,6+0,4 \frac{M_{B}}{M_{A}}, \text { onde } 1,0 \geq \alpha_{b} \geq 0,4
$$


$M_{A}$ é o momento fletor de $1^{a}$ ordem no extremo do pilar com maior valor absoluto, e $M_{B}$ é o momento fletor de $1^{\text {a }}$ ordem no outro extremo do pilar e toma-se para $M_{B}$ o sinal positivo, se tracionar a mesma face que $\mathrm{M}_{\mathrm{A}}$, e negativo em caso contrário.

- Pilares biapoiados com forças transversais significativas ao longo da altura

$$
\alpha_{b}=1,0
$$

- Pilares em balanço

$$
\alpha_{b}=0,8+0,2 \frac{M_{C}}{M_{A}}, \text { onde } 1,0 \geq \alpha_{b} \geq 0,85
$$

$M_{A}$ é o momento fletor de $1^{a}$ ordem no engaste, e $M_{C}$ é o momento fletor de $1^{a}$ ordem no meio do pilar em balanço.

- Pilares biapoiados ou em balanço com momentos fletores menores que o mínimo

$$
\alpha_{b}=1,0
$$

Caso $\lambda>\lambda_{1}$, a norma brasileira propõe quatro métodos para avaliação dos efeitos de segunda ordem em pilares sujeitos à flexo-compressão normal. O Método Geral consiste na análise de segunda ordem não-linear com adequadas discretização do elemento e consideração da relação momento-curvatura em cada seção. Os métodos aproximados são: Método do pilar-padrão com curvatura aproximada, Método do pilar-padrão com rigidez $\kappa$ aproximada, Método do pilar-padrão acoplado a diagramas M, N e 1/r. A presente pesquisa utilizou os dois primeiros métodos aproximados para avaliação de segunda ordem.

\section{- Método do pilar-padrão com curvatura aproximada}

O método do pilar-padrão com curvatura aproximada é permitido para pilares de seção constante e de armadura simétrica e constante ao longo de seu eixo e $\lambda \leq 90$. A nãolinearidade geométrica é analisada de forma aproximada, supondo-se que a configuração deformada da barra seja senoidal. A não-linearidade física é avaliada através de uma expressão aproximada da curvatura na seção crítica. A excentricidade de segunda ordem $\mathrm{e}_{2}$ é dada pela seguinte fórmula:

$$
e_{2}=\frac{l_{e}^{2}}{10} \cdot \frac{1}{r}
$$

$1 / r$ é a curvatura na seção crítica, que pode ser avaliada pela expressão:

$$
\frac{1}{r}=\frac{0,005}{h \cdot(v+0,5)} \leq \frac{0,005}{h}
$$


onde $h$ é a dimensão da seção transversal na direção considerada, $v=\frac{N_{s d}}{A_{c} \cdot f_{c d}}$ é a força normal adimensional. Para calcular $v$, o esforço $\mathrm{N}_{\mathrm{sd}}$ utilizado foi a força última encontrada nos ensaios.

Assim, a excentricidade total no pilar é dada por:

$$
e=\alpha_{b} \cdot e_{1}+\frac{l_{e}^{2}}{10} \cdot \frac{1}{r}
$$

E, segundo a norma, o momento total máximo:

$$
M_{u, \text { total }}=N_{u}\left(\alpha_{b} \cdot e_{1}+\frac{l_{e}^{2}}{10} \cdot \frac{1}{r}\right)
$$

\section{- Método do pilar-padrão com rigidez $\kappa$ aproximada}

O método do pilar-padrão com rigidez $\kappa$ aproximada pode ser empregado apenas no cálculo de pilares com $\lambda \leq 90$, seção retangular constante, armadura simétrica e constante ao longo de seu eixo. A não-linearidade geométrica deve ser considerada de forma aproximada, supondo-se que a deformação da barra seja senoidal. A não-linearidade física deve ser levada em conta através de uma expressão aproximada da rigidez.

O momento total máximo no pilar deve ser calculado pela expressão, majorando o momento de $1^{\text {a }}$ ordem:

$$
M_{u, \text { total }}=\frac{\alpha_{b} \cdot M_{1}}{1-\frac{\lambda^{2}}{120 \cdot \kappa / v}}
$$

$\kappa$ é valor da rigidez adimensional, dado aproximadamente pela expressão:

$$
\kappa=32 v \cdot\left(1+5 \cdot \frac{M_{u, t o t a l}}{h \cdot N_{u}}\right)
$$

As variáveis $M_{1}, \alpha_{b}, h, \lambda$ e $v$ têm as mesmas definições dadas anteriormente.

Observa-se que o valor da rigidez adimensional $\kappa$ é necessário para o cálculo de $\mathrm{M}_{\mathrm{u} \text {,total }}$, $\mathrm{e}$ para o cálculo de $\kappa$ utiliza-se o valor de $\mathbf{M}_{\mathrm{u} \text {,total }}$. Assim, a solução deveria ser obtida de forma iterativa. No entanto, substituindo a expressão (3.20) na (3.19) e admitindo $M_{u, t o t a l}=N_{u} \cdot e=N_{u}\left(\alpha_{b} \cdot e_{1}+e_{2}\right)$, é possível calcular a excentricidade de segunda ordem em função de informações conhecidas: 
Simplificando e isolando $e_{2}$ :

$$
\mathrm{N}_{\mathrm{u}}\left(\alpha_{\mathrm{b}} \cdot \mathrm{e}_{1}+\mathrm{e}_{2}\right)=\frac{\mathrm{N}_{\mathrm{u}} \cdot \alpha_{\mathrm{b}} \cdot \mathrm{e}_{1}}{1-\frac{\lambda^{2}}{\frac{120}{v} \cdot 32 v \cdot\left(1+5 \cdot \frac{\mathrm{N}_{u}\left(\alpha_{b} \cdot \mathrm{e}_{1}+\mathrm{e}_{2}\right)}{\mathrm{N}_{\mathrm{u}} \cdot \mathrm{h}}\right)}}
$$

$$
e_{2}=\frac{\sqrt{\left(1-\frac{\lambda^{2}}{3840}\right)^{2} \cdot h^{2}+10 \alpha_{b} e_{1} \cdot h\left(1+\frac{\lambda^{2}}{3840}\right)+25 \alpha_{b}^{2} \cdot e_{1}^{2}}-5 \alpha_{b} e_{1}-\left(1-\frac{\lambda^{2}}{3840}\right) h}{10}
$$

A excentricidade total será:

$$
e=\alpha_{b} e_{1}+\frac{\sqrt{\left(1-\frac{\lambda^{2}}{3840}\right)^{2} \cdot h^{2}+10 \alpha_{b} e_{1} \cdot h\left(1+\frac{\lambda^{2}}{3840}\right)+25 \alpha_{b}^{2} \cdot e_{1}^{2}}-5 \alpha_{b} e_{1}-\left(1-\frac{\lambda^{2}}{3840}\right) h}{10}
$$

Conhecendo a excentricidade final da força de ruína, para realizar o cálculo da capacidade dos pilares, é necessário conhecer as tensões, $\sigma_{\mathrm{s}, \mathrm{i}}$, às quais as armaduras estão solicitadas, para tanto, supõe-se, inicialmente, que a seção em ruína esteja no domínio 5 de deformação. Este domínio é típico de elementos com solicitados por compressão excêntrica, visto que a seção encontra-se sob compressão não-uniforme.

\section{ALGORITMO C - Cálculo dos esforços últimos para pilares solicitados à compressão excêntrica segundo ABNT NBR 6118:2007:}

\section{C.1 Cálculo da posição da linha neutra no domínio 5}

Substituindo a tensão nas armaduras pela fórmula da lei de Hooke, $\sigma_{\mathrm{s}, \mathrm{i}}=\mathrm{E}_{\mathrm{s}} \cdot \varepsilon_{\mathrm{s}, \mathrm{i}}$, as deformações conforme a equação do Quadro 3.1 para o domínio 5 e organizando em função de x, as equações (3.44) e (3.45) - para elementos com duas e uma carga normal, respectivamente - apresentam-se da seguinte forma:

$$
\begin{gathered}
{\left[-2,24(p+1) \cdot b \cdot k_{\text {mod }} \cdot f_{c}\right] \cdot x^{3}+} \\
+0,8 b \cdot k_{\bmod } \cdot f_{c} \cdot\left\{7\left[\left(0,5 h-e_{c}\right)+p\left(0,5 h-e_{e}\right)\right]+1,2(p+1) \cdot h\right\} \cdot x^{2}+ \\
+\left\{\begin{array}{c}
{\left[\left(0,5 h-e_{c}\right)+p\left(0,5 h-e_{e}\right)\right]\left[-2,4 b \cdot h \cdot k_{m o d} \cdot f_{c}+0,014 E_{s} \sum_{i=1}^{n} A_{s, i}\right]} \\
-0,014(p+1) \cdot E_{s} \sum_{i=1}^{n}\left(A_{s, i} \cdot d_{i}\right)
\end{array}\right] \cdot x+ \\
-0,014 E_{s}\left\{\left[\left(0,5 h-e_{c}\right)+p\left(0,5 h-e_{e}\right)\right] \cdot \sum_{i=1}^{n}\left(A_{s, i} \cdot d_{i}\right)-(p+1) \sum_{i=1}^{n}\left(A_{s, i} \cdot d_{i}^{2}\right)\right\}=0
\end{gathered}
$$




$$
\begin{gathered}
\left(-2,24 b \cdot k_{\bmod } \cdot f_{c}\right) \cdot x^{3}+0,8 b \cdot k_{\bmod } \cdot f_{c} \cdot[7(0,5 h-e)+1,2 h] \cdot x^{2}+ \\
+\left[(0,5 h-e)\left(-2,4 b \cdot h \cdot k_{\bmod } \cdot f_{c}+0,014 E_{s} \cdot \sum_{i=1}^{n} A_{s, i}\right)-0,014 E_{s} \cdot \sum_{i=1}^{n}\left(A_{s, i} \cdot d_{i}\right)\right] \cdot x+ \\
-0,014 E_{s} \cdot\left[(0,5 h-e) \cdot \sum_{i=1}^{n}\left(A_{s, i} \cdot d_{i}\right)-\sum_{i=1}^{n}\left(A_{s, i} \cdot d_{i}^{2}\right)\right]=0
\end{gathered}
$$

\section{C.2 Cálculo do esforço normal resistente último no domínio 5}

Se o valor encontrado para $\mathrm{x}$ estiver no intervalo referente ao domínio 5 , como apresentado no Quadro 3.1, o próximo passo é calcular os esforços resistentes último através das expressões (3.41) e (3.42). Havendo apenas uma força atuante $\mathrm{N}_{\mathrm{u}}$ :

$$
\mathrm{N}_{\mathrm{u}}=0,8 \cdot \mathrm{b} \cdot \mathrm{k}_{\bmod } \cdot \mathrm{f}_{\mathrm{c}} \cdot \mathrm{x}+\sum_{\mathrm{i}=1}^{\mathrm{n}}\left(\mathrm{A}_{\mathrm{s}, \mathrm{i}} \cdot \sigma_{\mathrm{s}, \mathrm{i}}\right)
$$

Ressalta-se que $\left|\sigma_{s, i}\right| \leq f_{y}$.

Se $x<h$, supõe-se que a configuração de ruína esteja nos domínios 3 ou 4 .

\section{C.3 Cálculo da posição da linha neutra nos domínios 3 e 4}

Os domínios 3 e 4 têm a mesma expressão para o cálculo das deformações, portanto a equação para o cálculo da posição da linha neutra também é igual para ambos.

Substuindo a fórmula de $\varepsilon_{\mathrm{s}, \mathrm{i}}$ mostrada no Quadro 3.1 para os domínios 3 e 4 nas equações (3.44) e (3.45), quando houver, respectivamente, duas ou uma força de compressão aplicada no pilar, tem-se:

$$
\begin{gathered}
{\left[-0,32(p+1) \cdot b \cdot k_{\bmod } \cdot f_{c}\right] \cdot x^{3}+\left\{0,8 b \cdot k_{\bmod } \cdot f_{c} \cdot\left[\left(0,5 h-e_{c}\right)+p\left(0,5 h-e_{e}\right)\right]\right\} \cdot x^{2}} \\
+0,0035 E_{s}\left\{\left[\left(0,5 h-e_{c}\right)+p\left(0,5 h-e_{e}\right)\right] \cdot \sum_{i=1}^{n} A_{s, i}-(p+1) \cdot \sum_{i=1}^{n}\left(A_{s, i} \cdot d_{i}\right)\right\} \cdot x- \\
0,0035 E_{s}\left\{\left[\left(0,5 h-e_{c}\right)+p\left(0,5 h-e_{e}\right)\right] \cdot \sum_{i=1}^{n}\left(A_{s, i} \cdot d_{i}\right)-(p+1) \cdot \sum_{i=1}^{n}\left(A_{s, i} \cdot d_{i}^{2}\right)\right\}=0 \\
\left(-0,32 b \cdot k_{\bmod } \cdot f_{c}\right) \cdot x^{3}+\left[0,8 b \cdot k_{\bmod } \cdot f_{c} \cdot(0,5 h-e)\right] \cdot x^{2}+ \\
+0,0035 E_{s}\left[(0,5 h-e) \cdot \sum_{i=1}^{n} A_{s, i}-\sum_{i=1}^{n}\left(A_{s, i} \cdot d_{i}\right)\right] \cdot x+ \\
-0,0035 E_{s}\left[(0,5 h-e) \cdot \sum_{i=1}^{n}\left(A_{s, i} \cdot d_{i}\right)-\sum_{i=1}^{n}\left(A_{s, i} \cdot d_{i}^{2}\right)\right]=0
\end{gathered}
$$

\section{C.4 Cálculo do esforço normal resistente último nos domínios 3 e 4}


O cálculo dos esforços últimos em seções com deformações correspondentes aos domínios 3 e 4 é realizado usando as expressões (3.41) e (3.42), quando houver atuação de duas forças normais, e (3.59) quando houver apenas uma.

\section{C.5 Cálculo da posição da linha neutra no domínio 2}

Substituindo a expressão de deformação, apresentada no Quadro 3.1 correspondente ao domínio 2 nas equações (3.44) e (3.45), tem-se:

$$
\begin{gathered}
{\left[0,32(p+1) \cdot b \cdot k_{\text {mod }} \cdot f_{c}\right] \cdot x^{3}+} \\
+0,8 b \cdot k_{\text {mod }} \cdot f_{c} \cdot\left\{\left[\left(0,5 h-e_{c}\right)+p\left(0,5 h-e_{e}\right)\right]+0,4(p+1) \cdot d_{1}\right\} \cdot x^{2}+ \\
+\left\{\begin{array}{c}
{\left[\left(0,5 h-e_{c}\right)+p\left(0,5 h-e_{e}\right)\right]\left[0,8 b \cdot d_{1} \cdot k_{m o d} \cdot f_{c}+0,01 E_{s} \sum_{i=1}^{n} A_{s, i}\right]} \\
-0,01(p+1) \cdot E_{s} \sum_{i=1}^{n}\left(A_{s, i} \cdot d_{i}\right)
\end{array}\right] \cdot x+ \\
\left.-0,01 E_{s}\left\{\left(0,5 h-e_{c}\right)+p\left(0,5 h-e_{e}\right)\right] \cdot \sum_{i=1}^{n}\left(A_{s, i} \cdot d_{i}\right)-(p+1) \sum_{i=1}^{n}\left(A_{s, i} \cdot d_{i}^{2}\right)\right\}=0 \\
+\left[0,32 b \cdot k_{\bmod } \cdot f_{c}\right) \cdot x^{3}-0,8 b \cdot k_{m o d} \cdot f_{c} \cdot\left[(0,5 h-e)+0,4 d_{1}\right] \cdot x^{2}+ \\
\left.(0,5 h-e)\left(0,8 b \cdot d_{1} \cdot k_{m o d} \cdot f_{c}+0,01 E_{s} \cdot \sum_{i=1}^{n} A_{s, i}\right)-0,01 E_{s} \cdot \sum_{i=1}^{n}\left(A_{s, i} \cdot d_{i}\right)\right] \cdot x+ \\
-0,01 E_{s} \cdot\left[(0,5 h-e) \cdot \sum_{i=1}^{n}\left(A_{s, i} \cdot d_{i}\right)-\sum_{i=1}^{n}\left(A_{s, i} \cdot d_{i}^{2}\right)\right]=0
\end{gathered}
$$

onde a primeira faz o cálculo de $\mathrm{x}$, quando duas forças normais atuam na seção e a segundo, quando apenas uma atua.

\section{C.6 Cálculo do esforço normal resistente último no domínio 2}

Para calcular os esforços últimos em seções com deformações correspondentes ao domínio 2 também utiliza-se as expressões (3.41) e (3.42), quando houver atuação de duas forças normais, e (3.59) quando houver apenas uma.

\section{FIM DO ALGORITMO C}

\subsubsection{MODELO DA ACI 318-2002}

O código americano recomenda a consideração da existência de um momento mínimo devido a imperfeições locais quando os pilares forem esbeltos. Consequentemente, mesmo cargas aplicadas no eixo são sujeitas a uma excentricidade mínima, que deve ser prevista na verificação de segurança. Nos casos em que o pilar é robusto e for solicitado à compressão 
simples, o procedimento de verificação da capacidade resistente corresponde ao estabelecido no item 3.5.2.

Substituindo as reações (3.6) e (3.7) em (3.37) e (3.38) e sabendo que $y=\beta_{1} \cdot x$ e $\mathrm{f}_{\mathrm{c}, \text { elemento }}=\alpha_{1} \cdot \mathrm{f}_{\mathrm{c}}$, as equações de equilíbrio de forças e de momento apresentam-se, respectivamente, da seguinte forma:

$$
\begin{gathered}
N_{c}+N_{e}=\beta_{1} \cdot b \cdot \alpha_{1} \cdot f_{c} \cdot x+\sum_{i=1}^{n} A_{s, i} \cdot \sigma_{s, i} \\
N_{c} \cdot\left(0,5 \cdot h-e_{c}\right)+N_{e} \cdot\left(0,5 \cdot h-e_{e}\right)=0,5 \beta_{1}^{2} \cdot b \cdot \alpha_{1} \cdot f_{c} \cdot x^{2}+\sum_{i=1}^{n}\left(A_{s, i} \cdot \sigma_{s, i} \cdot d_{i}\right)
\end{gathered}
$$

onde a nomenclatura utilizada é a mesma usada no modelo da norma brasileira.

Para reduzir o número de incógnitas, inclui-se relação (3.41) em (3.65) e (3.66) e resolvendo o sistema formado por estas equações tem-se uma expressão não qual encontrase a posição da linha neutra $x$ :

$$
\begin{gathered}
{\left[\left(0,5 \cdot h-e_{c}\right)+p \cdot\left(0,5 \cdot h-e_{e}\right)\right] \cdot\left(\beta_{1} \cdot b \cdot \alpha_{1} \cdot f_{c} \cdot x+\sum_{i=1}^{n} A_{s, i} \cdot \sigma_{s, i}\right)} \\
-(1+p) \cdot\left[0,5 \cdot \beta_{1}^{2} \cdot b \cdot \alpha_{1} \cdot x^{2}+\sum_{i=1}^{n}\left(A_{s, i} \cdot \sigma_{s, i} \cdot d_{i}\right)\right]=0
\end{gathered}
$$

Para avaliar estes ensaios com apenas uma carga de compressão, seja esta aplicada centrada ou não, e, ainda, considerando a existência de excentricidade em casos de compressão centrada em pilares esbeltos, a expressão anterior apresenta-se assim:

$$
(0,5 \cdot h-e)\left(\beta_{1} \cdot b \cdot \alpha_{1} \cdot f_{c} \cdot x+\sum_{i=1}^{n} A_{s, i} \cdot \sigma_{s, i}\right)-0,5 \cdot \beta_{1}^{2} \cdot b \cdot \alpha_{1} \cdot f_{c} \cdot x^{2}+\sum_{i=1}^{n}\left(A_{s, i} \cdot \sigma_{s, i} \cdot d_{i}\right)=0
$$

É necessário conhecer as excentricidades finais dos esforços resistentes últimos $N_{c}, N_{e}$ ou $\mathrm{N}_{u}$, antes de calculá-los. Pelo ACI 318-2002, o deslocamento final, em relação ao eixo do pilar esbelto, das cargas atuantes é medido através da ampliação dos efeitos de primeira ordem, que diz respeito somente à geometria inicial do carregamento.

Para que os efeitos de segunda ordem possam ser negligenciados, a esbeltez do pilar equação (3.53) - deve ser menor que valor limite estabelecido como:

$$
\lambda_{\text {lim }} \leq 22
$$

Em casos contrários, a norma recomenda que seja feita uma avaliação de segunda ordem. 


\section{Efeitos de segunda ordem}

Caso $\lambda>\lambda_{1}$, o código recomenda três métodos para avaliação dos efeitos de segunda ordem em elementos comprimidos.

A primeira é uma análise não-linear de segunda ordem, que deve considerar a nãolinearidade dos materiais, curvatura e flambagem do membro, duração das cargas, fissuração, fadiga e interação com o apoio. Pode ser feita uma análise elástica dos efeitos de segunda ordem, a qual considera as características da seção levando em conta a influência das cargas axiais, a presença de fissuras junto ao comprimento do pilar e efeitos da duração do carregamento.

Foi utilizado neste trabalho o procedimento de ampliação de momento.

\section{- Moment magnification procedure - Nonsway}

Esse método recomenda que membros comprimidos sejam projetados para uma carga axial $P_{u}$ e um momento amplificado $M_{u}$ pelos efeitos da curvatura do pilar.

$$
\begin{gathered}
M_{u}=\delta_{n s} \cdot M_{1} \\
\delta_{n s}=\frac{C_{m}}{1-\frac{P_{u}}{0,75 \cdot P_{c}}} \geq 1
\end{gathered}
$$

sendo: $\delta_{n s}$, coeficiente de ampliação do momento de primeira ordem $M_{1} ; C_{m}$, equivalente ao $\alpha_{b}$ da norma brasileira e também igual 1; $P_{u}$, foi considerada igual a carga de ruína obtida nos ensaios da base de dados, $\mathrm{P}_{\mathrm{c}}$, carga crítica de flambagem.

$$
\mathrm{P}_{\mathrm{c}}=\frac{\pi^{2} \cdot \mathrm{EI}}{\ell_{\mathrm{e}}}
$$

onde, $\ell_{\mathrm{e}}$ é o comprimento de flambagem do pilar e o produto de inércia El é medido por

$$
E I=\frac{0,4 \cdot E_{c} \cdot I_{g}}{1+\beta_{d n s}}
$$

$E_{c}$ é o módulo elasticidade secante do concreto; $I_{g}$, a inércia da seção íntegra e $\beta_{\text {dns }}$, a razão entre o máximo fator de carga suportado e o máximo fator de carga associado a mesma combinação de cargas, e não deve ser maior que 1 , neste trabalhado foi considerado igual 1 . Considerando que o momento de primeira ordem $\mathrm{M}_{1}$ é igual o produto da carga axial pela excentricidade de primeira ordem e o momento amplificado $M_{u}$ é o produto da mesma 
carga pela excentricidade de segunda ordem, a expressão (3.70) pode ser escrita em função dessas excentricidades:

$$
\mathrm{e}_{2}=\delta_{\mathrm{ns}} \cdot \mathrm{e}_{1}
$$

Portanto, a excentricidade total, segundo este método:

$$
\mathrm{e}=\left(1+\delta_{\mathrm{ns}}\right) \cdot \mathrm{e}_{1}
$$

Para o cálculo da posição da linha neutra, é necessário conhecer as tensões, $\sigma_{\mathrm{s}, \mathrm{i}}$, às quais as armaduras estão solicitadas, para tanto, supõe-se, inicialmente, que a seção em ruína esteja no domínio 5 de deformação. Este domínio é típico de elementos com solicitados por compressão excêntrica, visto que a seção encontra-se sob compressão não-uniforme.

\section{ALGORITMO D - Cálculo dos esforços últimos para pilares solicitados à compressão} excêntrica segundo ACI 318-2002:

\section{D.1 Cálculo da posição da linha neutra nos domínios compression-controlled e transition}

Substuindo a fórmula de $\varepsilon_{\mathrm{s}, \mathrm{i}}$ mostrada no Quadro 3.2 para os domínios compression-controlled e transition nas equações (3.65) e (3.66), quando houver, respectivamente, duas ou uma força de compressão aplicada no pilar, tem-se:

$$
\begin{gathered}
{\left[-0,5(p+1) \cdot \beta_{1} \cdot b \cdot \alpha_{1} \cdot f_{c}\right] \cdot x^{3}+\left\{\beta_{1} \cdot b \cdot \alpha_{1} \cdot f_{c} \cdot\left[\left(0,5 h-e_{c}\right)+p\left(0,5 h-e_{e}\right)\right]\right\} \cdot x^{2}+} \\
+0,003 E_{s}\left\{\left[\left(0,5 h-e_{c}\right)+p\left(0,5 h-e_{e}\right)\right] \cdot \sum_{i=1}^{n} A_{s, i}-(p+1) \cdot \sum_{i=1}^{n}\left(A_{s, i} \cdot d_{i}\right)\right\} \cdot x+ \\
-0,003 E_{s}\left\{\left[\left(0,5 h-e_{c}\right)+p\left(0,5 h-e_{e}\right)\right] \cdot \sum_{i=1}^{n}\left(A_{s, i} \cdot d_{i}\right)-(p+1) \cdot \sum_{i=1}^{n}\left(A_{s, i} \cdot d_{i}^{2}\right)\right\}=0 \\
\left(-0,5 \cdot \beta_{1} \cdot b \cdot \alpha_{1} \cdot f_{c}\right) \cdot x^{3}+\left[\beta_{1} \cdot b \cdot \alpha_{1} \cdot f_{c} \cdot(0,5 h-e)\right] \cdot x^{2}+ \\
+0,003 E_{s}\left\{(0,5 h-e) \cdot \sum_{i=1}^{n} A_{s, i}-\sum_{i=1}^{n}\left(A_{s, i} \cdot d_{i}\right)\right\} \cdot x+ \\
-0,003 E_{s}\left\{(0,5 h-e) \cdot \sum_{i=1}^{n}\left(A_{s, i} \cdot d_{i}\right)-\sum_{i=1}^{n}\left(A_{s, i} \cdot d_{i}^{2}\right)\right\}=0
\end{gathered}
$$

D.2 Cálculo dos esforços últimos nos domínios compression-controlled e transition 
Se x estiver no intervalo especificado no Quadro 3.2 para seções com deformações correspondentes aos domínios compression-controlled e transition, calcula-se os esforços últimos usando as expressões a seguir:

$$
\begin{gathered}
N_{c}=\frac{1}{1+p} \cdot\left(\beta_{1} \cdot b \cdot \alpha_{1} \cdot f_{c} \cdot x+\sum_{i=1}^{n} A_{s, i} \cdot \sigma_{s, i}\right) \\
N_{e}=p \cdot N_{c}
\end{gathered}
$$

E quando houver apenas uma força $\mathrm{N}_{u}$ aplicada:

$$
\mathrm{N}_{\mathrm{u}}=\beta_{1} \cdot \mathrm{b} \cdot \alpha_{1} \cdot \mathrm{f}_{\mathrm{c}} \cdot \mathrm{x}+\sum_{\mathrm{i}=1}^{\mathrm{n}}\left(\mathrm{A}_{\mathrm{s}, \mathrm{i}} \cdot \sigma_{\mathrm{s}, \mathrm{i}}\right)
$$

Caso contrário:

\section{D.3 Cálculo da posição da linha neutra no domínio tension-controlled}

Substituindo a expressão de deformação, apresentada no Quadro 3.2, correspondente ao domínio tension-controlled nas equações (3.65) e (3.66), tem-se:

$$
\begin{gathered}
{\left[0,5(p+1) \cdot \beta_{1}^{2} \cdot b \cdot \alpha_{1} \cdot f_{c}\right] \cdot x^{3}+} \\
-\beta_{1} \cdot b \cdot \alpha_{1} \cdot f_{c} \cdot\left\{\left[\left(0,5 h-e_{c}\right)+p\left(0,5 h-e_{e}\right)\right]+0,4(p+1) \cdot d_{1}\right\} \cdot x^{2}+ \\
+\left\{\begin{array}{c}
\left.\left[\left(0,5 h-e_{c}\right)+p\left(0,5 h-e_{e}\right)\right]\left[\beta_{1} \cdot b \cdot d_{1} \cdot \alpha_{1} \cdot f_{c}+0,005 E_{s} \sum_{i=1}^{n} A_{s, i}\right]\right\} \cdot x+ \\
-0,005(p+1) \cdot E_{s} \sum_{i=1}^{n}\left(A_{s, i} \cdot d_{i}\right)
\end{array}\right. \\
\left.-0,005 E_{s}\left\{\left(0,5 h-e_{c}\right)+p\left(0,5 h-e_{e}\right)\right] \cdot \sum_{i=1}^{n}\left(A_{s, i} \cdot d_{i}\right)-(p+1) \sum_{i=1}^{n}\left(A_{s, i} \cdot d_{i}^{2}\right)\right\}=0 \\
+\left[(0,5 h-e)\left(\beta_{1} \cdot b \cdot d_{1} \cdot \alpha_{1} \cdot f_{c}+0,005 E_{s} \cdot \sum_{i=1}^{n} A_{s, i}\right)-0,005 E_{s} \cdot \sum_{i=1}^{n}\left(A_{s, i} \cdot d_{i}\right)\right] \cdot x+ \\
\quad\left(0,5 \cdot \beta_{1}^{2} \cdot b \cdot \alpha_{1} \cdot f_{c}\right) \cdot x^{3}-\beta_{1} \cdot b \cdot \alpha_{1} \cdot f_{c} \cdot\left[(0,5 h-e)+0,4 d_{1}\right] \cdot x^{2}+ \\
-0,005 E_{s} \cdot\left[(0,5 h-e) \cdot \sum_{i=1}^{n}\left(A_{s, i} \cdot d_{i}\right)-\sum_{i=1}^{n}\left(A_{s, i} \cdot d_{i}^{2}\right)\right]=0
\end{gathered}
$$

onde a primeira faz o cálculo de $x$ quando duas forças normais atuam na seção e a segundo, quando apenas uma atua.

\section{D.4 Cálculo do esforço normal resistente último no domínio tension- controlled}


Para calcular os esforços últimos em seções com deformações correspondentes ao domínio tension-controlled também usa-se as expressões (3.77) e (3.78), quando houver atuação de duas forças normais, e (3.79) quando houver apenas uma.

\section{FIM DO ALGORITMO D}

Nos capítulos seguintes, são apresentados os dados dos modelos experimentais, e seus respectivos esforços de ruína experimentais e previstos segundo os métodos explanados, e a razão entre estes (erro de modelo). 
Avaliação estatística do erro de modelos de resistência 


\section{Capítulo 4: DADOS EXPERIMENTAIS SOBRE A}

\section{RESISTÊNCIA DE ELEMENTOS LINEARES DE}

\section{Concreto ARMado}

São apresentadas neste capítulo as características geométricas e mecânicas de todos os modelos encontrados, os valores observados para a força última experimental. Limitandose às informações disponíveis na bibliografia analisada, são detalhadas também as metodologias de ensaio e as conclusões dos respectivos pesquisadores, de forma que tais informações orientassem análises e conclusões do presente trabalho.

Devido à escassez de dados sobre ensaios de vigas de concreto armado, foram estabelecidas as características dos elementos a serem avaliados, nas quais variou-se altura da seção transversal, taxa de armadura longitudinal e resistência característica do concreto. São apresentadas na Tabela 4.1 as características das vigas analisadas:

TABELA 4.1 - CARACTERÍSTICAS FÍSICAS E GEOMÉTRICAS DOS MODELOS DE VIGA

\begin{tabular}{|c|c|c|c|c|c|c|c|c|c|c|c|}
\hline \multirow[b]{2}{*}{ VIGA } & \multirow{2}{*}{$\begin{array}{c}\mathrm{f}_{\mathrm{ck}} \\
\mathrm{MPa}\end{array}$} & \multirow{2}{*}{$\begin{array}{c}\mathrm{f}_{\mathrm{y}} \\
\mathrm{MPa}\end{array}$} & \multirow{2}{*}{$\begin{array}{c}\mathrm{E}_{\mathrm{s}} \\
\mathrm{MPa}\end{array}$} & \multirow{2}{*}{$\begin{array}{l}b_{w} \\
c m\end{array}$} & \multirow{2}{*}{$\begin{array}{c}\mathrm{h} \\
\mathrm{cm}\end{array}$} & \multicolumn{4}{|c|}{$A_{s, \text { inf }}$} & \multicolumn{2}{|c|}{$A_{s, \text { sup }}$} \\
\hline & & & & & & $\mathrm{n}$ & $n_{i}$ & $\underset{(\mathrm{mm})}{\phi}$ & $\rho_{s}$ & $n_{i}$ & $\begin{array}{c}\phi \\
(\mathrm{mm})\end{array}$ \\
\hline$V f_{c k}-30-055$ & $20-100$ & 543,5 & 210000 & 15 & 30 & 1 & 2 & 12,5 & $0,55 \%$ & 2 & 6,3 \\
\hline$V f_{c k}-30-080$ & $20-100$ & 543,5 & 210000 & 15 & 30 & $\begin{array}{l}1 \\
2\end{array}$ & $\begin{array}{l}3 \\
2\end{array}$ & $\begin{array}{l}10 \\
6,3\end{array}$ & $0,80 \%$ & 2 & 6,3 \\
\hline$V f_{c k}-30-104$ & $20-100$ & 543,5 & 210000 & 15 & 30 & $\begin{array}{l}1 \\
1\end{array}$ & $\begin{array}{l}3 \\
2\end{array}$ & $\begin{array}{c}12,5 \\
8\end{array}$ & $1,04 \%$ & 2 & 6,3 \\
\hline$V f_{c k}-40-127$ & $20-100$ & 543,5 & 210000 & 15 & 40 & $\begin{array}{l}1 \\
1\end{array}$ & $\begin{array}{l}3 \\
2\end{array}$ & $\begin{array}{l}16 \\
10\end{array}$ & $1,27 \%$ & 2 & 8 \\
\hline$V f_{c k}-40-151$ & $20-100$ & 543,5 & 210000 & 15 & 40 & $\begin{array}{l}2 \\
1\end{array}$ & $\begin{array}{l}2 \\
2\end{array}$ & $\begin{array}{c}16 \\
8\end{array}$ & $1,51 \%$ & 2 & 8 \\
\hline$V f_{c k}-40-174$ & $20-100$ & 543,5 & 210000 & 15 & 40 & $\begin{array}{l}1 \\
1\end{array}$ & $\begin{array}{l}3 \\
2\end{array}$ & $\begin{array}{c}20 \\
8\end{array}$ & $1,74 \%$ & 2 & 8 \\
\hline$V f_{c k}-50-200$ & $20-100$ & 543,5 & 210000 & 15 & 50 & $\begin{array}{l}2 \\
1\end{array}$ & $\begin{array}{l}2 \\
2\end{array}$ & $\begin{array}{c}20 \\
12,5\end{array}$ & $2,00 \%$ & 2 & 10 \\
\hline$V f_{c k}-50-226$ & $20-100$ & 543,5 & 210000 & 15 & 50 & $\begin{array}{l}2 \\
2\end{array}$ & $\begin{array}{l}3 \\
2\end{array}$ & $\begin{array}{c}16 \\
12,5\end{array}$ & $2,26 \%$ & 2 & 10 \\
\hline$V f_{c k}-50-251$ & $20-100$ & 543,5 & 210000 & 15 & 50 & $\begin{array}{l}2 \\
1\end{array}$ & $\begin{array}{l}2 \\
2\end{array}$ & $\begin{array}{l}20 \\
20\end{array}$ & $2,51 \%$ & 2 & 10 \\
\hline$V f_{c k}-60-276$ & $20-100$ & 543,5 & 210000 & 15 & 60 & $\begin{array}{l}2 \\
1\end{array}$ & $\begin{array}{l}3 \\
3\end{array}$ & $\begin{array}{l}20 \\
16\end{array}$ & $2,76 \%$ & 3 & 10 \\
\hline$V f_{c k}-60-303$ & $20-100$ & 543,5 & 210000 & 15 & 60 & $\begin{array}{l}1 \\
2\end{array}$ & $\begin{array}{l}3 \\
2\end{array}$ & $\begin{array}{l}25 \\
20\end{array}$ & $3,03 \%$ & 3 & 10 \\
\hline$V f_{c k}-60-327$ & $20-100$ & 543,5 & 210000 & 15 & 60 & 2 & 3 & 25 & $3,27 \%$ & 3 & 10 \\
\hline
\end{tabular}


A resistência característica do concreto variou em 5MPa para concretos de resistência usual, 20 a $50 \mathrm{MPa}$, e em $10 \mathrm{MPa}$ para concretos de alta resistência, 60 a 100MPa.

Os dados referentes aos modelos de pilares são apresentados a seguir:

\subsection{AGOSTINI (1992)}

Pesquisa referente a uma tese de doutorado da Escola Politécnica da USP foi dirigida ao estudo de pilares de concreto de alta resistência com seção quadrada, solicitados à compressão centrada. Teve por objetivo iniciar, no Brasil, a investigação do comportamento de pilares em concreto de alta resistência, principalmente em relação à aplicação dos critérios clássicos de dimensionamento para as estruturas de concreto armado com resistência usual.

A primeira fase do estudo constituiu-se da investigação das propriedades dos materiais, obtendo, assim, um concreto com resistência à compressão em torno de $80 \mathrm{MPa}$ aos 28 dias e trabalhabilidade adequada. Estudou ainda os processos de cura e execução a serem utilizados. Em seguida, para analisar a ductilidade na ruptura, foram executados corpos-deprova cilíndricos de concretos com resistências, aos 28 dias, em torno de $40 \mathrm{MPa}, 60 \mathrm{MPa}$ e 80Mpa. Alguns destes corpos-de-prova possuíam armadura helicoidal.

A investigação dos pilares de concreto com alta resistência iniciou com doze pilares, P1I(II) a P6-I(II), nos quais se variou a resistência do concreto e as taxas das armaduras longitudinal e transversal.

Devido à diferença entre as deformações nos pilares e nos corpos-de-prova de concreto de alta resistência, foram ensaiados seis pilares com as mesmas dimensões dos anteriores, P7I(II), PCNSA-I(II) e PCNCA-I(II). Para avaliar a deformação, esses pilares foram executados com resistência do concreto usual e alta, com e sem armadura.

$\mathrm{Na}$ segunda etapa experimental da pesquisa, também analisaram-se pilares de alta resistência com armaduras usuais. Contudo, por imprevistos técnicos, as dimensões das peças foram reduzidas. Foram executados quatro pilares, P8, P9, P10 e P11, nos quais a variante foi a existência e taxas de armaduras com objetivo de verificar o confinamento conferido por estas. Com o mesmo propósito foram ensaiados mais quatorze pilares, PL4T150-I(II), PL4T175-I(II), PL4T200-I(II), PL4T225-I(II), PL4T250-I(II), PL4T275I(II) e PL4T300-I(II), nos quais somente a taxa de armadura transversal foi alterada.

Resolvido o problema técnico que levou a alteração nas dimensões dos pilares, realizou-se novos ensaios de pilares com as dimensões iniciais, PL4T225-I(II), PL6T225-I(II), 
PL4T300-I(II) e PL6T300-I(II). Desta vez, variou-se tanto taxa da armadura longitudinal quanto transversal.

TABELA 4.2 - CARACTERÍSTICAS FÍSICAS E GEOMÉTRICAS DOS MODELOS DE AGOSTINI (1992)

\begin{tabular}{|c|c|c|c|c|c|c|c|c|c|c|c|c|c|}
\hline \multirow[b]{2}{*}{ PILAR } & \multirow{2}{*}{$\begin{array}{c}\mathrm{f}_{\mathrm{c}} \\
\mathrm{MPa}\end{array}$} & \multirow{2}{*}{$\begin{array}{c}\mathrm{f}_{\mathrm{y}} \\
\mathrm{MPa}\end{array}$} & \multirow{2}{*}{$\begin{array}{c}\mathrm{E}_{\mathrm{s}} \\
\mathrm{MPa}\end{array}$} & \multirow{2}{*}{$\begin{array}{c}\mathrm{b} \\
\mathrm{cm}\end{array}$} & \multirow{2}{*}{$\begin{array}{c}\mathrm{h} \\
\mathrm{cm}\end{array}$} & \multirow{2}{*}{$\begin{array}{l}\Gamma_{e} \\
\mathrm{~cm}\end{array}$} & \multicolumn{3}{|c|}{$A_{s 1}$} & \multicolumn{3}{|c|}{$A_{s w}$} & \multirow{2}{*}{$\begin{array}{c}\mathrm{e}_{\mathrm{i}} \\
\mathrm{mm}\end{array}$} \\
\hline & & & & & & & $\mathrm{n}$ & $\begin{array}{c}\Phi \\
\mathrm{mm}\end{array}$ & $\rho_{1}$ & $\begin{array}{c}\Phi \\
\mathrm{mm}\end{array}$ & $\mathrm{s}$ & $\rho_{w}$ & \\
\hline P1-I & 51,00 & 728 & 219200 & 12 & 12 & 72 & 4 & 6,3 & $0,87 \%$ & 4,2 & 7,5 & $0,51 \%$ & 0 \\
\hline P1-II & 51,00 & 728 & 219200 & 12 & 12 & 72 & 4 & 6,3 & $0,87 \%$ & 4,2 & 7,5 & $0,51 \%$ & 0 \\
\hline P2-I & 57,40 & 728 & 219200 & 12 & 12 & 72 & 8 & 6,3 & $1,73 \%$ & 4,2 & 7,5 & $0,51 \%$ & 0 \\
\hline P2-II & 57,40 & 728 & 219200 & 12 & 12 & 72 & 8 & 6,3 & $1,73 \%$ & 4,2 & 7,5 & $0,51 \%$ & 0 \\
\hline P3-I & 59,80 & 728 & 219200 & 12 & 12 & 72 & 8 & 6,3 & $1,73 \%$ & 4,2 & 7,5 & $0,86 \%$ & 0 \\
\hline P3-II & 59,80 & 728 & 219200 & 12 & 12 & 72 & 8 & 6,3 & $1,73 \%$ & 4,2 & 7,5 & $0,86 \%$ & 0 \\
\hline P4-I & 82,60 & 728 & 219200 & 12 & 12 & 72 & 4 & 6,3 & $0,87 \%$ & 4,2 & 7,5 & $0,51 \%$ & 0 \\
\hline P4-II & 82,60 & 728 & 219200 & 12 & 12 & 72 & 4 & 6,3 & $0,87 \%$ & 4,2 & 7,5 & $0,51 \%$ & 0 \\
\hline P5-I & 74,00 & 728 & 219200 & 12 & 12 & 72 & 8 & 6,3 & $1,73 \%$ & 4,2 & 7,5 & $0,51 \%$ & 0 \\
\hline P5-II & 74,00 & 728 & 219200 & 12 & 12 & 72 & 8 & 6,3 & $1,73 \%$ & 4,2 & 7,5 & $0,51 \%$ & 0 \\
\hline P6-I & 70,40 & 728 & 219200 & 12 & 12 & 72 & 8 & 6,3 & $1,73 \%$ & 4,2 & 7,5 & $0,86 \%$ & 0 \\
\hline P6-II & 70,40 & 728 & 219200 & 12 & 12 & 72 & 8 & 6,3 & $1,73 \%$ & 4,2 & 7,5 & $0,86 \%$ & 0 \\
\hline P7-I & 73,80 & 728 & 219200 & 12 & 12 & 72 & & & & & & & 0 \\
\hline P7-II & 73,80 & 728 & 219200 & 12 & 12 & 72 & & & & & & & 0 \\
\hline P8 & 80,90 & 728 & 210000 & 8 & 8 & 48 & & & & & & & 0 \\
\hline P9 & 80,50 & 728 & 210000 & 8 & 8 & 48 & 4 & 6,3 & $1,95 \%$ & & & & 0 \\
\hline P10 & 80,70 & 728 & 210000 & 8 & 8 & 48 & 4 & 6,3 & $1,95 \%$ & 4,2 & 5 & $1,04 \%$ & 0 \\
\hline P11 & 80,70 & 728 & 210000 & 8 & 8 & 48 & 4 & 6,3 & $1,95 \%$ & 4,2 & 7,5 & $0,69 \%$ & 0 \\
\hline PCNCA-I & 19,80 & 728 & 219200 & 12 & 12 & 72 & 4 & 6,3 & $0,87 \%$ & 4,2 & 7,5 & $0,51 \%$ & 0 \\
\hline PCNCA-II & 19,80 & 728 & 219200 & 12 & 12 & 72 & 4 & 6,3 & $0,87 \%$ & 4,2 & 7,5 & $0,51 \%$ & 0 \\
\hline PCNSA-I & 19,80 & 728 & 219200 & 12 & 12 & 72 & & & & & & & 0 \\
\hline PCNSA-II & 19,80 & 728 & 219200 & 12 & 12 & 72 & & & & & & & 0 \\
\hline PL4T150-I & 70,40 & 499 & 210000 & . & 8 & 48 & 4 & 10 & 4 & 5 & 4,9 & & 0 \\
\hline PL4 & 70,40 & 499 & 210 & 8 & 8 & $4 \varepsilon$ & 4 & 10 & 4,9 & 5 & 4,9 & & 0 \\
\hline PLC & 74,00 & 499 & 2100 & 8 & 8 & $4 \varepsilon$ & 4 & 10 & $4,91 \%$ & 5 & 4,2 & & 0 \\
\hline PL4 & 74,00 & 499 & 2100 & 8 & 8 & 48 & 4 & 10 & $4,91 \%$ & 5 & 4,2 & & 0 \\
\hline PLC & 76,00 & 499 & 210000 & 8 & 8 & 48 & 4 & 10 & $4,91 \%$ & 5 & 3,7 & & 0 \\
\hline PL4T200-II & 76,00 & 499 & 210000 & 8 & 8 & 48 & 4 & 10 & $4,91 \%$ & 5 & 3,7 & 1,7 & 0 \\
\hline PL4T225-I & 71,00 & 499 & 210000 & 8 & 8 & $4 \varepsilon$ & 4 & 10 & $4,91 \%$ & 5 & 3,25 & 2,2 & 0 \\
\hline PL4T225-II & 71,00 & 499 & 210000 & 8 & 8 & $4 \varepsilon$ & 4 & 10 & $4,91 \%$ & 5 & 3,25 & 2,2 & 0 \\
\hline PL4T250-I & 77,00 & 499 & 210000 & 8 & 8 & 48 & 4 & 10 & $4,91 \%$ & 5 & 3 & $2,25 \%$ & 0 \\
\hline PL4T250-II & 77,00 & 499 & 210000 & 8 & 8 & 48 & 4 & 10 & $4,91 \%$ & 5 & 3 & $2,25 \%$ & 0 \\
\hline PL4T275-I & 70,80 & 499 & 210000 & 8 & 8 & 48 & 4 & 10 & $4,91 \%$ & 5 & 2,65 & $2,75 \%$ & 0 \\
\hline PL4T275-II & 70,80 & 499 & 210000 & 8 & 8 & 48 & 4 & 10 & $4,91 \%$ & 5 & 2,65 & $2,75 \%$ & 0 \\
\hline PL4T300-I & 77,60 & 499 & 210000 & 8 & 8 & 48 & 4 & 10 & $4,91 \%$ & 5 & 2,45 & $3,00 \%$ & 0 \\
\hline PL4T300-II & 77,60 & 499 & 210000 & 8 & 8 & 48 & 4 & 10 & $4,91 \%$ & 5 & 2,45 & $3,00 \%$ & 0 \\
\hline PL4T225-I & 84,20 & 544 & 210000 & 12 & 12 & 72 & 4 & 12,5 & $3,41 \%$ & 6,3 & 4 & $2,25 \%$ & 0 \\
\hline PL4T225-II & 84,20 & 544 & 210000 & 12 & 12 & 72 & 4 & 12,5 & $3,41 \%$ & 6,3 & 4 & $2,25 \%$ & 0 \\
\hline PL6T225-I & 73,30 & 544 & 210000 & 12 & 12 & 72 & 6 & 12,5 & $5,11 \%$ & 6,3 & 4 & $2,25 \%$ & 0 \\
\hline PL6T225-II & 73,30 & 544 & 210000 & 12 & 12 & 72 & 6 & 12,5 & $5,11 \%$ & 6,3 & 4 & $2,25 \%$ & 0 \\
\hline PL4T300-I & 83,70 & 544 & 210000 & 12 & 12 & 72 & 4 & 12,5 & $3,41 \%$ & 6,3 & 3 & $3,00 \%$ & 0 \\
\hline PL4T300-II & 83,70 & 544 & 210000 & 12 & 12 & 72 & 4 & 12,5 & $3,41 \%$ & 6,3 & 3 & $3,00 \%$ & 0 \\
\hline PL6T300-I & 72,40 & 544 & 210000 & 12 & 12 & 72 & 6 & 12,5 & $5,11 \%$ & 6,3 & 3 & $3,00 \%$ & 0 \\
\hline PL6T300-II & 72,40 & 544 & 210000 & 12 & 12 & 72 & 6 & 12,5 & $5,11 \%$ & 6,3 & 3 & $3,00 \%$ & 0 \\
\hline PL6T150-I & 71,20 & 544 & 210000 & 12 & 12 & 72 & 6 & 12,5 & $5,11 \%$ & 6,3 & 6 & $1,50 \%$ & 30 \\
\hline PL6T150-II & 71,20 & 544 & 210000 & 12 & 12 & 72 & 6 & 12,5 & $5,11 \%$ & 6,3 & 6 & $1,50 \%$ & 30 \\
\hline
\end{tabular}


Por fim, para obter informações sobre o comportamento da armadura de confinamento quando a peça for solicitada à compressão excêntrica, os pilares PL6T150-I(II) foram ensaiados com carga excêntrica em $3 \mathrm{~cm}$.

Os ensaios dos pilares ocorreram nos laboratórios de estruturas da UNICAMP e da Escola Politécnica da USP, com aparelhos que possuíam atuador de carga com capacidade de $100 \mathrm{tf}$ e $300 \mathrm{tf}$, respectivamente. A Figura 4.1 apresenta o esquema simplificado de ensaio (carregamento). Quando a ação era centrada as placas de apoio, assim como a rótula da prensa localizavam-se no eixo do pilar.

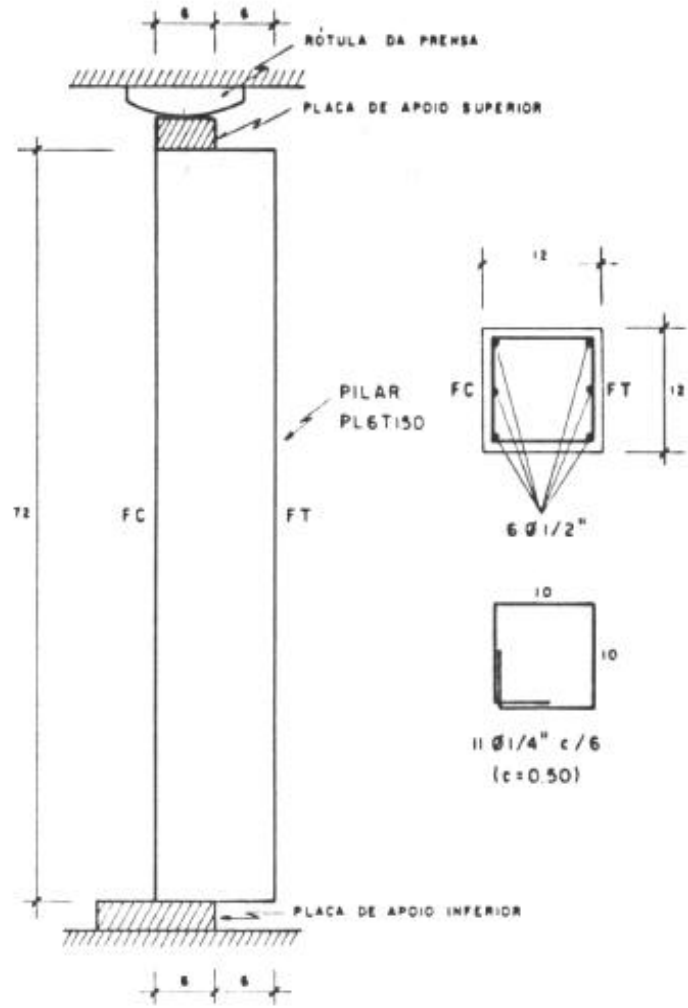

FIGURA 4.1 - ESQUEMA ESTÁTICO DE CARREGAMENTO, (AGOSTINI, 1992)

Do ponto de vista de análise estrutural, as conclusões mais relevantes do autor foram:

a) Em corpos-de-prova e pilares de concretos com alta resistência, a armadura transversal contribuiu apenas evitando a ruptura brusca; enquanto em concretos com resistência usual, a armadura transversal permite um acréscimo de tensão, funcionando como cintamento do núcleo.

b) Mesmo com cargas aplicadas em toda a superfície de concreto, sempre existia uma excentricidade acidental, embora esse efeito diminuísse com o aumento da taxa de armadura longitudinal. A explicação dada pelo autor é que a maior homogeneidade na distribuição das armaduras longitudinais compensa as excentricidades acidentais decorrentes da heterogeneidade do concreto, mas isso deveria ser verificado em pilares de dimensões maiores.

c) O acréscimo de deformação e o decréscimo da tensão última dos pilares de concreto armado com alta resistência em relação a seus corpos-de-prova ou pilares nãoarmados sugeriram que as armaduras longitudinais e transversais definiriam um núcleo de concreto que passou a ser a seção transversal resistente. O mesmo não foi observado para pilares de concreto com resistência usual. 
d) Os estribos individuais e melhor executados foram mais solicitados e mais eficientes como armadura de confinamento. Esses fatos evidenciaram a importância do formato e taxa da armadura transversal na tensão última dos pilares.

e) A partir dos ensaios com pilares solicitados à flexo-compressão, observou-se que a ductilidade foi obtida com armaduras que não impediriam a ruptura frágil caso estes pilares fossem solicitados à compressão centrada, embora a carga última tenha sofrido substancial redução sob solicitação excêntrica.

\subsection{PAIVA (1994)}

A motivação desta pesquisa foi realizar um estudo comparativo com AGOSTINI (1992). Foram estudados pilares em concreto armado de alta resistência com seção retangular, solicitados à compressão centrada. Possuía o objetivo de estabelecer, para tais pilares, as taxas mínimas de armaduras longitudinais e transversais que garantissem segurança nos estados limites últimos.

A primeira etapa experimental constituiu-se na análise da seção resistente, com o ensaio de oito pilares, P1CA-USUAL, P2CA-USUAL, P1CA-CAR, P2CA-CAR, P1SA-USUAL, P2SA-USUAL, P1SA-CAR e P2SA-CAR. Os parâmetros variáveis eram: presença ou não de armadura e a resistência usual ou alta (em torno de 70MPa).

Devido à fragilidade na ruptura de pilares em concreto de alta resistência com armaduras usuais, variou-se a taxa de armaduras transversais de confinamento, buscando a ductilização dos pilares. Foram ensaiados doze pilares, P8/10-150-1(2), P8/10-175-1(2), P8/10-200-1(2), P8/10-225-1(2), P8/10-250-1(2) e P8/10-275-1(2).

Alterando a relação entre os lados da seção transversal e a taxa de armadura longitudinal, foram executados mais seis pilares em concreto de alta resistência. Separados aos pares com taxas volumétricas de armadura transversal de 2,00\%, $2,25 \%$ e $2,50 \%$, os pilares possuíam de dimensões de $8 \mathrm{~cm}$ x $12 \mathrm{~cm} \mathrm{x} 48 \mathrm{~cm}$ e armadura longitudinal com seis barras de $10 \mathrm{~mm}$.

Os pilares foram ensaiados na Máquina Universal de Ensaios (máquina hidráulica) de 100tf, do Laboratório de Estruturas e Materiais de

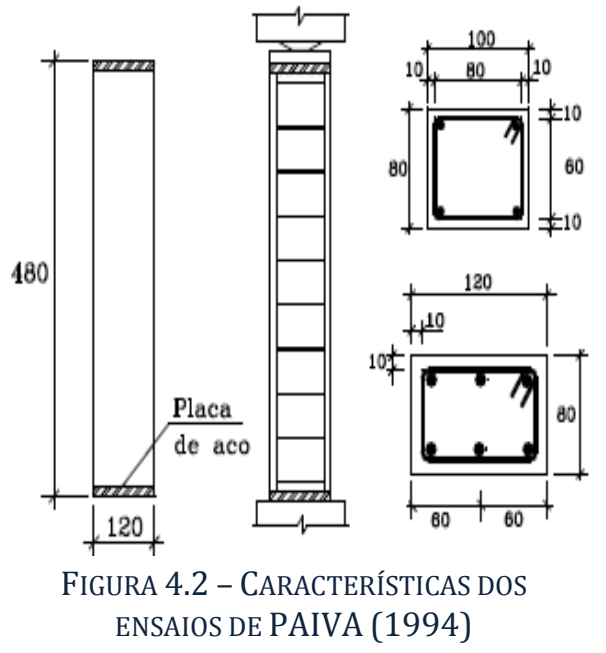


Construção da UNICAMP, Figura 4.2.

TABELA 4.3 - CARACTERÍSTICAS FÍSICAS E GEOMÉTRICAS DOS MODELOS DE PAIVA (1994)

\begin{tabular}{|c|c|c|c|c|c|c|c|c|c|c|c|c|c|}
\hline \multirow[b]{2}{*}{ PILAR } & \multirow{2}{*}{$\begin{array}{c}\mathrm{f}_{\mathrm{c}} \\
\mathrm{MPa}\end{array}$} & \multirow{2}{*}{$\begin{array}{c}\mathrm{f}_{\mathrm{y}} \\
\mathrm{MPa}\end{array}$} & \multirow{2}{*}{$\begin{array}{c}\mathrm{E}_{\mathrm{s}} \\
\mathrm{MPa}\end{array}$} & \multirow{2}{*}{$\begin{array}{l}\mathrm{b} \\
\mathrm{cm}\end{array}$} & \multirow{2}{*}{$\begin{array}{l}\mathrm{h} \\
\mathrm{cm}\end{array}$} & \multirow{2}{*}{$\begin{array}{l}\text { le } \\
\mathrm{cm}\end{array}$} & \multicolumn{3}{|c|}{$A_{s l}$} & \multicolumn{3}{|c|}{$A_{s w}$} & \multirow{2}{*}{$\begin{array}{c}e_{i} \\
m m\end{array}$} \\
\hline & & & & & & & $\mathrm{n}$ & $\begin{array}{c}\Phi \\
\mathrm{mm}\end{array}$ & $\mathrm{cm}$ & $\begin{array}{c}\Phi \\
\mathrm{mm}\end{array}$ & $\mathrm{s}$ & $\rho_{w}$ & \\
\hline P1SA-USUAL & 21,10 & 493 & 210000 & 10 & 8 & 48 & & & & & & & 0 \\
\hline P2SA-USUAL & 21,10 & 493 & 210000 & 10 & 8 & $4 \varepsilon$ & & & & & & & 0 \\
\hline P1CA-USUAL & 19,20 & 493 & 210000 & 10 & 8 & 48 & 4 & 6,3 & $1,56 \%$ & 5 & 8 & $0,86 \%$ & 0 \\
\hline P2CA-USUAL & 19,20 & 493 & 210000 & 10 & 8 & 48 & 4 & 6,3 & $1,56 \%$ & 5 & 8 & $0,86 \%$ & 0 \\
\hline P1SA-CAR & 55,70 & 493 & 210000 & 10 & 8 & 48 & & & & & & & 0 \\
\hline P2SA-CAR & 55,70 & 493 & 210000 & 10 & 8 & 48 & & & & & & & 0 \\
\hline P1CA-CAR & 61,90 & 493 & 210000 & 10 & 8 & 48 & 4 & 6,3 & $1,56 \%$ & 5 & 4,6 & $1,50 \%$ & 0 \\
\hline P2CA-CAR & 61,90 & 493 & 210000 & 10 & 8 & 48 & 4 & 6,3 & $1,56 \%$ & 5 & 4,6 & $1,50 \%$ & 0 \\
\hline P8/10-150-1 & 74,48 & 493 & 210000 & 10 & 8 & 48 & 4 & 10,0 & $3,93 \%$ & 5 & 3,9 & $1,75 \%$ & 0 \\
\hline P8/10-150-2 & 74,48 & 493 & 210000 & 10 & 8 & 48 & 4 & 10,0 & $3,93 \%$ & 5 & 3,9 & $1,75 \%$ & 0 \\
\hline P8/10-175-1 & 65,83 & 493 & 210000 & 10 & 8 & 48 & 4 & 10,0 & $3,93 \%$ & 5 & 3,4 & $2,00 \%$ & 0 \\
\hline P8/10-175-2 & 65,83 & 493 & 210000 & 10 & 8 & 48 & 4 & 10,0 & $3,93 \%$ & 5 & 3,4 & $2,00 \%$ & 0 \\
\hline P8/10-200-1 & 66,27 & 493 & 210000 & 10 & 8 & 48 & 4 & 10,0 & $3,93 \%$ & 5 & 3 & $2,25 \%$ & 0 \\
\hline P8/10-200-2 & 66,27 & 493 & 210000 & 10 & 8 & 48 & 4 & 10,0 & $3,93 \%$ & 5 & 3 & $2,25 \%$ & 0 \\
\hline P8/10-225-1 & 63,60 & 493 & 210000 & 10 & 8 & 48 & 4 & 10,0 & $3,93 \%$ & 5 & 2,7 & $2,50 \%$ & 0 \\
\hline P8/10-225-2 & 63,60 & 493 & 210000 & 10 & 8 & 48 & 4 & 10,0 & $3,93 \%$ & 5 & 2,7 & $2,50 \%$ & 0 \\
\hline$P 8 / 10-250-1$ & 63,85 & 493 & 210000 & 10 & 8 & 48 & 4 & 10,0 & $3,93 \%$ & 5 & 2,5 & $2,75 \%$ & 0 \\
\hline P8/10-250-2 & 63,85 & 493 & 210000 & 10 & 8 & 48 & 4 & 10,0 & $3,93 \%$ & 5 & 2,5 & $2,75 \%$ & 0 \\
\hline$P 8 / 10-275-1$ & 54,11 & 493 & 210000 & 10 & 8 & 48 & 4 & 10,0 & $3,93 \%$ & 5 & 2,3 & $3,00 \%$ & 0 \\
\hline P8/10-275-2 & 54,11 & 493 & 210000 & 10 & 8 & 48 & 4 & 10,0 & $3,93 \%$ & 5 & 2,3 & $3,00 \%$ & 0 \\
\hline P8/12-200-1 & 66,72 & 493 & 210000 & 12 & 8 & 48 & 6 & 10,0 & $4,91 \%$ & 5 & 3,3 & $2,00 \%$ & 0 \\
\hline P8/12-200-2 & 66,72 & 493 & 210000 & 12 & 8 & 48 & 6 & 10,0 & $4,91 \%$ & 5 & 3,3 & $2,00 \%$ & 0 \\
\hline$P 8 / 12-225-1$ & 64,87 & 493 & 210000 & 12 & 8 & 48 & 6 & 10,0 & $4,91 \%$ & 5 & 2,9 & $2,25 \%$ & 0 \\
\hline P8/12-225-2 & 64,87 & 493 & 210000 & 12 & 8 & 48 & 6 & 10,0 & $4,91 \%$ & 5 & 2,9 & $2,25 \%$ & 0 \\
\hline$P 8 / 12-250-1$ & 63,80 & 493 & 210000 & 12 & 8 & 48 & 6 & 10,0 & $4,91 \%$ & 5 & 2,6 & $2,50 \%$ & 0 \\
\hline$P 8 / 12-250-2$ & 63,80 & 493 & 210000 & 12 & 8 & 48 & 6 & 10,0 & $4,91 \%$ & 5 & 2,6 & $2,50 \%$ & 0 \\
\hline
\end{tabular}

Através dos ensaios e análises realizadas, o pesquisador chegou às seguintes conclusões a respeito de pilares de concreto com alta resistência e seção transversal retangular, quando solicitados à compressão centrada:

a) Somente nos pilares em concreto de resistência usual, seção resistente coincide com a seção transversal.

b) O confinamento promovido pela armadura longitudinal mostrou-se eficiente a partir de uma taxa volumétrica de 2,00\% e melhorando até taxa de 2,50\%.

c) Verificou-se surgimento de excentricidade acidental mesmo com confinamento adequado e maior taxa de armadura longitudinal, provando que, em pilares com seções retangulares, a homogeneidade da armadura não compensa a heterogeneidade do concreto. 
d) Em pilares de alta resistência, a seção resistente é definida pelas armaduras e, para evitar a ruptura frágil, são necessárias taxas de armaduras transversais em torno de $2,20 \%$ e de armaduras longitudinais superiores a 3,20\%.

\subsection{LIMA (1997)}

Trata-se da primeira pesquisa experimental, desenvolvida no SET, envolvendo pilares de concreto de alto desempenho, com resistência aos 15 dias em torno de $80 \mathrm{MPa}$.

Foram ensaiados 23 pilares, dos quais dez eram solicitados à flexão normal composta, avaliando a distribuição de tensões ao longo da seção transversal, para níveis diferentes de excentricidades e taxas de armadura, e ainda, buscou-se utilizar dimensões que representassem os pilares de edifícios de concreto armado.

Os pilares solicitados à compressão centrada foram divididos em quatro séries, P1, P2, P3 e P4, diferindo pelas dimensões da seção ou pela taxa de armadura transversal.

Os pilares ensaiados sob carga excêntrica foram distribuídos em cinco séries, P5, P6, P7, P8 e P9. Variou-se todos os parâmetros: dimensões dos pilares, taxas de armaduras longitudinal e transversal e excentricidade.

TABELA 4.4 - CARACTERÍSTICAS FÍSICAS E GEOMÉTRICAS DOS MODELOS DE LIMA (1997)

\begin{tabular}{|c|c|c|c|c|c|c|c|c|c|c|c|c|c|}
\hline \multirow[b]{2}{*}{ PILAR } & \multirow{2}{*}{$\begin{array}{c}f_{c} \\
M P a\end{array}$} & \multirow{2}{*}{$\begin{array}{c}\mathrm{f}_{\mathrm{y}} \\
\mathrm{MPa}\end{array}$} & \multirow{2}{*}{$\begin{array}{c}\mathrm{E}_{\mathrm{s}} \\
\mathrm{MPa}\end{array}$} & \multirow{2}{*}{$\begin{array}{l}\mathrm{b} \\
\mathrm{cm}\end{array}$} & \multirow{2}{*}{$\begin{array}{l}\mathrm{h} \\
\mathrm{cm}\end{array}$} & \multirow{2}{*}{$\begin{array}{l}\text { le } \\
\mathrm{cm}\end{array}$} & \multicolumn{3}{|c|}{$A_{s 1}$} & \multicolumn{3}{|c|}{$A_{s w}$} & \multirow{2}{*}{$\begin{array}{c}e_{i} \\
m m\end{array}$} \\
\hline & & & & & & & $n$ & $\begin{array}{c}\Phi \\
(\mathrm{mm})\end{array}$ & $\rho_{1}$ & $\begin{array}{c}\Phi \\
(\mathrm{mm})\end{array}$ & $\mathrm{s}$ & $\rho_{w}$ & \\
\hline $\mathrm{P} 1 / 1$ & 83,80 & 543,3 & 205028 & 20 & 20 & 120 & 8 & 12,5 & $2,45 \%$ & 6,3 & 5 & $1,03 \%$ & 0 \\
\hline $\mathrm{P} 1 / 2$ & 83,80 & 543,3 & 205028 & 20 & 20 & 120 & 8 & 12,5 & $2,45 \%$ & 6,3 & 5 & $1,03 \%$ & 0 \\
\hline $\mathrm{P} 1 / 3$ & 83,80 & 543,3 & 205028 & 20 & 20 & 120 & 8 & 12,5 & $2,45 \%$ & 6,3 & 5 & $1,03 \%$ & 0 \\
\hline $\mathrm{P} 1 \mathrm{r} / 2$ & 85,10 & 543,3 & 205028 & 20 & 20 & 120 & 8 & 12,5 & $2,45 \%$ & 6,3 & 5 & $1,03 \%$ & 0 \\
\hline $\mathrm{P} 1 \mathrm{r} / 3$ & 85,10 & 543,3 & 205028 & 20 & 20 & 120 & 8 & 12,5 & $2,45 \%$ & 6,3 & 5 & $1,03 \%$ & 0 \\
\hline $\mathrm{P} 2 / 2$ & 87,40 & 543,3 & 205028 & 20 & 20 & 120 & 8 & 12,5 & $2,45 \%$ & 6,3 & 10 & $0,51 \%$ & 0 \\
\hline $\mathrm{P} 2 / 3$ & 92,00 & 543,3 & 205028 & 20 & 20 & 120 & 8 & 12,5 & $2,45 \%$ & 6,3 & 10 & $0,51 \%$ & 0 \\
\hline P3/1 & 94,90 & 543,3 & 205028 & 30 & 15 & 90 & 8 & 12,5 & $2,18 \%$ & 6,3 & 5 & $1,03 \%$ & 0 \\
\hline $\mathrm{P} 3 / 2$ & 94,90 & 543,3 & 205028 & 30 & 15 & 90 & 8 & 12,5 & $2,18 \%$ & 6,3 & 5 & $1,03 \%$ & 0 \\
\hline $\mathrm{P} 3 / 3$ & 94,90 & 543,3 & 205028 & 30 & 15 & 90 & 8 & 12,5 & $2,18 \%$ & 6,3 & 5 & $1,03 \%$ & 0 \\
\hline $\mathrm{P} 4 / 1$ & 80,50 & 543,3 & 205028 & 30 & 15 & 90 & 8 & 12,5 & $2,18 \%$ & 6,3 & 2,5 & $2,05 \%$ & 0 \\
\hline $\mathrm{P} 4 / 2$ & 80,50 & 543,3 & 205028 & 30 & 15 & 90 & 8 & 12,5 & $2,18 \%$ & 6,3 & 2,5 & $2,05 \%$ & 0 \\
\hline $\mathrm{P} 4 / 3$ & 80,50 & 543,3 & 205028 & 30 & 15 & 90 & 8 & 12,5 & $2,18 \%$ & 6,3 & 2,5 & $2,05 \%$ & 0 \\
\hline $\mathrm{P} 5 / 1$ & 81,10 & 543,3 & 205028 & 30 & 15 & 174 & 8 & 12,5 & $2,18 \%$ & 6,3 & 5 & $1,58 \%$ & 15 \\
\hline $\mathrm{P} 5 / 2$ & 79,50 & 543,3 & 205028 & 30 & 15 & 174 & 8 & 12,5 & $2,18 \%$ & 6,3 & 5 & $1,58 \%$ & 15 \\
\hline $\mathrm{P} 6 / 1$ & 85,70 & 710,5 & 201242 & 30 & 15 & 174 & 8 & 16 & $3,57 \%$ & 6,3 & 5 & $1,58 \%$ & 15 \\
\hline $\mathrm{P} 6 / 2$ & 83,70 & 710,5 & 201242 & 30 & 15 & 174 & 8 & 16 & $3,57 \%$ & 6,3 & 5 & $1,58 \%$ & 15 \\
\hline P7/1 & 87,30 & 681,2 & 200419 & 30 & 15 & 174 & 8 & 9,5 & $1,26 \%$ & 6,3 & 7,5 & $1,05 \%$ & 15 \\
\hline $\mathrm{P} 7 / 2$ & 93,50 & 681,2 & 200419 & 30 & 15 & 174 & 4 & 9,5 & $0,63 \%$ & 6,3 & 7,5 & $1,05 \%$ & 15 \\
\hline P8/1 & 87,10 & 681,7 & 200419 & 30 & 15 & 174 & 8 & 9,5 & $1,26 \%$ & 6,3 & 7,5 & $1,05 \%$ & 25 \\
\hline P8/2 & 92,80 & 681,2 & 200419 & 30 & 15 & 174 & 4 & 9,5 & $0,63 \%$ & 6,3 & 7,5 & $1,05 \%$ & 25 \\
\hline $\mathrm{P} 9 / 1$ & 101,30 & 676,4 & 203141 & 30 & 12 & 247 & 8 & 10 & $1,75 \%$ & 6,3 & 6 & $1,56 \%$ & 30 \\
\hline $\mathrm{Pg} / 2$ & 83,30 & 676.5 & 203141 & 30 & 12 & 247 & 8 & 10 & $1.75 \%$ & 6.3 & 12 & $0.78 \%$ & 30 \\
\hline
\end{tabular}


A estrutura de reação dos ensaios, Figura 4.3, era composta por um pórtico espacial metálico ancorado por meio de tirantes em uma laje de reação. O pórtico era constituído por quatro colunas e uma grelha horizontal composta por quatro vigas metálicas, duas centrais onde foi fixada a célula de carga e que apoiavam-se nas vigas duas laterais, todas fixadas por parafusos. O macaco hidráulico foi posto na parte inferior do pórtico.
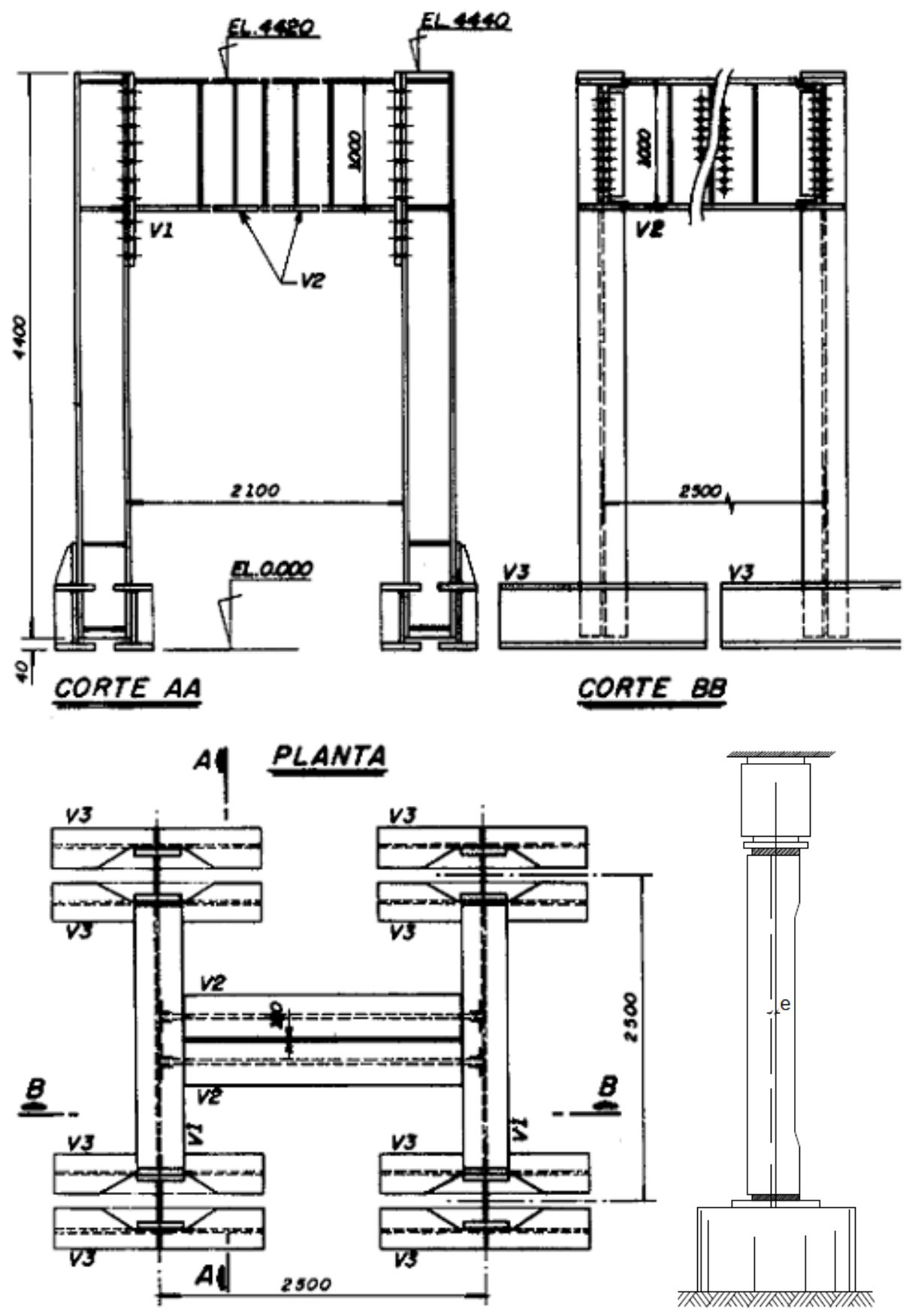

FIGURA 4.3 - ESQUEMA DE MONTAGEM DO PÓRTICO E DE CARREGAMENTO (LIMA, 1997)

Nos casos de compressão excêntrica, neste assim como nos demais trabalho, a carga excêntrica foi aplicada na direção de menor inércia. 
O trabalho tinha como um dos objetivos desenvolver uma metodologia de cálculo para pilares de concreto de alto desempenho, portanto a maioria das conclusões feitas pelo pesquisador dizem respeito principalmente a exatidão do método proposto, a que não interessa ao presente trabalho. As demais conclusões são:

a) A seção resistente é formada pelo núcleo limitado pelo eixo da armadura mais externa, pois as relações entre a força última experimental e a força última teórica, considerando a seção do núcleo resultam em valores mais próximos de 1 .

b) A ductilidade aumenta com as taxas de armadura transversal e longitudinal.

c) Em pilares solicitados à compressão centrada, a ductilidade pode ser alcançada com menores taxas de armaduras que propostas em AGOSTINI (1992) e PAIVA (1994).

d) A deformação última no concreto na face mais comprimida resultou um valor médio de 2,5\%o confirmando a alteração proposta para o diagrama de domínios de deformação, quando se tratar de concreto de alto desempenho.

\subsection{VALLADARES (1997)}

Estudo realizado na UFMG referente a uma dissertação de mestrado, que tinha por objetivo analisar a evolução de deformações e deslocamentos residuais ou permanentes no concreto e nas armações, a evolução do mecanismo de fissuração e as cargas máximas ou de ruína.

Os pilares ensaiados eram geometricamente idênticos sujeitos à ação excêntrica de $5 \mathrm{~cm}$ em uma das direções principais. Possuíam seção transversal quadrada, armaduras longitudinal e transversal e excentricidade iguais em todos os modelos, a única variável era a resistência do concreto.

TABELA 4.5 - CARACTERÍSTICAS FÍSICAS E GEOMÉTRICAS DOS MODELOS DE VALLADARES (1997)

\begin{tabular}{|c|c|c|c|c|c|c|c|c|c|c|c|c|c|}
\hline \multirow[b]{2}{*}{ PILAR } & \multirow{2}{*}{$\begin{array}{c}\mathrm{f}_{\mathrm{c}} \\
\mathrm{MPa}\end{array}$} & \multirow{2}{*}{$\begin{array}{c}\mathrm{f}_{\mathrm{y}} \\
\mathrm{MPa}\end{array}$} & \multirow{2}{*}{$\begin{array}{c}\mathrm{E}_{\mathrm{s}} \\
\mathrm{MPa}\end{array}$} & \multirow{2}{*}{$\begin{array}{c}\mathrm{b} \\
\mathrm{cm}\end{array}$} & \multirow{2}{*}{$\begin{array}{c}\mathrm{h} \\
\mathrm{cm}\end{array}$} & \multirow{2}{*}{$\begin{array}{l}\text { le } \\
\mathrm{cm}\end{array}$} & \multicolumn{3}{|c|}{$\overline{A_{s l}}$} & \multicolumn{3}{|c|}{$A_{s w}$} & \multirow{2}{*}{$\begin{array}{c}e_{i} \\
m m\end{array}$} \\
\hline & & & & & & & $\mathrm{n}$ & $\begin{array}{c}\Phi \\
(\mathrm{mm})\end{array}$ & $\mathrm{mm}$ & $\begin{array}{c}\Phi \\
(\mathrm{mm})\end{array}$ & $\mathrm{s}$ & $\rho_{w}$ & \\
\hline BR-PE01 & 29,50 & 500 & 210000 & 15 & 15 & 75 & 4 & 10 & $1,40 \%$ & 5 & 12 & $0,58 \%$ & 50 \\
\hline BR-PE02 & 30,00 & 500 & 210000 & 15 & 15 & 75 & 4 & 10 & $1,40 \%$ & 5 & 12 & $0,58 \%$ & 50 \\
\hline MR-PE01 & 58,70 & 500 & 210000 & 15 & 15 & 75 & 4 & 10 & $1,40 \%$ & 5 & 12 & $0,58 \%$ & 50 \\
\hline MR-PE01 & 60,60 & 500 & 210000 & 15 & 15 & 75 & 4 & 10 & $1,40 \%$ & 5 & 12 & $0,58 \%$ & 50 \\
\hline AR-PE01 & 66,00 & 500 & 210000 & 15 & 15 & 75 & 4 & 10 & $1,40 \%$ & 5 & 12 & $0,58 \%$ & 50 \\
\hline AR-PE02 & 76,10 & 500 & 210000 & 15 & 15 & 75 & 4 & 10 & $1,40 \%$ & 5 & 12 & $0,58 \%$ & 50 \\
\hline AR-PE03 & 81,40 & 500 & 210000 & 15 & 15 & 75 & 4 & 10 & $1,40 \%$ & 5 & 12 & $0,58 \%$ & 50 \\
\hline AR-PE04 & 79,20 & 500 & 210000 & 15 & 15 & 75 & 4 & 10 & $1,40 \%$ & 5 & 12 & $0,58 \%$ & 50 \\
\hline
\end{tabular}

Os modelos eram bi-articulados com excentricidades idênticas em suas extremidades, Figura 4.4, e foram ensaiados aos 28 dias. Os exemplares não foram carregados 
monotonicamente até a ruína, ou seja, com a intensificação da solicitação, os exemplares eram totalmente descarregados, formando ciclos de caracterizados por deformações máximas e deformações residuais relacionadas.

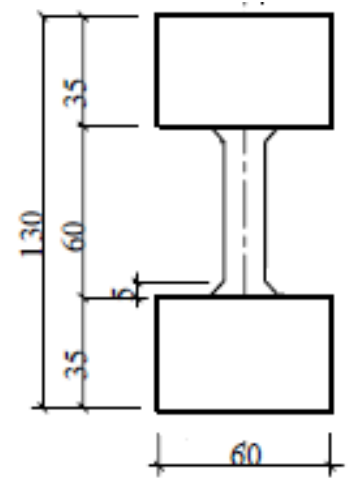

FIGURA 4.4 - DISPOSITIVO EXPERIMENTAL E MODELO DE VALLADARES (1997)

A partir dos resultados dos ensaios, o autor chegou às seguintes conclusões:

a) Há uma queda de ductilidade estrutural associada à ruína com o aumento da resistência à compressão, o que evidencia o comportamento frágil de pilares em concreto de alta resistência em relação a pilares idênticos de concreto de resistência normal.

b) $\mathrm{O}$ aumento da resistência do concreto acarreta em redução da deformabilidade estrutural.

c) Concretos com alta resistência apresentam módulos de elasticidade elevados, início de fissuração em estágios mais avançados de solicitação (maior resistência à tração) e melhor aderência às armaduras com o aumento da resistência do concreto em estágios pós-fissuração.

d) Concretos com alta resistência apresentam ruínas bruscas acompanhadas por grandes perdas de cobrimentos de concreto e consequente flambagem das barras longitudinais de armação nas regiões expostas, enquanto em concretos de baixas resistências, as ruínas são tipicamente dúcteis.

\subsection{VANDERLEI (1999)}

Esta pesquisa foi desenvolvida no SET EESC/USP com o objetivo de analisar o comportamento de pilares de concreto armado sujeitos à flexo-compressão normal, dando continuidade a LIMA (1997). No entanto, foi utilizada uma metodologia de ensaio julgada 
como mais adequada, no que diz respeito à representação e controle das ações, e com a qual pudesse se aferir o modelo teórico.

Foram mantidas a seção transversal, a resistência do concreto e as taxas de armaduras longitudinais e transversais utilizadas em LIMA (1997). Ensaiou-se seis pilares executados com concreto de resistência à compressão, aos 28 dias, em torno de $80 \mathrm{MPa}$ e submetidos à carga excêntrica em $38 \mathrm{~cm}$ na direção de menor inércia.

TABELA 4.6 - CARACTERÍSTICAS FÍSICAS E GEOMÉTRICAS DOS MODELOS DE VANDERLEI (1999)

\begin{tabular}{|c|c|c|c|c|c|c|c|c|c|c|c|c|c|}
\hline \multirow[b]{2}{*}{ PILAR } & \multirow{2}{*}{$\begin{array}{c}\mathrm{f}_{\mathrm{c}} \\
\mathrm{MPa}\end{array}$} & \multirow{2}{*}{$\begin{array}{c}f_{y} \\
M P a\end{array}$} & \multirow{2}{*}{$\begin{array}{c}\mathrm{E}_{\mathrm{s}} \\
\mathrm{MPa}\end{array}$} & \multirow{2}{*}{$\begin{array}{c}\mathrm{b} \\
\mathrm{cm}\end{array}$} & \multirow{2}{*}{$\begin{array}{c}\mathrm{h} \\
\mathrm{cm}\end{array}$} & \multirow{2}{*}{$\begin{array}{c}l_{e} \\
\mathrm{~cm}\end{array}$} & \multicolumn{3}{|c|}{$A_{s 1}$} & \multicolumn{3}{|c|}{$A_{s w}$} & \multirow{2}{*}{$\begin{array}{c}e_{i} \\
m m\end{array}$} \\
\hline & & & & & & & $n$ & $\begin{array}{c}\Phi \\
(\mathrm{mm})\end{array}$ & $\rho_{1}$ & $\begin{array}{c}\Phi \\
(\mathrm{mm})\end{array}$ & s & $\rho_{w}$ & \\
\hline $\mathrm{P} 1 / 1 \mathrm{R}$ & 88,89 & 502,1 & 168841 & 30 & 15 & 105 & 8 & 12,5 & $2,18 \%$ & 6,3 & 5 & $1,58 \%$ & 380 \\
\hline $\mathrm{P} 1 / 2$ & 85,68 & 502,1 & 168841 & 30 & 15 & 105 & 8 & 12,5 & $2,18 \%$ & 6,3 & 10 & $0,79 \%$ & 380 \\
\hline $\mathrm{P} 1 / 3$ & 82,61 & 502,1 & 168841 & 30 & 15 & 105 & 8 & 12,5 & $2,18 \%$ & 6,3 & 15 & $0,53 \%$ & 380 \\
\hline $\mathrm{P} 2 / 1$ & 90,07 & 623,0 & 194060 & 30 & 15 & 105 & 8 & 10 & $1,40 \%$ & 6,3 & 10 & $0,79 \%$ & 380 \\
\hline P2/2 & 89,61 & 623,0 & 194060 & 30 & 15 & 105 & 8 & 10 & $1,40 \%$ & 6,3 & 5 & $1,58 \%$ & 380 \\
\hline P3/1 & 87,41 & 622,9 & 194388 & 30 & 15 & 105 & 8 & 16 & $3,57 \%$ & 6,3 & 10 & $0,79 \%$ & 380 \\
\hline
\end{tabular}

Foram aplicadas duas forças independentes, uma centrada no eixo dos pilares e outra com excentricidade bem definida, facilitando assim a aplicação e o controle das forças para que a distribuição de tensões fosse de acordo com o esperado no modelo teórico adotado. $\mathrm{O}$ modelo que se pretendeu atingir era de uma pilar com força excêntrica aplicada na direção do eixo longitudinal, provocando uma situação de flexo-compressão normal. As aplicações das forças eram feitas por duas bombas, uma para atuador hidráulico da força centrada de $5000 \mathrm{kN}$ e a outra para os dois atuadores da força excêntrica de $300 \mathrm{kN}$ cada. As forças eram aplicadas em etapas

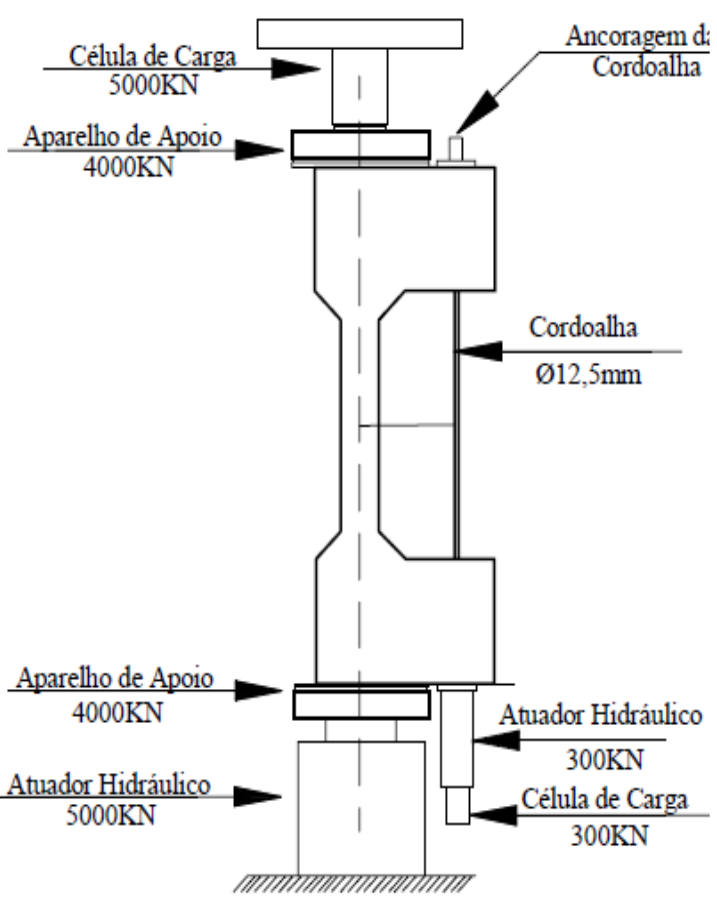

FIgURA 4.5 - SiSTEMA ESTÁTICO DE ENSAIO DE VANDERLEI (1999) onde a força excêntrica era $5 \%$ da força centrada.

As principais conclusões feitas a partir da análise dos resultados foram:

a) O sistema de ensaio adotado não apresentou centralização, com precisão, da força aplicada no eixo dos modelos, o que ocasionou aparecimento de excentricidades 
acidentais desconhecidas e, consequentemente, grandes diferenças entre momento experimental e teórico.

b) Apesar do pequeno número de ensaios, percebeu-se que a ductilização da seção transversal é função das taxas de armadura longitudinal e transversal.

c) Houve uma mudança na inclinação da curva força x deformação em torno de $55 \%$ da força de ruptura, provavelmente decorrente do destacamento do cobrimento da armadura.

d) As deformações últimas do concreto, na face mais comprimida do pilar, variaram entre $0,23 \%$ e $0,3 \%$, confirmando a alteração dos limites nos domínios de deformação, para casos de concreto com alta resistência.

\subsection{QUEIROGA (1999)}

Estudo desenvolvido no SET EESC/USP com pretensão dar continuidade a LIMA (1997) sobre pilares de concreto de alto desempenho. Visava verificar a formação de um núcleo resistente e determinar as taxas de armaduras longitudinal e transversal capazes de promover esse confinamento em peças com tais configurações.

Os modelos possuíam resistência à compressão, aos 15 dias, em torno de 60MPa e eram solicitados à compressão centrada.

Foram confeccionados e ensaiados modelos separados em seis séries com dois exemplares idênticos. As peças a mesma área de armadura longitudinal e diferiam apenas pela a taxa de armadura transversal (espaçamento entre os estribos) e pelas dimensões e formato da seção transversal.

TABELA 4.7 - CARACTERÍSTICAS FÍSICAS E GEOMÉTRICAS DOS MODELOS DE QUEIROGA (1999)

\begin{tabular}{|c|c|c|c|c|c|c|c|c|c|c|c|c|c|}
\hline \multirow[b]{2}{*}{ PILAR } & \multirow{2}{*}{$\begin{array}{c}\mathrm{f}_{\mathrm{c}} \\
\mathrm{MPa}\end{array}$} & \multirow{2}{*}{$\begin{array}{c}\mathrm{f}_{\mathrm{y}} \\
\mathrm{MPa}\end{array}$} & \multirow{2}{*}{$\begin{array}{c}\mathrm{E}_{\mathrm{s}} \\
\mathrm{MPa}\end{array}$} & \multirow{2}{*}{$\begin{array}{l}\mathrm{b} \\
\mathrm{cm}\end{array}$} & \multirow{2}{*}{$\begin{array}{l}\mathrm{h} \\
\mathrm{cm}\end{array}$} & \multirow{2}{*}{$\begin{array}{l}\text { le } \\
\mathrm{cm}\end{array}$} & \multicolumn{3}{|c|}{$\overline{A_{s I}}$} & \multicolumn{3}{|c|}{$A_{s w}$} & \multirow{2}{*}{$\begin{array}{l}\mathrm{e}_{\mathrm{i}} \\
\mathrm{mm}\end{array}$} \\
\hline & & & & & & & $\mathrm{n}$ & $\begin{array}{c}\Phi \\
(\mathrm{mm})\end{array}$ & $\rho_{\mathrm{l}}$ & $\begin{array}{c}\Phi \\
(\mathrm{mm})\end{array}$ & $\mathrm{s}$ & $\rho_{w}$ & \\
\hline P1 & 59,60 & 502,1 & 168800 & 20 & 20 & 120 & 8 & 12,5 & $2,45 \%$ & 6,3 & 15 & $0,34 \%$ & 0 \\
\hline P2 & 64,35 & 502,1 & 168800 & 20 & 20 & 120 & 8 & 12,5 & $2,45 \%$ & 6,3 & 15 & $0,34 \%$ & 0 \\
\hline P3 & 53,40 & 502,1 & 168800 & 20 & 20 & 120 & 8 & 12,5 & $2,45 \%$ & 6,3 & 10 & $0,51 \%$ & 0 \\
\hline P4 & 53,40 & 502,1 & 168800 & 20 & 20 & 120 & 8 & 12,5 & $2,45 \%$ & 6,3 & 10 & $0,51 \%$ & 0 \\
\hline P5 & 55,90 & 502,1 & 168800 & 20 & 20 & 120 & 8 & 12,5 & $2,45 \%$ & 6,3 & 5 & $1,03 \%$ & 0 \\
\hline P6 & 55,90 & 502,1 & 168800 & 20 & 20 & 120 & 8 & 12,5 & $2,45 \%$ & 6,3 & 5 & $1,03 \%$ & 0 \\
\hline P7 & 66,90 & 502,1 & 168800 & 30 & 15 & 90 & 8 & 12,5 & $2,18 \%$ & 6,3 & 15 & $0,34 \%$ & 0 \\
\hline P8 & 66,90 & 502,1 & 168800 & 30 & 15 & 90 & 8 & 12,5 & $2,18 \%$ & 6,3 & 15 & $0,34 \%$ & 0 \\
\hline P9 & 63,88 & 502,1 & 168800 & 30 & 15 & 90 & 8 & 12,5 & $2,18 \%$ & 6,3 & 10 & $0,79 \%$ & 0 \\
\hline P10 & 63,88 & 502,1 & 168800 & 30 & 15 & 90 & 8 & 12,5 & $2,18 \%$ & 6,3 & 10 & $0,79 \%$ & 0 \\
\hline P11 & 65,47 & 502,1 & 168800 & 30 & 15 & 90 & 8 & 12,5 & $2,18 \%$ & 6,3 & 5 & $1,58 \%$ & 0 \\
\hline P12 & 65,47 & 502,1 & 168800 & 30 & 15 & 90 & 8 & 12,5 & $2,18 \%$ & 6,3 & 5 & $1,58 \%$ & 0 \\
\hline
\end{tabular}


Os modelos foram ensaiados no Laboratório de Estruturas da EESC-USP na INSTRON, máquina hidráulica, servo-controlada e computadorizada, com capacidade para carga estática de $2500 \mathrm{kN}$ e altura útil de ensaio de $4 \mathrm{~m}$. A utilização da INSTRON, permitiu a aplicação de deslocamentos com velocidade controlada $(\mathrm{mm} / \mathrm{s})$, variando-se a mesma à medida que as forças últimas teóricas previstas pelo pesquisador se aproximavam.

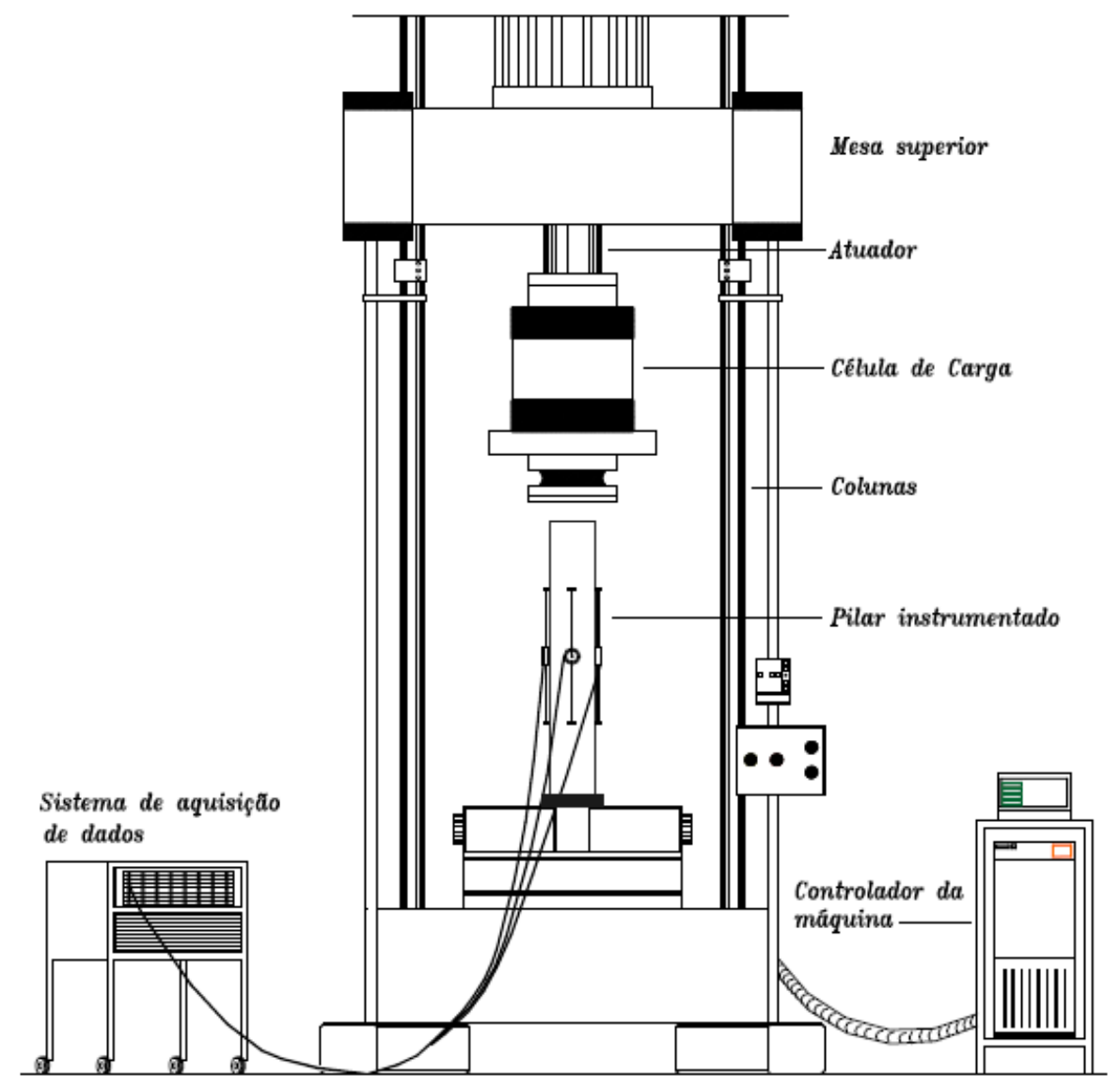

FIGURA 4.6 - SisTEMA DE ENSAIO NA INSTRON, ADAPTADO DE QUEIROGA (1999)

Como o objetivo do trabalho era avaliar a seção resistente de concreto e a eficiência do confinamento, as observações feitas pelo autor dizem respeito a estes aspectos. São elas:

a) A taxa de armadura transversal necessária para promover ruptura dúctil em pilares de concreto com alta resistência não deve ser avaliada pelos mesmos critérios utilizados para concreto com resistência usual.

b) A configuração dos estribos e o espaçamento entre eles são fatores importantes para a eficiência do confinamento promovido pela armadura transversal.

c) Em todos os modelos a força última de ruptura ficou situada entre a força última teórica para a seção íntegra e a força última teórica para o núcleo definido pelo eixo dos estribos, sendo que esta última apresenta valores a favor da segurança. 


\subsection{RAMOS (2001)}

Este trabalho deu continuidade aos estudos realizados no SET EESC/USP sobre pilares de concreto armado solicitados à compressão centrada, LIMA (1997) e QUEIROGA (1999), nos quais a resistência média à compressão era em torno, respectivamente, de $80 \mathrm{MPa}$ e $60 \mathrm{MPa}$. Este foi o primeiro trabalho com concreto de baixa resistência, $25 \mathrm{MPa}$.

Tinha por objetivos estudar, para os pilares ensaiados, a ductilidade, o cintamento, a possível formação de um núcleo resistente, e ainda, verificar as recomendações da NBR 6118/1978 sobre as taxas de armaduras longitudinais e transversais.

Foram ensaiados 16 modelos de pilares, divididos em quatro séries. Nos quais variou-se formato e dimensões da seção transversal e armaduras longitudinais e transversais.

TABELA 4.8 - CARACTERÍSTICAS FÍSICAS E GEOMÉTRICAS DOS MODELOS DE RAMOS (2001)

\begin{tabular}{|c|c|c|c|c|c|c|c|c|c|c|c|c|c|}
\hline PILAR & $\mathrm{f}_{\mathrm{c}}$ & $\mathrm{f}_{\mathrm{y}}$ & $\mathrm{E}_{\mathrm{s}}$ & $\mathrm{b}$ & $\mathrm{h}$ & $\mathrm{l}_{\mathrm{e}}$ & \multicolumn{6}{|c|}{$\mathrm{A}_{\mathrm{sl}}$} & $\mathrm{e}_{\mathrm{i}}$ \\
\cline { 9 - 12 } & $\mathrm{MPa}$ & $\mathrm{MPa}$ & $\mathrm{MPa}$ & $\mathrm{cm}$ & $\mathrm{cm}$ & $\mathrm{cm}$ & $\mathrm{n}$ & $\begin{array}{c}\Phi \\
(\mathrm{mm})\end{array}$ & $\rho_{\mathrm{l}}$ & $\begin{array}{c}\Phi \\
(\mathrm{mm})\end{array}$ & $\mathrm{s}$ & $\rho_{\mathrm{w}}$ & $\mathrm{mm}$ \\
\hline $\mathrm{P} 1-10,0-120$ & 24,90 & 611 & 205000 & 20 & 20 & 120 & 4 & 10 & $0,79 \%$ & 5 & 12 & $0,28 \%$ & 0 \\
$\mathrm{P} 1-12,5-200$ & 24,90 & 561 & 193000 & 20 & 20 & 120 & 4 & 12,5 & $1,23 \%$ & 6,3 & 20 & $0,26 \%$ & 0 \\
$\mathrm{P} 1-12,5-150$ & 28,50 & 561 & 193000 & 20 & 20 & 120 & 4 & 12,5 & $1,23 \%$ & 6,3 & 15 & $0,35 \%$ & 0 \\
$\mathrm{P} 1-12,5-100$ & 28,50 & 561 & 193000 & 20 & 20 & 120 & 4 & 12,5 & $1,23 \%$ & 6,3 & 10 & $0,53 \%$ & 0 \\
$\mathrm{P} 2-10,0-120$ & 23,50 & 611 & 205000 & 30 & 15 & 90 & 6 & 10 & $1,05 \%$ & 5 & 12 & $0,28 \%$ & 0 \\
$\mathrm{P} 2-12,5-150$ & 23,50 & 561 & 193000 & 30 & 15 & 90 & 6 & 12,5 & $1,64 \%$ & 6,3 & 15 & $0,36 \%$ & 0 \\
$\mathrm{P} 2-12,5-100$ & 24,50 & 561 & 193000 & 30 & 15 & 90 & 6 & 12,5 & $1,64 \%$ & 6,3 & 10 & $0,54 \%$ & 0 \\
$\mathrm{P} 2-12,5-75$ & 24,50 & 561 & 193000 & 30 & 15 & 90 & 6 & 12,5 & $1,64 \%$ & 6,3 & 7,5 & $0,72 \%$ & 0 \\
$\mathrm{P} 3-10,0-120$ & 27,50 & 611 & 205000 & 30 & 15 & 90 & 6 & 10 & $1,05 \%$ & 5 & 12 & $0,28 \%$ & 0 \\
$\mathrm{P} 3-12,5-150$ & 27,50 & 561 & 193000 & 30 & 15 & 90 & 6 & 12,5 & $1,64 \%$ & 6,3 & 15 & $0,36 \%$ & 0 \\
$\mathrm{P} 3-12,5-100$ & 24,10 & 561 & 193000 & 30 & 15 & 90 & 6 & 12,5 & $1,64 \%$ & 6,3 & 10 & $0,54 \%$ & 0 \\
$\mathrm{P} 3-12,5-75$ & 24,10 & 561 & 193000 & 30 & 15 & 90 & 6 & 12,5 & $1,64 \%$ & 6,3 & 7,5 & $0,72 \%$ & 0 \\
$\mathrm{P} 4-10,0-120$ & 23,30 & 611 & 205000 & 30 & 15 & 90 & 6 & 10 & $1,05 \%$ & 5 & 12 & $0,28 \%$ & 0 \\
$\mathrm{P} 4-12,5-150$ & 23,30 & 561 & 193000 & 30 & 15 & 90 & 6 & 12,5 & $1,64 \%$ & 6,3 & 15 & $0,36 \%$ & 0 \\
$\mathrm{P} 4-12,5-100$ & 23,70 & 561 & 193000 & 30 & 15 & 90 & 6 & 12,5 & $1,64 \%$ & 6,3 & 10 & $0,54 \%$ & 0 \\
$\mathrm{P} 4-12,5-75$ & 23,70 & 561 & 193000 & 30 & 15 & 90 & 6 & 12,5 & $1,64 \%$ & 6,3 & 7,5 & $0,72 \%$ & 0 \\
\hline
\end{tabular}

Os ensaios foram realizados 14 dias após a moldagem dos pilares, na INSTRON, mesma máquina utilizada em QUEIROGA (1999).

As conclusões feitas pelo autor foram:

a) É muito difícil obter um estado de solicitação de compressão centrada. Pois a heterogeneidade do concreto cria esforços de flexão no pilar. No entanto, presumese que esta parcela de excentricidade pode ser reduzida com maiores cuidados no amassamento e vibração do concreto 
b) As maiores excentricidades da força aplicada ocorreram na direção do eixo de maior inércia.

c) Como os efeitos do confinamento dado pela armadura transversal, no intervalo das taxas utilizadas, foi observado um pequeno cintamento do concreto e um expressivo aumento na ductilidade dos pilares.

d) Não ocorre formação de núcleo resistente na fase de pré-pico e, portanto, a seção resistente é a seção transversal total.

e) O ganho de ductilidade no pré-pico não depende da taxa de armadura transversal, mas sim da redução da resistência do concreto e o ganho de ductilidade no pós-pico depende de ambos.

\subsection{LIMA JUNIOR (2003)}

Este trabalho é referente a uma tese de doutorado do SET EESC/USP, que teve como objetivo investigar o comportamento pós-pico de pilares com concretos de alta resistência confinados com e sem adição de fibras metálicas e submetidos à flexo-compressão normal. Neste trabalho, não se analisou os modelos confeccionados em concreto com adição fibras.

O programa experimental foi dividido em duas fases. Na primeira fase, analisaram-se dez pilares de concreto armado, sujeitos à compressão centrada. Dois fatores foram estudados: a taxa de armadura transversal e a resistência à compressão do concreto.

TABELA 4.9 - CARACTERÍSTICAS FÍSICAS E GEOMÉTRICAS DOS MODELOS DE LIMA JUNIOR (2003)

\begin{tabular}{|c|c|c|c|c|c|c|c|c|c|c|c|c|c|}
\hline \multirow[b]{2}{*}{ PILAR } & \multirow{2}{*}{$\begin{array}{c}\mathrm{f}_{\mathrm{c}} \\
\mathrm{MPa}\end{array}$} & \multirow{2}{*}{$\begin{array}{c}\mathrm{f}_{\mathrm{y}} \\
\mathrm{MPa}\end{array}$} & \multirow{2}{*}{$\begin{array}{c}\mathrm{E}_{\mathrm{s}} \\
\mathrm{MPa}\end{array}$} & \multirow{2}{*}{$\begin{array}{c}\mathrm{b} \\
\mathrm{cm}\end{array}$} & \multirow{2}{*}{$\begin{array}{c}\mathrm{h} \\
\mathrm{cm}\end{array}$} & \multirow{2}{*}{$\begin{array}{c}\text { le } \\
\mathrm{cm}\end{array}$} & \multicolumn{3}{|c|}{$A_{s 1}$} & \multicolumn{3}{|c|}{$A_{s w}$} & \multirow{2}{*}{$\begin{array}{c}\mathrm{e}_{\mathrm{i}} \\
\mathrm{mm}\end{array}$} \\
\hline & & & & & & & $\mathrm{n}$ & $\begin{array}{c}\Phi \\
(\mathrm{mm})\end{array}$ & $\rho_{1}$ & $\begin{array}{c}\Phi \\
(\mathrm{mm})\end{array}$ & $s$ & $\rho_{w}$ & \\
\hline P1-40-15 & 43,03 & 597,5 & 197750 & 15 & 15 & 50 & 4 & 12,5 & $2,18 \%$ & 6,3 & 15 & $0,48 \%$ & 0 \\
\hline P2-40-15 & 43,03 & 597,5 & 197750 & 15 & 15 & 50 & 4 & 12,5 & $2,18 \%$ & 6,3 & 15 & $0,48 \%$ & 0 \\
\hline P1-60-5 & 66,85 & 597,5 & 197750 & 15 & 15 & 50 & 4 & 12,5 & $2,18 \%$ & 6,3 & 5 & $1,44 \%$ & 0 \\
\hline P2-60-5 & 66,85 & 597,5 & 197750 & 15 & 15 & 50 & 4 & 12,5 & $2,18 \%$ & 6,3 & 5 & $1,44 \%$ & 0 \\
\hline P1-60-15 & 66,85 & 597,5 & 197750 & 15 & 15 & 50 & 4 & 12,5 & $2,18 \%$ & 6,3 & 15 & $0,48 \%$ & 0 \\
\hline P2-60-15 & 66,85 & 597,5 & 197750 & 15 & 15 & 50 & 4 & 12,5 & $2,18 \%$ & 6,3 & 15 & $0,48 \%$ & 0 \\
\hline P1-80-5 & 97,50 & 597,5 & 197750 & 15 & 15 & 50 & 4 & 12,5 & $2,18 \%$ & 6,3 & 5 & $1,44 \%$ & 0 \\
\hline P2-80-5 & 97,50 & 597,5 & 197750 & 15 & 15 & 50 & 4 & 12,5 & $2,18 \%$ & 6,3 & 5 & 1,4 & 0 \\
\hline P1-80-15 & 97,50 & 597,5 & 197750 & 15 & 15 & 50 & 4 & 12,5 & $2,18 \%$ & 6 & 15 & 0,4 & 0 \\
\hline P2-80-15 & 97,50 & 597,5 & 197750 & 15 & 15 & 50 & 4 & 12,5 & $2,18 \%$ & 6,3 & 15 & $0,48 \%$ & 0 \\
\hline
\end{tabular}

$\mathrm{Na}$ segunda fase, analisaram-se nove pilares sujeitos à flexo-compressão normal e divididos em três séries de acordo com a resistência à compressão do concreto. Três fatores foram estudados: a excentricidade inicial, a taxa de armadura transversal e a resistência à compressão do concreto. 
TABELA 4.9 - CARACTERÍSTICAS FÍSICAS E GEOMÉTRICAS DOS MODELOS DE LIMA JUNIOR (2003) CONTINUAÇÃO

\begin{tabular}{|c|c|c|c|c|c|c|c|c|c|c|c|c|c|}
\hline \multirow[b]{2}{*}{ PILAR } & \multirow{2}{*}{$\begin{array}{c}\mathrm{f}_{\mathrm{c}} \\
\mathrm{MPa}\end{array}$} & \multirow{2}{*}{$\begin{array}{c}f_{y} \\
M P a\end{array}$} & \multirow{2}{*}{$\begin{array}{c}\mathrm{E}_{\mathrm{s}} \\
\mathrm{MPa}\end{array}$} & \multirow{2}{*}{$\begin{array}{c}\mathrm{b} \\
\mathrm{cm}\end{array}$} & \multirow{2}{*}{$\begin{array}{c}\mathrm{h} \\
\mathrm{cm}\end{array}$} & \multirow{2}{*}{$\begin{array}{c}l_{e} \\
\mathrm{~cm}\end{array}$} & \multicolumn{3}{|c|}{$A_{s 1}$} & \multicolumn{3}{|c|}{$A_{s w}$} & \multirow{2}{*}{$\begin{array}{c}\mathrm{e}_{\mathrm{i}} \\
\mathrm{mm}\end{array}$} \\
\hline & & & & & & & $\mathrm{n}$ & $\begin{array}{c}\Phi \\
(\mathrm{mm})\end{array}$ & $\rho_{1}$ & $\begin{array}{c}\Phi \\
(\mathrm{mm})\end{array}$ & $\mathrm{s}$ & w & \\
\hline P1-40 & 39,21 & 597,5 & 97750 & 15 & 15 & 170 & 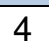 & 12,5 & $2,18 \%$ & 6,3 & 15 & $0,48 \%$ & 10 \\
\hline P2-40 & 39,21 & 597,5 & 97750 & 15 & 15 & 170 & 4 & 12,5 & $2,18 \%$ & 6,3 & 15 & $0,48 \%$ & 20 \\
\hline P3-40 & 39,21 & 597,5 & 197750 & 15 & 15 & 170 & 4 & 12,5 & $2,18 \%$ & 6,3 & 15 & 0 & 30 \\
\hline P1-60-15 & 66,38 & 597,5 & 197750 & 15 & 15 & 170 & 4 & 12,5 & $2,18 \%$ & 6,3 & 15 & 0,4 & 10 \\
\hline P2-60-15 & 66,38 & 597,5 & 197750 & 15 & 15 & 170 & 4 & 12,5 & $2,18 \%$ & 6,3 & 15 & 0,4 & 20 \\
\hline P3-60-15 & 66,38 & 597,5 & 197750 & 15 & 15 & 170 & 4 & 12,5 & $2,18 \%$ & 6,3 & 15 & 0,4 & 30 \\
\hline P1-60-5 & 62,48 & 597,5 & 197750 & 15 & 15 & 170 & 4 & 12,5 & $2,18 \%$ & 6,3 & 5 & 1,4 & 10 \\
\hline P2-60-5 & 62,48 & 597,5 & 197750 & 15 & 15 & 170 & 4 & 12 & & 6 , & 5 & & 20 \\
\hline P3-60-5 & 62,48 & 597,5 & 197750 & 15 & 15 & 170 & 4 & 12,5 & $2,18 \%$ & 6,3 & 5 & $1,44 \%$ & 30 \\
\hline
\end{tabular}

Os ensaios foram realizados 28 dias após a moldagem dos pilares, na INSTRON, mesma máquina utilizada em QUEIROGA (1999) e RAMOS (2001).

As principais conclusões do autor foram:

a) Tanto a flambagem das barras da armadura longitudinal, quanto a perda de massa de concreto nos pilares sujeitos à flexo-compressão ocorrem de modo bem mais crítico que nos pilares submetidos à compressão centrada.

b) Em pilares sujeitos a flexo-compressão normal, quando os valores dos três fatores analisados - resistência do concreto, taxa de armadura transversal e excentricidade inicial - são elevados, a ductilidade desses elementos estruturais é melhorada.

c) O efeito da flexão faz com que as tensões de confinamento se distribuam de modo diferenciado dentro da seção transversal dos pilares; contudo, observou-se que a tensão de confinamento na região comprimida da seção transversal é pouco modificada.

\subsection{OLIVEIRA (2004)}

Dando continuidade aos estudos realizados no SET EESC/USP sobre pilares de concreto armado solicitados à compressão centrada, LIMA (1997), QUEIROGA (1999) e RAMOS (2001), este estudo foi realizado com concreto de resistência média à compressão de $40 \mathrm{MPa}$.

Os modelos, a metodologia e a idade dos ensaios foram exatamente iguais a RAMOS (2001), a única diferença foi a resistência do concreto. 
TABELA 4.10 - CARACTERÍSTICAS FÍSICAS E GEOMÉTRICAS DOS MODELOS DE OLIVEIRA (2004)

\begin{tabular}{|c|c|c|c|c|c|c|c|c|c|c|c|c|c|}
\hline \multirow[b]{2}{*}{ PILAR } & \multirow{2}{*}{$\begin{array}{c}\mathrm{f}_{\mathrm{c}} \\
\mathrm{MPa}\end{array}$} & \multirow{2}{*}{$\begin{array}{c}\mathrm{f}_{\mathrm{y}} \\
\mathrm{MPa}\end{array}$} & \multirow{2}{*}{$\begin{array}{c}\mathrm{E}_{\mathrm{s}} \\
\mathrm{MPa}\end{array}$} & \multirow{2}{*}{$\begin{array}{c}\mathrm{b} \\
\mathrm{cm}\end{array}$} & \multirow{2}{*}{$\begin{array}{c}\mathrm{h} \\
\mathrm{cm}\end{array}$} & \multirow{2}{*}{$\begin{array}{l}\mathrm{C}_{\mathrm{e}} \\
\mathrm{cm}\end{array}$} & \multicolumn{3}{|c|}{$A_{s l}$} & \multicolumn{3}{|c|}{$A_{s w}$} & \multirow{2}{*}{$\begin{array}{c}\mathrm{e}_{\mathrm{i}} \\
\mathrm{mm}\end{array}$} \\
\hline & & & & & & & $\mathrm{n}$ & $\begin{array}{c}\Phi \\
(\mathrm{mm})\end{array}$ & $\rho_{1}$ & $\begin{array}{c}\Phi \\
(\mathrm{mm})\end{array}$ & $\mathrm{s}$ & $\rho_{w}$ & \\
\hline $\mathrm{P} 1-10,0-120$ & 46,57 & 590 & 203400 & 20 & 20 & 120 & 4 & 10 & $0,79 \%$ & 5 & 12 & $0,28 \%$ & 0 \\
\hline P1-12, & 6,29 & 556,5 & 206900 & 20 & 20 & 120 & 4 & 12,5 & & 6,3 & 20 & & 0 \\
\hline $\mathrm{P} 1-12,5-150$ & 46,30 & 56,5 & 206900 & 20 & 20 & 120 & 4 & 12,5 & & 6,3 & 15 & & 0 \\
\hline $\mathrm{P} 1-12,5-100$ & 43,89 & 556,5 & 206900 & 20 & 20 & 120 & 4 & 12,5 & & 6,3 & 10 & & 0 \\
\hline P2-10,0-120 & 46,08 & 590 & 203400 & 30 & 15 & 90 & 6 & 10 & & & 2 & & 0 \\
\hline P2-1! & 45,01 & 556,5 & 206900 & 30 & 15 & 90 & 6 & 12,5 & & & 5 & & 0 \\
\hline P2-1 & 43,18 & 556,5 & 206900 & 30 & 15 & 90 & & 12,5 & & & 0 & & 0 \\
\hline P2-1 & 43,07 & 556,5 & 206900 & 30 & 15 & 9 & & 12,5 & & 6,3 & 7,5 & & 0 \\
\hline P3- & 46,08 & 590 & 203400 & 30 & 1 & 9 & & & & & 2 & & 0 \\
\hline & 45,01 & 556,5 & 206900 & 30 & 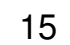 & 90 & & 12,5 & & & 5 & & 0 \\
\hline & 43,41 & 556,5 & 206900 & 30 & 1 & 9 & & 12,5 & & & 0 & & 0 \\
\hline & 42,5 & 556,5 & 206900 & 30 & 15 & 90 & & 12,5 & & 6,3 & 7,5 & & 0 \\
\hline & 46,08 & 590 & 203400 & 30 & 15 & 90 & & 10 & & 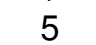 & 12 & $0,28 \%$ & 0 \\
\hline P4-12 & 45,01 & 556,5 & 206900 & 30 & 15 & 90 & & 12,5 & 1,6 & 6 & 15 & $0,36 \%$ & 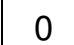 \\
\hline & 43,01 & 556,5 & 206900 & 30 & 15 & 90 & 6 & 12,5 & 1,6 & 6 & 10 & $0,54 \%$ & 0 \\
\hline P4-12,5-075 & 42,55 & 556,5 & 206900 & 30 & 15 & 90 & 0 & 12,5 & $1,64 \%$ & 6,3 & 7,5 & $0,72 \%$ & 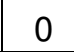 \\
\hline
\end{tabular}

As conclusões feitas por este autor foram:

a) A variável $k_{\text {mod,2 }}$, que representa redução da resistência à compressão em estruturas concreto quando comparadas com os corpos-de-prova, não pode ser considerada constante para diferentes resistências do concreto.

b) Para a faixa de resistência do concreto nos pilares ensaiados, foi constatado o confinamento do núcleo, que se apresentou maior nos pilares com maiores taxas de armadura transversal.

\subsection{ADORNO (2004)}

Desenvolvido na UnB, foi um estudo teórico-experimental de pilares de concreto armado de seção retangular submetidos à flexão normal composta, utilizando como base teórica o método desenvolvido por MELLO (2003). A pretensão era estabelecer parâmetros para a utilização prática do método em questão. Para tanto, foram analisados: cargas e modos de ruptura, deformações do concreto e das armaduras, deslocamentos vertical e horizontal das peças, evolução da fissuração e ductilidade dos modelos.

O programa experimental compôs-se de duas séries de ensaios. A primeira série, PSA, compreendeu quatro pilares em concreto simples, e a outra, PCA4, era composta por oito pilares com armadura longitudinal de quatro barras de $10 \mathrm{~mm}$ de diâmetro e armadura transversal constituída de estribos de $5,0 \mathrm{~mm}$ espaçados a cada $10 \mathrm{~cm}$. Todos os pilares tinham dimensões de $12 \mathrm{~cm}$ x $25 \mathrm{~cm}$ x $172 \mathrm{~cm}$. 
TABELA 4.11 - CARACTERÍSTICAS FÍSICAS E GEOMÉTRICAS DOS MODELOS DE ADORNO (2004)

\begin{tabular}{|c|c|c|c|c|c|c|c|c|c|c|c|c|c|}
\hline \multirow[b]{2}{*}{ PILAR } & \multirow{2}{*}{$\begin{array}{c}f_{c} \\
M P a\end{array}$} & \multirow{2}{*}{$\begin{array}{c}\mathrm{f}_{\mathrm{y}} \\
\mathrm{MPa}\end{array}$} & \multirow{2}{*}{$\begin{array}{c}\mathrm{E}_{\mathrm{s}} \\
\mathrm{MPa}\end{array}$} & \multirow{2}{*}{$\begin{array}{c}\mathrm{b} \\
\mathrm{cm}\end{array}$} & \multirow{2}{*}{$\begin{array}{c}\mathrm{h} \\
\mathrm{cm}\end{array}$} & \multirow{2}{*}{$\begin{array}{c}l_{e} \\
\mathrm{~cm}\end{array}$} & \multicolumn{3}{|c|}{$A_{s l}$} & \multicolumn{3}{|c|}{$A_{s w}$} & \multirow{2}{*}{$\begin{array}{c}e_{i} \\
m m\end{array}$} \\
\hline & & & & & & & $\mathrm{n}$ & $\begin{array}{c}\Phi \\
(\mathrm{mm})\end{array}$ & $\rho_{\mathrm{l}}$ & $\begin{array}{c}\Phi \\
(\mathrm{mm})\end{array}$ & $\mathrm{s}$ & $\rho_{w}$ & \\
\hline PSA-15a & 42,40 & & & 25 & 12 & 172 & & & & & & & 15 \\
\hline PSA-15b & 55,20 & & & 25 & 12 & 172 & & & & & & & 15 \\
\hline PSA-20 & 51,70 & & & 25 & 12 & 172 & & & & & & & 20 \\
\hline PSA-30 & 50,50 & & & 25 & 12 & 172 & & & & & & & 30 \\
\hline PCA4-15a & 38,80 & 582 & 212200 & 25 & 12 & 172 & 4 & 10 & $1,05 \%$ & 5 & 10 & $0,35 \%$ & 15 \\
\hline PCA4-15b & 40,20 & 582 & 212200 & 25 & 12 & 172 & 4 & 10 & $1,05 \%$ & 5 & 10 & $0,35 \%$ & 15 \\
\hline PCA4-20 & 40,70 & 582 & 212200 & 25 & 12 & 172 & 4 & 10 & $1,05 \%$ & 5 & 10 & $0,35 \%$ & 20 \\
\hline PCA4-25 & 42,10 & 582 & 212200 & 25 & 12 & 172 & 4 & 10 & $1,05 \%$ & 5 & 10 & $0,35 \%$ & 25 \\
\hline PCA4-30a & 40,50 & 582 & 212200 & 25 & 12 & 172 & 4 & 10 & $1,05 \%$ & 5 & 10 & 0,3 & 30 \\
\hline PCA4-30b & 41,30 & 582 & 212200 & 25 & 12 & 172 & 4 & 10 & $1,05 \%$ & 5 & 10 & $0,35 \%$ & 30 \\
\hline
\end{tabular}

Os modelos eram biarticulados com excentricidades idênticas em suas extremidades, que variavam de $15 \mathrm{~mm}$ a $30 \mathrm{~mm}$. A estrutura de ensaio era composta de um pórtico metálico ancorado, por meio de tirantes, na laje de reação do Laboratório de Estruturas da Escola de Engenharia Civil da Universidade Federal de Goiás.

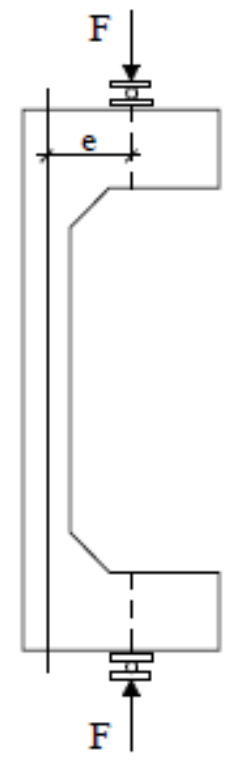

FIGURA 4.7 - ESQUEMA DE APLICAÇÃO DE FORÇAS NO MODELO DE ADORNO (2004)

As conclusões relevantes ao presente trabalho foram:

a) Foi validado o principio clássico de Bernoulli, de que as seções transversais permanecem planas em peças deformada.

b) Por se tratar de pilares com baixa resistência, a variação da excentricidade inicial bem como a taxa de armadura longitudinal não influíram no comportamento da armadura transversal, confirmando o pequeno grau de confinamento do concreto interno aos estribos.

c) Com o aumento da taxa de armadura longitudinal, as deformações da face tracionada ou menos comprimida diminuíram, enquanto que as armaduras mais comprimidas apresentaram um crescimento de suas deformações, o que mostra a mudança na distribuição de deformações na seção para maiores taxas, com o aço aumentando sua absorção de tensões em relação ao concreto. 
d) $\mathrm{O}$ aumento da excentricidade inicial da força solicitante provocou crescimento do encurtamento do concreto e redução do esforço normal e do momento fletor últimos.

e) $\mathrm{O}$ aumento da taxa de armadura longitudinal proporcionou aumento nas deformações do concreto da face mais comprimida, maior ductilidade e, consequentemente, elevou o esforço normal e o momento fletor últimos.

\subsection{ARAÚJO (2004)}

Esta pesquisa foi desenvolvida na UFG e que teve por intuito complementar os resultados obtidos em ADORNO (2004).

Foram ensaiados nove pilares com resistência à compressão em torno de $40 \mathrm{MPa}$, aos 28 dias, e sujeitos à flexo-compressão normal, divididos em três séries: PSA, PCA4 e PCA6. Manteve-se as mesmas características geométricas das peças ensaiadas por ADORNO (2004), distinguindo desta apenas pela aplicação de cargas com maiores excentricidade. A primeira série era composta por exemplares em concreto simples. As série PCA4 e PCA6 continham modelos em concreto armado, com armaduras longitudinais compostas, respectivamente, por quatro e seis barras de $10 \mathrm{~mm}$ de diâmetro.

Os modelos eram biarticulados com excentricidades idênticas em suas extremidades. Em cada série foram testados três exemplares, com excentricidades iniciais iguais a $40 \mathrm{~mm}$, $50 \mathrm{~mm}$ e $60 \mathrm{~mm}$. A estrutura de reação também foi a mesma utilizada nos ensaios de ADORNO (2004). Por serem pesquisas conjuntas, as conclusões desta e de ADORNO (2004) também são semelhantes.

TABELA 4.12 - CARACTERÍSTICAS FÍSICAS E GEOMÉTRICAS DOS MODELOS DE ARAÚJO (2004)

\begin{tabular}{|c|c|c|c|c|c|c|c|c|c|c|c|c|c|}
\hline \multirow[b]{2}{*}{ PILAR } & \multirow{2}{*}{$\begin{array}{c}f_{c} \\
M P a\end{array}$} & \multirow{2}{*}{$\begin{array}{c}\mathrm{f}_{\mathrm{y}} \\
\mathrm{MPa}\end{array}$} & \multirow{2}{*}{$\begin{array}{c}\mathrm{E}_{\mathrm{s}} \\
\mathrm{MPa}\end{array}$} & \multirow{2}{*}{$\begin{array}{l}\mathrm{b} \\
\mathrm{cm}\end{array}$} & \multirow{2}{*}{$\begin{array}{c}\mathrm{h} \\
\mathrm{cm}\end{array}$} & \multirow{2}{*}{$\begin{array}{c}C_{e} \\
\mathrm{~cm}\end{array}$} & \multicolumn{3}{|c|}{$A_{s 1}$} & \multicolumn{3}{|c|}{$A_{s w}$} & \multirow{2}{*}{$\begin{array}{c}\mathrm{e}_{\mathrm{i}} \\
\mathrm{mm}\end{array}$} \\
\hline & & & & & & & $\mathrm{n}$ & $\begin{array}{c}\Phi \\
(\mathrm{mm})\end{array}$ & $\rho_{\mathrm{l}}$ & $\begin{array}{c}\Phi \\
(\mathrm{mm})\end{array}$ & $\mathrm{s}$ & $\rho_{w}$ & \\
\hline PCA4-40 & 45,80 & 582 & 212200 & 25 & 12 & 172 & 4 & 10 & $1,05 \%$ & 5 & 10 & $0,35 \%$ & 40 \\
\hline PCA4-50 & 45,80 & 582 & 212200 & 25 & 12 & 172 & 4 & 10 & $1,05 \%$ & 5 & 10 & $0,35 \%$ & 50 \\
\hline PCA4-60 & 45,80 & 582 & 212200 & 25 & 12 & 172 & 4 & 10 & $1,05 \%$ & 5 & 10 & $0,35 \%$ & 60 \\
\hline PCA6-40 & 42,70 & 582 & 212200 & 25 & 12 & 172 & 6 & 10 & $1,57 \%$ & 5 & 10 & $0,35 \%$ & 40 \\
\hline PCA6-50 & 42,70 & 582 & 212200 & 25 & 12 & 172 & 6 & 10 & $1,57 \%$ & 5 & 10 & $0,35 \%$ & 50 \\
\hline PCA6-60 & 42,70 & 582 & 212200 & 25 & 12 & 172 & 6 & 10 & $1,57 \%$ & 5 & 10 & $0,35 \%$ & 60 \\
\hline
\end{tabular}

\subsection{DANTAS (2006)}

Esta pesquisa também faz parte da linha de pesquisa desenvolvida na UnB sobre pilares em concreto armado submetidos a carregamento axial com diferentes excentricidades. Difere 
dos demais trabalhos aqui apresentados por possuir um índice de esbeltez maior e fazer análise teórico-numérica dos efeitos de segunda ordem no programa CACODI.

O programa experimental foi composto por seis pilares, nos quais a variável analisada foi a excentricidade de aplicação da carga, que variou de 0 a $60 \mathrm{~cm}$. Os demais parâmetros foram mantidos constantes.

TABELA 4.13 - CARACTERÍSTICAS FÍSICAS E GEOMÉTRICAS DOS MODELOS DE DANTAS (2006)

\begin{tabular}{|c|c|c|c|c|c|c|c|c|c|c|c|c|c|}
\hline \multirow[b]{2}{*}{ PILAR } & \multirow{2}{*}{$\begin{array}{c}f_{c} \\
M P a\end{array}$} & \multirow{2}{*}{$\begin{array}{c}f_{y} \\
M P a\end{array}$} & \multirow{2}{*}{$\begin{array}{c}\mathrm{E}_{\mathrm{s}} \\
\mathrm{MPa}\end{array}$} & \multirow{2}{*}{$\begin{array}{c}\mathrm{b} \\
\mathrm{cm}\end{array}$} & \multirow{2}{*}{$\begin{array}{c}\mathrm{h} \\
\mathrm{cm}\end{array}$} & \multirow{2}{*}{$\begin{array}{c}\text { le } \\
\mathrm{cm}\end{array}$} & \multicolumn{3}{|c|}{$A_{s 1}$} & \multicolumn{3}{|c|}{$A_{s w}$} & \multirow{2}{*}{$\begin{array}{c}e_{i} \\
m m\end{array}$} \\
\hline & & & & & & & $\mathrm{n}$ & $\begin{array}{c}\Phi \\
(\mathrm{mm})\end{array}$ & $\rho_{\mathrm{l}}$ & $\begin{array}{c}\Phi \\
(\mathrm{mm})\end{array}$ & $\mathrm{s}$ & $\rho_{w}$ & \\
\hline PFN 00-3 & 35,80 & 592 & 189000 & 25 & 12 & 262 & 6 & 10 & $1,57 \%$ & 5 & 5 & $0,71 \%$ & 0 \\
\hline PFN 15-3 & 35,80 & 592 & 189000 & 25 & 12 & 262 & 6 & 10 & $1,57 \%$ & 5 & 5 & $0,71 \%$ & 15 \\
\hline PFN 30-3 & 33,93 & 592 & 189000 & 25 & 12 & 262 & 6 & 10 & $1,57 \%$ & 5 & 5 & $0,71 \%$ & 30 \\
\hline PFN 40-3 & 33,93 & 592 & 189000 & 25 & 12 & 262 & 6 & 10 & $1,57 \%$ & 5 & 5 & $0,71 \%$ & 40 \\
\hline PFN 50-3 & 37,60 & 592 & 189000 & 25 & 12 & 262 & 6 & 10 & $1,57 \%$ & 5 & 5 & $0,71 \%$ & 50 \\
\hline PFN 60-3 & 37,60 & 592 & 189000 & 25 & 12 & 262 & 6 & 10 & $1,57 \%$ & 5 & 5 & $0,71 \%$ & 60 \\
\hline
\end{tabular}

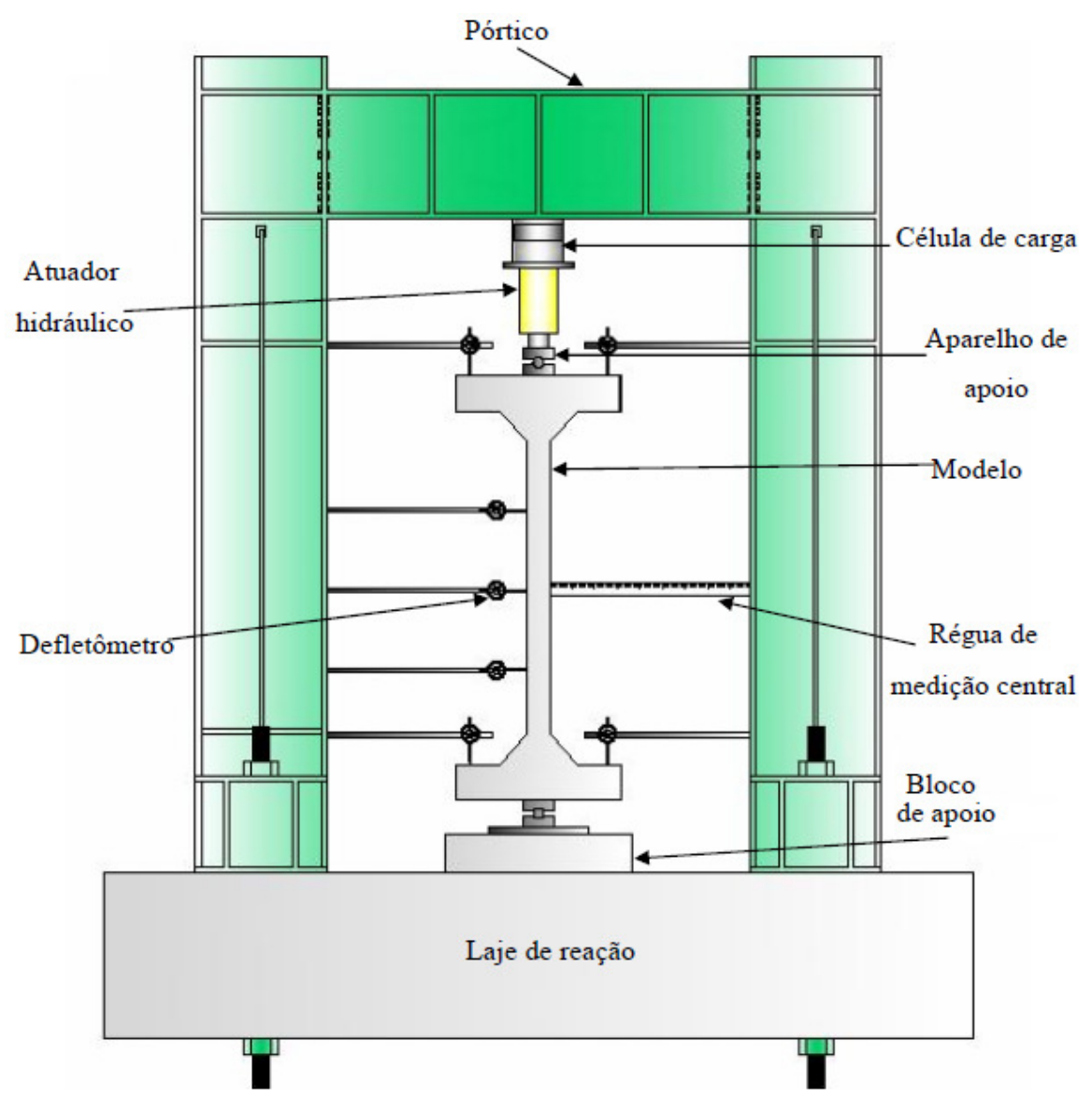

FIGURA 4.8 - SISTEMA GERAL DE ENSAIO, (DANTAS, 2006) 


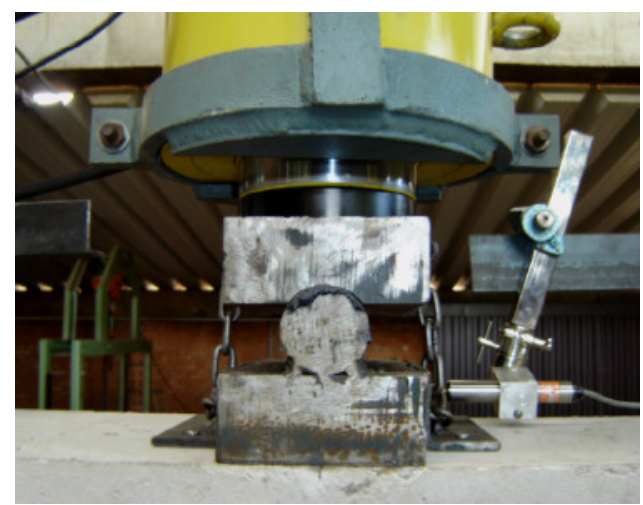

(A)

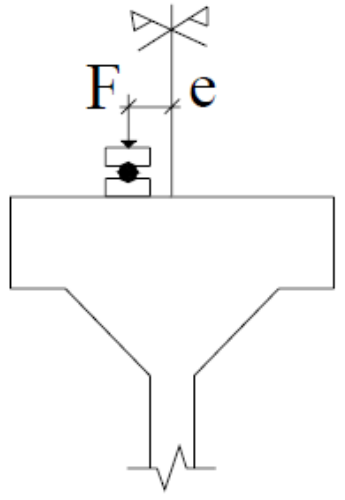

(B)

Figura 4.9 - DETALHE DA ARTICULAÇÃo SUPERIOR (A) E ESQUEMA DE CARREGAMENTO (B), (DANTAS, 2006)

As conclusões feitas pelo pesquisador foram:

a) O acréscimo de excentricidade, além de diminuir a carga de ruptura, aumentou os deslocamentos horizontais, as rotações de extremidade e as deformações na armadura e no concreto.

b) Comparando com os resultados de ARAÚJO (2004), onde foram ensaiados pilares com altura em torno de $2 / 3$ da altura dos pilares desta pesquisa, houve uma redução de cerca de $35 \%$ na carga de ruptura, ou seja, pilares mais esbeltos são menos resistentes.

c) A esbeltez também aumentou os deslocamentos horizontais.

\subsection{SANTOS (2009)}

Este estudo buscou complementar os estudos desenvolvidos na UnB sobre pilares submetidos à flexo-compressão normal.

As variáveis do estudo foram: a excentricidade de aplicação da carga e o índice de esbeltez dos pilares. Foram mantidas constantes as seções transversais em $12 \mathrm{~cm}$ x $25 \mathrm{~cm}$, a armadura longitudinal em seis barras de $10 \mathrm{~mm}$, a armadura transversal composta por estribos de $5,0 \mathrm{~mm}$ espaçados em $10 \mathrm{~cm}$ e a resistência do concreto à compressão em torno 40MPa.

De acordo com a altura do modelo, os pilares foram divididos em dois grupos, com $175 \mathrm{~cm}$ e $225 \mathrm{~cm}$. Em cada grupo havia sete pilares, nos quais as excentricidades de aplicação da carga foram de: $0,15 \mathrm{~mm}, 24 \mathrm{~mm}, 30 \mathrm{~mm}, 40 \mathrm{~mm}, 50 \mathrm{~mm}$ e $60 \mathrm{~mm}$. 
TABELA 4.14 - CARACTERÍSTICAS FÍSICAS E GEOMÉTRICAS DOS MODELOS DE SANTOS (2009)

\begin{tabular}{|c|c|c|c|c|c|c|c|c|c|c|c|c|c|}
\hline \multirow[b]{2}{*}{ PILAR } & \multirow{2}{*}{$\begin{array}{c}\mathrm{f}_{\mathrm{c}} \\
\mathrm{MPa}\end{array}$} & \multirow{2}{*}{$\begin{array}{c}\mathrm{f}_{\mathrm{y}} \\
\mathrm{MPa}\end{array}$} & \multirow{2}{*}{$\begin{array}{c}\mathrm{E}_{\mathrm{s}} \\
\mathrm{MPa}\end{array}$} & \multirow{2}{*}{$\begin{array}{c}\mathrm{b} \\
\mathrm{cm}\end{array}$} & \multirow{2}{*}{$\begin{array}{c}\mathrm{h} \\
\mathrm{cm}\end{array}$} & \multirow{2}{*}{$\begin{array}{l}\zeta_{e} \\
\mathrm{~cm}\end{array}$} & \multicolumn{3}{|c|}{$A_{s 1}$} & \multicolumn{3}{|c|}{$A_{s w}$} & \multirow{2}{*}{$\begin{array}{c}\mathrm{e}_{\mathrm{i}} \\
\mathrm{mm}\end{array}$} \\
\hline & & & & & & & $\mathrm{n}$ & $\begin{array}{c}\Phi \\
(\mathrm{mm})\end{array}$ & $\rho_{\mathrm{l}}$ & $\begin{array}{c}\Phi \\
(\mathrm{mm})\end{array}$ & $\mathrm{s}$ & $\rho_{w}$ & \\
\hline PFN 00-2 & 45,80 & 592 & 189000 & 25 & 12 & 162 & 6 & 10 & $1,57 \%$ & 5 & 10 & $0,35 \%$ & 0 \\
\hline PFN 15-2 & 38,50 & 592 & 189000 & 25 & 12 & 162 & 6 & 10 & $1,57 \%$ & 5 & 10 & $0,35 \%$ & 15 \\
\hline PFN 24-2 & 45,80 & 592 & 189000 & 25 & 12 & 162 & 6 & 10 & $1,57 \%$ & 5 & 10 & $0,35 \%$ & 24 \\
\hline PFN 30-2 & 37,20 & 592 & 189000 & 25 & 12 & 162 & 6 & 10 & $1,57 \%$ & 5 & 10 & $0,35 \%$ & 30 \\
\hline PFN 40-2 & 37,20 & 592 & 189000 & 25 & 12 & 162 & 6 & 10 & $1,57 \%$ & 5 & 10 & $0,35 \%$ & 40 \\
\hline PFN 50-2 & 37,20 & 592 & 189000 & 25 & 12 & 162 & 6 & 10 & $1,57 \%$ & 5 & 10 & $0,35 \%$ & 50 \\
\hline PFN 60-2 & 38,50 & 592 & 189000 & 25 & 12 & 162 & 6 & 10 & $1,57 \%$ & 5 & 10 & $0,35 \%$ & 60 \\
\hline PFN 00-2,5 & 45,80 & 592 & 189000 & 25 & 12 & 212 & 6 & 10 & $1,57 \%$ & 5 & 10 & $0,35 \%$ & 0 \\
\hline PFN 15-2,5 & 43,10 & 592 & 189000 & 25 & 12 & 212 & 6 & 10 & $1,57 \%$ & 5 & 10 & $0,35 \%$ & 15 \\
\hline PFN 24-2,5 & 45,80 & 592 & 189000 & 25 & 12 & 212 & 6 & 10 & $1,57 \%$ & 5 & 10 & $0,35 \%$ & 24 \\
\hline PFN 30-2,5 & 41,60 & 592 & 189000 & 25 & 12 & 212 & 6 & 10 & $1,57 \%$ & 5 & 10 & $0,35 \%$ & 30 \\
\hline PFN 40-2,5 & 41,60 & 592 & 189000 & 25 & 12 & 212 & 6 & 10 & $1,57 \%$ & 5 & 10 & $0,35 \%$ & 40 \\
\hline PFN 50-2,5 & 41,60 & 592 & 189000 & 25 & 12 & 212 & 6 & 10 & $1,57 \%$ & 5 & 10 & $0,35 \%$ & 50 \\
\hline PFN 60-2,5 & 43,10 & 592 & 189000 & 25 & 12 & 212 & 6 & 10 & $1,57 \%$ & 5 & 10 & $0,35 \%$ & 60 \\
\hline
\end{tabular}

A metodologia de ensaio foi a mesma utilizada por DANTAS (2006). No entanto, programa utilizado para fazer a análise teórico-numérica dos efeitos de segunda ordem foi o FLEXO 2.

Comparada com a pesquisa de DANTAS (2006), não foram acrescentadas conclusões relevantes, sobre os parâmetros avaliados. 


\section{Capítulo 5: ERRo DE MOdelo}

\subsection{CONSIDERAÇõES SOBRE ERRO DE MODELO}

Entende-se por erro de modelo a variável aleatória que permite comparar os resultados reais com os resultados obtidos segundo a previsão do modelo que pretende-se avaliar. Nesta pesquisa, os resultados tidos como reais correspondem aos valores obtidos experimentalmente, no caso dos pilares, e para as vigas, foram estipuladas seções e os resultados "reais" foram obtidos por comparação.

Depois de terem sido computados, segundo os algoritmos apresentados no capítulo 3, os valores teóricos para a força de compressão resistente dos pilares e para o momento último resistente das vigas, a variável aleatória erro de modelo, $E_{m}$, foi calculada.

$$
E_{m}=\frac{F_{\text {exp }}}{F_{\text {teo }}}
$$

sendo: $F_{\text {exp }}$, a força de compressão resistente ou momento resistente último obtidos experimentalmente e $F_{\text {teo }}$, a força de compressão resistente ou momento resistente último obtidos seguindo os requisitos de cada modelo estudado.

A variável aleatória pode indicar se o modelo analítico é conservador, apresentando valores teóricos de resistência inferiores aos reais (experimentais), ou apresenta-se contra a segurança, prevendo resistências maiores que obtidas na prática. Desta forma, a variável Erro de Modelo representa o caráter de tendenciosidade do modelo, sendo a média da variável aleatória $\mathrm{E}_{\mathrm{m}}$ é conhecida como fator de tendenciosidade (bias factor) do modelo. O modelo ideal seria aquele com variável Erro de Modelo de média 1 (um) e desvio padrão 0 (zero).

Para que seja corrigida esta tendência dos modelos matemáticos, aplica-se o valor médio da variável erro de modelo, $M_{E}$, sobre o valor teórico obtido através do modelo, obtendo assim, em média, o valor correto para previsão da resistência, $F_{\text {teo }}^{\text {cor }}$.

$$
F_{\text {teo }}^{\text {cor }}=M_{E} \cdot F_{\text {teo }}
$$


A seguir são apresentados os resultados teóricos de todas as amostras da variável aleatória erro de modelo $\left(E_{m}\right)$, obtidas a partir dos resultados experimentais de 206 pilares dos quais 140 são solicitados à compressão centrada e 66 são solicitados à flexo-compressão normal.

Os resultados teóricos e "reais" para as vigas foram obtidos a partir de uma amostra de 144 elementos nos quais variou-se os parâmetros: resistência do concreto, altura da seção transversal e taxa de armadura. Como mencionado, as amostras de variável erro de modelo foram obtidas por comparação com o modelo do ACI 318-2002, cuja as estaísticas do erro de modelo de resistência é apresentado em NOWAK E SZERSZEN (2003).

Considerando o resultado experimental um valor constante para qualquer modelo analisado e dado por $F_{\text {exp }}=E_{m} \cdot F_{\text {teo }}$, tem-se:

$$
\begin{gathered}
F_{\text {exp }}^{N B R}=F_{\text {exp }}^{A C l}=E_{m}^{A C l} \cdot F_{\text {teo }}^{A C l} \\
E_{m}^{N B R}=E_{m}^{A C l} \cdot \frac{F_{\text {teo }}^{A C l}}{F_{\text {teo }}^{N B R}} \\
M_{E}^{N B R}=M_{E}^{A C l} \cdot \frac{F_{\text {teo }}^{A C l}}{F_{\text {teo }}^{N B R}}
\end{gathered}
$$

onde $F_{\text {teo }}^{\text {norma }}$,é o valor teórico do momento resistente último segundo os requisitos de norma (ACI 318 ou NBR 6118), e $M_{E}^{\text {norma }}$ a média da variável erro do modelo de norma.

Nota-se pela equação (5.3) que a variável erro do modelo da ABNT NBR 6118:2007 para as vigas, $E_{m}^{N B R}$, apresenta-se aqui como produto entre duas variáveis aleatórias, $E_{M}^{A C l} e$ $\mathrm{F}_{\text {teo }}^{\mathrm{ACl}} / \mathrm{F}_{\text {teo }}^{\mathrm{NBR}}$. E o desvio padrão da variável erro de modelo da ABNT NBR 6118:2007, $\sigma_{\mathrm{E}}^{\mathrm{NBR}}$, calculado conforme a equação (5.6).

$$
\begin{aligned}
\left(C_{\mathrm{V}}^{\mathrm{NBR}}\right)^{2} & =\left(C_{\mathrm{V}}^{\mathrm{ACI}}\right)^{2}+\left(C_{\mathrm{V}}^{\mathrm{R}}\right)^{2} \\
\sigma_{\mathrm{E}}^{\mathrm{NBR}} & =\mathrm{C}_{\mathrm{V}}^{\mathrm{NBR}} \cdot \mathrm{M}_{\mathrm{E}}^{\mathrm{NBR}}
\end{aligned}
$$

sendo: $\mathrm{C}_{\mathrm{V}}^{\mathrm{NBR}}$ o coeficiente de variação da variável erro de modelo da norma brasileira, $\mathrm{C}_{\mathrm{V}}^{\mathrm{ACl}}$ o coeficiente de variação da variável erro de modelo da norma americana, $C_{v}^{R}$ o coeficiente de variação da variável razão $\mathrm{F}_{\text {teo }}^{\mathrm{ACl}} / \mathrm{F}_{\text {teo }}^{\mathrm{NBR}}$.

Segundo NOWAK E SZERSZEN (2003) os valores de $M_{E}^{A C l}$ e $C_{V}^{A C l}$ para vigas solicitadas à flexão, são, respectivamente, 1,0 e 0,06. 


\subsection{ERro do Modelo Para Vigas}

TABELA 5.1 - ERRO DO MODELO DE VIGAS E PARÂMETROS VARIÁVEIS

\begin{tabular}{|c|c|c|c|c|c|c|c|}
\hline \multirow{3}{*}{ VIGAS } & \multicolumn{3}{|c|}{ PARÂMETROS } & \multicolumn{4}{|c|}{ TEÓRICA } \\
\hline & \multirow{2}{*}{$\begin{array}{c}\mathrm{f}_{\mathrm{ck}} \\
\mathrm{MPa}\end{array}$} & \multirow{2}{*}{$\begin{array}{c}\mathrm{h} \\
\mathrm{cm}\end{array}$} & \multirow{2}{*}{$\frac{A_{s, \text { inf }}}{\rho_{s}}$} & \multirow{2}{*}{$\begin{array}{l}\mathrm{M}_{\mathrm{u}, \mathrm{NBR}} \\
\mathrm{kN} . \mathrm{cm}\end{array}$} & \multirow{2}{*}{$\begin{array}{l}\mathrm{M}_{\mathrm{u}, \mathrm{ACl}} \\
\mathrm{kN} \cdot \mathrm{m}\end{array}$} & \multirow{2}{*}{$\mathrm{M}_{\mathrm{u}, \mathrm{ACl}} / \mathrm{M}_{\mathrm{u}, \mathrm{NBR}}$} & \multirow{2}{*}{$\mathrm{M}_{\mathrm{E}}^{\mathrm{NBR}}$} \\
\hline & & & & & & & \\
\hline V20-30-055 & 20 & 30 & $0,55 \%$ & 3283,45 & 3258,84 & 0,9925 & 1,0124 \\
\hline V20-30-080 & 20 & 30 & $0,80 \%$ & 4378,32 & 4325,29 & 0,9879 & 1,0076 \\
\hline V20-30-104 & 20 & 30 & $1,04 \%$ & 5684,47 & 5594,73 & 0,9842 & 1,0039 \\
\hline V20-40-127 & 20 & 40 & $1,27 \%$ & 12396,96 & 12160,83 & 0,9810 & 1,0006 \\
\hline V20-40-151 & 20 & 40 & $1,51 \%$ & 13429,09 & 12984,60 & 0,9669 & 0,9862 \\
\hline V20-40-174 & 20 & 40 & $1,74 \%$ & 15917,25 & 15321,21 & 0,9626 & 0,9818 \\
\hline V20-50-200 & 20 & 50 & $2,00 \%$ & 25151,25 & 23533,34 & 0,9357 & 0,9544 \\
\hline V20-50-226 & 20 & 50 & $2,26 \%$ & 25543,14 & 26849,74 & 1,0512 & 1,0722 \\
\hline V20-50-251 & 20 & 50 & $2,51 \%$ & 29466,63 & 26905,33 & 0,9131 & 0,9313 \\
\hline V20-60-276 & 20 & 60 & $2,76 \%$ & 47530,17 & 43341,13 & 0,9119 & 0,9301 \\
\hline V20-60-303 & 20 & 60 & $3,03 \%$ & 48327,51 & 44066,60 & 0,9118 & 0,9301 \\
\hline V20-60-327 & 20 & 60 & $3,27 \%$ & 49767,12 & 45415,53 & 0,9126 & 0,9308 \\
\hline V25-30-055 & 25 & 30 & $0,55 \%$ & 3320,64 & 3308,59 & 0,9964 & 1,0163 \\
\hline V25-30-080 & 25 & 30 & $0,80 \%$ & 4458,48 & 4432,51 & 0,9942 & 1,0141 \\
\hline V25-30-104 & 25 & 30 & $1,04 \%$ & 5820,10 & 5776,16 & 0,9925 & 1,0123 \\
\hline V25-40-127 & 25 & 40 & $1,27 \%$ & 12753,83 & 12638,22 & 0,9909 & 1,0108 \\
\hline V25-40-151 & 25 & 40 & $1,51 \%$ & 13934,52 & 13770,78 & 0,9882 & 1,0080 \\
\hline V25-40-174 & 25 & 40 & $1,74 \%$ & 16618,79 & 16401,20 & 0,9869 & 1,0066 \\
\hline V25-50-200 & 25 & 50 & $2,00 \%$ & 27548,63 & 27559,07 & 1,0004 & 1,0204 \\
\hline V25-50-226 & 25 & 50 & $2,26 \%$ & 29414,26 & 27555,84 & 0,9368 & 0,9556 \\
\hline V25-50-251 & 25 & 50 & $2,51 \%$ & 29164,97 & 27997,58 & 0,9600 & 0,9792 \\
\hline V25-60-276 & 25 & 60 & $2,76 \%$ & 46488,94 & 50170,15 & 1,0792 & 1,1008 \\
\hline V25-60-303 & 25 & 60 & $3,03 \%$ & 54390,89 & 51060,03 & 0,9388 & 0,9575 \\
\hline V25-60-327 & 25 & 60 & $3,27 \%$ & 56134,79 & 52762,96 & 0,9399 & 0,9587 \\
\hline
\end{tabular}


TABELA 5.1 - ERRO DO MODELO DE VIGAS E PARÂMETROS VARIÁVEIS (CONTINUAÇÃO)

\begin{tabular}{|c|c|c|c|c|c|c|c|}
\hline \multirow{3}{*}{ VIGAS } & \multicolumn{3}{|c|}{ PARARÂMETROS } & \multicolumn{4}{|c|}{ TEÓRICA } \\
\hline & \multirow{2}{*}{$\begin{array}{c}\mathrm{f}_{\mathrm{ck}} \\
\mathrm{MPa}\end{array}$} & \multirow{2}{*}{$\begin{array}{c}\mathrm{h} \\
\mathrm{cm} \\
\end{array}$} & \multirow{2}{*}{$\begin{array}{l}A_{s, \text { inf }} \\
\rho_{s}\end{array}$} & \multirow{2}{*}{$\begin{array}{l}\mathrm{M}_{\mathrm{u}, \mathrm{NBR}} \\
\mathrm{kN} . \mathrm{cm}\end{array}$} & \multirow{2}{*}{$\begin{array}{l}\mathrm{M}_{\mathrm{u}, \mathrm{ACl}} \\
\mathrm{kN} \cdot \mathrm{m}\end{array}$} & \multirow{2}{*}{$\mathrm{M}_{\mathrm{u}, \mathrm{ACl}} / \mathrm{M}_{\mathrm{u}, \mathrm{NBR}}$} & \multirow{2}{*}{$\mathrm{M}_{\mathrm{E}}^{\mathrm{NBR}}$} \\
\hline & & & & & & & \\
\hline V30-30-055 & 30 & 30 & $0,55 \%$ & 3347,67 & 3336,00 & 0,9965 & 1,0164 \\
\hline V30-30-080 & 30 & 30 & $0,80 \%$ & 4516,72 & 4491,58 & 0,9944 & 1,0143 \\
\hline V30-30-104 & 30 & 30 & $1,04 \%$ & 5918,65 & 5876,10 & 0,9928 & 1,0127 \\
\hline V30-40-127 & 30 & 40 & $1,27 \%$ & 13013,14 & 12901,20 & 0,9914 & 1,0112 \\
\hline V30-40-151 & 30 & 40 & $1,51 \%$ & 14301,77 & 14143,23 & 0,9889 & 1,0087 \\
\hline V30-40-174 & 30 & 40 & $1,74 \%$ & 17106,83 & 16896,15 & 0,9877 & 1,0074 \\
\hline V30-50-200 & 30 & 50 & $2,00 \%$ & 28727,81 & 28290,86 & 0,9848 & 1,0045 \\
\hline V30-50-226 & 30 & 50 & $2,26 \%$ & 30534,07 & 29537,56 & 0,9674 & 0,9867 \\
\hline V30-50-251 & 30 & 50 & $2,51 \%$ & 33163,17 & 30550,12 & 0,9212 & 0,9396 \\
\hline V30-60-276 & 30 & 60 & $2,76 \%$ & 51448,79 & 48757,61 & 0,9477 & 0,9666 \\
\hline V30-60-303 & 30 & 60 & $3,03 \%$ & 52772,09 & 55775,82 & 1,0569 & 1,0781 \\
\hline V30-60-327 & 30 & 60 & $3,27 \%$ & 62228,25 & 57730,08 & 0,9277 & 0,9463 \\
\hline V35-30-055 & 35 & 30 & $0,55 \%$ & 3368,19 & 3357,28 & 0,9968 & 1,0167 \\
\hline V35-30-080 & 35 & 30 & $0,80 \%$ & 4560,95 & 4537,43 & 0,9948 & 1,0147 \\
\hline V35-30-104 & 35 & 30 & $1,04 \%$ & 5993,49 & 5953,69 & 0,9934 & 1,0132 \\
\hline V35-40-127 & 35 & 40 & $1,27 \%$ & 13210,08 & 13105,36 & 0,9921 & 1,0119 \\
\hline V35-40-151 & 35 & 40 & $1,51 \%$ & 14580,70 & 14432,39 & 0,9898 & 1,0096 \\
\hline V35-40-174 & 35 & 40 & $1,74 \%$ & 17477,50 & 17280,40 & 0,9887 & 1,0085 \\
\hline V35-50-200 & 35 & 50 & $2,00 \%$ & 29496,57 & 29087,79 & 0,9861 & 1,0059 \\
\hline V35-50-226 & 35 & 50 & $2,26 \%$ & 31855,90 & 31181,22 & 0,9788 & 0,9984 \\
\hline V35-50-251 & 35 & 50 & $2,51 \%$ & 34171,65 & 33143,90 & 0,9699 & 0,9893 \\
\hline V35-60-276 & 35 & 60 & $2,76 \%$ & 55215,81 & 52081,34 & 0,9432 & 0,9621 \\
\hline V35-60-303 & 35 & 60 & $3,03 \%$ & 57039,51 & 53613,16 & 0,9399 & 0,9587 \\
\hline V35-60-327 & 35 & 60 & $3,27 \%$ & 60596,41 & 61768,95 & 1,0194 & 1,0397 \\
\hline
\end{tabular}


TABELA 5.1 - ERRo DO MODELO DE VIGAS E PARÂMETROS VARIÁVEIS (CONTINUAÇÃO)

\begin{tabular}{|c|c|c|c|c|c|c|c|}
\hline \multirow{3}{*}{ VIGAS } & \multicolumn{3}{|c|}{ PARARÂMETROS } & \multicolumn{4}{|c|}{ TEÓRICA } \\
\hline & \multirow{2}{*}{$\begin{array}{c}\mathrm{f}_{\mathrm{ck}} \\
\mathrm{MPa}\end{array}$} & \multirow{2}{*}{$\begin{array}{c}\mathrm{h} \\
\mathrm{cm}\end{array}$} & \multirow{2}{*}{$\frac{A_{s, \text { inf }}}{\rho_{s}}$} & \multirow{2}{*}{$\begin{array}{l}\mathrm{M}_{\mathrm{u}, \mathrm{NBR}} \\
\mathrm{kN} \cdot \mathrm{cm}\end{array}$} & \multirow{2}{*}{$\begin{array}{l}\mathrm{M}_{\mathrm{u}, \mathrm{ACl}} \\
\mathrm{kN} \cdot \mathrm{m}\end{array}$} & \multirow{2}{*}{$\mathrm{M}_{\mathrm{u}, \mathrm{ACl}} / \mathrm{M}_{\mathrm{u}, \mathrm{NBR}}$} & \multirow{2}{*}{$M_{E}^{N B R}$} \\
\hline & & & & & & & \\
\hline V40-30-055 & 40 & 30 & $0,55 \%$ & 3384,31 & 3375,42 & 0,9974 & 1,0173 \\
\hline V40-30-080 & 40 & 30 & $0,80 \%$ & 4595,69 & 4576,54 & 0,9958 & 1,0157 \\
\hline V40-30-104 & 40 & 30 & $1,04 \%$ & 6052,27 & 6019,86 & 0,9946 & 1,0145 \\
\hline V40-40-127 & 40 & 40 & $1,27 \%$ & 13364,74 & 13279,47 & 0,9936 & 1,0135 \\
\hline V40-40-151 & 40 & 40 & $1,51 \%$ & 14799,75 & 14678,98 & 0,9918 & 1,0117 \\
\hline V40-40-174 & 40 & 40 & $1,74 \%$ & 17768,59 & 17608,10 & 0,9910 & 1,0108 \\
\hline V40-50-200 & 40 & 50 & $2,00 \%$ & 30100,30 & 29767,43 & 0,9889 & 1,0087 \\
\hline V40-50-226 & 40 & 50 & $2,26 \%$ & 32626,71 & 32087,32 & 0,9835 & 1,0031 \\
\hline V40-50-251 & 40 & 50 & $2,51 \%$ & 35122,38 & 34051,87 & 0,9695 & 0,9889 \\
\hline V40-60-276 & 40 & 60 & $2,76 \%$ & 57282,85 & 55800,93 & 0,9741 & 0,9936 \\
\hline V40-60-303 & 40 & 60 & $3,03 \%$ & 60270,48 & 56643,17 & 0,9398 & 0,9586 \\
\hline V40-60-327 & 40 & 60 & $3,27 \%$ & 65185,02 & 65740,05 & 1,0085 & 1,0287 \\
\hline V45-30-055 & 45 & 30 & $0,55 \%$ & 3397,31 & 3389,90 & 0,9978 & 1,0178 \\
\hline V45-30-080 & 45 & 30 & $0,80 \%$ & 4623,69 & 4607,73 & 0,9965 & 1,0165 \\
\hline V45-30-104 & 45 & 30 & $1,04 \%$ & 6099,65 & 6072,63 & 0,9956 & 1,0155 \\
\hline V45-40-127 & 45 & 40 & $1,27 \%$ & 13489,42 & 13418,32 & 0,9947 & 1,0146 \\
\hline V45-40-151 & 45 & 40 & $1,51 \%$ & 14976,33 & 14875,64 & 0,9933 & 1,0131 \\
\hline V45-40-174 & 45 & 40 & $1,74 \%$ & 18003,25 & 17869,44 & 0,9926 & 1,0124 \\
\hline V45-50-200 & 45 & 50 & $2,00 \%$ & 30586,98 & 30309,45 & 0,9909 & 1,0107 \\
\hline V45-50-226 & 45 & 50 & $2,26 \%$ & 33248,08 & 32893,74 & 0,9893 & 1,0091 \\
\hline V45-50-251 & 45 & 50 & $2,51 \%$ & 35888,79 & 35435,91 & 0,9874 & 1,0071 \\
\hline V45-60-276 & 45 & 60 & $2,76 \%$ & 58618,25 & 57257,65 & 0,9768 & 0,9963 \\
\hline V45-60-303 & 45 & 60 & $3,03 \%$ & 62607,44 & 59253,02 & 0,9464 & 0,9653 \\
\hline V45-60-327 & 45 & 60 & $3,27 \%$ & 67809,60 & 63126,02 & 0,9309 & 0,9495 \\
\hline
\end{tabular}


TABELA 5.1 - ERRO DO MODELO DE VIGAS E PARÂMETROS VARIÁVEIS (CONTINUAÇÃO)

\begin{tabular}{|c|c|c|c|c|c|c|c|}
\hline \multirow{3}{*}{ VIGAS } & \multicolumn{3}{|c|}{ PARARÂMETROS } & \multicolumn{4}{|c|}{ TEÓRICA } \\
\hline & \multirow{2}{*}{$\begin{array}{c}\mathrm{f}_{\mathrm{ck}} \\
\mathrm{MPa}\end{array}$} & \multirow{2}{*}{$\begin{array}{c}\mathrm{h} \\
\mathrm{cm}\end{array}$} & \multirow{2}{*}{$\frac{A_{s, \text { inf }}}{\rho_{s}}$} & \multirow{2}{*}{$\begin{array}{l}M_{u, N B R} \\
k N . c m\end{array}$} & \multirow{2}{*}{$\begin{array}{l}\mathrm{M}_{\mathrm{u}, \mathrm{ACl}} \\
\mathrm{kN} \cdot \mathrm{m}\end{array}$} & \multirow{2}{*}{$\mathrm{M}_{\mathrm{u}, \mathrm{ACl}} / \mathrm{M}_{\mathrm{u}, \mathrm{NBR}}$} & \multirow{2}{*}{$M_{E}^{N B R}$} \\
\hline & & & & & & & \\
\hline V50-30-055 & 50 & 30 & $0,55 \%$ & 3408,00 & 3401,71 & 0,9982 & 1,0181 \\
\hline V50-30-080 & 50 & 30 & $0,80 \%$ & 4646,75 & 4633,18 & 0,9971 & 1,0170 \\
\hline V50-30-104 & 50 & 30 & $1,04 \%$ & 6138,66 & 6115,70 & 0,9963 & 1,0162 \\
\hline V50-40-127 & 50 & 40 & $1,27 \%$ & 13592,06 & 13531,65 & 0,9956 & 1,0155 \\
\hline V50-40-151 & 50 & 40 & $1,51 \%$ & 15121,70 & 15036,13 & 0,9943 & 1,0142 \\
\hline V50-40-174 & 50 & 40 & $1,74 \%$ & 18196,44 & 18082,72 & 0,9938 & 1,0136 \\
\hline V50-50-200 & 50 & 50 & $2,00 \%$ & 30987,64 & 30751,80 & 0,9924 & 1,0122 \\
\hline V50-50-226 & 50 & 50 & $2,26 \%$ & 33759,62 & 33458,51 & 0,9911 & 1,0109 \\
\hline V50-50-251 & 50 & 50 & $2,51 \%$ & 36519,74 & 36148,35 & 0,9898 & 1,0096 \\
\hline V50-60-276 & 50 & 60 & $2,76 \%$ & 59717,62 & 59063,31 & 0,9890 & 1,0088 \\
\hline V50-60-303 & 50 & 60 & $3,03 \%$ & 63930,21 & 61695,48 & 0,9650 & 0,9843 \\
\hline V50-60-327 & 50 & 60 & $3,27 \%$ & 69350,01 & 65660,30 & 0,9468 & 0,9657 \\
\hline V60-30-055 & 60 & 30 & $0,55 \%$ & 3424,58 & 3419,82 & 0,9986 & 1,0186 \\
\hline V60-30-080 & 60 & 30 & $0,80 \%$ & 4682,47 & 4672,22 & 0,9978 & 1,0178 \\
\hline V60-30-104 & 60 & 30 & $1,04 \%$ & 6199,10 & 6181,77 & 0,9972 & 1,0171 \\
\hline V60-40-127 & 60 & 40 & $1,27 \%$ & 13751,10 & 13705,49 & 0,9967 & 1,0166 \\
\hline V60-40-151 & 60 & 40 & $1,51 \%$ & 15346,95 & 15282,35 & 0,9958 & 1,0157 \\
\hline V60-40-174 & 60 & 40 & $1,74 \%$ & 18495,76 & 18409,91 & 0,9954 & 1,0153 \\
\hline V60-50-200 & 60 & 50 & $2,00 \%$ & 31608,43 & 31430,39 & 0,9944 & 1,0143 \\
\hline V60-50-226 & 60 & 50 & $2,26 \%$ & 34552,22 & 34324,91 & 0,9934 & 1,0133 \\
\hline V60-50-251 & 60 & 50 & $2,51 \%$ & 37497,35 & 37216,98 & 0,9925 & 1,0124 \\
\hline V60-60-276 & 60 & 60 & $2,76 \%$ & 61421,01 & 60932,48 & 0,9920 & 1,0119 \\
\hline V60-60-303 & 60 & 60 & $3,03 \%$ & 65979,73 & 64981,46 & 0,9849 & 1,0046 \\
\hline V60-60-327 & 60 & 60 & $3,27 \%$ & 71736,76 & 71024,38 & 0,9901 & 1,0099 \\
\hline
\end{tabular}


TABELA 5.1 - ERRo DO MODELO DE VIGAS E PARÂMETROS VARIÁVEIS (CONTINUAÇÃO)

\begin{tabular}{|c|c|c|c|c|c|c|c|}
\hline \multirow{3}{*}{ VIGAS } & \multicolumn{3}{|c|}{ PARARÂMETROS } & \multicolumn{4}{|c|}{ TEÓRICA } \\
\hline & \multirow{2}{*}{$\begin{array}{c}\mathrm{f}_{\mathrm{ck}} \\
\mathrm{MPa}\end{array}$} & \multirow{2}{*}{$\begin{array}{l}\mathrm{h} \\
\mathrm{cm}\end{array}$} & \multirow{2}{*}{\begin{tabular}{|c|}
$A_{s, \text { inf }}$ \\
$\rho_{s}$ \\
\end{tabular}} & \multirow{2}{*}{$\begin{array}{l}\mathrm{M}_{\mathrm{u}, \mathrm{NBR}} \\
\mathrm{kN} . \mathrm{cm}\end{array}$} & \multirow{2}{*}{$\begin{array}{l}\mathrm{M}_{\mathrm{u}, \mathrm{ACl}} \\
\mathrm{kN} \cdot \mathrm{m}\end{array}$} & \multirow{2}{*}{$\mathrm{M}_{\mathrm{u}, \mathrm{ACl}} / \mathrm{M}_{\mathrm{u}, \mathrm{NBR}}$} & \multirow{2}{*}{$\mathrm{M}_{\mathrm{E}}^{\mathrm{NBR}}$} \\
\hline & & & & & & & \\
\hline V70-30-055 & 70 & 30 & $0,55 \%$ & 3436,82 & 3433,07 & 0,9989 & 1,0189 \\
\hline V70-30-080 & 70 & 30 & $0,80 \%$ & 4708,86 & 4700,77 & 0,9983 & 1,0182 \\
\hline V70-30-104 & 70 & 30 & $1,04 \%$ & 6243,76 & 6230,07 & 0,9978 & 1,0178 \\
\hline V70-40-127 & 70 & 40 & $1,27 \%$ & 13868,60 & 13832,59 & 0,9974 & 1,0174 \\
\hline V70-40-151 & 70 & 40 & $1,51 \%$ & 15513,36 & 15462,36 & 0,9967 & 1,0166 \\
\hline V70-40-174 & 70 & 40 & $1,74 \%$ & 18716,91 & 18649,13 & 0,9964 & 1,0163 \\
\hline V70-50-200 & 70 & 50 & $2,00 \%$ & 32067,10 & 31926,53 & 0,9956 & 1,0155 \\
\hline V70-50-226 & 70 & 50 & $2,26 \%$ & 35137,82 & 34958,35 & 0,9949 & 1,0148 \\
\hline V70-50-251 & 70 & 50 & $2,51 \%$ & 38219,65 & 37998,28 & 0,9942 & 1,0141 \\
\hline V70-60-276 & 70 & 60 & $2,76 \%$ & 62679,53 & 62293,83 & 0,9938 & 1,0137 \\
\hline V70-60-303 & 70 & 60 & $3,03 \%$ & 67493,99 & 67029,91 & 0,9931 & 1,0130 \\
\hline V70-60-327 & 70 & 60 & $3,27 \%$ & 73500,17 & 72959,73 & 0,9926 & 1,0125 \\
\hline V80-30-055 & 80 & 30 & $0,55 \%$ & 3446,24 & 3443,18 & 0,9991 & 1,0191 \\
\hline V80-30-080 & 80 & 30 & $0,80 \%$ & 4729,16 & 4722,55 & 0,9986 & 1,0186 \\
\hline V80-30-104 & 80 & 30 & $1,04 \%$ & 6278,10 & 6266,93 & 0,9982 & 1,0182 \\
\hline V80-40-127 & 80 & 40 & $1,27 \%$ & 13958,96 & 13929,57 & 0,9979 & 1,0179 \\
\hline V80-40-151 & 80 & 40 & $1,51 \%$ & 15641,34 & 15599,71 & 0,9973 & 1,0173 \\
\hline V80-40-174 & 80 & 40 & $1,74 \%$ & 18886,97 & 18831,65 & 0,9971 & 1,0170 \\
\hline V80-50-200 & 80 & 50 & $2,00 \%$ & 32419,81 & 32305,07 & 0,9965 & 1,0164 \\
\hline V80-50-226 & 80 & 50 & $2,26 \%$ & 35588,15 & 35441,66 & 0,9959 & 1,0158 \\
\hline V80-50-251 & 80 & 50 & $2,51 \%$ & 38775,09 & 38594,41 & 0,9953 & 1,0152 \\
\hline V80-60-276 & 80 & 60 & $2,76 \%$ & 63647,34 & 63332,52 & 0,9951 & 1,0150 \\
\hline V80-60-303 & 80 & 60 & $3,03 \%$ & 68658,46 & 68279,67 & 0,9945 & 1,0144 \\
\hline V80-60-327 & 80 & 60 & $3,27 \%$ & 74856,23 & 74415,11 & 0,9941 & 1,0140 \\
\hline
\end{tabular}


TABELA 5.1 - ERRO DO MODELO DE VIGAS E PARÂMETROS VARIÁVEIS (CONTINUAÇÃO)

\begin{tabular}{|c|c|c|c|c|c|c|c|}
\hline \multirow{3}{*}{ VIGAS } & \multicolumn{3}{|c|}{ PARARÂMETROS } & \multicolumn{4}{|c|}{ TEÓRICA } \\
\hline & \multirow{2}{*}{$\begin{array}{r}\mathrm{f}_{\mathrm{ck}} \\
\mathrm{MPa}\end{array}$} & \multirow{2}{*}{$\begin{array}{c}\mathrm{h} \\
\mathrm{cm}\end{array}$} & \multirow{2}{*}{$\frac{A_{s, \text { inf }}}{\rho_{s}}$} & \multirow{2}{*}{$\begin{array}{l}\mathrm{M}_{\mathrm{u}, \mathrm{NBR}} \\
\mathrm{kN} . \mathrm{cm}\end{array}$} & \multirow{2}{*}{$\begin{array}{l}\mathrm{M}_{\mathrm{u}, \mathrm{ACl}} \\
\mathrm{kN} \cdot \mathrm{m}\end{array}$} & \multirow{2}{*}{$\mathrm{M}_{\mathrm{u}, \mathrm{ACl}} / \mathrm{M}_{\mathrm{u}, \mathrm{NBR}}$} & \multirow{2}{*}{$\mathrm{M}_{\mathrm{E}}^{\mathrm{NBR}}$} \\
\hline & & & & & & & \\
\hline V90-30-055 & 90 & 30 & $0,55 \%$ & 3453,71 & 3451,14 & 0,9993 & 1,0192 \\
\hline V90-30-080 & 90 & 30 & $0,80 \%$ & 4745,25 & 4739,72 & 0,9988 & 1,0188 \\
\hline V90-30-104 & 90 & 30 & $1,04 \%$ & 6305,33 & 6295,97 & 0,9985 & 1,0185 \\
\hline V90-40-127 & 90 & 40 & $1,27 \%$ & 14030,60 & 14005,99 & 0,9982 & 1,0182 \\
\hline V90-40-151 & 90 & 40 & $1,51 \%$ & 15742,81 & 15707,95 & 0,9978 & 1,0177 \\
\hline V90-40-174 & 90 & 40 & $1,74 \%$ & 19021,82 & 18975,50 & 0,9976 & 1,0175 \\
\hline V90-50-200 & 90 & 50 & $2,00 \%$ & 32699,48 & 32603,41 & 0,9971 & 1,0170 \\
\hline V90-50-226 & 90 & 50 & $2,26 \%$ & 35945,22 & 35822,56 & 0,9966 & 1,0165 \\
\hline V90-50-251 & 90 & 50 & $2,51 \%$ & 39215,51 & 39064,22 & 0,9961 & 1,0161 \\
\hline V90-60-276 & 90 & 60 & $2,76 \%$ & 64414,73 & 64151,11 & 0,9959 & 1,0158 \\
\hline V90-60-303 & 90 & 60 & $3,03 \%$ & 69581,79 & 69264,60 & 0,9954 & 1,0154 \\
\hline V90-60-327 & 90 & 60 & $3,27 \%$ & 75931,48 & 75562,11 & 0,9951 & 1,0150 \\
\hline V100-30-055 & 100 & 30 & $0,55 \%$ & 3459,77 & 3457,58 & 0,9994 & 1,0194 \\
\hline V100-30-080 & 100 & 30 & $0,80 \%$ & 4758,32 & 4753,60 & 0,9990 & 1,0190 \\
\hline V100-30-104 & 100 & 30 & $1,04 \%$ & 6327,45 & 6319,46 & 0,9987 & 1,0187 \\
\hline V100-40-127 & 100 & 40 & $1,27 \%$ & 14088,81 & 14067,78 & 0,9985 & 1,0185 \\
\hline V100-40-151 & 100 & 40 & $1,51 \%$ & 15825,24 & 15795,46 & 0,9981 & 1,0181 \\
\hline V100-40-174 & 100 & 40 & $1,74 \%$ & 19131,36 & 19091,78 & 0,9979 & 1,0179 \\
\hline V100-50-200 & 100 & 50 & $2,00 \%$ & 32926,67 & 32844,58 & 0,9975 & 1,0175 \\
\hline V100-50-226 & 100 & 50 & $2,26 \%$ & 36235,28 & 36130,47 & 0,9971 & 1,0170 \\
\hline V100-50-251 & 100 & 50 & $2,51 \%$ & 39573,29 & 39444,01 & 0,9967 & 1,0167 \\
\hline V100-60-276 & 100 & 60 & $2,76 \%$ & 65038,11 & 64812,86 & 0,9965 & 1,0165 \\
\hline V100-60-303 & 100 & 60 & $3,03 \%$ & 70331,85 & 70060,83 & 0,9961 & 1,0161 \\
\hline V100-60-327 & 100 & 60 & $3,27 \%$ & 76804,95 & 76489,34 & 0,9959 & 1,0158 \\
\hline
\end{tabular}




\subsection{ERRo doS MOdELOS PARA PILARES}

TABELA 5.2 - ERRO DOS MODELOS DE PILARES E PARÂMETROS VARIÁVEIS

\begin{tabular}{|c|c|c|c|c|c|c|c|c|c|}
\hline \multirow{3}{*}{ FONTE } & \multirow{3}{*}{ PILAR } & \multicolumn{2}{|c|}{ EXPERIMENTAL } & \multicolumn{3}{|c|}{ TEÓRICO } & \multicolumn{3}{|c|}{ ERRO DE MODELO } \\
\hline & & \multirow{2}{*}{$\begin{array}{c}e_{i} \\
m m\end{array}$} & \multirow{2}{*}{$\frac{N_{\exp }}{k N}$} & \multirow{2}{*}{$\frac{N_{N B R-K}}{k N}$} & \multirow{2}{*}{$\frac{\mathrm{N}_{\mathrm{NBR}-\mathrm{C}}}{\mathrm{kN}}$} & \multirow{2}{*}{$\frac{N_{\mathrm{ACl}}}{\mathrm{kN}}$} & \multicolumn{2}{|c|}{ ABNT NBR 6118} & \multirow{2}{*}{$\mathrm{ACl} 318$} \\
\hline & & & & & & & rigidez & curvatura & \\
\hline \multirow{44}{*}{ 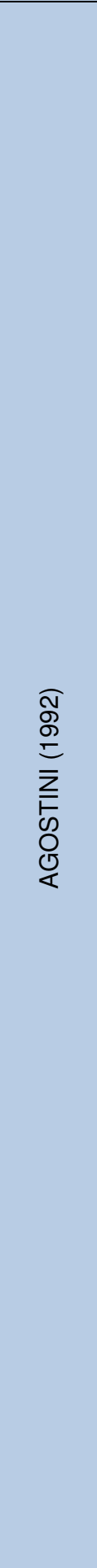 } & P1-I & 0 & 655 & 547.00 & 547.00 & 693.29 & 1.1974 & 1.1974 & 0.9448 \\
\hline & P1-II & 0 & 664 & 547.00 & 547.00 & 693.29 & 1.2139 & 1.2139 & 0.9578 \\
\hline & P2-I & 0 & 679 & 652.43 & 652.43 & 832.89 & 1.0407 & 1.0407 & 0.8152 \\
\hline & P2-II & 0 & 758 & 652.43 & 652.43 & 832.89 & 1.1618 & 1.1618 & 0.9101 \\
\hline & P3-I & 0 & 793 & 675.12 & 675.12 & 862.25 & 1.1746 & 1.1746 & 0.9197 \\
\hline & P3-II & 0 & 841 & 675.12 & 675.12 & 862.25 & 1.2457 & 1.2457 & 0.9754 \\
\hline & P4-I & 0 & 1279 & 845.83 & 845.83 & 1081.32 & 1.5121 & 1.5121 & 1.1828 \\
\hline & P4-II & 0 & 1327 & 845.83 & 845.83 & 1081.32 & 1.5689 & 1.5689 & 1.2272 \\
\hline & P5-I & 0 & 1318 & 809.36 & 809.36 & 1039.14 & 1.6285 & 1.6285 & 1.2684 \\
\hline & P5-II & 0 & 1212 & 809.36 & 809.36 & 1039.14 & 1.4975 & 1.4975 & 1.1663 \\
\hline & P6-I & 0 & 1203 & 775.33 & 775.33 & 995.09 & 1.5516 & 1.5516 & 1.2089 \\
\hline & P6-II & 0 & 1143 & 775.33 & 775.33 & 995.09 & 1.4742 & 1.4742 & 1.1486 \\
\hline & P7-I & 0 & 1040 & 696.61 & 696.61 & 903.31 & 1.4929 & 1.4929 & 1.1513 \\
\hline & P7-II & 0 & 1069 & 696.61 & 696.61 & 903.31 & 1.5346 & 1.5346 & 1.1834 \\
\hline & P8 & 0 & 453 & 277.91 & 277.91 & 440.10 & 1.6300 & 1.6300 & 1.0293 \\
\hline & P9 & 0 & 376 & 339.28 & 339.28 & 505.22 & 1.1082 & 1.1082 & 0.7442 \\
\hline & P10 & 0 & 463 & 325.35 & 325.35 & 502.13 & 1.4231 & 1.4231 & 0.9221 \\
\hline & P11 & 0 & 387 & 325.35 & 325.35 & 502.13 & 1.1895 & 1.1895 & 0.7707 \\
\hline & PCNCA-I & 0 & 345 & 251.01 & 251.01 & 308.90 & 1.3745 & 1.3745 & 1.1169 \\
\hline & PCNCA-II & 0 & 315 & 251.01 & 251.01 & 308.90 & 1.2549 & 1.2549 & 1.0197 \\
\hline & PCNSA-I & 0 & 268 & 186.90 & 186.90 & 242.35 & 1.4340 & 1.4340 & 1.1058 \\
\hline & PCNSA-II & 0 & 245 & 186.90 & 186.90 & 242.35 & 1.3109 & 1.3109 & 1.0109 \\
\hline & PL4T150-I & 0 & 353 & 327.64 & 327.64 & 528.78 & 1.0774 & 1.0774 & 0.6676 \\
\hline & PL4T150-II & 0 & 378 & 327.64 & 327.64 & 528.78 & 1.1537 & 1.1537 & 0.7149 \\
\hline & PL4T175-I & 0 & 417 & 340.05 & 340.05 & 548.34 & 1.2263 & 1.2263 & 0.7605 \\
\hline & PL4T175-II & 0 & 417 & 340.05 & 340.05 & 548.34 & 1.2263 & 1.2263 & 0.7605 \\
\hline & PL4T200-I & 0 & 427 & 346.95 & 346.95 & 559.20 & 1.2307 & 1.2307 & 0.7636 \\
\hline & PL4T200-II & 0 & 466 & 346.95 & 346.95 & 559.20 & 1.3431 & 1.3431 & 0.8333 \\
\hline & PL4T225-I & 0 & 400 & 329.71 & 329.71 & 532.04 & 1.2132 & 1.2132 & 0.7518 \\
\hline & PL4T225-II & 0 & 408 & 329.71 & 329.71 & 532.04 & 1.2375 & 1.2375 & 0.7669 \\
\hline & PL4T250-I & 0 & 490 & 350.39 & 350.39 & 564.64 & 1.3984 & 1.3984 & 0.8678 \\
\hline & PL4T250-II & 0 & 532 & 350.39 & 350.39 & 564.64 & 1.5183 & 1.5183 & 0.9422 \\
\hline & PL4T275-I & 0 & 388 & 329.02 & 329.02 & 530.95 & 1.1793 & 1.1793 & 0.7308 \\
\hline & PL4T275-II & 0 & 450 & 329.02 & 329.02 & 530.95 & 1.3677 & 1.3677 & 0.8475 \\
\hline & PL4T300-I & 0 & 472 & 352.46 & 352.46 & 567.90 & 1.3391 & 1.3391 & 0.8311 \\
\hline & PL4T300-II & 0 & 464 & 352.46 & 352.46 & 567.90 & 1.3165 & 1.3165 & 0.8171 \\
\hline & PL4T225-I & 0 & 1450 & 994.64 & 994.64 & 1279.52 & 1.4578 & 1.4578 & 1.1332 \\
\hline & PL4T225-II & 0 & 1370 & 994.64 & 994.64 & 1279.52 & 1.3774 & 1.3774 & 1.0707 \\
\hline & PL6T225-I & 0 & 1376 & 988.22 & 988.22 & 1270.52 & 1.3924 & 1.3924 & 1.0830 \\
\hline & PL6T225-II & 0 & 1385 & 988.22 & 988.22 & 1270.52 & 1.4015 & 1.4015 & 1.0901 \\
\hline & PL4T300-I & 0 & 1200 & 989.90 & 989.90 & 1273.40 & 1.2122 & 1.2122 & 0.9424 \\
\hline & PL4T300-II & 0 & 1325 & 989.90 & 989.90 & 1273.40 & 1.3385 & 1.3385 & 1.0405 \\
\hline & I-PL6T300 & 0 & 1300 & 979.64 & 979.64 & 1259.50 & 1.3270 & 1.3270 & 1.0322 \\
\hline & PL6T300-II & 0 & 1361 & 979.64 & 979.64 & 1259.50 & 1.3893 & 1.3893 & 1.0806 \\
\hline
\end{tabular}


TABELA 5.2 - ERRo dOS MODELOS DE PILARES E PARÂMETROS VARIÁVEIS (CONTINUAÇÃO)

\begin{tabular}{|c|c|c|c|c|c|c|c|c|c|}
\hline \multirow{3}{*}{ FONTE } & \multirow{3}{*}{ PILAR } & \multicolumn{2}{|c|}{ EXPERIMENTAL } & \multicolumn{3}{|c|}{ TEÓRICO } & \multicolumn{3}{|c|}{ ERRO DE MODELO } \\
\hline & & \multirow{2}{*}{$\frac{e_{i}}{m m}$} & \multirow{2}{*}{$\frac{N_{\text {exp }}}{k N}$} & \multirow{2}{*}{$\frac{\mathrm{N}_{\mathrm{NBR}-\mathrm{K}}}{\mathrm{kN}}$} & \multirow{2}{*}{$\frac{\mathrm{N}_{\mathrm{NBR}-\mathrm{C}}}{\mathrm{kN}}$} & \multirow{2}{*}{$\frac{N_{A C l}}{k N}$} & \multicolumn{2}{|c|}{ ABNT NBR 6118} & \multirow{2}{*}{$\mathrm{ACl} 318$} \\
\hline & & & & & & & rigidez & curvatura & \\
\hline \multirow{26}{*}{ 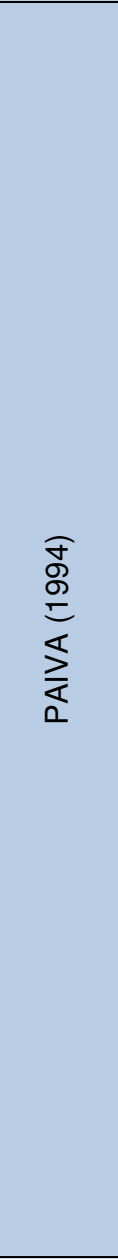 } & $\begin{array}{l}\text { P1SA- } \\
\text { USUAL }\end{array}$ & 0 & 138.4 & 90.60 & 90.60 & 143.48 & 1.5275 & 1.5275 & 0.9646 \\
\hline & $\begin{array}{l}\text { P2SA- } \\
\text { USUAL }\end{array}$ & 0 & 144 & 90.60 & 90.60 & 143.48 & 1.5893 & 1.5893 & 1.0036 \\
\hline & $\begin{array}{l}\text { P1CA- } \\
\text { USUAL }\end{array}$ & 0 & 180 & 123.92 & 123.92 & 186.65 & 1.4525 & 1.4525 & 0.9644 \\
\hline & $\begin{array}{l}\text { P2CA- } \\
\text { USUAL }\end{array}$ & 0 & 190.4 & 123.92 & 123.92 & 186.65 & 1.5364 & 1.5364 & 1.0201 \\
\hline & P1SA-CAR & 0 & 500 & 239.18 & 239.18 & 378.76 & 2.0905 & 2.0905 & 1.3201 \\
\hline & P2SA-CAR & 0 & 510.4 & 239.18 & 239.18 & 378.76 & 2.1340 & 2.1340 & 1.3476 \\
\hline & P1CA-CAR & 0 & 500 & 310.19 & 310.19 & 479.37 & 1.6119 & 1.6119 & 1.0430 \\
\hline & P2CA-CAR & 0 & 524.8 & 310.19 & 310.19 & 479.37 & 1.6919 & 1.6919 & 1.0948 \\
\hline & $P 8 / 10-150-1$ & 0 & 560 & 405.87 & 405.87 & 650.69 & 1.3797 & 1.3797 & 0.8606 \\
\hline & $P 8 / 10-150-2$ & 0 & 575 & 405.87 & 405.87 & 650.69 & 1.4167 & 1.4167 & 0.8837 \\
\hline & P8/10-175-1 & 0 & 600 & 368.62 & 368.62 & 591.93 & 1.6277 & 1.6277 & 1.0136 \\
\hline & P8/10-175-2 & 0 & 575 & 368.62 & 368.62 & 591.93 & 1.5599 & 1.5599 & 0.9714 \\
\hline & P8/10-200-1 & 0 & 600 & 370.51 & 370.51 & 594.92 & 1.6194 & 1.6194 & 1.0085 \\
\hline & $P 8 / 10-200-2$ & 0 & 600 & 370.51 & 370.51 & 594.92 & 1.6194 & 1.6194 & 1.0085 \\
\hline & P8/10-225-1 & 0 & 500 & 359.01 & 359.01 & 576.78 & 1.3927 & 1.3927 & 0.8669 \\
\hline & P8/10-225-2 & 0 & 525 & 359.01 & 359.01 & 576.78 & 1.4623 & 1.4623 & 0.9102 \\
\hline & P8/10-250-1 & 0 & 515 & 360.09 & 360.09 & 578.48 & 1.4302 & 1.4302 & 0.8903 \\
\hline & P8/10-250-2 & 0 & 510 & 360.09 & 360.09 & 578.48 & 1.4163 & 1.4163 & 0.8816 \\
\hline & P8/10-275-1 & 0 & 490 & 318.12 & 318.12 & 512.34 & 1.5403 & 1.5403 & 0.9564 \\
\hline & P8/10-275-2 & 0 & 550 & 318.12 & 318.12 & 512.34 & 1.7289 & 1.7289 & 1.0735 \\
\hline & P8/12-200-1 & 0 & 650 & 472.43 & 472.43 & 761.04 & 1.3759 & 1.3759 & 0.8541 \\
\hline & P8/12-200-2 & 0 & 700 & 472.43 & 472.43 & 761.04 & 1.4817 & 1.4817 & 0.9198 \\
\hline & P8/12-225-1 & 0 & 825 & 462.86 & 462.86 & 745.97 & 1.7824 & 1.7824 & 1.1059 \\
\hline & P8/12-225-2 & 0 & 850 & 462.86 & 462.86 & 745.97 & 1.8364 & 1.8364 & 1.1394 \\
\hline & P8/12-250-1 & 0 & 750 & 457.32 & 457.32 & 737.26 & 1.6400 & 1.6400 & 1.0173 \\
\hline & P8/12-250-2 & 0 & 675 & 457.32 & 457.32 & 737.26 & 1.4760 & 1.4760 & 0.9156 \\
\hline \multirow{23}{*}{ 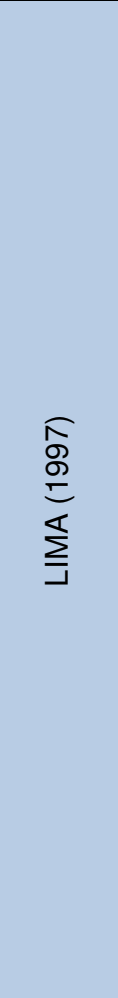 } & $\mathrm{P} 1 / 1$ & 0 & 2630 & 2910.78 & 2910.78 & 3325.32 & 0.9035 & 0.9035 & 0.7909 \\
\hline & $\mathrm{P} 1 / 2$ & 0 & 2701 & 2910.78 & 2910.78 & 3325.32 & 0.9279 & 0.9279 & 0.8123 \\
\hline & $\mathrm{P} 1 / 3$ & 0 & 2834 & 2910.78 & 2910.78 & 3325.32 & 0.9736 & 0.9736 & 0.8522 \\
\hline & $\mathrm{P} 1 \mathrm{r} / 2$ & 0 & 3063 & 2949.85 & 2949.85 & 3369.51 & 1.0384 & 1.0384 & 0.9090 \\
\hline & $\mathrm{P} 1 \mathrm{r} / 3$ & 0 & 2820 & 2949.85 & 2949.85 & 3369.51 & 0.9560 & 0.9560 & 0.8369 \\
\hline & $\mathrm{P} 2 / 2$ & 0 & 2950 & 3018.98 & 3018.98 & 3447.69 & 0.9772 & 0.9772 & 0.8556 \\
\hline & P2/3 & 0 & 3210 & 3157.23 & 3157.23 & 3604.06 & 1.0167 & 1.0167 & 0.8907 \\
\hline & P3/1 & 0 & 3415 & 3386.34 & 3386.34 & 4109.22 & 1.0085 & 1.0085 & 0.8311 \\
\hline & P3/2 & 0 & 3750 & 3386.34 & 3386.34 & 4109.22 & 1.1074 & 1.1074 & 0.9126 \\
\hline & P3/3 & 0 & 3230 & 3386.34 & 3386.34 & 4109.22 & 0.9538 & 0.9538 & 0.7860 \\
\hline & P4/1 & 0 & 3000 & 2930.57 & 2930.57 & 3558.59 & 1.0237 & 1.0237 & 0.8430 \\
\hline & P4/2 & 0 & 2650 & 2930.57 & 2930.57 & 3558.59 & 0.9043 & 0.9043 & 0.7447 \\
\hline & $P 4 / 3$ & 0 & 2610 & 2930.57 & 2930.57 & 3558.59 & 0.8906 & 0.8906 & 0.7334 \\
\hline & P5/1 & 15 & 2842 & 2424.25 & 2450.19 & 2258.11 & 1.1723 & 1.1599 & 1.2586 \\
\hline & P5/2 & 15 & 2806 & 2383.20 & 2408.66 & 2219.46 & 1.1774 & 1.1650 & 1.2643 \\
\hline & $\mathrm{P} 6 / 1$ & 15 & 3227 & 2750.08 & 2778.60 & 2973.69 & 1.1734 & 1.1614 & 1.0852 \\
\hline & $\mathrm{P} 6 / 2$ & 15 & 3218 & 2698.66 & 2726.59 & 2917.33 & 1.1924 & 1.1802 & 1.1031 \\
\hline & P7/1 & 15 & 3012 & 2432.54 & 2459.67 & 2277.69 & 1.2382 & 1.2246 & 1.3224 \\
\hline & P7/2 & 15 & 3118 & 2492.08 & 2520.83 & 2343.02 & 1.2512 & 1.2369 & 1.3308 \\
\hline & P8/1 & 25 & 3252 & 2126.21 & 2184.07 & 2398.16 & 1.5295 & 1.4890 & 1.3560 \\
\hline & P8/2 & 25 & 3250 & 2152.34 & 2214.89 & 1971.18 & 1.5100 & 1.4673 & 1.6488 \\
\hline & $\mathrm{Pg} / 1$ & 30 & 2388 & 894.02 & 961.22 & 1674.92 & 2.6711 & 2.4843 & 1.4257 \\
\hline & $\mathrm{P} 9 / 2$ & 30 & 2143 & 759.03 & 825.84 & 1399.62 & 2.8233 & 2.5949 & 1.5311 \\
\hline
\end{tabular}


TABEla 5.2 - ERro doS MOdelos de PILARES E PARÂMETROS VARIÁVEIS (CONTINUAÇÃO)

\begin{tabular}{|c|c|c|c|c|c|c|c|c|c|}
\hline \multirow{3}{*}{ FONTE } & \multirow{3}{*}{ PILAR } & \multicolumn{2}{|c|}{ EXPERIMENTAL } & \multicolumn{3}{|c|}{ TEÓRICO } & \multicolumn{3}{|c|}{ ERRO DE MODELO } \\
\hline & & \multirow{2}{*}{$\frac{\mathrm{e}_{\mathrm{i}}}{\mathrm{mm}}$} & \multirow{2}{*}{$\frac{N_{\exp }}{k N}$} & \multirow{2}{*}{$\frac{\mathrm{N}_{\mathrm{NBR}-\mathrm{K}}}{\mathrm{kN}}$} & \multirow{2}{*}{$\frac{N_{N B R-C}}{k N}$} & \multirow{2}{*}{$\frac{N_{A C l}}{k N}$} & \multicolumn{2}{|c|}{ ABNT NBR 6118} & \multirow{2}{*}{$\mathrm{ACl} 318$} \\
\hline & & & & & & & rigidez & curvatura & \\
\hline \multirow{8}{*}{ 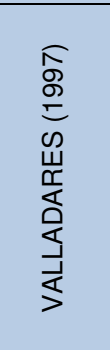 } & BR-PE01 & 50 & 338 & 340.16 & 340.16 & 303.95 & 0.9936 & 0.9936 & 1.1120 \\
\hline & BR-PE02 & 50 & 320 & 344.32 & 344.32 & 307.71 & 0.9294 & 0.9294 & 1.0399 \\
\hline & MR-PE01 & 50 & 527 & 577.02 & 577.02 & 498.18 & 0.9133 & 0.9133 & 1.0579 \\
\hline & MR-PE01 & 50 & 460 & 592.09 & 592.09 & 511.31 & 0.7769 & 0.7769 & 0.8997 \\
\hline & AR-PE01 & 50 & 604 & 634.76 & 634.76 & 541.17 & 0.9515 & 0.9515 & 1.1161 \\
\hline & AR-PE02 & 50 & 501 & 713.97 & 713.97 & 609.60 & 0.7017 & 0.7017 & 0.8218 \\
\hline & AR-PE03 & 50 & 527 & 755.26 & 755.26 & 645.34 & 0.6978 & 0.6978 & 0.8166 \\
\hline & AR-PE04 & 50 & 457 & 738.14 & 738.14 & 630.52 & 0.6191 & 0.6191 & 0.7248 \\
\hline \multirow{6}{*}{ 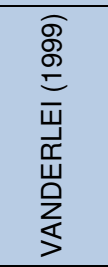 } & P1/1R & 380 & 3157 & 2237.57 & 2237.57 & 1626.06 & 1.4109 & 1.4109 & 1.9415 \\
\hline & $\mathrm{P} 1 / 2$ & 380 & 2825.8 & 2166.77 & 2166.77 & 1577.62 & 1.3042 & 1.3042 & 1.7912 \\
\hline & $\mathrm{P} 1 / 3$ & 380 & 2967.8 & 2099.03 & 2099.03 & 1529.56 & 1.4139 & 1.4139 & 1.9403 \\
\hline & $\mathrm{P} 2 / 1$ & 380 & 2788.9 & 2189.32 & 2189.32 & 1580.94 & 1.2739 & 1.2739 & 1.7641 \\
\hline & $\mathrm{P} 2 / 2$ & 380 & 2902.2 & 2179.21 & 2179.21 & 1576.73 & 1.3318 & 1.3318 & 1.8406 \\
\hline & P3/1 & 380 & 3307.6 & 2443.91 & 2443.91 & 1793.58 & 1.3534 & 1.3534 & 1.8441 \\
\hline \multirow{12}{*}{ 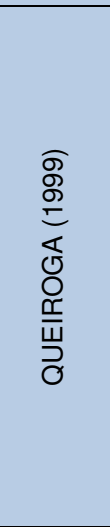 } & P1 & 0 & 2278 & 2132.59 & 2132.59 & 2417.41 & 1.0682 & 1.0682 & 0.9423 \\
\hline & P2 & 0 & 2292 & 2275.59 & 2275.59 & 2578.81 & 1.0072 & 1.0072 & 0.8888 \\
\hline & P3 & 0 & 1835 & 1945.85 & 1945.85 & 2206.75 & 0.9430 & 0.9430 & 0.8315 \\
\hline & P4 & 0 & 1864 & 1945.85 & 1945.85 & 2206.75 & 0.9579 & 0.9579 & 0.8447 \\
\hline & P5 & 0 & 2158 & 2021.16 & 2021.16 & 2291.69 & 1.0677 & 1.0677 & 0.9417 \\
\hline & P6 & 0 & 2312 & 2057.08 & 2057.08 & 2311.36 & 1.1239 & 1.1239 & 1.0003 \\
\hline & P7 & 0 & 2373 & 2441.72 & 2441.72 & 2948.43 & 0.9719 & 0.9719 & 0.8048 \\
\hline & P8 & 0 & 2496 & 2441.72 & 2441.72 & 2948.43 & 1.0222 & 1.0222 & 0.8466 \\
\hline & P9 & 0 & 2446 & 2346.19 & 2346.19 & 2832.96 & 1.0425 & 1.0425 & 0.8634 \\
\hline & P10 & 0 & 2440 & 2346.19 & 2346.19 & 2832.96 & 1.0400 & 1.0400 & 0.8613 \\
\hline & P11 & 0 & 2288 & 2396.49 & 2396.49 & 2893.75 & 0.9547 & 0.9547 & 0.7907 \\
\hline & P12 & 0 & 2497 & 2396.49 & 2396.49 & 2893.75 & 1.0419 & 1.0419 & 0.8629 \\
\hline \multirow{16}{*}{ 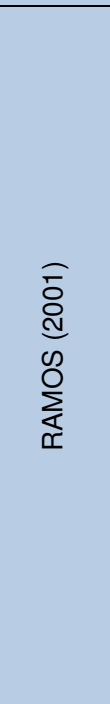 } & $P 1-10,0-120$ & 0 & 1072 & 903.10 & 903.10 & 1003.50 & 1.1870 & 1.1870 & 1.0683 \\
\hline & $P 1-12,5-200$ & 0 & 1085 & 970.50 & 970.50 & 1077.27 & 1.1180 & 1.1180 & 1.0072 \\
\hline & $P 1-12,5-150$ & 0 & 1223 & 1079.45 & 1079.45 & 1199.72 & 1.1330 & 1.1330 & 1.0194 \\
\hline & P1-12,5-100 & 0 & 1292 & 1079.45 & 1079.45 & 1199.72 & 1.1969 & 1.1969 & 1.0769 \\
\hline & P2-10,0-120 & 0 & 1325 & 951.94 & 951.94 & 1121.12 & 1.3919 & 1.3919 & 1.1819 \\
\hline & $P 2-12,5-150$ & 0 & 1400 & 1048.93 & 1048.93 & 1226.40 & 1.3347 & 1.3347 & 1.1416 \\
\hline & $P 2-12,5-100$ & 0 & 1175 & 1080.73 & 1080.73 & 1264.57 & 1.0872 & 1.0872 & 0.9292 \\
\hline & P2-12,5-75 & 0 & 1215 & 1080.73 & 1080.73 & 1264.57 & 1.1242 & 1.1242 & 0.9608 \\
\hline & P3-10,0-120 & 0 & 1265 & 1078.65 & 1078.65 & 1273.99 & 1.1728 & 1.1728 & 0.9929 \\
\hline & P3-12,5-150 & 0 & 1322 & 1176.06 & 1176.06 & 1379.13 & 1.1241 & 1.1241 & 0.9586 \\
\hline & P3-12,5-100 & 0 & 1468 & 1068.01 & 1068.01 & 1249.30 & 1.3745 & 1.3745 & 1.1751 \\
\hline & P3-12,5-75 & 0 & 1485 & 1068.01 & 1068.01 & 1249.30 & 1.3904 & 1.3904 & 1.1887 \\
\hline & $P 4-10,0-120$ & 0 & 1238 & 945.60 & 945.60 & 1113.47 & 1.3092 & 1.3092 & 1.1118 \\
\hline & $P 4-12,5-150$ & 0 & 1340 & 1042.57 & 1042.57 & 1218.76 & 1.2853 & 1.2853 & 1.0995 \\
\hline & $P 4-12,5-100$ & 0 & 1355 & 1055.29 & 1055.29 & 1234.03 & 1.2840 & 1.2840 & 1.0980 \\
\hline & P4-12,5-75 & 0 & 1365 & 1055.29 & 1055.29 & 1234.03 & 1.2935 & 1.2935 & 1.1061 \\
\hline \multirow{10}{*}{ 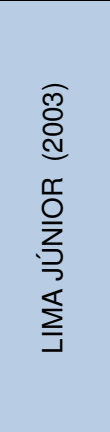 } & P1-40-15 & 0 & 983.3 & 908.39 & 908.39 & 1059.88 & 1.0825 & 1.0825 & 0.9277 \\
\hline & P2-40-15 & 0 & 1015.7 & 908.39 & 908.39 & 1059.88 & 1.1181 & 1.1181 & 0.9583 \\
\hline & P1-60-5 & 0 & 1557.1 & 1287.36 & 1287.36 & 1525.78 & 1.2095 & 1.2095 & 1.0205 \\
\hline & P2-60-5 & 0 & 1525 & 1287.36 & 1287.36 & 1525.78 & 1.1846 & 1.1846 & 0.9995 \\
\hline & P1-60-15 & 0 & 1479.7 & 1287.36 & 1287.36 & 1525.78 & 1.1494 & 1.1494 & 0.9698 \\
\hline & P2-60-15 & 0 & 1438.3 & 1287.36 & 1287.36 & 1525.78 & 1.1172 & 1.1172 & 0.9427 \\
\hline & $P 1-80-5$ & 0 & 1853.1 & 1773.38 & 1773.38 & 2112.00 & 1.0450 & 1.0450 & 0.8774 \\
\hline & P2-80-5 & 0 & 1890.8 & 1773.38 & 1773.38 & 2112.00 & 1.0662 & 1.0662 & 0.8953 \\
\hline & P1-80-15 & 0 & 1881.5 & 1773.38 & 1773.38 & 2112.00 & 1.0610 & 1.0610 & 0.8909 \\
\hline & P2-80-15 & 0 & 1923.8 & 1773.38 & 1773.38 & 2112.00 & 1.0848 & 1.0848 & 0.9109 \\
\hline
\end{tabular}


TABEla 5.2 - ERro doS MOdElos De PILARES E PARÂMETROS VARIÁVEIS (CONTINUAÇÃo)

\begin{tabular}{|c|c|c|c|c|c|c|c|c|c|}
\hline \multirow{3}{*}{ FONTE } & \multirow{3}{*}{ PILAR } & \multicolumn{2}{|c|}{ EXPERIMENTAL } & \multicolumn{3}{|c|}{ TEÓRICO } & \multicolumn{3}{|c|}{ ERRO DE MODELO } \\
\hline & & \multirow{2}{*}{$\begin{array}{c}e_{i} \\
m m\end{array}$} & \multirow{2}{*}{$\begin{array}{c}N_{\text {exp }} \\
k N\end{array}$} & \multirow{2}{*}{$\frac{\mathrm{N}_{\mathrm{NBR}-\mathrm{K}}}{\mathrm{kN}}$} & \multirow{2}{*}{$\frac{N_{\text {NBR-C }}}{k N}$} & \multirow{2}{*}{$\frac{N_{A C l}}{k N}$} & \multicolumn{2}{|c|}{ ABNT NBR 6118} & \multirow{2}{*}{$\mathrm{ACl} 318$} \\
\hline & & & & & & & rigidez & curvatura & \\
\hline \multirow{9}{*}{ 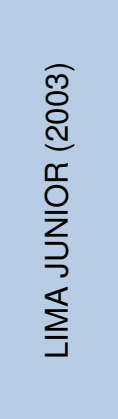 } & P1-40 & 10 & 823 & 729.52 & 727.35 & 659.64 & 1.1281 & 1.1315 & 1.2476 \\
\hline & P2-40 & 20 & 653 & 710.81 & 721.43 & 655.77 & 0.9187 & 0.9051 & 0.9958 \\
\hline & P3-40 & 30 & 500 & 599.87 & 612.95 & 523.18 & 0.8335 & 0.8157 & 0.9557 \\
\hline & $\mathrm{P} 1-60-15$ & 10 & 1053 & 1091.46 & 1088.00 & 984.74 & 0.9648 & 0.9678 & 1.0693 \\
\hline & P2-60-15 & 20 & 875 & 1061.52 & 1078.53 & 978.14 & 0.8243 & 0.8113 & 0.8946 \\
\hline & P3-60-15 & 30 & 722 & 882.31 & 903.55 & 748.50 & 0.8183 & 0.7991 & 0.9646 \\
\hline & P1-60-5 & 10 & 1087 & 1039.67 & 1036.40 & 937.44 & 1.0455 & 1.0488 & 1.1595 \\
\hline & P2-60-5 & 20 & 859 & 1011.37 & 1027.45 & 931.20 & 0.8493 & 0.8361 & 0.9225 \\
\hline & P3-60-5 & 30 & 685 & 842.18 & 862.21 & 714.25 & 0.8134 & 0.7945 & 0.9590 \\
\hline \multirow{16}{*}{ 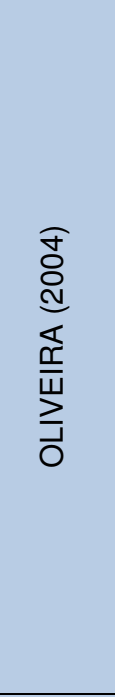 } & $\mathrm{P} 1-10,0-120$ & 0 & 1732.4 & 1551.96 & 1551.96 & 1741.68 & 1.1163 & 1.1163 & 0.9947 \\
\hline & P1-12,5-200 & 0 & 1810.6 & 1621.21 & 1621.21 & 1824.05 & 1.1168 & 1.1168 & 0.9926 \\
\hline & $\mathrm{P} 1-12,5-150$ & 0 & 1939.1 & 1621.51 & 1621.51 & 1824.39 & 1.1959 & 1.1959 & 1.0629 \\
\hline & $\mathrm{P} 1-12,5-100$ & 0 & 1880.1 & 1548.85 & 1548.85 & 1742.40 & 1.2139 & 1.2139 & 1.0790 \\
\hline & P2-10,0-120 & 0 & 2022.7 & 1665.35 & 1665.35 & 1987.26 & 1.2146 & 1.2146 & 1.0178 \\
\hline & P2-12,5-150 & 0 & 2335.1 & 1737.10 & 1737.10 & 2079.14 & 1.3442 & 1.3442 & 1.1231 \\
\hline & P2-12,5-100 & 0 & 1985.5 & 1679.06 & 1679.06 & 2009.18 & 1.1825 & 1.1825 & 0.9882 \\
\hline & P2-12,5-075 & 0 & 2099 & 1675.58 & 1675.58 & 2004.98 & 1.2527 & 1.2527 & 1.0469 \\
\hline & P3-10,0-120 & 0 & 2054.6 & 1665.35 & 1665.35 & 1987.26 & 1.2337 & 1.2337 & 1.0339 \\
\hline & P3-12,5-150 & 0 & 2266.5 & 1737.10 & 1737.10 & 2079.14 & 1.3048 & 1.3048 & 1.0901 \\
\hline & P3-12,5-100 & 0 & 2283.2 & 1686.36 & 1686.36 & 2017.98 & 1.3539 & 1.3539 & 1.1314 \\
\hline & P3-12,5-075 & 0 & 2159.3 & 1659.08 & 1659.08 & 1985.10 & 1.3015 & 1.3015 & 1.0878 \\
\hline & P4-10,0-120 & 0 & 1951.9 & 1665.35 & 1665.35 & 1987.26 & 1.1721 & 1.1721 & 0.9822 \\
\hline & P4-12,5-150 & 0 & 2295.7 & 1737.10 & 1737.10 & 2079.14 & 1.3216 & 1.3216 & 1.1042 \\
\hline & P4-12,5-100 & 0 & 2084.9 & 1673.67 & 1673.67 & 2002.69 & 1.2457 & 1.2457 & 1.0411 \\
\hline & P4-12,5-075 & 0 & 2042.4 & 1659.08 & 1659.08 & 1985.10 & 1.2310 & 1.2310 & 1.0289 \\
\hline \multirow{10}{*}{ 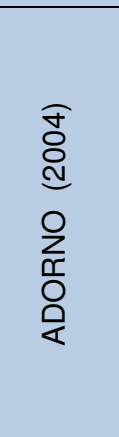 } & PSA-15a & 15 & 677 & 563.21 & 585.54 & 605.90 & 1.2020 & 1.1562 & 1.1173 \\
\hline & PSA-15b & 15 & 653 & 733.23 & 762.30 & 788.82 & 0.8906 & 0.8566 & 0.8278 \\
\hline & PSA-20 & 20 & 389 & 642.09 & 679.59 & 703.12 & 0.6058 & 0.5724 & 0.5532 \\
\hline & PSA-30 & 30 & 303 & 376.24 & 423.94 & 386.33 & 0.8053 & 0.7147 & 0.7843 \\
\hline & PCA4-15a & 15 & 553 & 579.76 & 599.23 & 611.26 & 0.9538 & 0.9228 & 0.9047 \\
\hline & PCA4-15b & 15 & 566 & 598.46 & 618.63 & 631.27 & 0.9458 & 0.9149 & 0.8966 \\
\hline & PCA4-20 & 20 & 460 & 573.20 & 599.89 & 608.81 & 0.8025 & 0.7668 & 0.7556 \\
\hline & PCA4-25 & 25 & 360 & 506.61 & 533.38 & 509.89 & 0.7106 & 0.6749 & 0.7060 \\
\hline & PCA4-30a & 30 & 291 & 425.86 & 448.67 & 404.30 & 0.6833 & 0.6486 & 0.7198 \\
\hline & PCA4-30b & 30 & 298 & 432.93 & 456.21 & 411.13 & 0.6883 & 0.6532 & 0.7248 \\
\hline \multirow{3}{*}{$\begin{array}{l}\text { बे } \\
\text { Q }\end{array}$} & PCA4-40 & 40 & 277 & 369.57 & 388.32 & 323.03 & 0.7495 & 0.7133 & 0.8575 \\
\hline & PCA4-50 & 50 & 217 & 318.48 & 327.74 & 272.54 & 0.6814 & 0.6621 & 0.7962 \\
\hline & PCA4-60 & 60 & 210 & 287.46 & 294.13 & 239.23 & 0.7305 & 0.7140 & 0.8778 \\
\hline \multirow{3}{*}{ 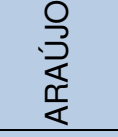 } & PCA6-40 & 40 & 320 & 381.20 & 398.89 & 327.60 & 0.8395 & 0.8022 & 0.9768 \\
\hline & PCA6-50 & 50 & 280 & 316.98 & 330.13 & 257.07 & 0.8833 & 0.8482 & 1.0892 \\
\hline & PCA6-60 & 60 & 210 & 280.75 & 286.91 & 233.72 & 0.7480 & 0.7319 & 0.8985 \\
\hline \multirow{6}{*}{ 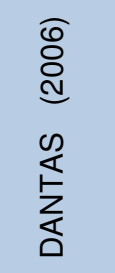 } & PFN 00-3 & 0 & 1053 & 587.90 & 378.42 & 722.99 & 1.7911 & 2.7826 & 1.4565 \\
\hline & PFN 15-3 & 15 & 447 & 354.49 & 378.42 & 722.99 & 1.2610 & 1.1812 & 0.6183 \\
\hline & PFN 30-3 & 30 & 255 & 265.36 & 288.26 & 368.36 & 0.9610 & 0.8846 & 0.6923 \\
\hline & PFN 40-3 & 40 & 170 & 225.54 & 243.90 & 272.80 & 0.7537 & 0.6970 & 0.6232 \\
\hline & PFN 50-3 & 50 & 155 & 212.93 & 227.44 & 232.38 & 0.7279 & 0.6815 & 0.6670 \\
\hline & PFN 60-3 & 60 & 131 & 198.69 & 206.37 & 191.49 & 0.6593 & 0.6348 & 0.6841 \\
\hline
\end{tabular}


TABELA 5.2- ERRo dOS MODELOS DE PILARES E PARÂMETROS VARIÁVEIS (CONTINUAÇÃO)

\begin{tabular}{|c|c|c|c|c|c|c|c|c|c|}
\hline \multirow{3}{*}{ FONTE } & \multirow{3}{*}{ PILAR } & \multicolumn{2}{|c|}{ EXPERIMENTAL } & \multicolumn{3}{|c|}{ TEÓRICO } & \multicolumn{3}{|c|}{ ERRO DE MODELO } \\
\hline & & \multirow{2}{*}{$\frac{e_{i}}{m m}$} & \multirow{2}{*}{$\frac{N_{\text {exp }}}{k N}$} & \multirow{2}{*}{$\frac{N_{N B R-K}}{k N}$} & \multirow{2}{*}{$\frac{N_{N B R-C}}{k N}$} & \multirow{2}{*}{$\frac{N_{A C l}}{k N}$} & \multicolumn{2}{|c|}{ ABNT NBR 6118} & \multirow{2}{*}{$\mathrm{ACl} 318$} \\
\hline & & & & & & & rigidez & curvatura & \\
\hline \multirow{14}{*}{ 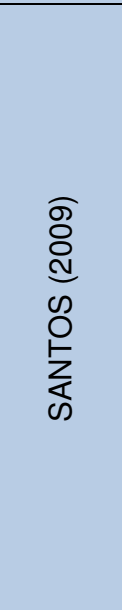 } & PFN 00-2 & 0 & 1255 & 1017.40 & 746.99 & 899.79 & 1.2335 & 1.6801 & 1.3948 \\
\hline & PFN 15-2 & 15 & 662 & 623.29 & 641.16 & 625.94 & 1.0621 & 1.0325 & 1.0576 \\
\hline & PFN 24-2 & 24 & 456 & 610.13 & 637.68 & 590.87 & 0.7474 & 0.7151 & 0.7717 \\
\hline & PFN 30-2 & 30 & 317 & 434.21 & 453.84 & 393.43 & 0.7301 & 0.6985 & 0.8057 \\
\hline & PFN 40-2 & 40 & 294.4 & 344.99 & 359.50 & 288.73 & 0.8534 & 0.8189 & 1.0196 \\
\hline & PFN 50-2 & 50 & 232 & 285.59 & 296.31 & 247.32 & 0.8124 & 0.7830 & 0.9380 \\
\hline & PFN 60-2 & 60 & 198.4 & 249.78 & 258.16 & 218.98 & 0.7943 & 0.7685 & 0.9060 \\
\hline & PFN 00-2,5 & 0 & 1078 & 1017.40 & 595.80 & 899.79 & 1.0596 & 1.8093 & 1.1981 \\
\hline & PFN 15-2,5 & 15 & 670.4 & 538.41 & 565.49 & 852.52 & 1.2451 & 1.1855 & 0.7864 \\
\hline & PFN 24-2,5 & 24 & 360.8 & 481.47 & 515.33 & 590.87 & 0.7494 & 0.7001 & 0.6106 \\
\hline & PFN 30-2,5 & 30 & 336 & 385.58 & 412.24 & 431.70 & 0.8714 & 0.8151 & 0.7783 \\
\hline & PFN 40-2,5 & 40 & 246 & 315.59 & 335.79 & 314.86 & 0.7795 & 0.7326 & 0.7813 \\
\hline & PFN 50-2,5 & 50 & 201.2 & 267.38 & 282.82 & 246.50 & 0.7525 & 0.7114 & 0.8162 \\
\hline & PFN 60-2,5 & 60 & 164.8 & 247.28 & 254.93 & 217.05 & 0.6665 & 0.6464 & 0.7593 \\
\hline & & & & & & Mèc & 1.193 & 1.195 & 0.995 \\
\hline & & & & & es & Padrão & 0.323 & 0.341 & 0.230 \\
\hline
\end{tabular}

\subsection{DISTRIBUIÇõES DE PROBABILIDADE PARA AS VARIÁVEIS} ALEATÓRIAS ERRO DE MODELO

Obtidas as amostras da variável aleatória erro de modelo, foram construídos histogramas buscando aqueles que melhor ajustam-se às variáveis, de maneira que a informação estatística sobre o modelo possa ser processada através de curvas de distribuição estatística e, posteriormente, fazer um estudo de confiabilidade dos modelos.

Apresentam-se a seguir as figuras que ilustram os ajustes de distribuição estatística para o erro de modelo foram realizados pelo software EasyFit 5.2 Standard com base em testes de aderência consagrados pela teoria de probabilidades, Chi-Quadrado, Kolmogorov-Smirnov e Anderson-Darling.

Nenhuma curva padronizada de distribuição estatística se ajustou adequadamente ao modelo de vigas solicitadas à flexão pura. Sugere-se que, futuramente, análises adicionais sejam feitas para investigar o motivação de tal inadequação. No entanto, o motivo provável deve-se à extrapolação baseada no uso dados estatísticos de erro de modelo proveniente de NOWAK e SZERSZEN (2003), feita para que fosse computado o erro de modelo para o modelo da norma brasileira. E como os modelos das normas brasileira e americana e brasileira são muito parecidos, a variável dada pela razão $\mathrm{F}_{\text {teo }}^{\mathrm{ACl}} / \mathrm{F}_{\text {teo }}^{\mathrm{NBR}}$, aproxima-se em média da unidade com pequena dispersão. Na Figura 5.1, são apresentadas as curvas de 
distribuição de probabilidade para a variável $\mathrm{F}_{\text {teo }}^{\mathrm{ACl}} / \mathrm{F}_{\text {teo }}^{\mathrm{NBR}}$, a variável erro de modelo para norma brasileira seria obtida através da equação (5.3)

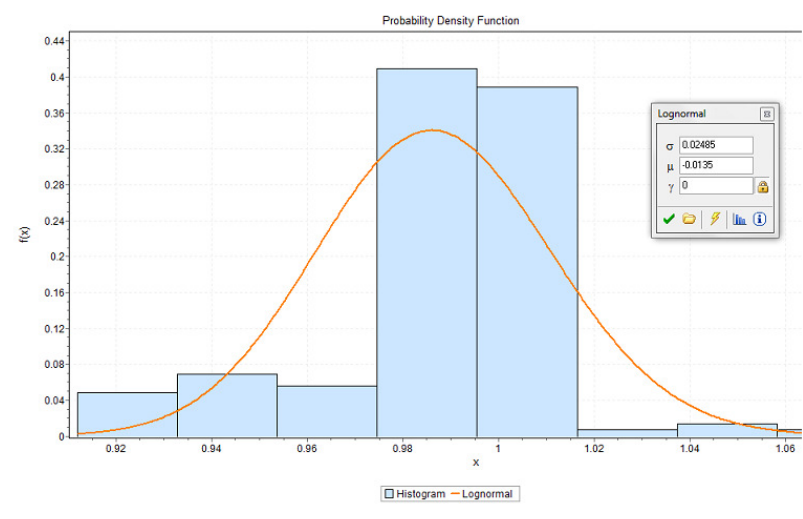

(A)

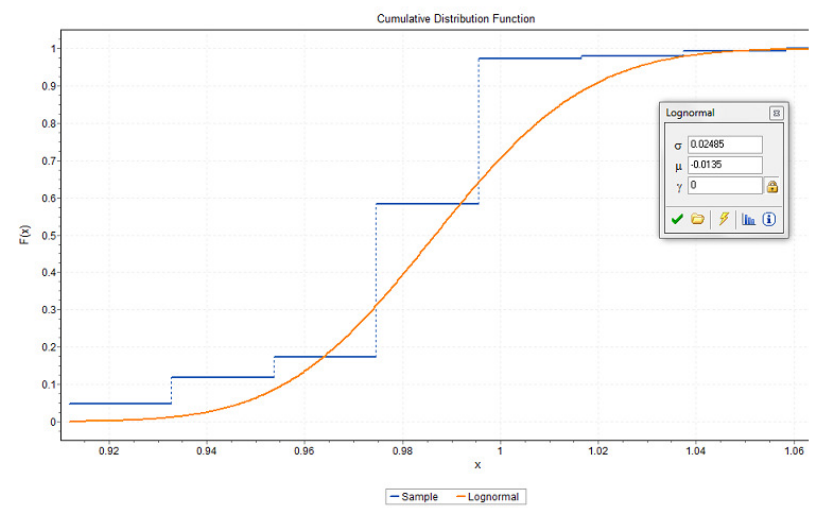

(B)

FIGURA 5.1 - VARIÁVEL ERRO DO MODELO ABNT NBR 6118:2007 PARA VIGAS - (A) HISTOGRAMA E DistRibuIÇão DE DENSIDADE DE PROBABILIDADE, (B) DisTRIBUIÇÃo ACUMULADA DE PROBABILIDADE

Os histogramas para as amostras da variável erro de modelo foram ajustados por curvas de distribuição lognormal, para um estudo de confiabilidade mais apurado deverá se estudar mais detalhadamente qual a melhor curva de ajuste para cada modelo.

Nas figuras 5.2, 5.3 e 5.4 são apresentadas os histogramas e as curvas de distribuição de densidade de probabilidade e de distribuição acumulada de probabilidade da variável erro de modelo $E_{m}$ para pilares conforme, respectivamente, os métodos da rigidez aproximada e da curvatura aproximada propostos pela ABNT NBR 6118:2007 e o método proposto pelo ACI 318-2002.

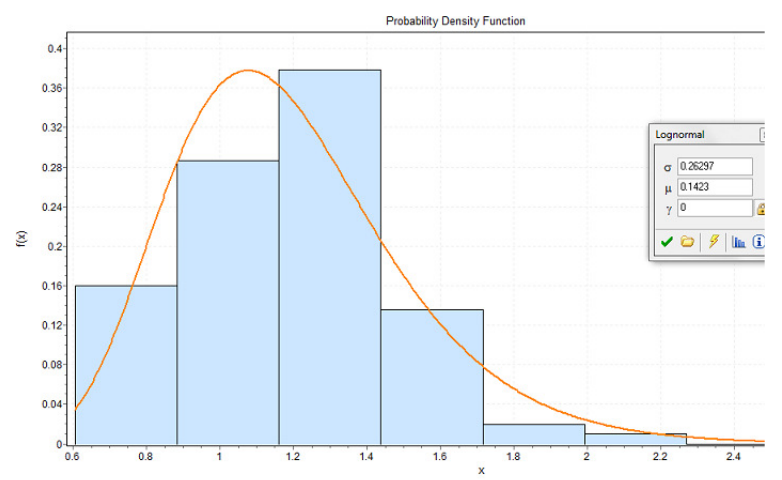

(A)

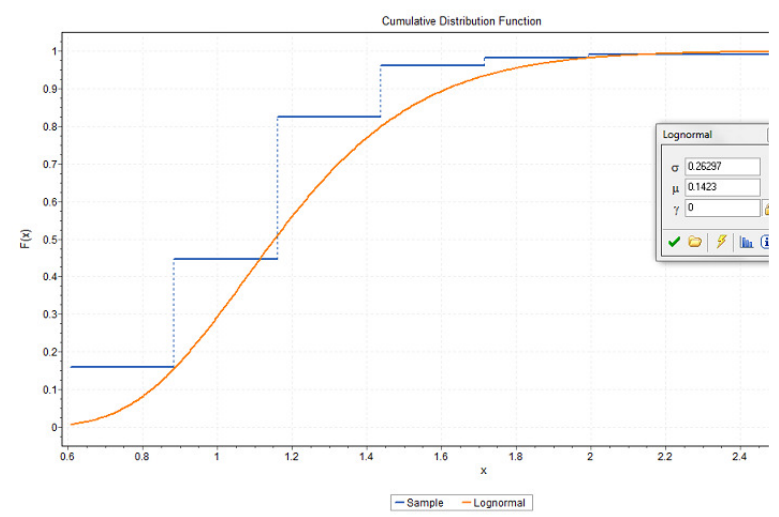

(B)

FIGURA 5.2 - VARIÁVEL ERRO DO MODELO ABNT NBR 6118:2007 PARA PILARES COM RIGIDEZ APROXIMADA - (A) HisTograma E DisTRIBUIÇÃo DE DENSIDADE DE PROBABILIDADE, (B) DisTRIBUIÇÃo ACUMULADA DE PROBABILIDADE 


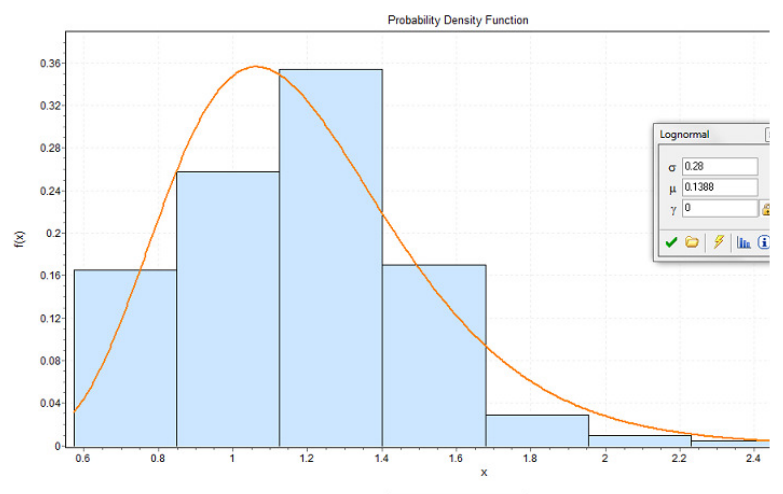

(A)

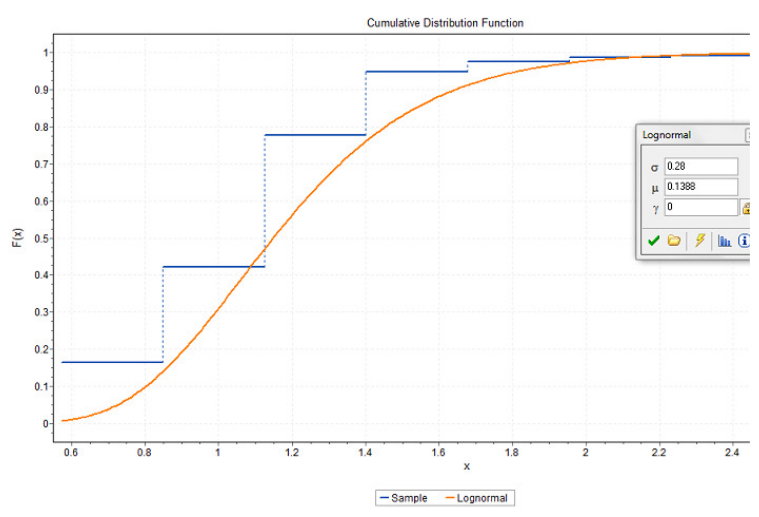

(B)

FIGURA 5.3 - VARIÁVEL ERRO DO MODELO ABNT NBR 6118:2007 PARA PILARES COM CURVATURA APROXIMADA (A) Histograma E DiSTRIBUiÇão DE DENSIDADE DE PROBABILIDADE, (B) DisTRIBUiÇÃo ACUMULADA DE PROBABILIDADE

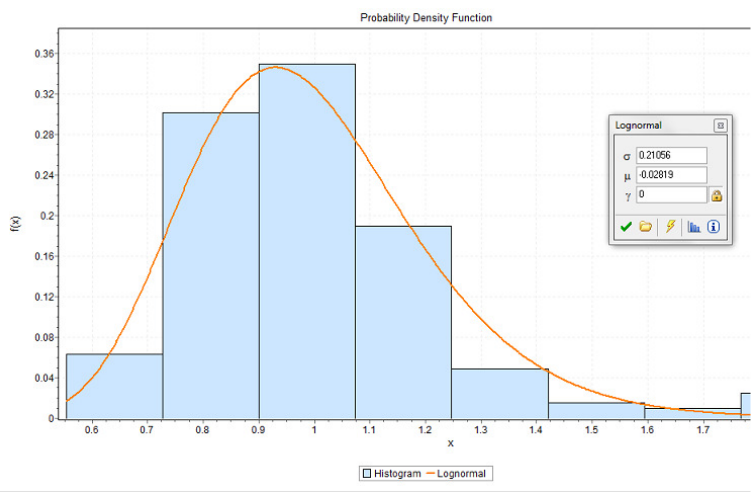

(A)

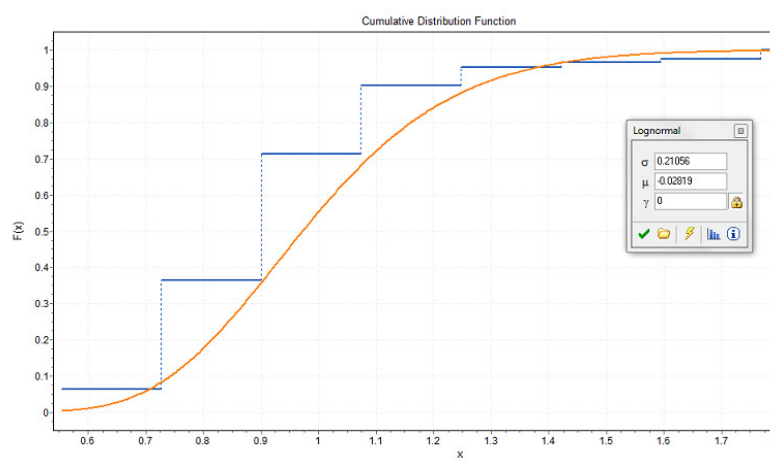

-sample - Lognormal

(B)

FIGURA 5.4 - VARIÁVEL ERRO DO MODELO ACI 318-2002 PARA PILARES - (A) HISTOGRAMA E DisTRIBUIÇÃO DE DENSIDADE DE PROBABILIDADE, (B) DISTRIBUIÇÃo ACUMULADA DE PROBABILIDADE

Para avaliar a necessidade do uso de um modelo distinto para pilares solicitados à compressão centrada, no qual não há consideração de excentricidade mínima devida à imperfeições, separou-se os dados de pilares que foram carregados sem excentricidade inicial dos demais pilares. Para o cálculo da capacidade resistente última foi utilizada equação (3.35).

A tabela abaixo mostra os parâmetros estatísticos, média e desvio padrão, para cada modelo e cada tipo de solicitação.

\begin{tabular}{|c|c|c|c|c|}
\cline { 3 - 5 } \multicolumn{2}{c|}{} & NBR (rigidez) & NBR (curvatura) & ACl \\
\hline compressão & $\mu$ & 0.889 & 0.904 & 1.015 \\
centrada & $\sigma$ & 0.143 & 0.223 & 0.145 \\
\hline flexo- & $\mu$ & 0.999 & 0.969 & 1.030 \\
compressão & $\sigma$ & 0.393 & 0.371 & 0.347 \\
normal & $\mu$ & 1.193 & 1.195 & 0.995 \\
\hline todos & $\sigma$ & 0.323 & 0.341 & 0.230 \\
\hline
\end{tabular}

As Figuras 5.5, 5.6 e 5.7 representam a amostra de erro modelo para pilares solicitados por compressão excêntrica, e as Figuras 5.8, 5.9 e 5.10, para pilares carregados, inicialmente, 
de forma centrada. Devido a amostra ser pequena, as curvas de distribuição de estatística são pouco representativas. Portanto, outras análises devem ser feitas para que se possa optar ou não por um modelo com a consideração de excentricidade mínima para pilares solicitados, teoricamente, por compressão centrada.

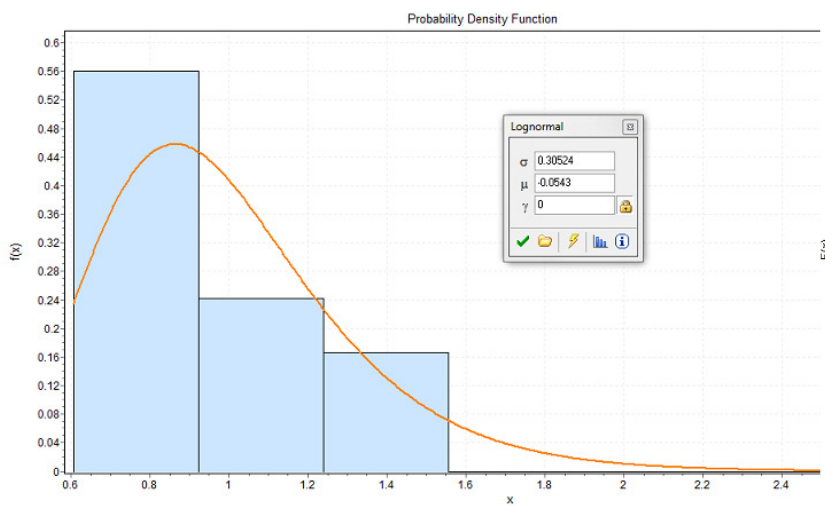

(A)

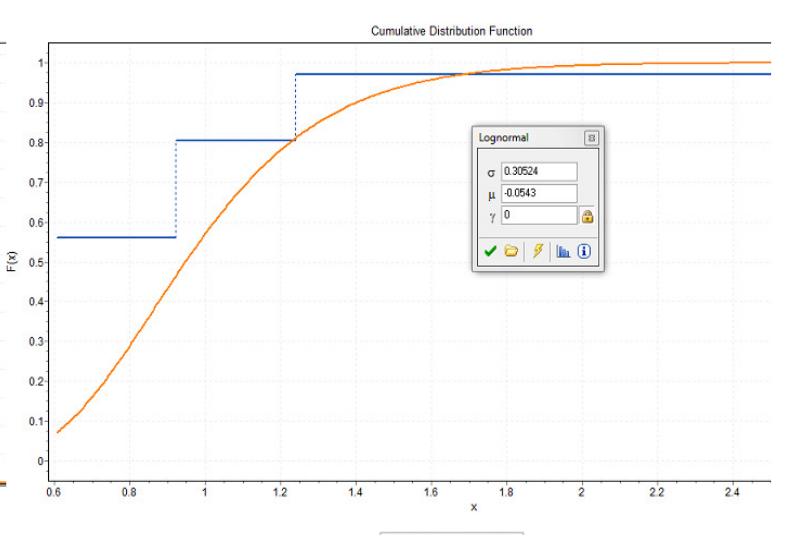

(B)

FIGURA 5.5 - VARIÁVEL ERRO DO MODELO NBR 6118:2007 PARA PILARES SOB COMPRESSÃO EXCÊNTRICA PELO MÉTODO DA RIGIDEZ APROXIMADA - (A) HISTOGRAMA E DisTRIBUIÇÃO DE DENSIDADE DE PROBABILIDADE, (B) DISTRIBUIÇÃo ACUMULADA DE PROBABILIDADE

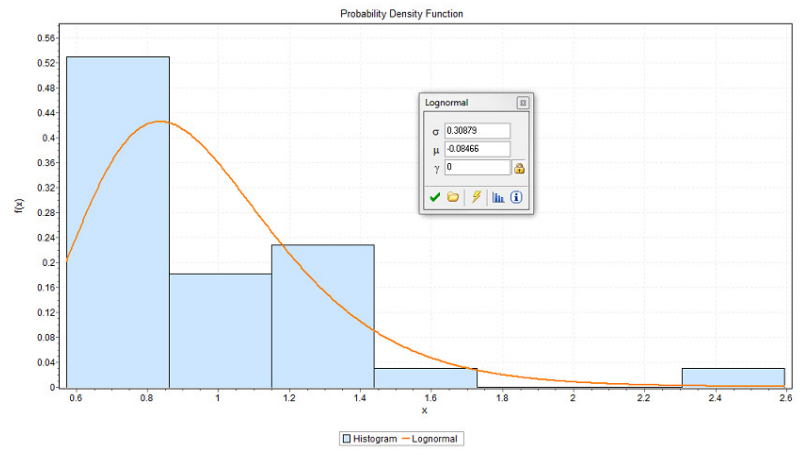

(A)

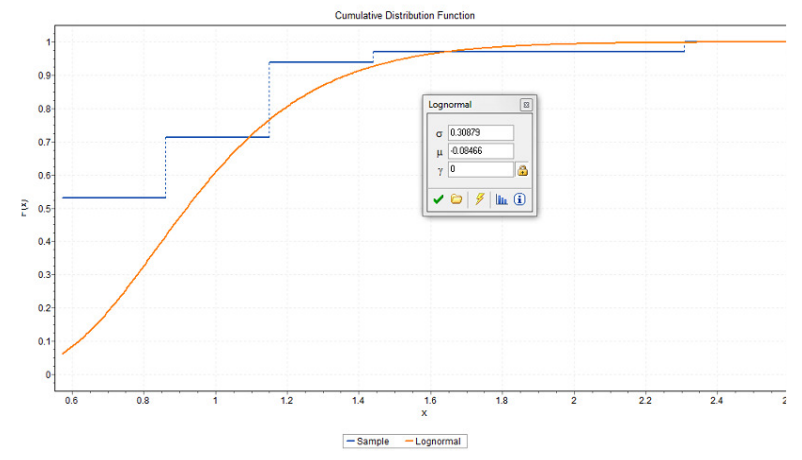

(B)

FIGURA 5.6 - VARIÁVEL ERRO DO MODELO NBR 6118:2007 PARA PILARES SOB COMPRESSÃO EXCÊNTRICA PELO MÉTODO DA CURVATURA APROXIMADA - (A) HISTOGRAMA E DisTRIBUIÇÃO DE DENSIDADE DE PROBABILIDADE, (B) DiSTRIBUIÇÃO ACUMULADA DE PROBABILIDADE

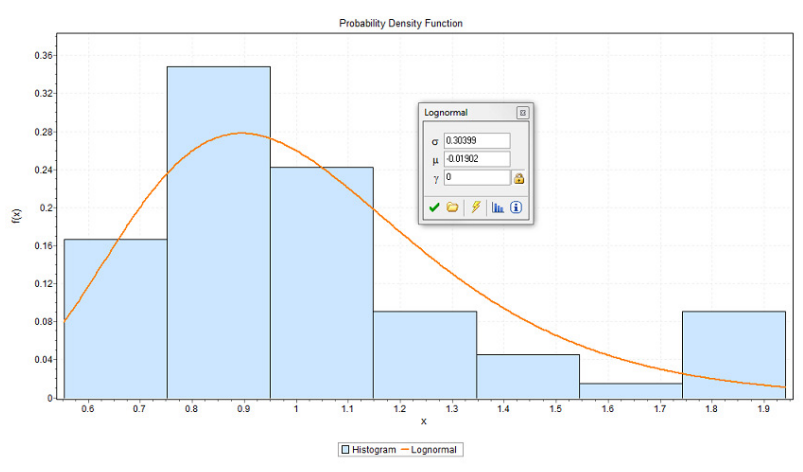

(A)

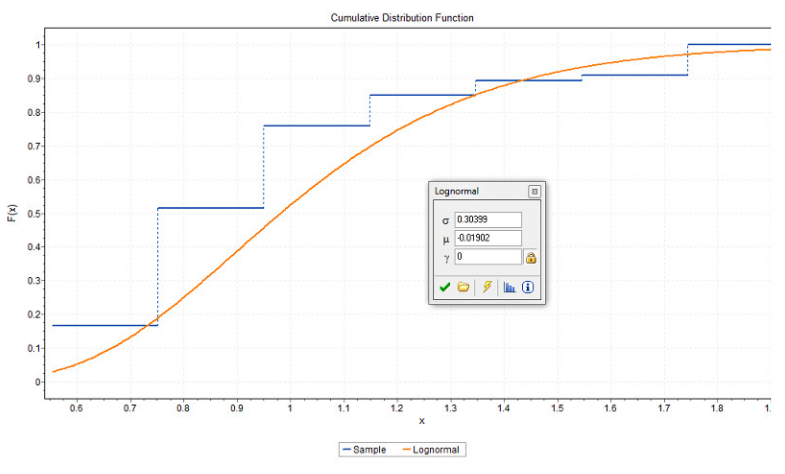

(B)

FIGURA 5.7 - VARIÁVEL ERRO DO MODELO ACI 318-2002 PARA PILARES SOB COMPRESSÃO EXCÊNTRICA PELO MÉTODO DA CURVATURA APROXIMADA - (A) HISTOGRAMA E DisTRIBUIÇÃo DE DENSIDADE DE PROBABILIDADE, (B) DisTRIBUIÇÃo ACUMULADA DE PROBABILIDADE 


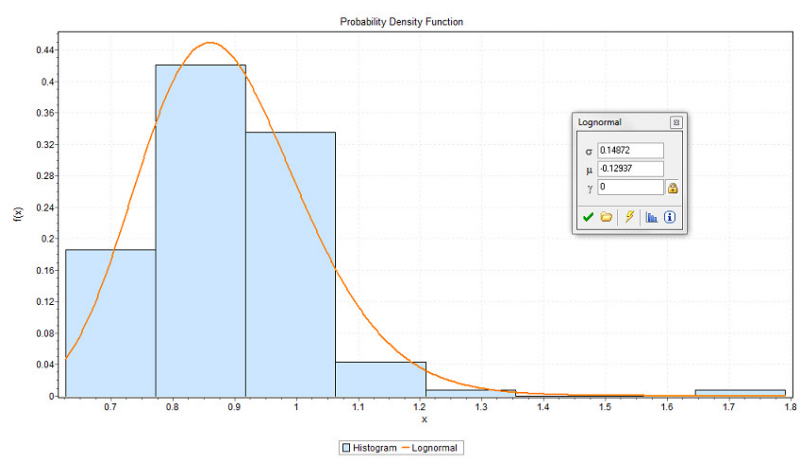

(A)

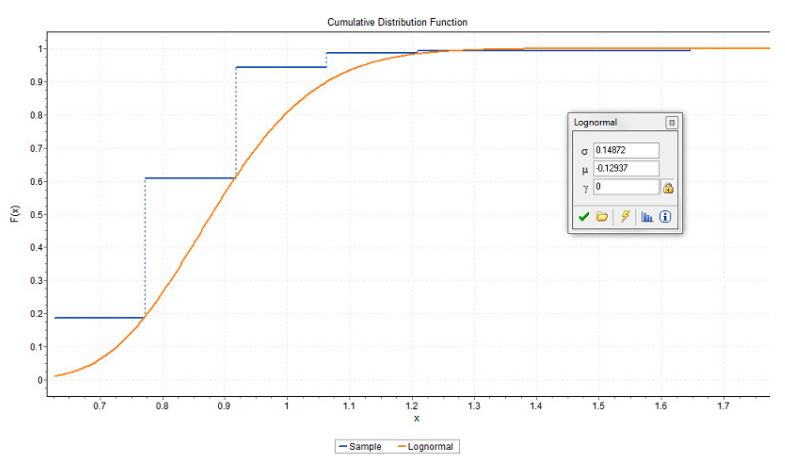

(B)

FIGURA 5.8 - VARIÁVEL ERRO DO MODELO NBR 6118:2007 PARA PILARES SOB COMPRESSÃO CENTRADA PELO MÉTODO DA RIGIDEZ APROXIMADA - (A) HISTOGRAMA E DistRIBUIÇÃo DE DENSIDADE DE PROBABILIDADE, (B) DisTRIBUIÇÃo ACUMULADA DE PROBABILIDADE

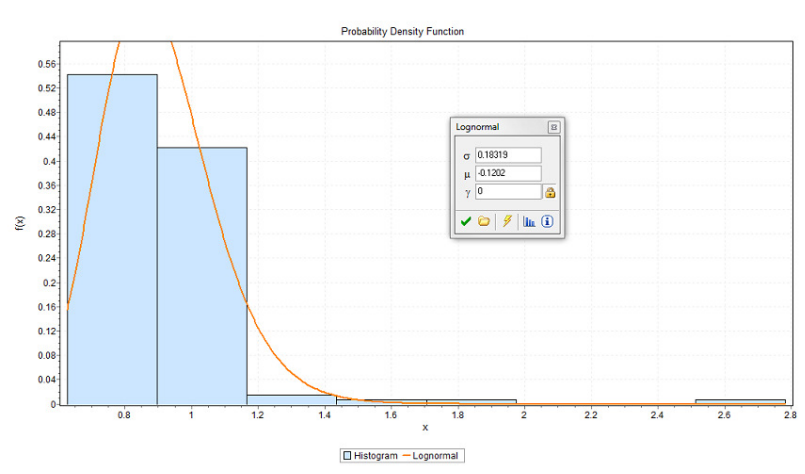

(A)

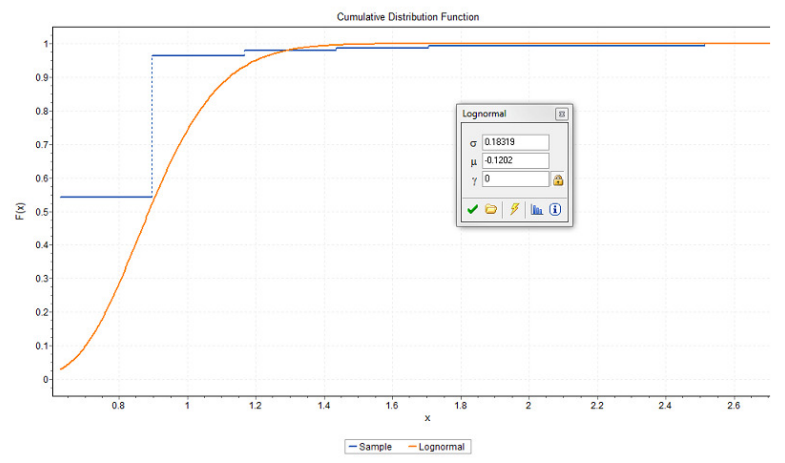

(B)

FIGURA 5.9 - VARIÁVEL ERRO DO MODELO NBR 6118:2007 PARA PILARES SOB COMPRESSÃO CENTRADA PELO MÉTODO DA CURVATURA APROXIMADA - (A) HISTOGRAMA E DistRibuIÇÃo DE DENSIDADE DE PROBABILIDADE, (B) DisTRIBUIÇÃo ACUMULADA DE PROBABILIDADE

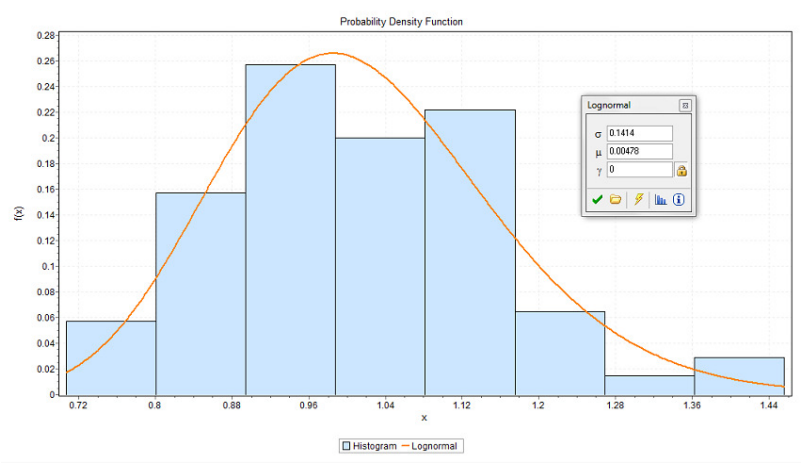

(A)

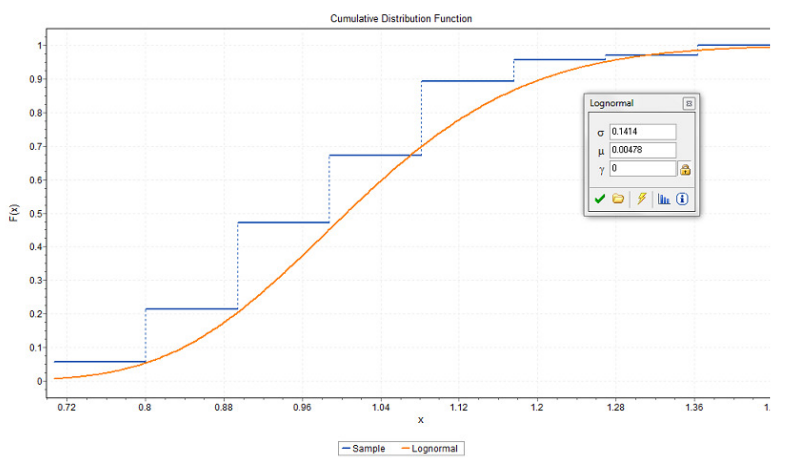

(B)

FIGURA 5.10 - VARIÁVEL ERRO DO MODELO ACI 318-2002 PARA PILARES SOB COMPRESSÃO CENTRADA - (A) HISTOGRAMA E DISTRIBUIÇÃO DE DENSIDADE DE PROBABILIDADE, (B) DISTRIBUIÇÃO ACUMULADA DE PROBABILIDADE 
Avaliação estatística do erro de modelos de resistência 


\section{Capítulo 6: ANÁliSE DE RESUltadoS}

Neste capítulo é a apresentada a análise do erro de modelo e da confiabilidade das normas ABNT NBR 6118:2007 e ACI 318-2002 para 206 pilares, 140 solicitados à compressão centrada e 66 à flexo-compressão normal, e 140 vigas dimensionadas à flexão pura.

O estado limite analisado é a resistência última. São avaliados os parâmetros de influência na resistência última para pilares (resistência do concreto, esbeltez, taxa de armadura longitudinal e transversal, e excentricidade de aplicação das cargas) e para vigas (resistência do concreto, altura útil da viga, posição da linha neutra e taxa de armadura longitudinal).

Para melhor avaliação da interferência das solicitações nos modelos de previsão da capacidade resistente dos pilares, fez-se três análises distintas:

- para solicitados à compressão centrada (cc);

- para pilares solicitados à compressão excêntrica (ce);

- modelo único para (todos) os pilares, havendo sempre uma excentricidade mínima na atuação das ações, assim como é sugerido na norma brasileira.

\subsection{ANÁliSE ESTATÍSTICA dA CORRELAÇÃo ENTRE A VARIÁVEL ERRO DE MODELO E OS PARÂMETROS VARIÁVEIS}

$\mathrm{Na}$ maioria dos problemas de engenharia há algum tipo de relação entre duas ou mais variáveis. Para investigar a natureza dessa interação é feita uma análise de regressão, a técnica estatística muito indicada para modelar e investigar a relação entre essas variáveis, seja ela de caráter simples ou múltiplo (MONTGOMERY,D.C.; RUNGER, G.C.; 1999).

Uma regressão linear simples por estimadores de mínimos quadrados para a interseção e inclinação pode ser utilizada para que um modelo analítico simplificado seja construído na tentativa de representar a correlação existente entre as variáveis erro de modelo e os demais parâmetros variáveis.

Segue uma análise, através de regressão linear, da variável erro de modelo, relacionando-a com cada parâmetro variável. 


\subsubsection{RESISTÊNCIA À COMPRESSÃO DO CONCRETO}

A resistência à compressão do concreto, assim como a resistência do aço, são parâmetros primordiais para o cálculo da resistência última de qualquer elemento de concreto armado.

Um fato importante a ser enfatizado sobre a resistência do concreto é que na pesquisa desenvolvida por SANTIAGO (2011) foi verificada a não-conformidade da resistência dos concretos produzidos em concreteiras brasileiras. Uma maneira de avaliar a questão da nãoconformidade da resistência de um concreto é através da reconstrução da sua distribuição normal com base no valor estimado da sua resistência característica $\left(f_{c k, e s t}\right)$ e compará-lo com a resistência característica à compressão do concreto estabelecida pela ABNT NBR 12655:2006:

$$
f_{c k}=f_{c m}-1.65 \cdot \sigma_{d}
$$

onde: $f_{c m}$ é resistência média à compressão e $\sigma_{d}$, o desvio padrão para amostras de concreto com vinte ou mais corpos de prova.

Verificou-se no estudo citado que, para concreto de classes superiores a C30, as curvas de distribuição estatísticas $f_{c k, e s t}$ e $f_{c k}$ não são equivalentes, o que configuram os concretos em não-conformes, e diminui a segurança das estruturas de concreto projetadas segundo a equação (6.1).

No entanto, a não-conformidade dos concretos nacionais não invalidam a presente pesquisa, pois o objetivo desta é a avaliação da erro de modelos de norma para a previsão da capacidade dos elementos estruturais e não a quantificação da influência de cada parâmetro variável isoladamente. Além disso o cálculo da capacidade resistente dos elementos é feito utilizando o valor médio da resistência do concreto.

Na Figura 6.2, apesar das amostras apresentarem-se muito dispersas, pode ser observada uma tendência positiva entre a variáveis $E_{m}$ dos modelos de previsão de carga de compressão última em pilares e a resistência média à compressão do concreto $f_{c}$, ou seja, quanto maior a resistência do concreto mais conservadores apresentam-se os modelos. Demonstrando assim, que os modelos não conseguem prever integralmente a capacidade última dos pilares, principalmente em pilares de alta resistência e solicitados à compressão excêntrica, caso em que a resistência dos elementos é mais subestimada.

No entanto, quando separadas as amostras que foram solicitadas por cargas centradas notase que, nos três modelos normativos, a relação entre as variáveis $E_{m}$ e $f_{c}$ torna-se negativa. 
Para investigar melhor este dados a capacidade última destes elementos foi calculada conforme as equações (3.35) e (3.37) seguindo os requisitos, respectivamente, da ABNT NBR 6118:2007 e do ACI 318-2002. Resultando na Figura 6.1, onde é confirmada a tendência negativa entre $f_{c}$ e $E_{m}$. Pode-se perceber também de acordo com esta figura que os modelos da norma brasileira tornam-se inseguros $\left(E_{m}<1,0\right)$, prevendo capacidade de carga dos pilares acima da experimental. Este fato ocorre, possivelmente, por ter-se desprezado a excentricidade acidental ou devido a imperfeições, o que não acontece no modelo americano. Portanto, apesar de serem apresentadas a regressão separada por tipo de solicitação, as análise que seguem serão focadas na consideração da existência de uma excentricidade mínima, mesmo que o pilar seja carregado axialmente.

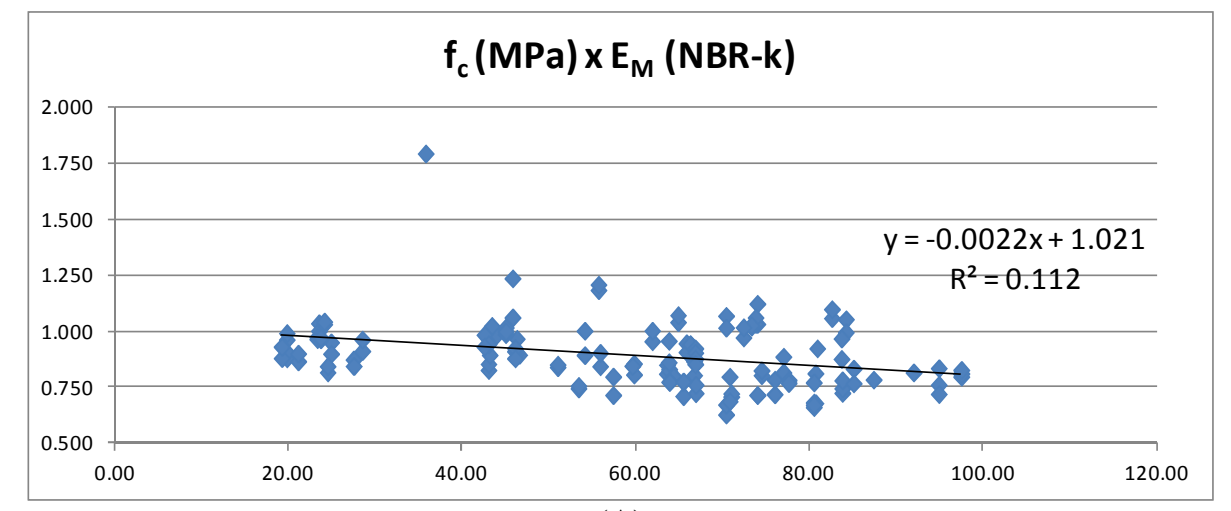

(A)

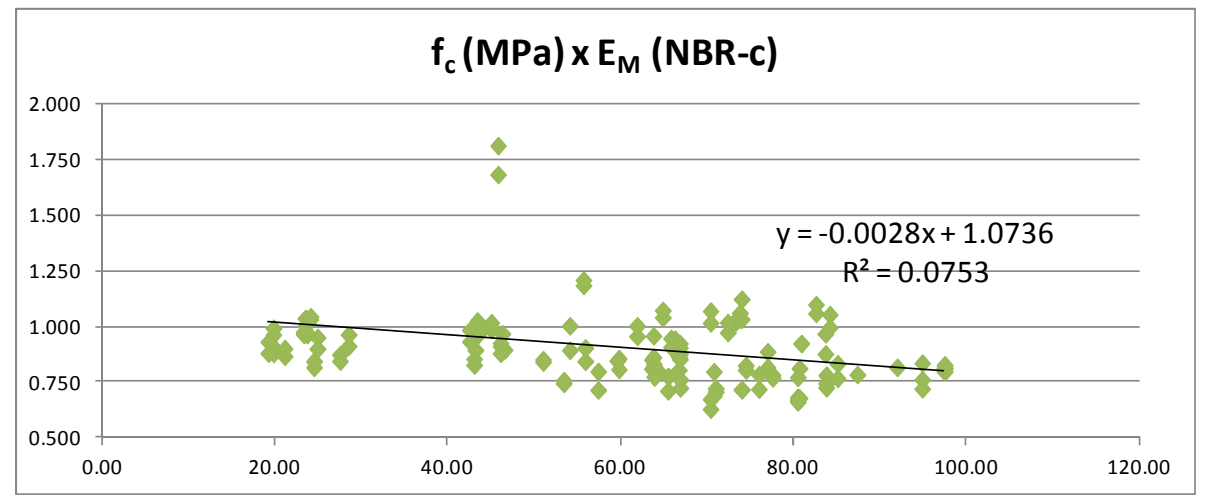

(B)

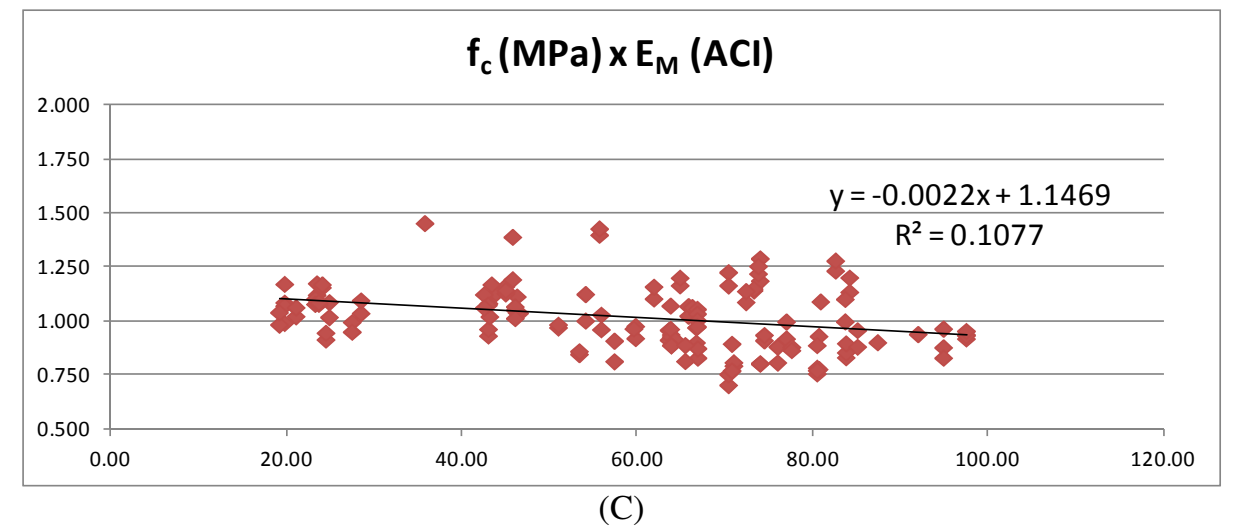

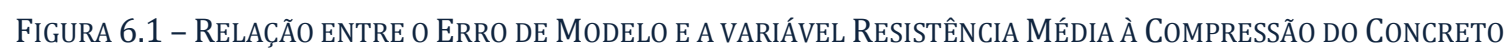
PARA PILARES SOB CARGA CENTRADA. (A) ABNT NBR 6118:2007, MODELO DA RIGIDEZ APROXIMADA, (B) ABNT NBR 6118:2007, MODELO DA CURVATURA APROXIMADA, (C) ACI 318-2002. 
É importante ressaltar também que, quando considerada a excentricidade mínima, os modelos brasileiros são mais conservadores e apresentam maior dispersão de resultados que o modelo da norma americana.

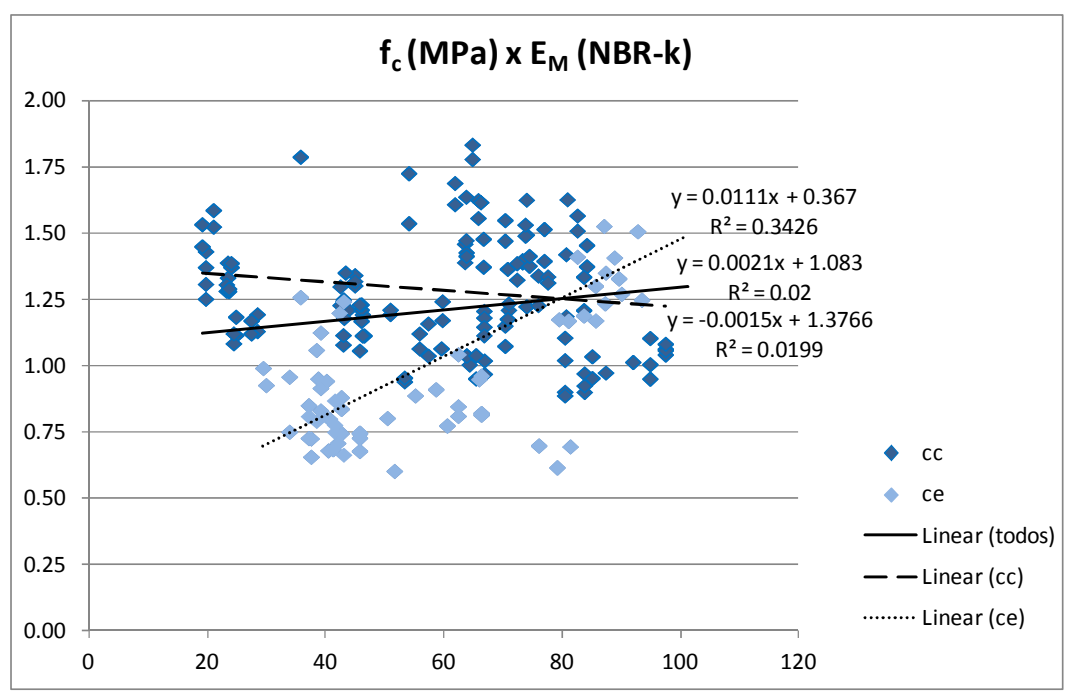

(A)

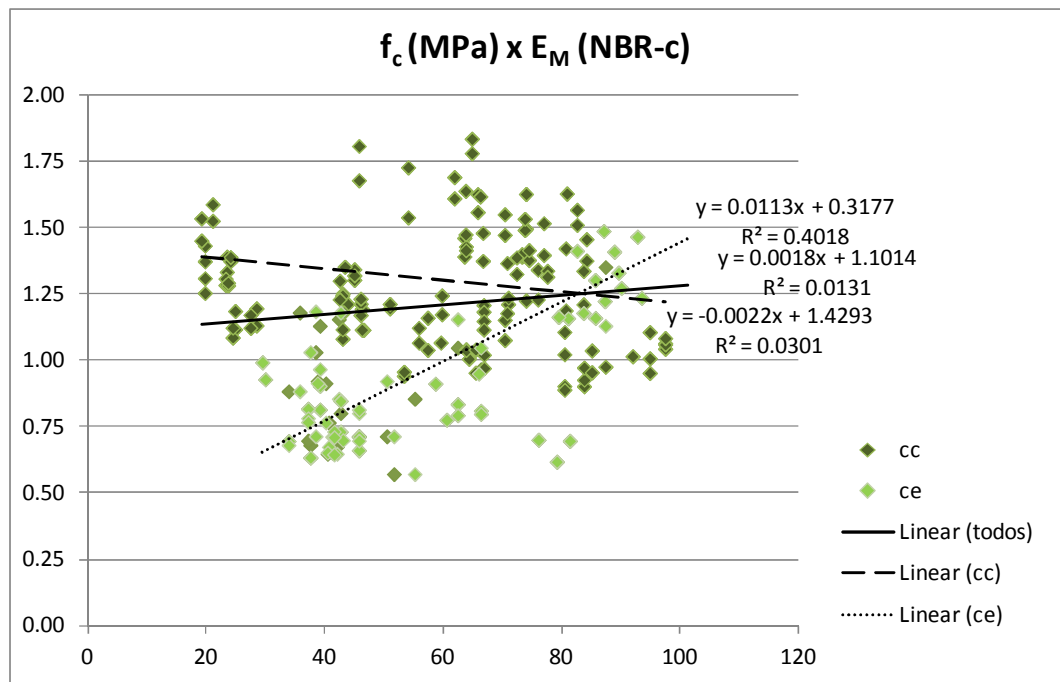

(B)

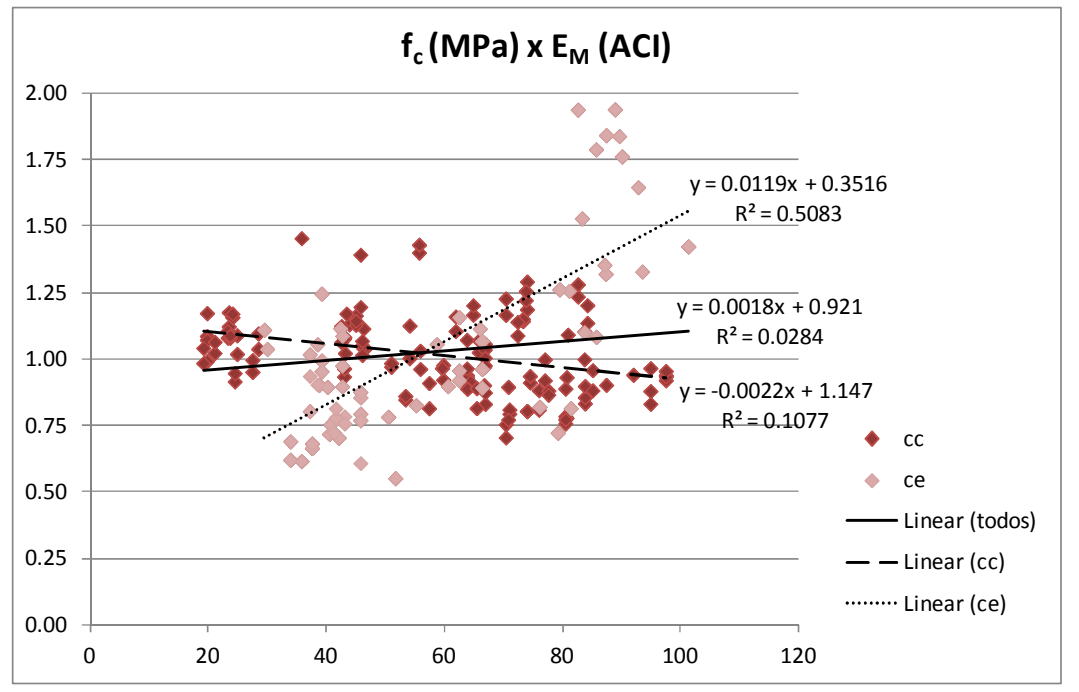

(C)

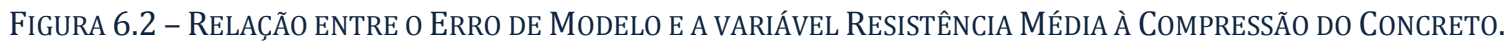

(A) ABNT NBR 6118:2007, MODELO DA RIGIDEZ APROXIMADA, (B) ABNT NBR 6118:2007, MODELO DA CURVATURA APROXIMADA, (C) ACI 318-2002. 
Para o modelo de previsão de resistência de vigas solicitadas a flexão pura da ABNT NBR 6118:2007, a variável erro de modelo foi dividida em dois grupos, o primeiro correspondente à resistências do concreto até $50 \mathrm{MPa}$ (valor limite de abrangência da ABNT NBR 6118:2007), e outro com resistências superiores (60 a 100MPa).

Conforme a Figura 6.3, a variável erro de modelo também apresenta tendência positiva assim como nos pilares. Contudo, para concretos com resistências inferiores a $40 \mathrm{MPa}$, a variável erro de modelo apresenta, pela regressão linear, valores menores que a unidade, indicando assim que, para estes valores de resistência, o modelo é não conservador.

Vale ressaltar também que, no caso das vigas, a correlação da variável erro de modelo com a resistência do concreto, representada por $\mathrm{R}^{2}$, é maior nos concretos de alta resistência.

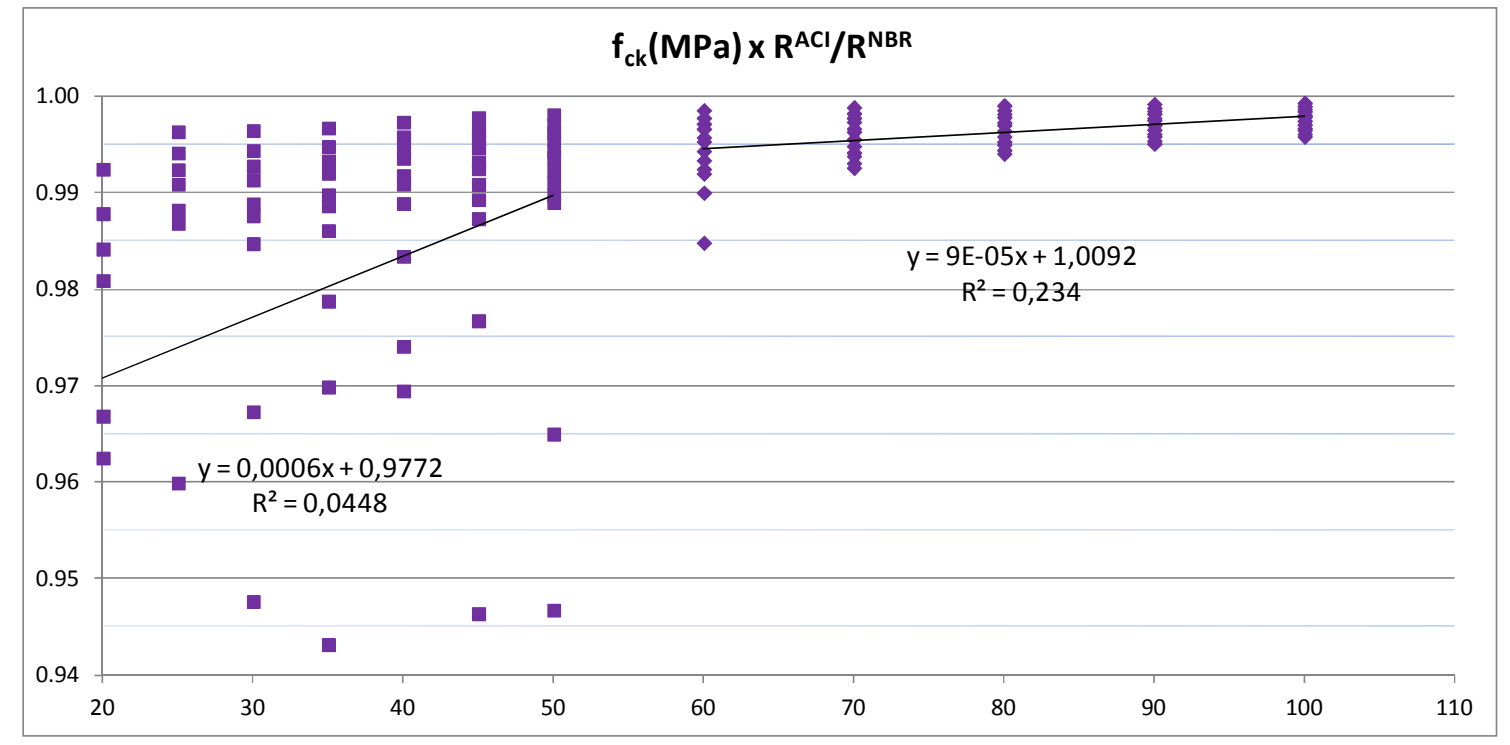

FIGURA 6.3 - RELAÇÃo ENTRE o ERRO DE MOdELO DE VIGAS DA ABNT NBR 6118:2007 E A VARIÁVEL RESISTÊNCIA MÉDIA À COMPRESSÃO DO CONCRETO.

\subsubsection{ESBELTEZ DOS PILARES}

Devido à grande dispersão dos valores de erro de modelo e pequena quantidade de esbeltezes para pilares solicitados axialmente, também não é possível estabelecer uma correlação entre a variável aleatória erro de modelo e a esbeltez dos pilares. O que nota-se pela Figura 6.4 (A) e (B) é que para maiores esbeltezes o erro dos modelo da norma brasileira diminui, aproximando-se da unidade e ficando menos conservador. Na Figura 6.4 (C), caso do modelo americano, a variável erro de modelo permanece em torno de um, aproximando-se de um modelo ideal, quando o parâmetro analisado for a esbeltez dos pilares. 


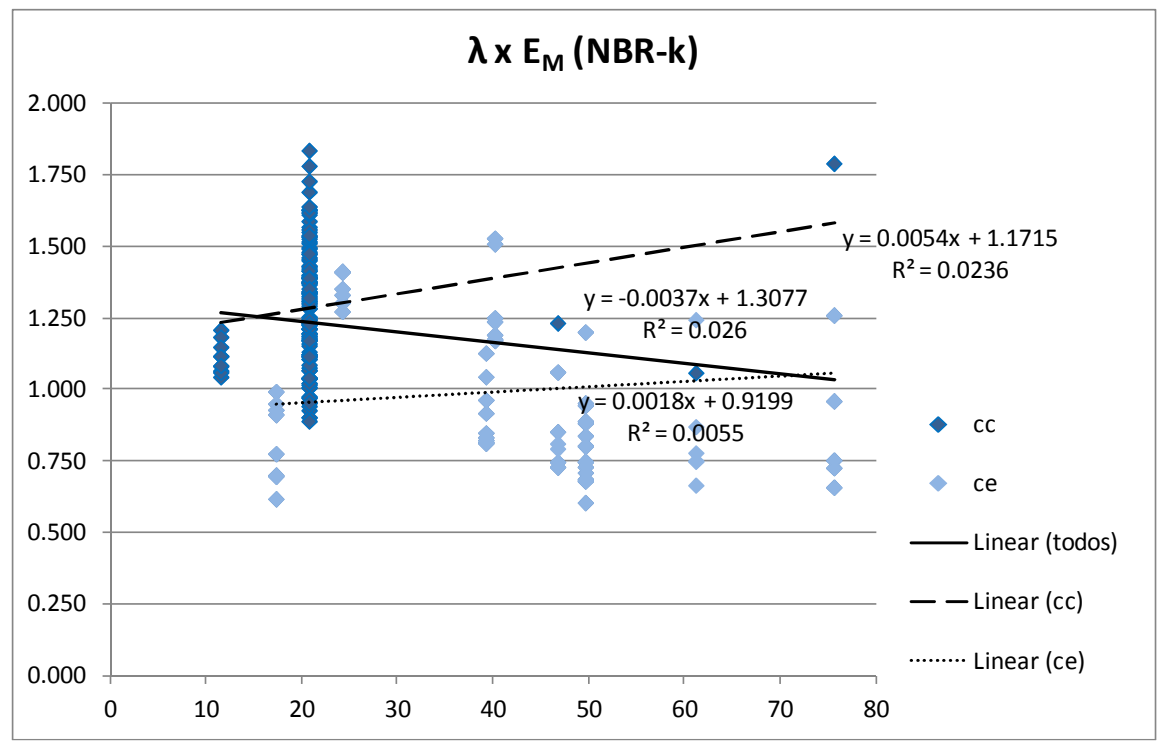

(A)

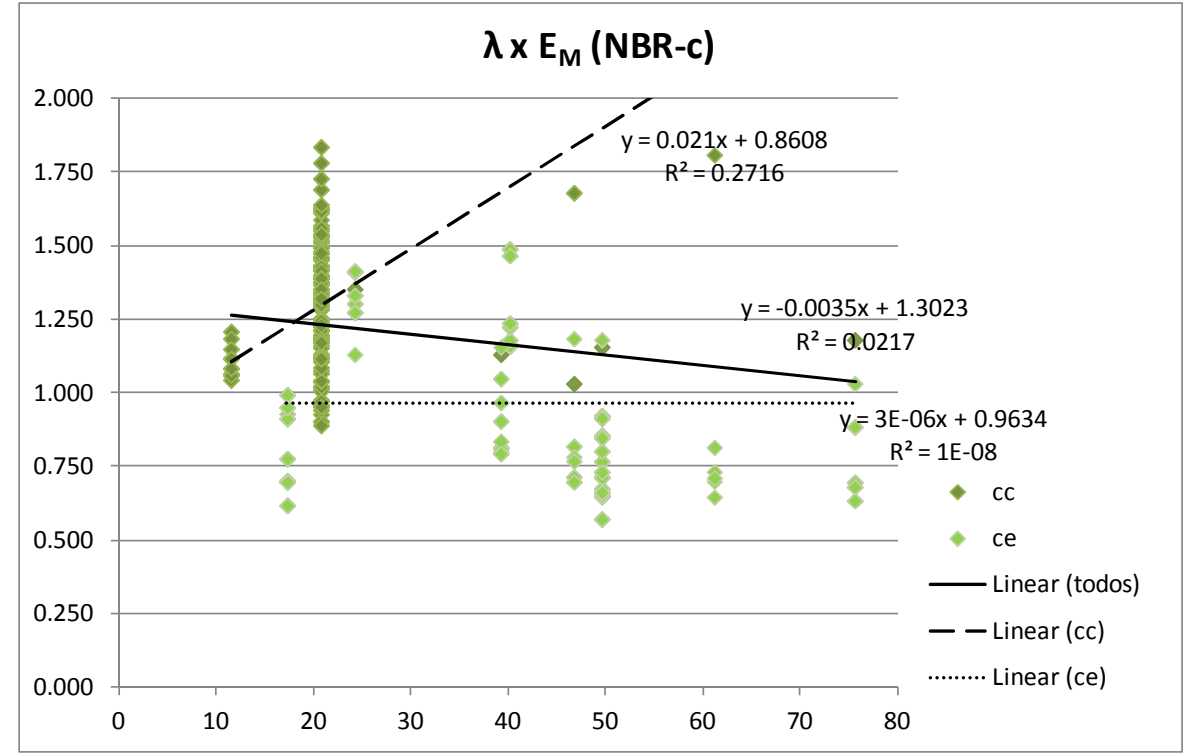

(B)

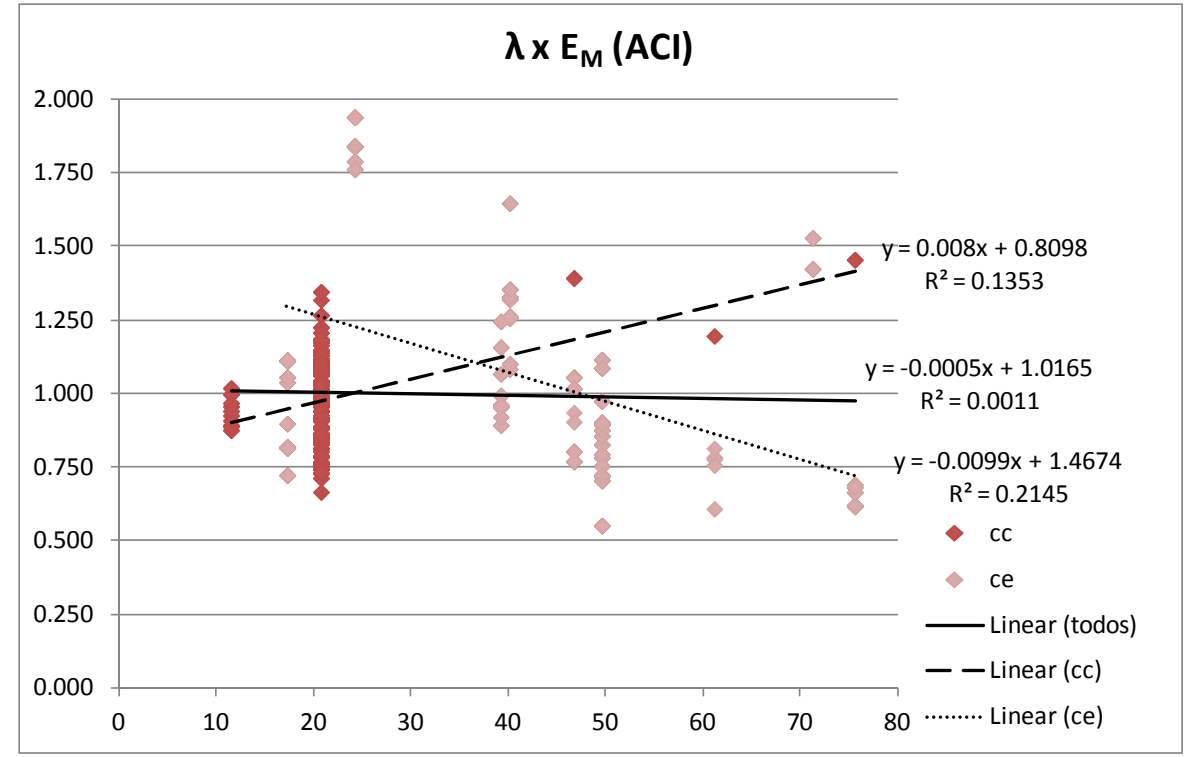

(C)

FIGURA 6.4 - RELAÇÃo ENTRE o ERRo DE MODELO E A VARIÁVEL ESBELTEZ DOS PILARES. (A) ABNT NBR 6118:2007, MODELO DA RIGIDEZ APROXIMADA, (B) ABNT NBR 6118:2007, MODELO DA CURVATURA APROXIMADA, (C) ACI 318-2002. 


\subsection{3. $\quad$ AltURA ÚTIL DAS VIGAS}

A altura útil das vigas apresenta certa correlação negativa (da ordem de 0,1063) com a variável erro de modelo. Esse fato indica que, para vigas com seção muito alta, o modelo da ABNT NBR 6118:2007 torna-se cada vez menos conservador, e até inseguro quando a viga possuir altura superior a $50 \mathrm{~cm}$.

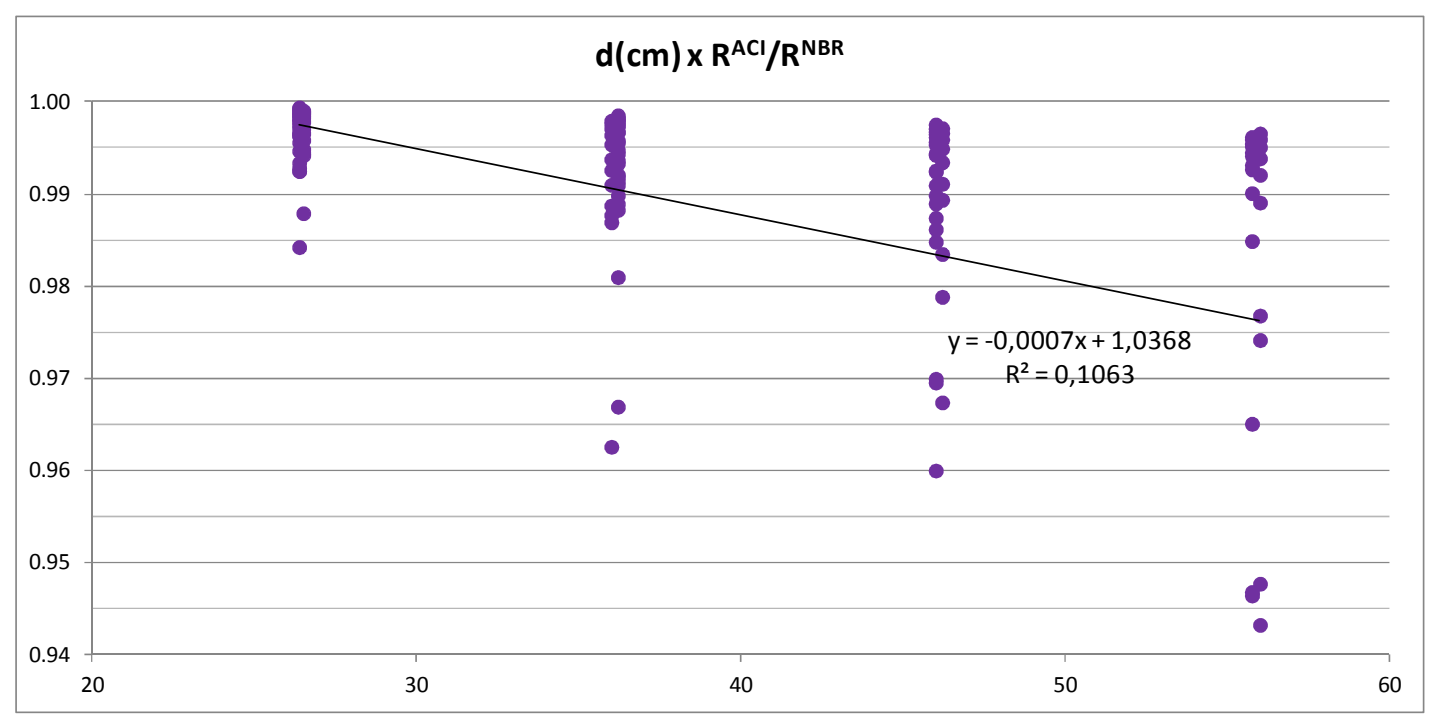

Figura 6.5 - ReLAÇÃo ENTRE o ERRo De Modelo de VIGAS DA ABNT NBR 6118:2007 E A VARIÁVEL ALTURA ÚTIL DA SEÇÃO DAS VIGAS.

\subsubsection{RAZÃo POSIÇÃO DA LINHA NEUTRA E ALTURA ÚTIL DAS VIGAS}

Quando analisada a relação entre profundidade da linha neutra e a altura útil das vigas, obtém-se informações referentes ao domínio de deformação em que ocorre o ruína do elemento. Sabendo que no domínio 2 , esta relação $x / d$ varia de $[0,0.259]$, no domínio 3 [0.259, 0.628] e no domínio $4[0.628,1]$, percebe-se que a maioria dos elementos analisados tem ruína nos domínios 2 e 3, portanto por deformação excessiva do aço. É fácil perceber assim, que à medida que a relação $\mathrm{x} / \mathrm{d}$ aumenta essa correlação diminuição e as amostras ficam mais esparsas.

A Figura 6.6 mostra que a variável $x / d$ tem uma correlação negativa (de ordem maior que 0,288) com a variável erro de modelo. É possível notar também que, apesar de ter sido feita uma regressão linear, a relação entre $x / d$ e $E_{m}$ é exponencial. 


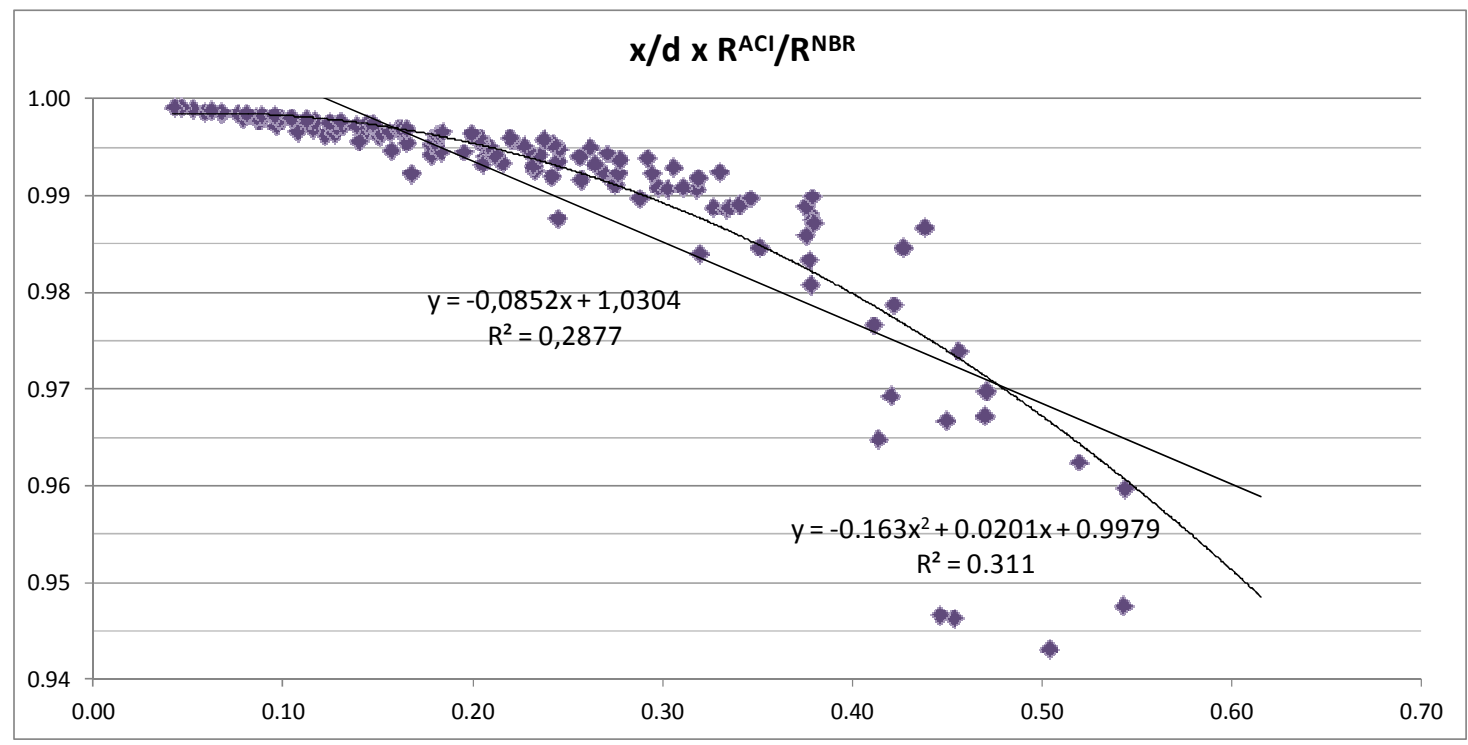

Figura 6.6 - RELAÇÃo ENTRE o ERRo de Modelo de Vigas dA ABNT NBR 6118:2007 E A VARIÁVEL DE RAZÃo POSIÇÃO DA LINHA NEUTRA E ALTURA ÚTIL DAS VIGAS

\subsubsection{TAXA DE ARMADURA LONGITUDINAL}

Nos pilares, a armadura longitudinal assim como a armadura transversal podem provocar confinamento da seção transversal, aumentando desta a capacidade resistente, ao mesmo tempo que diminui a área efetivamente resistente do concreto. Então, é importante avaliar o efeito da taxas de armadura sobre os modelos de previsão de carga.

Para os modelos da ABNT NBR 6118:2007 analisados há uma tendência positiva entre a taxa de armadura e a variável erro de modelo e ambos são conservadores em média. Desta forma é possível concluir que os modelos nacionais não conseguem mensurar o acréscimo de resistência devido o confinamento da seção de concreto. Ver Figura 6.7 (A) e (B)

Já o modelo do ACI 318-2002 possui uma tendência negativa, conformando-se contra a segurança para taxas de armadura longitudinal superiores a 2,0\%, contudo apresenta-se mais preciso que os outros dois modelos.

No entanto, todos modelos tendem a tornar-se conservadores quando solicitados excentricamente. Pode-se assim concluir que o acréscimo na capacidade resistente dos pilares devido ao confinamento da armadura é maior quando este são solicitados a flexocompressão, comparando com pilares sob compressão centrada. 


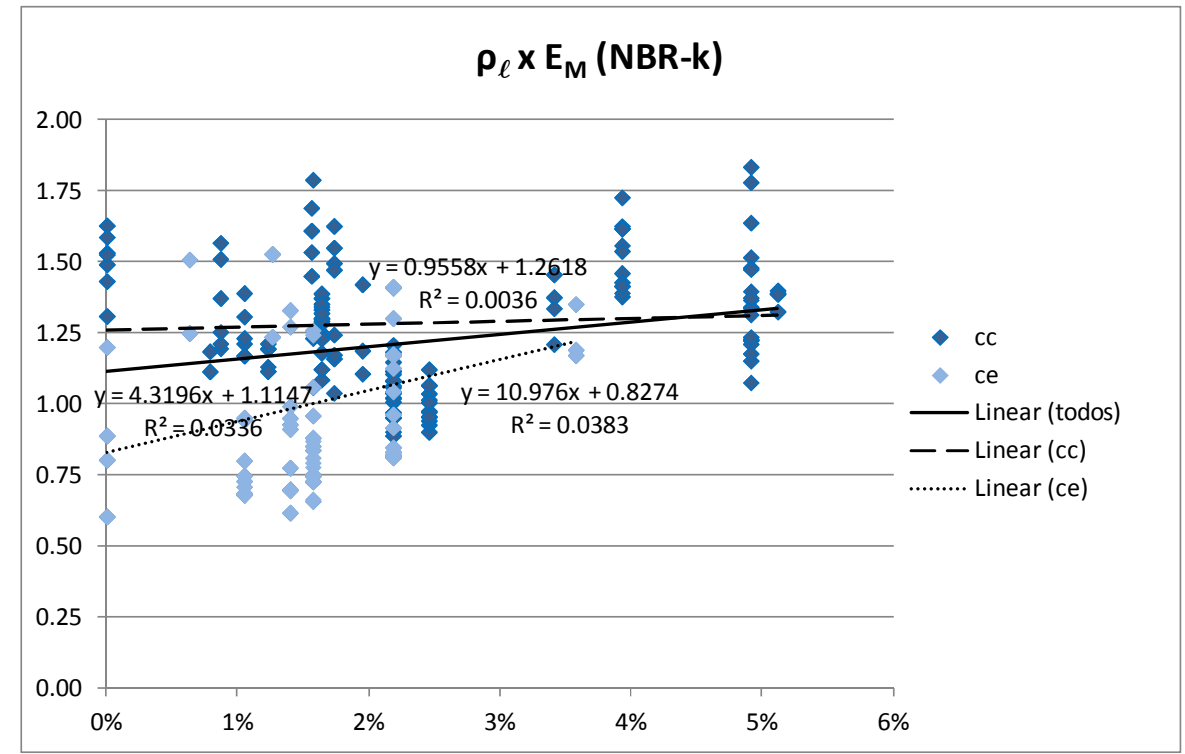

(A)

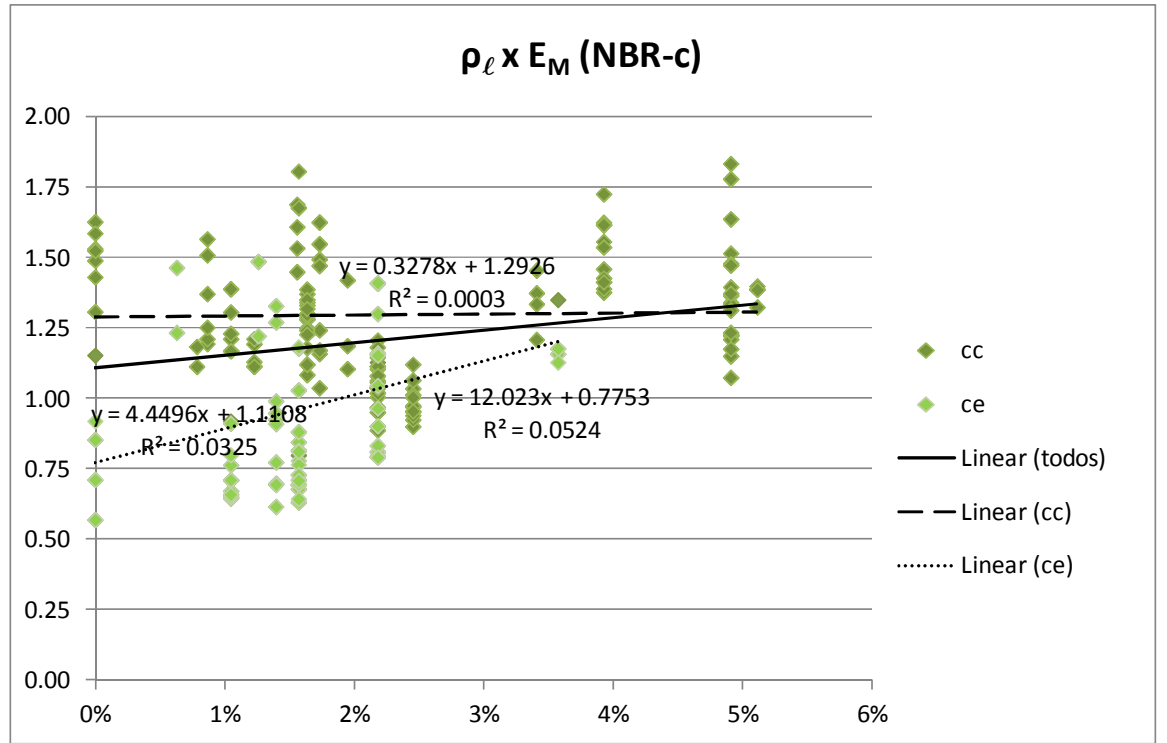

(B)

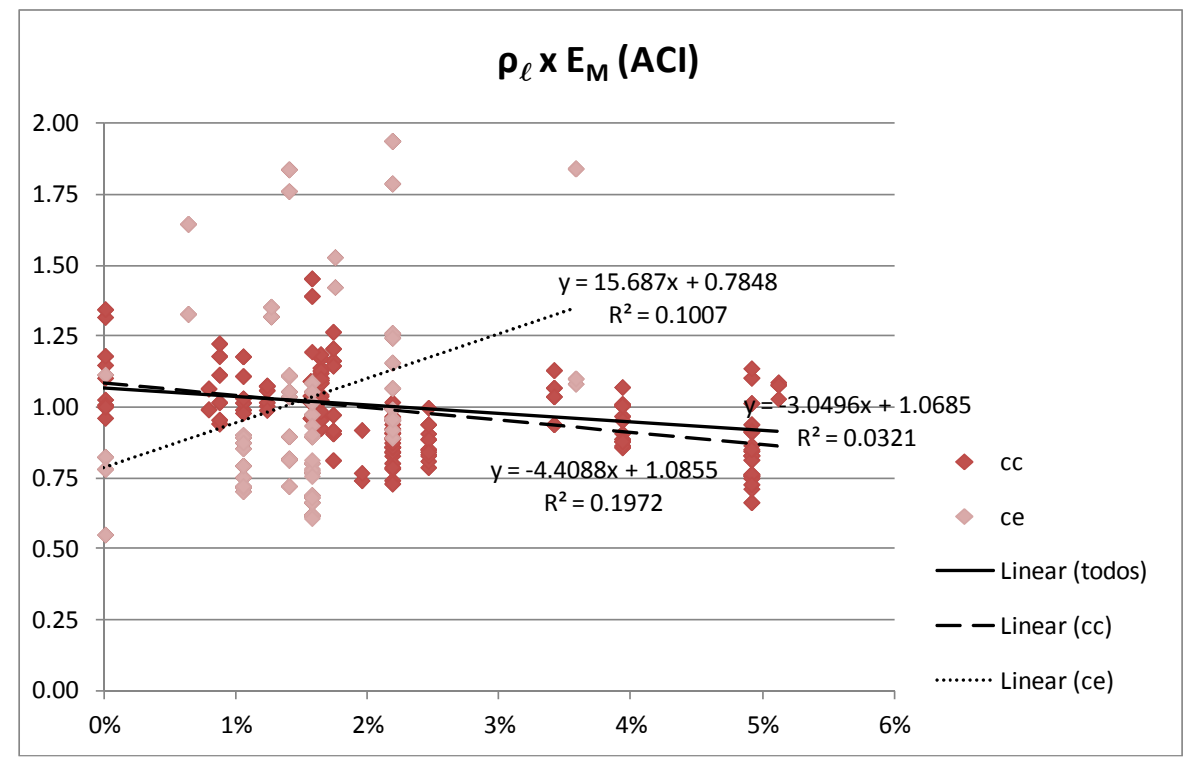

(C)

Figura 6.7 - Relação entre o ERro de Modelo e a variável TAXa de ARMAdura Longitudinal dos Pilares.

(A) ABNT NBR 6118:2007, MODELO DA RIGIDEZ APROXIMADA, (B) ABNT NBR 6118:2007, MODELO DA CURVATURA APROXIMADA, (C) ACI 318-2002. 
O modelo de vigas da norma brasileira apresenta uma correlação negativa com a taxa de armadura longitudinal o que eleva a concluir que o modelo superestima o acréscimo de resistência conferido pelo aumento da taxa de armadura. Também foi feita uma regressão polinomial para a taxa de armadura longitudinal, apresentando correlação próxima àquela encontrada para a regressão linear, descartando assim esta última a regressão polinomial.

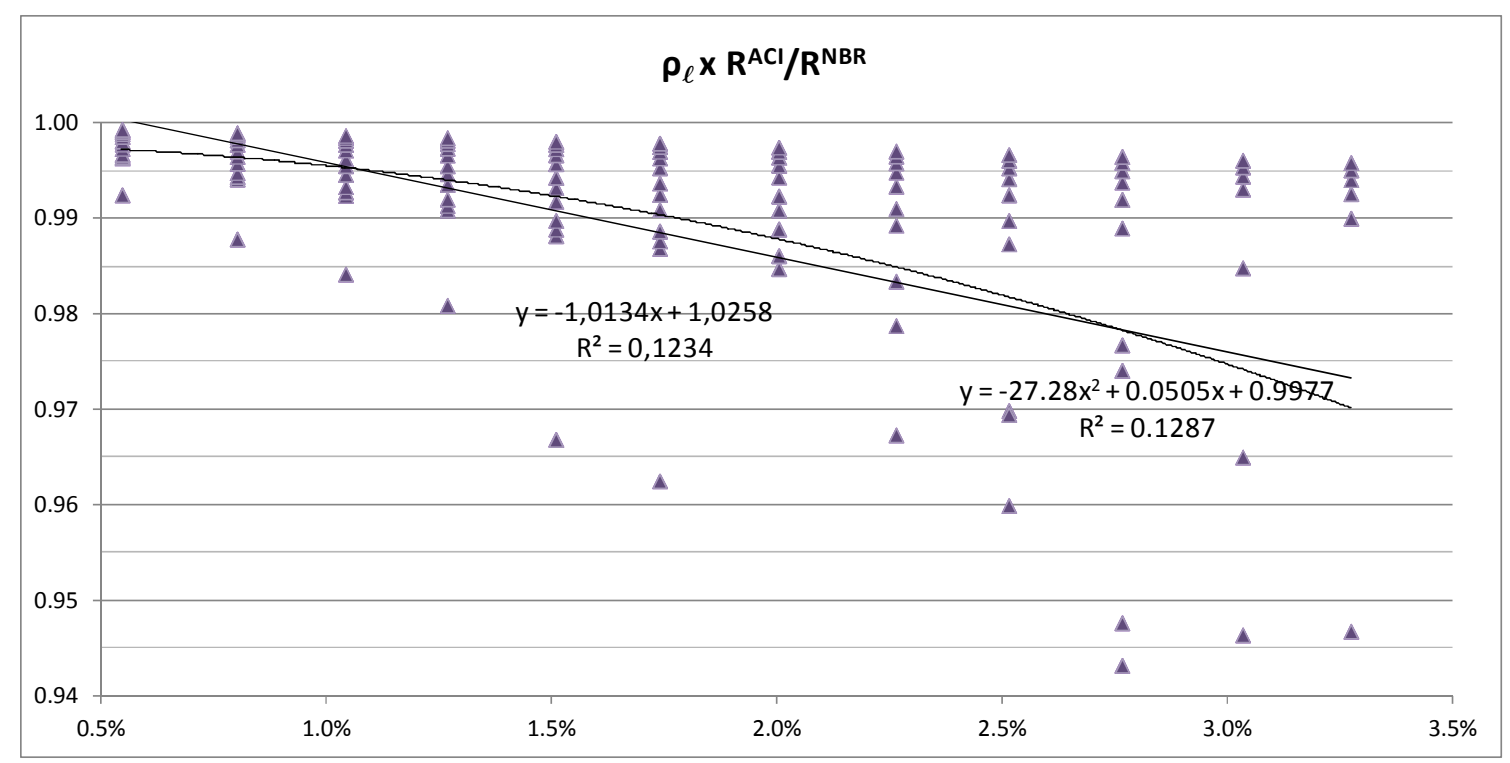

FigURA 6.8 - RELAÇÃo ENTRE o ERRO DE Modelo de VIGAS DA ABNT NBR 6118:2007 E A VARIÁVEL TAXA DE ARMADURA LONGITUDINAL DAS VIGAS.

\subsubsection{TAXA DE ARMADURA TRANSVERSAL DOS PILARES}

As mesmas conclusões sobre a armadura longitudinal podem ser extrapoladas armadura transversal, contudo esta apresenta correlação maior com a variável erro de modelo. Novamente o modelo americano mostra-se mais preciso e menos conservador que os modelos da ABNT NBR 6118:2007, apresentando uma variável erro de modelo menos tendenciosa e com menor correlação com a taxa de armadura transversal, conforme pode ser visto na Figura $7.9(\mathrm{C})$.

Assim como quando relacionados com a armadura longitudinal, os modelos da norma brasileira mostram-se com tendenciosidade positiva e conservadores em relação a armadura transversal. 


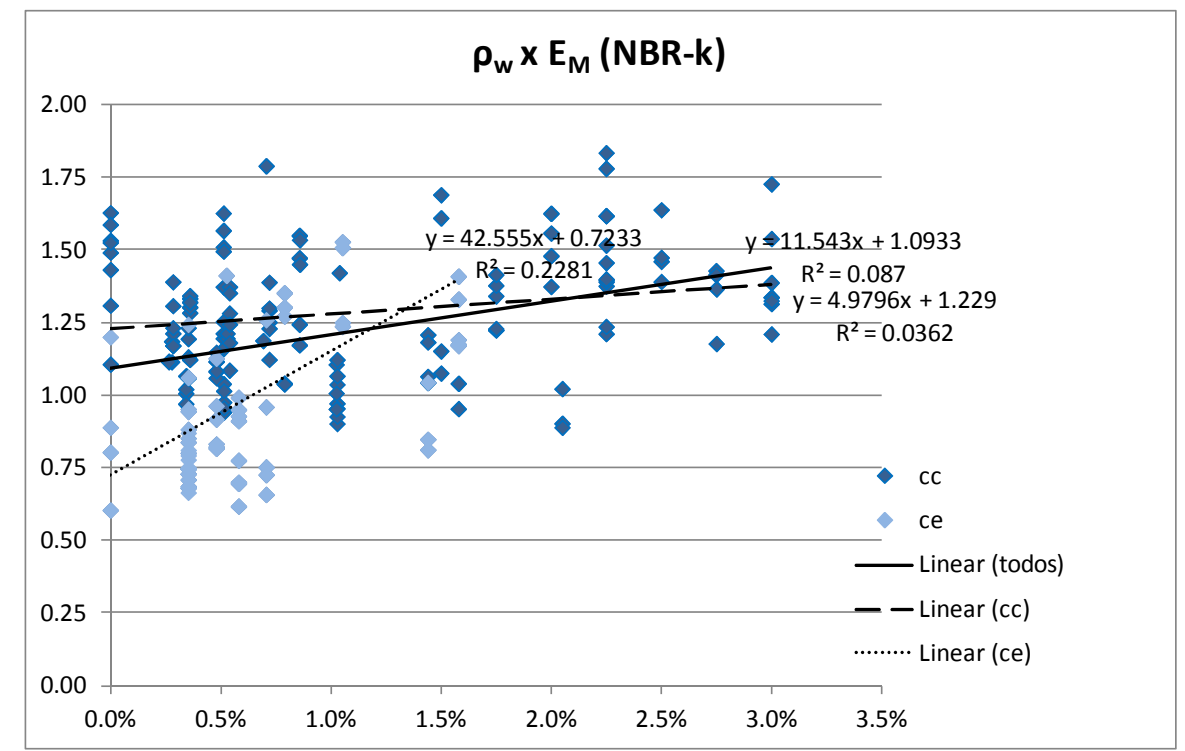

(A)

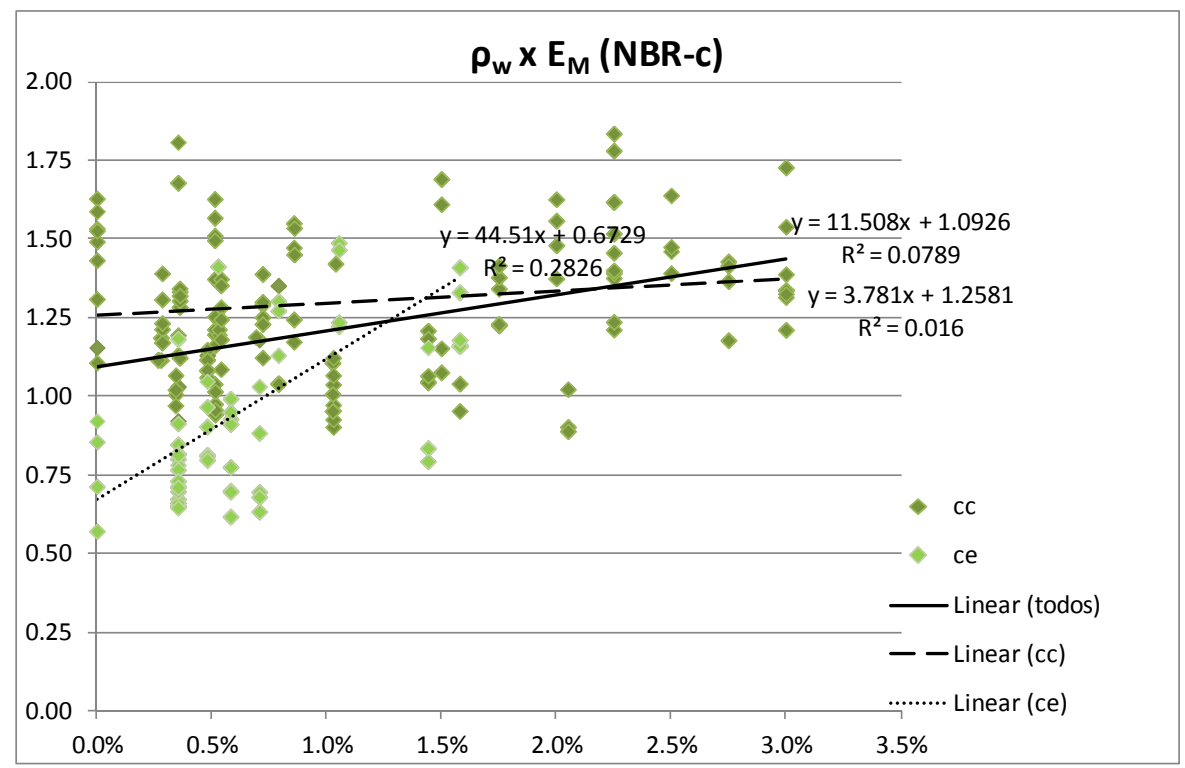

(B)

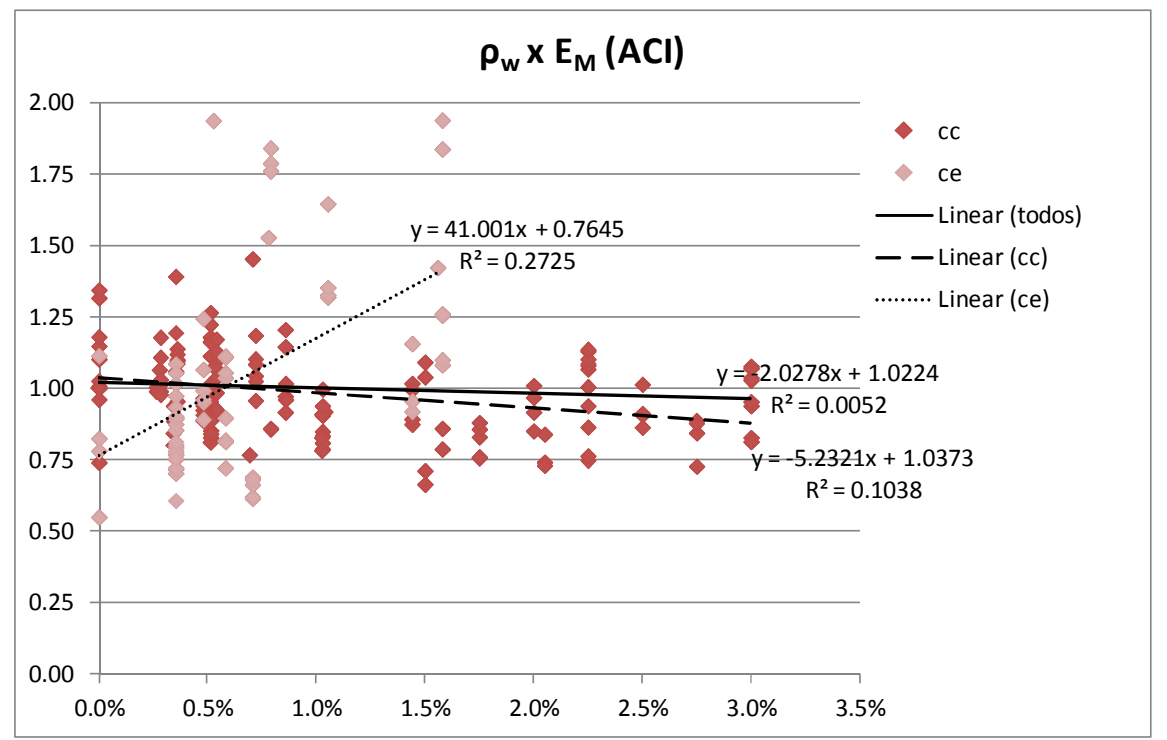

(C)

Figura 6.9 - RElaÇÃo ENTRE o ERro de Modelo E A VARIÁVEl TAXA DE ARMAdURA TranSVERSAl Dos Pilares.

(A) ABNT NBR 6118:2007, MODELO DA RIGIDEZ APROXIMADA, (B) ABNT NBR 6118:2007, MODELO DA CURVATURA APROXIMADA,(C) ACI 318-2002 


\subsubsection{EXCENTRICIDADE INICIAL DE APLICAÇÃO DE CARGA NOS PILARES}

Neste caso, todos modelos tem respostas semelhantes:

- tendência negativa entre as variáveis $e_{i} e E_{m}$ as observações da variável erro de modelo decrescem à medida que aumenta a excentricidade inicial,

- os modelos apresentam-se contra a segurança quando a excentricidade inicial está acima de $20 \mathrm{~mm}$

- assim como nas demais análise o modelo do ACI 318-2002 é menos tendencioso, apresentando menor correlação e também menos seguro.

Ressalta-se que, assim como a maioria dos estudos sobre pilares solicitados à flexocompressão a excentricidade e foi considerada constante, ou seja, é assumido que exista correlação perfeita entre carga axial e momento fletor. Portanto, análise que segue diz respeito apenas à excentricidade inicial de aplicação da carga de compressão, visto que considerando todos os pilares sujeitos a uma excentricidade, mesmo que mínima, a resposta é semelhante à avaliação feita somente com pilares com excentricidade de carregamento inicial, vide figura abaixo.

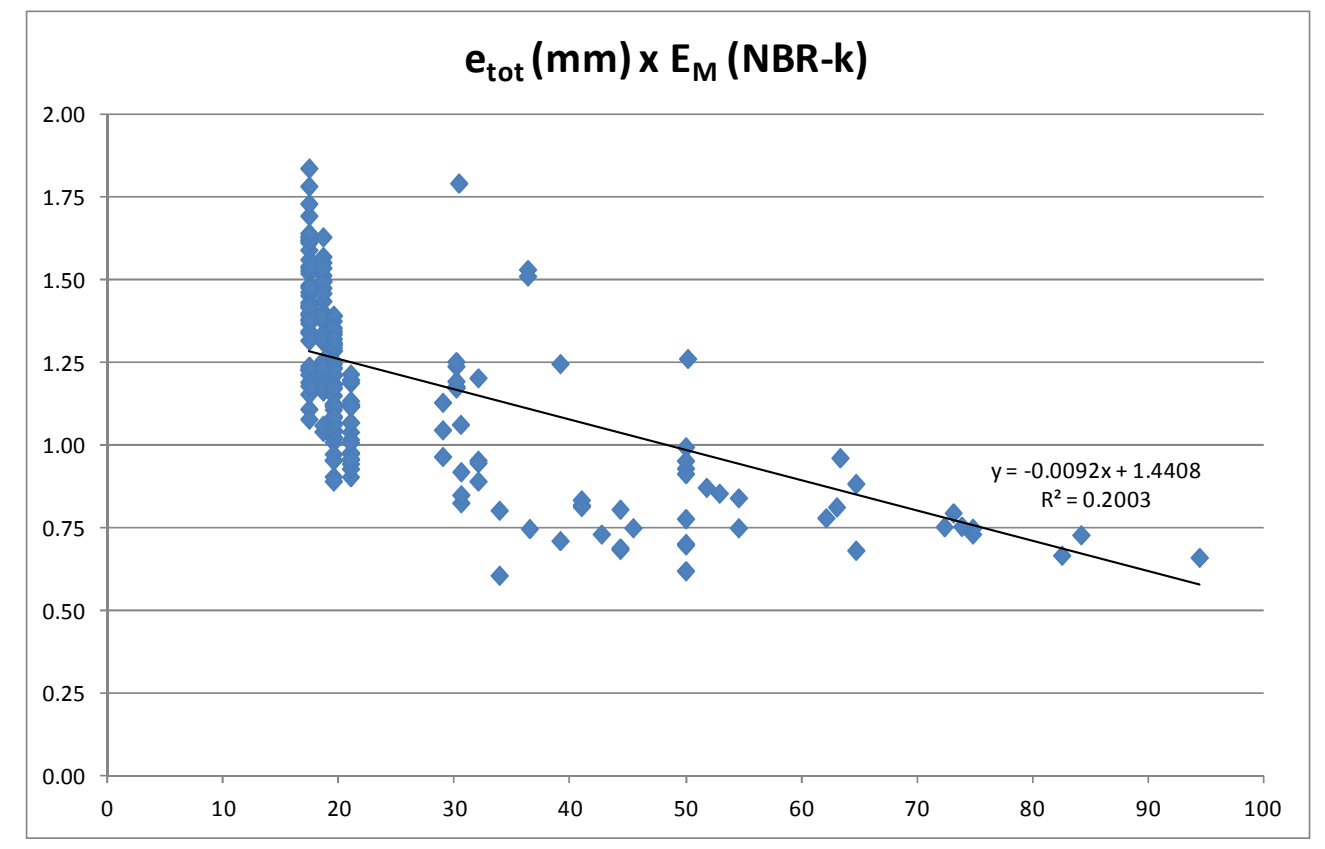

FiguRA 6.10 - RELAÇÃo ENTRE o ERRO DE MODELO E A VARIÁVEL EXCENTRICIDADE TOTAL DE APLICAÇÃO DE CARGA NOS PILARES. ABNT NBR 6118:2007, MODELO DA RIGIDEZ APROXIMADA. 


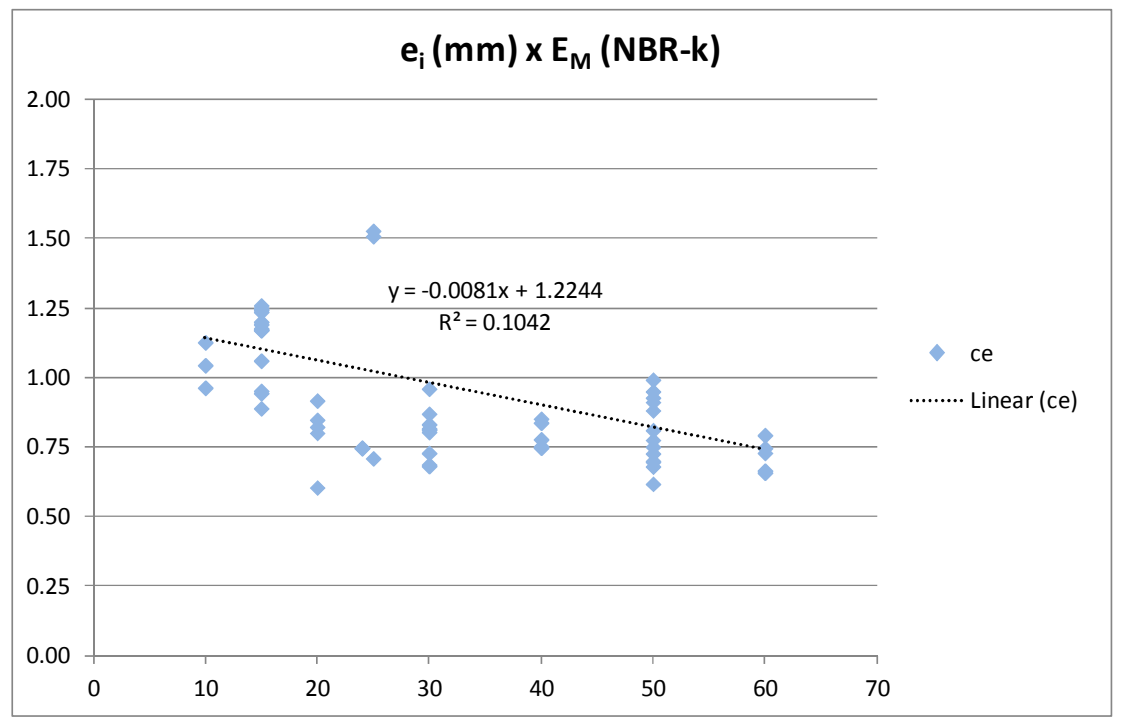

(A)

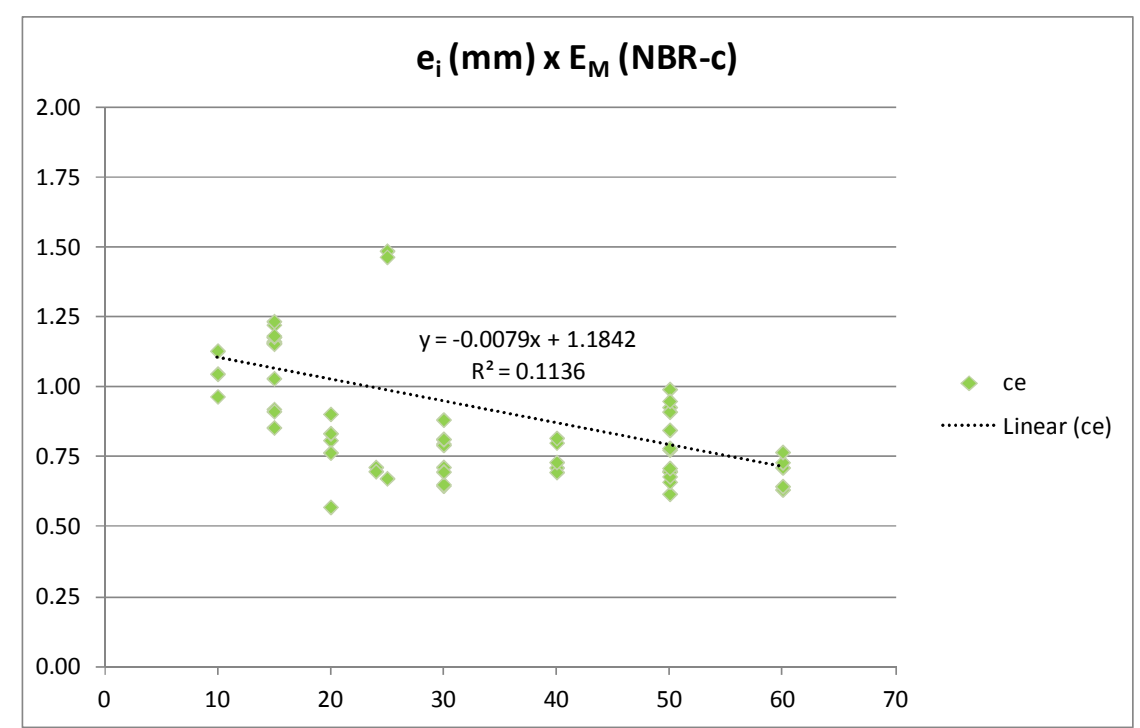

(B)

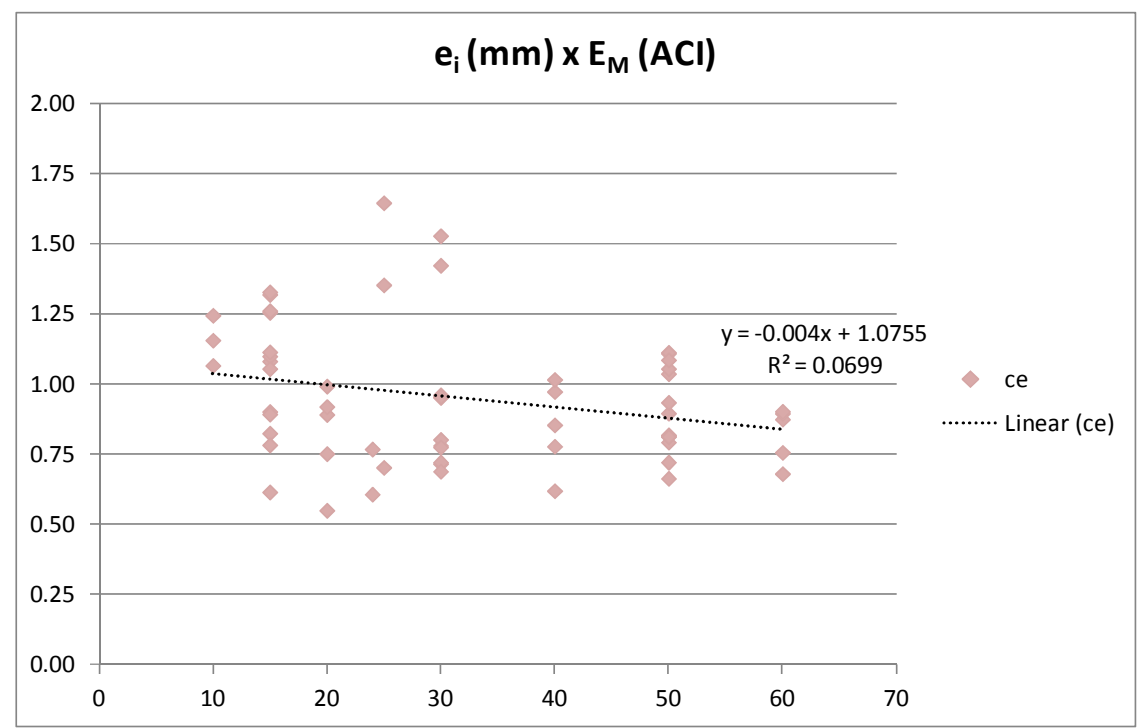

(C)

FIGURA 6.11 - RELAÇÃo ENTRE O ERRO DE MODELO E A VARIÁVEL EXCENTRICIDADE INICIAL DE APLICAÇÃo DE CARGA NOS PILARES. (A) ABNT NBR 6118:2007, MODELO DA RIGIDEZ APROXIMADA, (B) ABNT NBR 6118:2007, MODELO DA CURVATURA APROXIMADA,(C) ACI 318-2002. 
Avaliação estatística do erro de modelos de resistência 


\section{Capítulo 7: CoNCLUSõES}

A análise do erro de modelo dos pilares em concreto armado, dimensionados segundo critérios da ABNT NBR 6118:2007, sujeitos ao carregamento centrado e sob flexocompressão normal, indicou que:

No que se refere à resistência do concreto, a variável erro de modelo apresenta, para pilares solicitados à compressão excêntrica, tendência positiva tornando o modelo mais conservador para maiores resistências do concreto. No entanto, para pilares solicitados axialmente o modelo torna-se menos tendencioso e com o erro diminuindo com o ganho de resistência. Quando analisados sem a consideração da excentricidade acidental, os modelos para pilares solicitados à compressão centrada apresentam-se inseguros.

Portanto, os modelos da norma brasileira não podem ser extrapolados para concreto de alta resistência pois não conseguem mensurar a capacidade resistente total. Uma possível calibração da ABNT NBR 6118:2007 que permita a extensão de seus limites de aplicação para concretos de resistência mais elevada deve levar em consideração as especificidades relativas às propriedades mecânicas deste material e também ganho de resistência devido ao confinamento promovido pela armaduras longitudinal e transversal, pois a simples extrapolação do método para concreto usual não apresenta-se adequado.

Assim como os efeitos do aumento de ductilidade para concreto de alta resistência, devem ser considerado o confinamento do concreto usual pela armadura longitudinal e transversal pois os modelos mostram-se conservadores com o aumento das taxas de armadura.

Deve-se considerar a existência de excentricidade acidental em pilares solicitados (teoricamente) à compressão centrada.

Os pilares solicitados à compressão simples apresentaram-se mais dependentes e conservadores da do índice de esbeltez que aqueles solicitados à compressão excêntrica.

O erro do modelo da ABNT NBR 6118:2007 para previsão do momento resistente último de vigas não apresentou-se conclusivo, embora tenha demonstrado clara dependência da taxa de armadura longitudinal e da posição da linha neutra no estado limite último, 
consequentemente, com o modo de ruína (deformação excessiva do aço ou concreto) da viga.

Avaliações futuras podem ser feitas uma vez que sejam coletados dados que incluam elementos não considerados neste trabalho, assim como dados experimentais para resistência de vigas. 


\section{REFERÊNCIAS BIBLIOGRÁFICAS}

ADORNO, A. L. C. (2004). Análise teórico-experimental de pilares de concreto submetidos à flexo-compressão reta. Tese de doutorado. Faculdade de Tecnologia, Departamento de Engenharia Civil e Ambiental, Universidade de Brasília. Brasília.

AGOSTINI, L. R. S. (1992). Pilares de concreto de alta resistência. Tese de doutorado. Escola Politécnica, Universidade de São Paulo. São Paulo.

ANG, A. H-S; TANG, W. H. (1984). Probability Concepts in Engineering Planning and Design. Vol. 2 - Decision, Risk, and Reliability. New York: John Wiley \& Sons.

ARAÚJO, L. M. B. (2004). Análise teórico-experimental de pilares de concreto submetidos à flexão normal composta. Dissertação de Mestrado. Escola de Engenharia Civil, Universidade Federal de Goiás. Goiânia.

ASSOCIAÇÃO BRASILEIRA DE NORMAS TÉCNICAS (2003). NBR 8681: 2003 Ações e segurança nas estruturas - procedimento. Rio de Janeiro.

(2007). NBR 6118: 2007 - Projeto de estruturas de concreto - procedimento. Rio de Janeiro.

BECK, A. T. (2009). Curso de Confiabilidade Estrutural: Notas de Aula. São Carlos: EESC-USP.

BECK, A. T., DE OLIVEIRA, W. L. A., DE NARDIM, S., EL DEBS, A. L. H. C. (2009). Reliability-based Evaluation of Design Code Provisions for Circular Concrete-Filled Steel Columns. Engineering Structures, Elsevier, Vol.31, n.10, p. 2299-2308.

BOLADIM, E. A. (2011). Análise de confiabilidade em ligações parafusadas em chapas finas e perfis de aço formados a frio. Dissertação de Mestrado. Escola de Engenharia de São Carlos, Universidade de São Paulo. São Carlos.

CASTRO, L. A. (1997). Análise de segurança no projeto de estruturas: Método dos estados limites. Dissertação de Mestrado. Escola de Engenharia de São Carlos, Universidade de São Paulo, São Carlos. 
DANTAS, A. B. (2006). Estudo de pilares de concreto armado submetidos à flexão composta reta. Dissertação de Mestrado. Faculdade de Tecnologia, Departamento de Engenharia Civil e Ambiental, Universidade de Brasília. Brasília.

ELLINGWOOD, B. R.; CULVER, C. (1977). Analysis of Live Loads in Office Buildings. J.Struct. Div., ASCE 103, 1551-1560.

ELlingWOOD, B.; GALAMBOS, T. V.; MACGREGOR, J. G.; CORNELL, C. A. (1980). Development of a Probability Based Load Criterion for American National Standard A58. US National Bureau of Standard Special Publication 577, Washington, D.C.. ELLINGWOOD, B.; GALAMBOS, T. V. (1982). Probability-based criteria for structural design, Structural Safety, v. 1, n. 1, p. 15-26.

FUSCO, P. B. (1995). Técnicas de armar as estruturas de concreto, São Paulo, Pini. (1976). Estruturas de concreto: fundamentos do projeto estrutural. São Paulo, McGraw-Hill do Brasil, EDUSP.

(1977). Estruturas de concreto: fundamentos estatísticos da segurança das estruturas. São Paulo, McGraw-Hill do Brasil, EDUSP.

(1986). Estruturas de concreto: solicitações normais. Rio de Janeiro, Guanabara Dois.

KAEFER, L.F. (1998). A evolução do concreto armado. São Paulo.

LEONHARDT, F.; MÖNNIG, E. (1977). Construções de concreto: princípios básicos do dimensionamento de estruturas de concreto armado. Rio de Janeiro, Interciência, v.1.

LIMA, F. B. (1997). Pilares de concreto de alto desempenho: fundamentos e experimentação, Tese de doutorado. Escola de Engenharia de São Carlos, Universidade de São Paulo. São Carlos.

LIMA JUNIOR, H. C. (2003). Avaliação da ductilidade de pilares de concreto armado, submetidos à flexo-compressão reta com e sem adição de fibras metálicas. Tese de doutorado. Escola de Engenharia de São Carlos, Universidade de São Paulo. São Carlos.

NOGUEIRA, H. A. T. (2006). Avaliação da confiabilidade de pilares curtos em concreto armado projetados segundo a ABNT NBR 6118:2007. Dissertação de Mestrado. Escola de Engenharia, Universidade Federal de Minas Gerais. Belo Horizonte. 
NOWAK, A. S.; SZERSZEN, M. M. (2003). Calibration of Design Code for Buildings (ACI 318): Part 1 - Statistical Models Resistance, ACI Structural Journal, v. 100, n. 3, p. 377-382.

OLIVEIRA, W. L. A. (2004). Análise teórica e experimental de pilares de concreto armado sob ação de força centrada com resistência média à compressão do concreto de 40MPa. Dissertação de Mestrado. Escola de Engenharia de São Carlos, Universidade de São Paulo. São Carlos.

OLIVEIRA, W. L. A.; EL DEBS, A. L. H. C.; BECK, A. T. (2008). Avaliação da segurança de pilares mistos preenchidos de seção circular projetados segundo a norma NBR 8800:2008. Revista IBRACON de estruturas e materiais. Vol1, No 3, pp 212-235.

PAIVA, N. M. B. (1994). Pilares de concreto de alta resistência com seção transversal retangular solicitados à compressão simples. Dissertação de mestrado - Faculdade de Engenharia Civil, Universidade Estadual de Campinas. Campinas.

QUEIROGA, M. V. M. (1999). Análise experimental de pilares de concreto de alto desempenho submetidos à compressão simples. Dissertação de Mestrado - Escola de Engenharia de São Carlos, Universidade de São Paulo. São Carlos.

RAMOS, R. F. (2001). Análise experimental de pilares de concreto armado sob ação centrada com resistência do concreto de 25MPa. Dissertação de Mestrado. Escola de Engenharia de São Carlos, Universidade de São Paulo. São Carlos.

SANTIAGO, W. C. (2011). Estudo da (não-) conformidade de concretos produzidos no Brasil e sua influência na confiabilidade estrutural. Dissertação de Mestrado. Escola de Engenharia de São Carlos, Universidade de São Paulo. São Carlos.

SANTOS, G. S. (2009). Análise experimental e numérica de pilares de concreto armado submetidos à flexão composta reta. Dissertação de Mestrado. Faculdade de Tecnologia, Departamento de Engenharia Civil e Ambiental, Universidade de Brasília. Brasília.

SOUZA JUNIOR, A.C. (2009). Aplicação de Confiabilidade na Calibração de Coeficientes Parciais de Segurança de Normas Brasileiras de Projeto Estrutural. Dissertação de mestrado. Escola de Engenharia de São Carlos, Universidade de São Paulo. São Carlos. 
SZERSZEN, M. M.; NOWAK, A. S. (2003). Calibration of Design Code for Buildings (ACI 318): Part 2 - Reliability Analysis and Resistance Factors, ACI Structural Journal, v. 100 , n. 3, p. 383-391.

VALLADARES, L. M. (1997). Análise teórico-experimental do comportamento de pilares em concreto armado na flexão normal composta: efeitos da variação na resistência à compressão do concreto. Dissertação de mestrado. Universidade Federal de Minas Gerais. Belo Horizonte.

VANDERLEI, R. D. (1999). Análise experimental de pilares de concreto armado de alta resistência sob flexo-compressão reta. Dissertação de mestrado - Escola de Engenharia de São Carlos, Universidade de São Paulo. São Carlos.

VROUWENVELDER, T. The JCSS Probabilistic Model Code. Structural Safety, Vol.19, 1997, p.245-251. 